Jeon, Heesang (2018) Knowledge and contemporary capitalism in light of Marx's value theory. PhD thesis. SOAS University of London. http://eprints.soas.ac.uk/26177

Copyright $(\subset$ and Moral Rights for this thesis are retained by the author and/or other copyright owners.

A copy can be downloaded for personal non-commercial research or study, without prior permission or charge.

This thesis cannot be reproduced or quoted extensively from without first obtaining permission in writing from the copyright holder/s.

The content must not be changed in any way or sold commercially in any format or medium without the formal permission of the copyright holders.

When referring to this thesis, full bibliographic details including the author, title, awarding institution and date of the thesis must be given e.g. AUTHOR (year of submission) "Full thesis title", name of the School or Department, PhD Thesis, pagination. 


\title{
Knowledge and Contemporary Capitalism in Light of Marx's Value Theory
}

\author{
Heesang Jeon
}

Thesis submitted for the degree of $\mathrm{PhD}$

2015

Department of Economics

SOAS, University of London 


\section{Declaration for SOAS PhD thesis}

I have read and understood regulation 17.9 of the Regulations for students of the SOAS, University of London concerning plagiarism. I undertake that all the material presented for examination is my own work and has not been written for me, in whole or in part, by any other person. I also undertake that any quotation or paraphrase from the published or unpublished work of another person has been duly acknowledged in the work which I present for examination.

Signed:_Cutos Date: 29/09/2015 


\begin{abstract}
This thesis has two purposes. The first is to offer a critique of existing accounts of knowledge in contemporary capitalism. On the one hand, knowledge-based models of new growth theory are criticised for privileging some aspects of knowledge whilst endogenising it on the basis of a neoclassical framing; many restrictions are placed upon knowledge, in general, and its utilisation and diffusion, in particular. On the other hand, the bold argument of cognitive capitalism theory, that contemporary capitalism is undergoing a transition to a new stage of capitalism and therefore Marx's value theory has lost its validity, is shown to be based on flawed understandings of value theory. Externalities play essential roles in both new growth theory and cognitive capitalism theory, each being a theory of use value, although there is no place for externalities as such in Marx's value theory. Especially, for cognitive capitalism theory, unpaid life activities are seen to contribute significantly to production, with surplus being appropriated by capital as rent, which can and should be re-appropriated as basic income. The latter is, however, understood in cognitive capitalism theory as factor remuneration derived from the production of surplus products and, in this respect, it has an affinity with neoclassical economics despite its purported commitment to Marx's method.
\end{abstract}

The second purpose is to incorporate the role of knowledge into Marx's value theory in a consistent and coherent manner. Criticising the two contending approaches in the South Korean controversy on the value and price of information commodities, this thesis puts forward an alternative based on a structural distinction between knowledge and commodities. It is demonstrated that knowledge affects the determination of the productivity and complexity of (collective) commodityproducing labour within and across sectors, respectively, and therefore takes part in the determination of the value of commodities. This social process of virtual multiplication of labour is a relatively abstract formulation of the role of knowledge in contemporary capitalism, but it also provides a logical foundation upon which more concrete and complex, and constructive, theories of knowledge can be built. 


\section{Table of Contents}

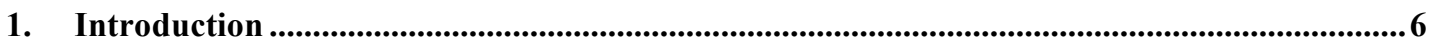

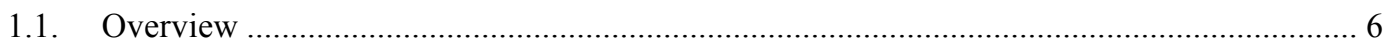

1.2. Method and the dual nature of the commodity .......................................................... 15

2. New growth theory: Trapped between knowledge and growth ..............................................35

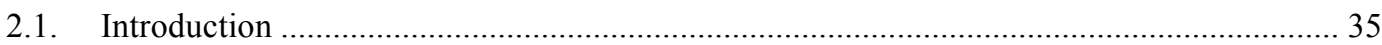

2.2. The Solow model: Competition and growth as two independent aspects of the economy .. 36

2.3. Externality-based endogenous growth models: Growth as exception? ........................... 42

2.4. So-called neo-Schumpeterian growth models ................................................................. 47

2.5. Knowledge-based growth models vs. Marx's value theory ........................................... 57

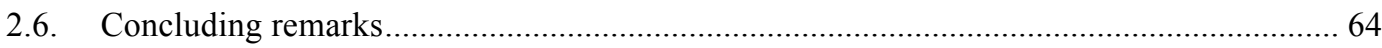

3. Knowledge in value theory: Virtual multiplication of labour ...............................................66

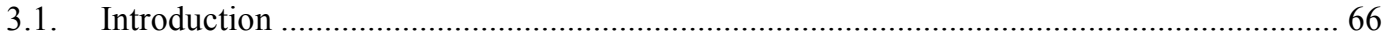



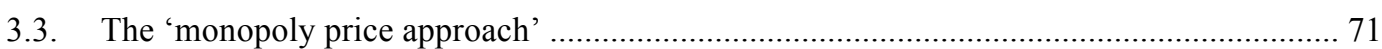

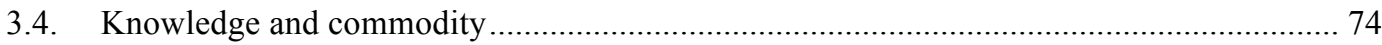

3.5. An alternative approach: The virtual multiplication of commodity-producing labour ........ 81

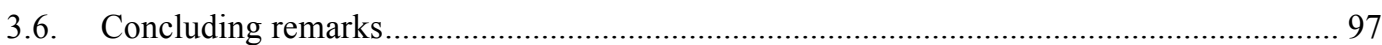

4. Cognitive capitalism theory: Cognitive capitalism or cognition in capitalism? .....................99

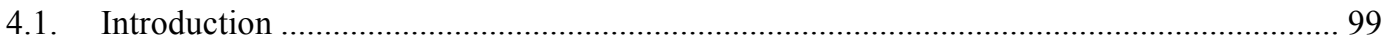

4.2. The regulation approach, post-Workerism and the knowledge economy ........................ 102

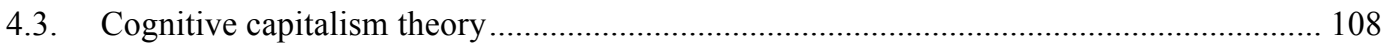

4.4. Misinterpretations of Marx's value theory in cognitive capitalism theory ..................... 111

4.5. The general intellect ................................................................................................ 124

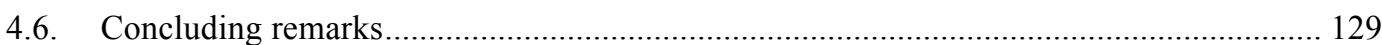

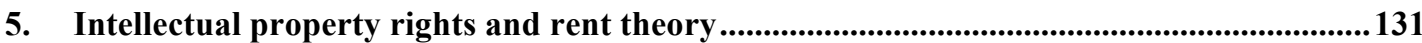

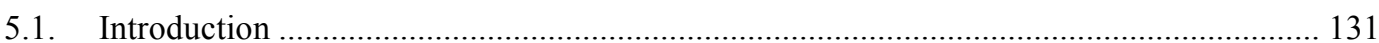

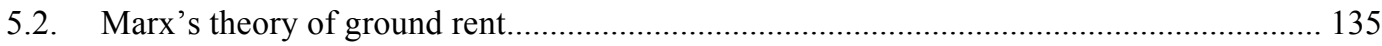

5.3. The 'Controversy' and intellectual property rights .................................................. 141

5.4. Cognitive capitalism theory, intellectual property rights and rent .................................. 148

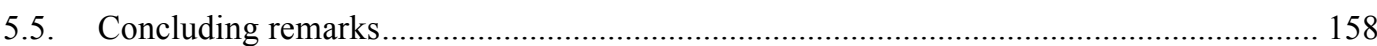

6. Summary of the thesis and directions for future research .................................................160

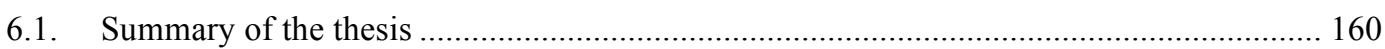

6.2. Extension of the virtual multiplication approach ........................................................ 162

6.3. Future directions: (constructive) value theories of knowledge ..................................... 167

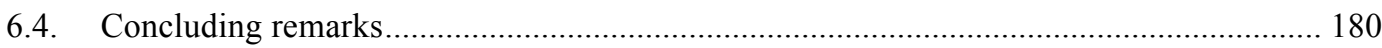

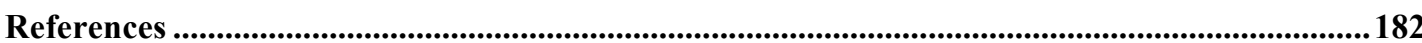




\section{Tables}

Table 1. Preliminary iPad Air2 cost estimates. Source: IHS Technology (2013)......

\section{Figures}

Figure 1. Knowledge production process and labour process (software) 79

Figure 2. Knowledge production process and labour process (automobile) ..................................... 80

Figure 3 . The determination of the productivity and complexity of commodity-producing labour .....96 


\section{Introduction ${ }^{1}$}

\subsection{Overview}

Discourses and theories of knowledge and the knowledge economy have been flourishing. Beniger (1986) provides a list of 76 terms which were introduced between 1950 and 1984 to conceptualise (putatively fundamental) technological and societal changes. More well-known terms such as post-Fordism, the creative economy (UNCTAD \& UNDP, 2008 and 2010; Howkins, 2001) and cognitive capitalism were introduced in the late 1990 s and early $2000{ }^{2}{ }^{2}$ and there is yet no sign that the pace is slowing down, with the sharing economy, Wikinomics, the gig economy and the flat white economy being recent additions. Despite the diversity and creativity in terms of naming and empirical details, the key elements and characteristics of the knowledge economy and the like are remarkably similar and relatively simple. First, much emphasis is placed upon the critical role of knowledge, information, flexibility and creativity and their (good or bad) impacts on the economy and the society as a whole. Second, knowledge, information and creativity are considered as exhibiting key characteristics of a public good, bringing to the fore the role of intellectual property rights and government in fostering innovation and maximising the growth potential of the economy. Third, whilst many try to incorporate both continuity and discontinuity of capitalism in the new era (David \& Foray, 2002), most lean toward the latter. ${ }^{3}$ For example, Stiglitz (1999, p. 37) says (somewhat self-contradictorily):

To be sure, we still face the economics of scarcity. But just as the importance of land in production changed dramatically as the economy moved from agriculture to industry, so too does the movement to a knowledge economy necessitate a rethinking of economic fundamentals.

Fourth, however, the definition of a term like the knowledge economy is at best ambiguous. The reality that it attempts to capture is considered as continually

\footnotetext{
${ }^{1}$ Parts of early drafts of this thesis were published in Jeon (2009, 2010a, 2010b, 2011, 2012, 2013) and Fine, Gimm and Jeon (2010). From the co-authored piece, only my own material is used.

${ }^{2}$ For a genealogy of the knowledge economy, see Kenway, Bullen, Fahey, and Robb (2006, Chapter 1).

3 For early critical literature surveys, see May (2002), Webster (2002) and Kumar (1995).
} 
evolving and thus hard to pin down (UNCTAD \& UNDP, 2010).

In sum, although framed within the context of a grand historical narrative, the knowledge economy and the like are underdeveloped theoretically and, subject to various often idiosyncratic detail, do not go further than positing that the economy is increasingly organised around the production, diffusion, exchange and consumption of knowledge. As Huws (1999, pp. 29-30) puts it in one aspect, "these are not academic inquiries into the nature of the universe; they are practical manuals for managers and policy-makers". Similarly, the notion of the knowledge economy is "so rhetorical rather than analytically useful" (Smith, 2002, p. 4).

In this respect, having played only a limited role in theories of contemporary capitalism until relatively recently, knowledge was thrust suddenly, but largely inappropriately, onto the analytical stage. For Mirowski (2011), such a hastened elevation of knowledge to a more prominent level in economic theories and discourses is ascribed to the rise of interest in information within the natural sciences (and its rapid propagation to the social sciences) and the promotion of the idea that the market not only allocates material goods but also processes and distributes knowledge and information in optimal ways (Hayek, 1945). At the same time, the scale and scope of the (material) technological developments since World War II have been certainly remarkable. This includes the rapid development of micro-electronics technologies and the widespread diffusion of information and communication technologies. Bio- and nano- and alternative energy technologies are emerging as new frontiers. Not only has all this changed the everyday life of ordinary people, but the economy, especially its industrial structure, has been reshaped significantly. Productivity for existing products has soared and the pace of the creation of new products has been accelerated, raising the question of measurement of intangibles in GDP and financial reporting (Gordon, 2000 and 2010; Corrado, Haltiwanger \& Sichel, 2005; Corrado \& Hulten, 2010; Lev, 2001). In addition, with the development of a stronger intellectual property rights regime, the separation between knowledge production (R\&D) and commodity production (manufacturing) has deepened, giving rise to the emergence of a group of companies specialised in IP (intellectual property) and manufacturing, respectively. Whilst it does not necessarily follow from these that our time is different (Standage, 1998), ${ }^{4}$ it

4 "Today we are repeatedly told that we are in the midst of a communications revolution. But the electric telegraph was, in many ways, far more disconcerting for the inhabitants of the time than today's advances are for us. If any generation has the right to claim that it bore the 
is true that there has been a significant change in the way knowledge is produced, traded and consumed, raising empirical and analytical questions. It is against the background of all of these material, ideological and academic developments that the knowledge economy should be located, be it a theory, a discourse or a policy initiative.

The main purpose of this thesis is, then, to situate knowledge in Marxist political economy, in general, and value theory, in particular. The method for doing so is to revisit Marx's value theory selectively with attempts to explain and incorporate the role of knowledge at various levels of analysis. This can be done within two extremes. On the one hand, at the most simple and abstract level, knowledge is a precondition for commodity production in the sense that one should first have a design and necessary skills to be able to produce something. On the other hand, whether the growing significance of knowledge constitutes a new stage of capitalism or even a new mode of production can be explored. Importantly, the progression from one to the other should be step-by-step following Marx's method, and especially the latter should not be taken up until the roles of knowledge and their variegated forms in contemporary capitalism are identified and clarified.

This by no means suggests that the role of knowledge is absent in Marx's works. Although there is no chapter in his Capital which specifically deals with knowledge, he provides detailed and rich accounts of machinery and large-scale industry in Capital, in the Grundrisse and in the 1861-63 manuscript. In these, his theory of knowledge, especially of science and technology, is intertwined with, and cannot be easily separated from, his analysis of the structures, processes and underlying tendencies of capitalism. For example, Marx's theory of competition presumes that there are productivity differences between competing capitals within a sector. Whilst knowledge production or R\&D as such is not mentioned, it is implicit in his analysis of competition that each individual capitalist ceaselessly attempts to increase the productivity of labour by way of the production and use of knowledge. In addition, the tendency of the organic composition of capital (OCC) to rise is inconceivable without assuming that a part of the total social labour is devoted to the production of knowledge. More fundamentally, for Marx, from very early on, it is a systemic character of capitalism that the productive powers of society develop on

full bewildering, world-shrinking brunt of such a revolution, it is not us - it is our nineteenth-century forebears" (Standage, 1998, p. 213). 
an unprecedented scale and at an incomparable speed: "The bourgeoisie cannot exist without constantly revolutionising the instruments of production, and thereby the relations of production, and with them the whole relations of society" (CW6, p. 487).

However, knowledge production as a structural element in capitalism is not recognised explicitly and Marxist scholars have not paid much attention to the role of knowledge, with labour process theory (LPT) being the most prominent exception. In some cases, based on the presumption that there is no role of knowledge in Marx's value theory, either the need to incorporate knowledge into value theory is discarded or the validity of value theory for contemporary capitalism is denied.

Therefore, there are a number of compelling reasons to develop a theory of knowledge in contemporary capitalism based on Marx's value theory. First, the excesses of grand specifications of contemporary capitalism centred on knowledge, information and creativity simply need to be corrected and the focus should be shifted to identifying and clarifying the roles of knowledge in capitalism. Second, the best way of repudiating the claim that value theory has lost its validity is to demonstrate that knowledge can be incorporated into value theory in a consistent and coherent manner without altering or abandoning any of the core elements of value theory. Third, given the relative underdevelopment of economic theories of knowledge in mainstream economics, it provides an opportunity to challenge the orthodoxy, especially its inadequacy for theorising knowledge and information (Mirowski, 2009).

For this purpose, Marx's distinction between value and use value, or the dual nature of the commodity, is of great importance. Simply put, whilst an increase in the level of social knowledge necessarily involves an expansion of use value production in quantity, quality and diversity, it does not directly affect value production (a growth in productivity may lead to an increase, decrease or no change in total value produced). Without such a distinction, mainstream economics can analyse knowledge and its contribution to production only in use value terms and technological development can only be conceived as leading to output growth and productivity growth in price terms, with productivity determined ex post (the ratio of output to a weighted sum of inputs). Hence, the productivity paradox that the rapid development and wide adoption of computers and information technologies have yet to boost total factor productivity sufficiently can never be resolved 
satisfactorily unless the economy grows at a much faster rate than usual for a sustained period. ${ }^{5}$ By contrast, such a conundrum does not exist in value theory as productivity (defined in use value terms) and total value produced are completely decoupled.

The remainder of this section is devoted to providing an overview of the thesis. Chapter 2 is concerned with reviewing the development of the new growth theory and Romer's 1990 model in particular, which is often considered as the theoretical foundation of theories of the knowledge economy (OECD, 1996; World Bank, 2007; Kenway et al., 2006). The focus is, then, placed upon assessing how knowledge is modelled and incorporated into endogenous growth models as the sole engine of growth (in the presence of intellectual property rights). They are, above all, an extension of Solow's neoclassical growth theory in the sense that the primary goal of modelling is to generate a long-term sustained growth path consisting of equilibrium points. Technically, this means that increasing returns at the aggregate level (growth) should be theorised as the outcome of non-increasing returns at the individual level (equilibrium), shifting the focus of growth theory from comparing equilibrium paths for the economy and different policy options to explaining and reconstructing growth on the basis of a set of growth-generating factors. Whereas Solow only identified the existence of an unobservable factor that bridges nonincreasing returns with increasing returns and left it unexplained, each endogenous growth model attempts to, and is compelled to, provide a theory of the engine of growth, be it knowledge, information, creativity, education or any combination of these. It is certainly a daunting task, because such factor(s) of production should exhibit both non-increasing returns and increasing returns at the same time. ${ }^{6}$ Whilst knowledge is simply and unduly assumed to do so in Romer's 1986 model - with the corresponding contradiction resolved magically by positive externalities of knowledge - in his more sophisticated 1990 model, the contradiction is projected to the economy by dividing it largely into two sectors, namely the intermediate and final goods sectors and the knowledge sector representing and being responsible for

5 For the productivity paradox literature, see Gordon (2000), Triplett (1999), Brynjolfsson (1993), Brynjolfsson and Yang (1996) and Brynjolfsson and Saunders (2010).

${ }^{6}$ It is a striking if unobserved feature of such models that externalities (around knowledge) are never internalised despite being attached to the long run. It is as if other branches of the mainstream, not least those associated with, and derived from, Coase simply do not exist. This is all indicative of the extent to which the mainstream is itself driven by the technical assumptions necessary to obtain desired results as opposed to consistency and realism. 
equilibrium and growth, respectively. Although it is a neat solution from a technical point of view and does generate a long-term sustained growth as expected, the presumption that knowledge production and commodity production are completely separated from each other and therefore a firm can produce either knowledge or commodity but not both is simply wrong. More generally, although many compromises are imposed upon the modelling of knowledge and the economy to fit them into the neoclassical framework, incorporation of knowledge into neoclassical growth theory remains less than successful. Knowledge-based endogenous growth models are inferior to micro-level theories of innovation and technological change, and so such models do not add much to the neoclassical understanding of growth.

By contrast, Chapter 3 demonstrates that knowledge can be incorporated into (Marxist) value theory in a consistent and coherent manner without abandoning any of the core elements of value theory or imposing simplifying assumptions on knowledge. First, an important structural distinction between knowledge and commodities is drawn at the most abstract and simple level of analysis; knowledge is indispensable for commodity production, but it is not a commodity. It follows that knowledge does not have value and nor does it transfer value to the final products during the production process. This abstract and fundamental distinction is reproduced at more concrete and complex levels of analysis, logically and historically. Second, this understanding of the nature of knowledge is different from two contending approaches put forward in the controversy on the value and price of information commodities among South Korean value theorists. The 'monopoly price approach' argues that knowledge (the source code of software) does not contribute to the value of commodities (installation packages of software) at all and the 'cost approach' considers knowledge as a means of production, transferring value to the final products in a piecemeal fashion. These two approaches are criticised and a new approach is proposed. In short, it is shown that knowledge takes part in the determination of the productivity and complexity of commodityproducing labour within and across sectors, respectively. If an individual capital's knowledge is more advanced than the sectoral average (within a sector) and/or if the sector is a knowledge-intensive one (or the sectoral average knowledge is more advanced than the economy-wide social average), commodity-producing labour of this capital acts as multiplied labour because it is more productive than the sectoral average labour and/or more complex than the economy-wide average labour. In short, knowledge can virtually multiply commodity-producing labour and individual capitals with advanced knowledge can realise surplus profit as long as the 
competitive advantage is maintained.

Chapter 4 is devoted to critically reviewing the key features of cognitive capitalism theory and the interpretations of value theory underpinning its rejection of the validity of value theory for contemporary capitalism. Instead of getting involved in the debate over whether we live in a new stage of capitalism, our critique focuses on demonstrating that the rejection of value theory in cognitive capitalism theory is based on serious misinterpretations of value theory. First, based on a naturalistic and physiological interpretation of abstract labour as pure expenditure of human energy, the proponents of cognitive capitalism theory ignore the role of knowledge in the determination of value (as in the monopoly price approach). Second, then, the separation between conception (knowledge production) and execution (commodity production) is seen as the condition of value production since, for them, only the latter is measurable by labour time and value is all about the imposition of measure. According to this understanding of value theory, the applicability of value is limited and attached to a specific form of the division of labour. And value is necessarily degraded into a technical category from a social category expressing the social relations between producers. Third, on the basis of the (casual) observation that cognitive labour is replacing simple and repetitive manual labour as the hegemonic form of labour in contemporary capitalism, it is argued that the form of the division of labour underpinning value production is collapsing and therefore new theories of value are required. Although no such theory has been developed as yet, with measurability as such being denied, any theory of value in cognitive capitalism can only be a theory of use value, in which Marx's distinction between value and use value would no longer be valid.

Chapter 5 is concerned with intellectual property rights and rent theory. Instead of situating intellectual property rights at more concrete and complex levels of analysis, the three interpretations of value theory criticised in Chapter 3 and Chapter 4 provide relatively crude and simple conclusions on the role of intellectual property rights. First, for the monopoly price approach, intellectual property rights are equated with monopoly pricing. Knowledge is understood as being freely available by nature and, therefore, if there were no intellectual property rights, the price of commodities produced in knowledge-intensive sectors would be much lower (zero in case of information commodities). From this point of view, knowledge becomes scarce only because of intellectual property rights, giving rights holders the power to extract surplus profit which they are not entitled to otherwise. However, intellectual property rights are not specific to knowledge-intensive sectors only and, 
therefore, to be consistent with the approach, we should conclude that monopoly pricing is preponderant across the economy (and, historically, not only in the contemporary period); where there are intellectual property rights, there must be monopoly pricing. This unfortunately leads to the (implicit) rejection of the validity of value theory for contemporary capitalism despite the strong adherence and commitment of the proponents of this approach to value theory.

Second, in the cost approach, intellectual property rights are seen to transform surplus profit into rent. It is argued that Marx's theory of ground rent applies to anything that is non-replicable and can be the source of surplus profit if its use is monopolised. In other words, some surplus profits become rents because they satisfy certain conditions. Consequently, rent becomes a special form of surplus profit, a classificatory concept, and Marx's rent theory is degraded into a static distribution theory, with property rights playing no role in determining value production, in general, and capital investments, in particular. By contrast, for Marx, ground rent is an economic category that expresses a historically specific form of landed property and its consequences for the development of large-scale agriculture. His theory of ground rent is, then, an application of his value theory to agriculture in the presence of a historically specific form of landed property. His emphasis is placed upon showing that the capitalist form of landed property obstructs the development of modern agriculture in a number of ways, which are expressed in different forms of ground rent (differential rent II and absolute rent). Whilst his analysis of ground rent is certainly useful for developing a theory of knowledge in contemporary capitalism, transplanting it to different industries organised around different (intellectual) property systems should be avoided.

Third, rent is suggested as the central category in cognitive capitalism theory. As a use value theory, it is interested in showing that knowledge plays much more important roles than in previous stage of capitalism whilst increasingly being produced outside both workplace and the capital-labour relation, which is then seen as exacerbating the measurability problem and making it difficult to identify who has contributed to production and how much. Regardless of these practical problems, it is also argued that capitalists do not play any meaningful role in the production process but they can continue to appropriate a portion of total output only by way of intellectual property rights. As a corollary, they no longer earn profit because they do not contribute to production but only appropriate rent by monopolising important factors of production, not least knowledge. From this point of view, then, intellectual property rights should be eradicated and the portion of 
total output that is being currently appropriated by capitalists as rent should be reappropriated by the members of society as basic income. Leaving aside the problem of measuring the contribution of workers and non-workers to the production of the 'common' (given its immeasurability), the idea that basic income can be justified because we are being paid less than our collective contributions ties the fate of basic income to that of cognitive capitalism theory and therefore can turn out to be detrimental to the cause of basic income.

In Chapter 6, we attempt to develop a constructive theory of knowledge on the basis of the virtual multiplication approach put forward in Chapter 3 and in light of the deficiencies and flaws of the theories criticised in earlier chapters. In doing this, the following principles are applied. First, we develop a value theory of knowledge, not a use value theory. This is simply because knowledge production in capitalism is driven primarily by value production and the drive for accumulation. As a result of knowledge production, the production of use value expands significantly in quantity, quality and diversity, but only as a by-product. This by no means suggests that the relations between knowledge and use value should be ignored, but any attempt to build a use value theory of knowledge cannot bypass known theoretical conundrums related to productivity such as the productivity paradox and Baumol's cost disease (Baumol, 2012). Second, as we develop a more complex and concrete theory of knowledge, for example, by bringing intellectual property rights into the analysis, so too the distinction between knowledge and commodities necessarily takes more complex and concrete forms. It is not only that these forms are the logical unfolding of the distinction, but they can and should be wedded to an analysis of the historically specific forms of knowledge production in contemporary capitalism. Third, given that intellectual property rights have different effects in different industries, there can be no general theory of intellectual property rights, not to mention a general rent theory. Rather, the focus should be placed upon analysing the interplay of intellectual property rights with industry-specific dynamics and its consequences. These principles underpin our brief analysis of the digital music industry, the semiconductor industry and outsourcing, respectively. In all three examples, intellectual property rights allow for specialisation and play important roles in shaping and transforming the value chain dynamics. However, in case of the recorded music industry, with the rapid and widespread adoption of digital technologies and the continuing introduction of new business models, especially the subscription streaming model, record labels (intellectual property rights holders) are increasingly trying to exploit and develop new business opportunities to 
generate new and stable royalty revenue streams, sometimes obstructing capital investments aimed at increasing the user base and launching innovative products and services. In the semiconductor industry, the distinction between knowledge and commodities appears as the division of innovative labour between (fabless and chipless) companies specialised in chip design and foundries specialised in manufacturing. Intellectual property rights are not only the basis of the deepening of specialisation in the industry but also can be seen as largely fostering innovation, with the industry as a whole relying on chipless companies (which license chip designs) such as ARM and Imagination Technologies for basic and fundamental industry-wide R\&D. In this respect, whilst chipless companies earn licensing fees and royalties, these have nothing to do with exploiting advances made by others. Outsourcing of manufacturing deals with the other side of specialisation and also relies on intellectual property rights. In this case, however, contract manufacturing companies earn neither licensing fees nor royalties, but are paid for their contract manufacturing services. Then, whilst licensing fees and royalties indeed arise from intellectual property rights, the latter is not necessarily economically realised through the former. In addition, outsourcing, by definition, does not involve any direct labour on the purchaser side. The contract manufacturing company (e.g. Foxconn) provides contract manufacturing services produced by workers employed by the company. And the final product of the purchaser (e.g. Apple's iPad) is produced by combining manufacturing services with other means of production. Foxconn workers contribute to the value of iPads only indirectly by way of producing manufacturing services. This suggests that information commodities whose production requires next to no direct labour is in fact not an exception.

\subsection{Method and the dual nature of the commodity}

Against this background, this section examines the dual nature of the commodity and its development and concretisation in the first volume of Capital. This is important for the following reasons. First, as mentioned earlier, in theorising knowledge on the basis of value theory, the distinction between value and use value is of great importance. Significantly, the dual nature is not simply two opposing aspects of a commodity, but it permeates the understanding of capitalism across all levels of abstraction, with the commodity being its most simple and abstract form. Then, tracing the development of the dual nature should be an essential part of complex and concrete analyses of knowledge. In other words, the logical and historical unfolding of the distinction between knowledge production and 
commodity production should be theorised as the result of, and in the context of, the logical and historical development of the dual nature of the commodity, progressing from the simple and abstract to the complex and concrete. ${ }^{7}$ Second, and more specifically, especially with the introduction of the large-scale industry based on machinery, the opposition between value and use value develops into real contradiction and struggle, in which knowledge plays a crucial role in establishing the dominance of value over use value (in the social labour process), such that human beings are degraded from being the subject of labour to human material for both the operation of machinery (in the labour process) and exploitation (in the valorisation process). With knowledge playing mediating roles in the development of the dual nature of the commodity, the dialectical relations between knowledge and commodity need to be recognised and analysed.

Whilst this section is concerned with laying out the methodological principles of this thesis, it is a contribution to the study of Marx's method and, to that extent, can be read independently of the other parts of the thesis.

\section{The dual nature of the commodity}

Marx opens Capital with the commodity. This is not an arbitrary choice; he does so because the commodity, to him, is the elementary form of the social wealth or the "economic cell-form" (CI, p. 90) of the bourgeois society. The analysis of the commodity "deal[s] with minutiae, but so similarly does microscopic anatomy". For Marx, the bourgeois society or the capitalist mode of production is an organic whole, of which the commodity form is the seed or gene with the capacity of underpinning the adult organism.

\footnotetext{
7 Jessop and Sum (2006, pp. 303-304) distinguish the movement from the abstract to the concrete from that from the simple to the complex. The former is "the increasing concretisation of a given phenomenon (for example, from commodities in general to labour power as a fictitious commodity to the wage relation, on to the determination of the nominal wage to the real wage, and so on)". The latter is about "introducing further dimensions of a given phenomenon (for example, state, capitalist state, patriarchal capitalist state, multicultural patriarchal capitalist state, and so on)". In his defence of the regulation approach on the basis of critical realism, Jessop (2001, p. 99) also argues that Marx tended to ignore the movement from the simple to the complex, although he considers that it is implicit in his method: "Although Marx himself did not explicate this distinction between types of theoretical movement, it is certainly implicit in his well-known statement that one should aim to reproduce the 'real-concrete' as a 'concrete-in-thought', i.e., as the concrete synthesis of multiple determinations and relations".
} 
Starting his presentation from commodity, not from the "concept of value" (CW24, p. 544), Marx immediately draws attention to the dual nature of commodity, being both a use value and a value. Use value and value are interdependent: a commodity is a value only if it is a use value and it can be consumed only after it is exchanged. At the same time they are mutually exclusive or in opposition with each other: commodities, as use-values, are distinguished from each other in quality, but as values, only in quantity; value abstracts from use value and contains nothing related to use value; use value explains consumption and value exchange. Significantly, for Marx, the dual nature is the essential characteristic of commodities: "Iron, linen, corn, etc. are only commodities because they have a dual nature, because they are at the same time objects of utility and bearers of value" (CI, p. 138). ${ }^{8}$

By the same token, labour has a dual nature; commodity-producing labour is at once concrete labour and abstract labour. As is the case with the commodity, labour is considered only in terms of quality in its relation with use value and only of quantity

\footnotetext{
${ }^{8}$ Marx "was the first to point out and examine critically this twofold nature of the labour" and "this point is crucial to an understanding of political economy" (CI, p. 132). He mentioned in a letter to Engels right after the publication of the first volume of Capital, dated August 24, 1867, that "the two-fold character of labour [emphasis removed]" (CW42, p. 407) is one of the two best points of the book, which is "fundamental to all understanding of the FACTS". In another letter to Engels dated January 8, 1868, he again pointed out that the dual nature of labour is one of "the three fundamentally new elements of" the first volume of Capital:

The economists, without exception, have missed the simple fact that, if the commodity has the double character of use value and exchange value, then the labour represented in the commodity must also have a double character; thus the bare analysis of labour sans phrase, as in Smith, Ricardo, etc., is bound to come up against the inexplicable everywhere. This is, in fact, the whole secret of the critical conception. (p. 514)
}

The discovery and refinement of the notion of the dual nature of the commodity had a long gestation period. The basic idea of the dual nature appears in his early works. For example, in On the Jewish Question written in 1844, Marx says:

Where the political state has attained its true development, man-not only in thought, in consciousness, but in reality, in life-leads a twofold life [emphasis added], a heavenly and an earthly life: life in the political community, in which he considers himself a communal being, and life in civil society, in which he acts as a private individual, regards other men as a means, degrades himself into a means, and becomes the plaything of alien powers. (CW3, p. 154)

In addition, in German Ideology written in 1845, he says:

The production of life, both of one's own in labour and of fresh life in procreation, now appears as a twofold relation [emphasis added]: on the one hand as a natural, on the other as a social relation-social in the sense that it denotes the co-operation of several individuals, no matter under what conditions, in what manner and to what end. (CW5, p. 43) 
in its relation with value. For this reason, concrete labour is concerned with how labour is performed and what it produces, whereas in abstract labour how and what are abstracted away, leaving only how much labour has been expended, i.e. the duration of labour. More importantly, whereas abstract labour is the substance of value, concrete labour is only $a$ factor of production. Whilst the final outcome of concrete labour is certainly a product of labour, labour alone is not sufficient to produce useful things. "As William Petty says, labour is the father of material wealth, the earth is its mother" (CI, p. 134).

At this abstract level of analysis, put forward in the first two sections of Chapter 1 of Volume 1 of Capital, a commodity is viewed only as an isolated thing with a dual nature, but with no particular relation with other commodities whatsoever. ${ }^{9}$ However, commodities as values are "expressions of an identical social substance, human labour" (p. 138) and therefore "purely social" (p. 139), presupposing "the social relation between commodity and commodity". At the same time, it is a contradiction that the value of a commodity is expressed in its use value, so it must be expressed in the relations with other commodities. With the level of abstraction becoming more concrete to encompass the value relations and value expressions, the dual nature of the commodity also takes a more concrete and complex form.

\section{The expression of value}

In the simplest value relation between two commodities A and B which contains "the whole mystery of the form of value", the value of a commodity A is expressed in the other commodity B. ${ }^{10}$ With the value of commodity A acquiring a form of

\footnotetext{
9 The dual nature of the commodity does not derive from the specific material characteristics of products of labour, but presupposes a historically specific society in which commodities are mass produced and exchanged in the market: "The product of labour is an object of utility in all states of society; but it is only a historically specific epoch of development which presents the labour expended in the production of a useful article as an 'objective' property of that article, i.e. as its value. It is only then that the product of labour becomes transformed into a commodity" (CI, pp. 153-154).

${ }^{10}$ Lapavitsas (2005) considers the simple form of value as a simple and accidental form of exchange, not of value, with "one trader taking the initiative and requesting exchange with the other" (p. 103). For him:
}

The successive 'forms of value' are treated as stages in the development of exchange value, which is also the process through which money emerges in commodity exchange ... the development of the form of value is not a summing up of the historical process of money's emergence but represents the logical unfolding of relations among commodity owners as they interact in exchange [emphasis added]”. (p. 102) 
expression independent of its material form, the dual nature of the commodity is externalised. In this expression of value, the material form of commodity A has nothing to do with its value whereas that of commodity B functions purely as the body of value. In other words, "the natural form of commodity A figures only as the aspect of use value, while the natural form of B figures only as the form of value, or aspect of value" (CI, p. 153). These two commodities "are two inseparable moments, which belong to and mutually condition each other" (pp. 139-140). At the same time, they are also mutually exclusive, given that a commodity can be either in the relative form or in the equivalent form, but not in both concurrently. The mutual dependence and exclusivity between the two commodities in the expression of value is an externalised and developed form of the mutual dependence and exclusivity between value and use value:

The internal opposition between use value and value, hidden within the commodity, is therefore represented on the surface by an external opposition, i.e. by a relation between two commodities such that the one commodity, whose own value is supposed to be expressed, counts directly only as a use value, whereas the other commodity, in which that value is to be expressed, counts directly only as exchange value. Hence the simple form of value of a commodity is the simple form of appearance of the opposition between use value and value which is contained within the commodity. (p. 153)

\section{The differentiation of commodities into commodities and money}

Marx's analysis then moves forward to the process of exchange, in Chapter 2 of Volume 1 of Capital. For each party taking part in an exchange, it is both an individual process obtaining a use value and a social process realising the value of his commodity. From the viewpoint of the former, a commodity owner wants a particular use value that can satisfy his particular need. In case of the latter, however, the same owner expects the exchange to have nothing to do with the use value of his commodity as he considers it only as a value: "Every other commodity counts as the particular equivalent of his own commodity. Hence his own commodity is the universal equivalent for all the others" (p. 180). Whereas there are two distinct roles in the expression of value, the relative form of value and the equivalent form, commodities, and their owners, enter into an exchange as equals. It is therefore not acceptable to respect the need of one party for the acquisition of a

By contrast, in Chapter 1 of the first volume of Capital, Marx analyses the expression of value and the form of value only, not exchange. 
particular use value whilst ignoring the same need of the other party. Consequently, exchange cannot occur unless by chance and the relations between the two commodities fail to go beyond the expression of value in thought.

According to Marx, to break the impasse, people already "acted before thinking" (CI, p. 180), by bringing their commodities into a relation with a particular commodity. As the result of this social action, "money necessarily crystallises out of the process of exchange" (p. 181), ${ }^{11}$ differentiating commodities into commodities and money, with the latter being the general equivalent in which all commodities express their values. This also establishes an all-round, if indirect, relation among all commodities, namely "the world of commodities" (p. 129). A commodity remains as both a use value and a value within the world of commodities, hence the dual nature is preserved, but the value side of the commodity attains the independent and external form of existence in money. The commodity, in its material form, is now considered only as a use value and, conversely, the material form of the money commodity only as pure value crystal. ${ }^{12}$ Marx sums up the process of externalisation dialectically, and as if value drives the transition as the self-acting subject, ${ }^{13}$ as

${ }_{11}$ "Money does not originate by convention, any more than the State does. It arises from exchange, grows naturally out of exchange, is a product of exchange [emphasis added]" (CW28, p. 102).

${ }^{12}$ In the Grundrisse, Marx often equates value with money as if money is a property of commodity: for example, "The exchange value of the commodity is its immanent monetary attribute" (CW28, p. 84); "In so far as money no longer exists as a quality of commodities, as their general attribute, but is individualised alongside them, it becomes itself a particular commodity among the other commodities (subject to the determination of demand and supply; can be divided into particular types of money, etc.)" (p. 88); "All commodities are transitory money" (p. 87); "All commodities are merely perishable money ... the commodity is only local money" (p. 164). Similarly, "money is an essential aspect of the commodity" (CW32, p. 132).

${ }_{13}^{13}$ The externalisation of the dual nature of the commodity is both the precondition for, and the result of, the internal opposition between value and use value. As we have seen earlier, the dual nature presupposes the historical condition that commodity production and exchange are generalised in the economy, which requires the everyday use of money more than anything else. At the same time, the differentiation of commodities into commodities and money and the development of the all-round relation among all commodities are the result of the externalisation of the dual nature. According to Marx (CW28, p. 208), in "every organic system", "everything posited is ... also a premiss".

On the difference between precondition/result and cause/effect, Ollman (2003, p. 121) writes: 
follows:

The need to give an external expression [emphasis added] to this opposition [between use value and value] for the purposes of commercial intercourse produces the drive [emphasis added] towards an independent form of value, which finds neither rest nor peace until an independent form has been achieved by the differentiation of commodities into commodities and money. (CI, p. 181)

The complex interaction by which the cause is itself shaped and made adequate to its task by the effect, now functioning in its turn as a cause, is easily lost or distorted, even where-as in Marx's case-causes and effects are viewed as internally related. If Marx still uses the formulation 'cause' and 'effect' (or 'condition,' 'determine,' and 'produce' in the sense of 'cause'), this is usually a shorthand and first approximation for bringing out for purposes of exposition some special feature in a conclusion whose essential connections have been uncovered by studying them as preconditions and results.

He continues:

Unable to follow Marx's practice in making abstractions, lacking a conception of internal relations and a workable grasp of the often conflicting demands of inquiry and exposition, most of Marx's readers have forced his words on precondition and result into a causal framework. The components of capitalism get divided into causes (or conditions, generally understood as weak or broad causes) and effects, with the result that the former, separated from their real causes, are made to appear historical, possibly natural, as something that cannot be changed or even seriously questioned.

Given this distinction, whereas knowledge is the cause and economic growth the effect in new growth theory, knowledge is the precondition and accumulation the result in value theory, see Section 2.5. In addition, in the following quotes from Marx, "arise from" should be understood as linking preconditions with results, not causes with effects: "The properties of a thing do not arise from [emphasis added] its relations to other things, they are, on the contrary, merely activated by such relations" (CI, p. 149); "The form of value, that is, the expression of the value of a commodity, arises from [emphasis added] the nature of commodity-value, as opposed to value and its magnitude arising from their mode of expression as exchange-value" (p. 152).

In a similar vein, Leopold (2007, pp. 48-49) argues that Marx takes a two-stage approach in reconstructing and reinterpreting Hegel's philosophy:

These two stages - which he characterises as the 'transformation of the empirical into the speculative and the speculative into the empirical' - are said to form the systole and diastole of Hegel's speculative method. ... Marx ... portrays this two-stage process at the heart of absolute idealism in terms of a distinctive and recurring pattern of 'inversion'. Initially, concepts which are themselves derived from the finite empirical world are characterised as elements of an a priori categorical framework. Subsequently, that (purportedly) a priori categorical framework is characterised as actualising itself in the essential features of the finite world. In this way, the empirical world - from which the categorical framework is in fact derived - becomes transformed into (or, more accurately, is redescribed as) the manifestation of that conceptual system. Marx describes the subject of the 'inversion' here in a variety of ways. At one point, he summarises speculative construction as a process in which 'the fact which serves as a starting point [that is, empirical reality] is not seen as such but as a mystical result'. The same twofold process is characterised in terms of a series of parallel reversals whereby 'the condition is posited as the conditioned, the determinator as the determined, the producer as the product'. 
The contradiction inherent in the dual nature of the commodity, that an act of exchange cannot be both the social process of value realisation and the individual process of use value acquisition to both parties, is "both realised and resolved" (CI, p. 198) by the selection of a particular commodity as money. It is resolved because with money, value realisation (sale) and use value acquisition (purchase) are separated from each other, and it is realised or actualised because the internal opposition between value and use value is externalised. Importantly, the new external opposition between money and commodities gives rise to the two functions of money - measure and instrument of circulation, respectively. First, the mutual exclusivity between the social process (value realisation) and the individual process (use value acquisition) takes the form of the essential difference between money, the general equivalent, and (particular) commodities. It is the basis of the function of money as measure in the sense that a measure should first be separated out from what is to be measured by it. Second, the mutual dependence between the two processes - the unity of the two processes - is expressed by the circulation of commodities, the constant repetition of sale and purchase. The function of money as instrument of circulation, then, arises from this unity. ${ }^{14}$ In short, whilst the (external) separation between the two processes, between money and commodities and between sale and purchase seemingly abolishes the contradiction, the internal bond between the two opposing sides ensures that they do not become completely independent of each other. Rather, the internal mutual dependence asserts itself through the external (seeming) independence between the opposing moments of circulation. ${ }^{15}$

This has a few implications. First, despite sale and purchase forming an internal

${ }^{14}$ In this respect, the two functions of money also derives from the dual nature of the commodity (CW 28, p. 123):

\begin{abstract}
Money has a dual determination: (1) as the measure or element in which the commodity is realised as exchange value, and (2) as means of exchange, instrument of circulation; and these two determinations have effects in quite different directions. Money only circulates commodities which have already been notionally transformed into money, not only in the mind of the individual but in the imagination of society (directly, of the parties involved in the process of purchase and sale). The notional transformation into money and the real one are not governed by the same laws at all. The relationship between them must be investigated.
\end{abstract}

15 For Say who denies the existence of overproduction on the grounds that a sale is always a purchase and vice-versa, not only is there no distinction between the external independence and the internal dependence between sale and purchase, but there is no place of contradiction in exchange. For Marx's critique of Say, see Marx (CW32, pp. 131-134). 
unity, the circulation of commodities mediated by money, alternating endlessly between sale and purchase, can be either halted or delayed for many reasons, inflicting cracks on the unity: "As soon as money is an external thing alongside the commodity, the exchangeability of the commodity for money is immediately linked to external conditions, which may or may not be present. It is subject to external circumstances" (CW28, p. 85). Second, however, the external independence between sale and purchase is the mode of existence of the internal dependence, and thus cannot break away from its control: "If the assertion of their external independence proceeds to a certain critical point, their unity violently makes itself felt by producing - a crisis" (CI, p. 209). In the same vein, Marx argues that the separation between sale and purchase "appears in the crisis" and is the "elementary form of the crisis" (CW32, p. 133). ${ }^{16}$ Third, whilst the circulation of commodities is regulated by the dual necessity of value realisation and use value distribution, the inner logic of circulation exists only in and through the seeming independence between sale and purchase and the corresponding instability at the surface level. ${ }^{17}$ Whatever triggers it and whichever form it takes, the instability of circulation, even to the extent that it leads to a crisis, is a form of appearance of its inner logic. ${ }^{18}$ These points are of great significance to more concrete and complex analyses, not

${ }^{16}$ Similarly, Marx (CW32, pp. 139-40) says:

The difficulty of converting the commodity into money, of selling it, only arises from the fact that the commodity must be turned into money but the money need not be immediately turned into commodity, and therefore sale and purchase can be separated. We have said that this form contains the possibility of crisis, that is to say, the possibility that elements which are correlated, which are inseparable, are separated and consequently are forcibly reunited, their coherence is violently asserted against their mutual independence. Crisis is nothing but the forcible assertion of the unity of phases of the production process which have become independent of each other.

17 "Exchange does not alter the inner conditions ... but it projects them outwards, gives them a form independent of one another, and thus lets their inner unity exist only as an inner necessity which is therefore given violent external expression in crises" (CW28, p. 376).

18 "As the exchange value of a commodity has a dual form of existence, as a specific commodity and as money, so the act of exchange consists of two mutually independent acts: exchange of the commodity for money, exchange of the money for a commodity, buying and selling. Since these have now acquired a form of existence distinct from one another in space and time and indifferent to one another, their immediate identity ceases to exist. They may correspond or not; they may coincide or not; disparities may occur between them. True, they will always seek to get into balance, but the earlier direct equality has now been replaced by the continual movement towards equalisation, which of course presupposes continual inequality. It is possible that consonance between them may now be fully attained only by passing through the most extreme dissonances [emphasis added]" (CW28, pp. 85-86). 
least to crisis theory. For now, however, suffice it to say that money is not the final outcome of the development of the dual nature of the commodity. As more historical as well as conceptual elements are brought into the analysis, the dual nature of the commodity develops into more concrete and complex forms. We cannot fully trace each and every step of concretisation that the dual nature goes through, but the following examples show how deeply the dual nature of the commodity is embedded in Marx's analysis, not least in his analysis of the concept of capital.

\section{The dual nature of capital}

First, the concept of capital is built on the dual nature of the commodity. Whereas money is the outcome of the externalisation of the dual nature, capital derives from the imposition of the dual nature on human being's capacity to labour, that is, its commodification into labour power. ${ }^{19}$ Valorisation (and thus capital) arise neither from labour power as value alone nor from labour power as use value alone, but from labour power as the unity of value and use value: from its value, the labour time required to reproduce labour power which should be exceeded for valorisation to succeed; and from its use value, the power to create value. As Marx puts it, valorisation "must have its origin both in circulation [value] and not in circulation [use value]" (CI, p. 268). It needs both circulation, governed by exchange between value equivalents, and its absence, where exchange gives way to consumption (of labour power as use value).

Second, with the commodification of the human capacity to labour, the dual nature of labour is reconstructed into a subject-object duality. Labour - the effect of the consumption of labour power - is, on the one hand, concrete labour, subjective and purposeful human activity, however dire the conditions of labour are. It is "the living, form-giving fire" (CW28, p. 286) as Marx famously puts it, transforming the means of production into products of labour during the labour process. At the same time, as abstract labour, far from being consciously performed, labour is extracted from labour power during the valorisation process, of which the means of

\footnotetext{
19 "In the process of production ... dead labour is replaced by living labour, something stagnant by something flowing, a constant by a variable. The result is the reproduction of $v$ plus an increment of $v$. From the point of view of capitalist production, therefore, the whole process appears as the independent motion of what was originally constant value, but has now been transformed into labour power. Both the process and its result are ascribed to this independent motion of value" (CI, p. 322).
} 
production are the subject, consuming the commodity labour power, the human raw materials, for valorisation: "Instead of being consumed by him [the worker] as material elements of his productive activity, they consume him as the ferment necessary to their own life-process" (CI, p. 425). Consequently, in the capitalist production process, "the unity of the labour process and the process of valorisation" (p. 304) and a developed form of the dual nature of the commodity, human beings are rendered also to have the dual nature, of being both the subject of labour and the object of valorisation. ${ }^{20}$ It is worth noting that this inversion of subject and object is reproduced in the transformation of surplus value into a form of profit (CIII, p. 136):

Yet the way that surplus value is transformed into the form of profit, by way of the rate of profit, is only a further extension of that inversion of subject and object which already occurs in the course of the production process itself.

\section{Concepts with a dual nature}

Third, at a relatively abstract level of analysis of capital in which the labour process is assumed to be intact despite the introduction of the capitalist relations, Marx deploys pairs of concepts that embody the dual nature of labour. For example, value creation and value transfer have bearings on abstract labour and concrete labour, respectively: "By the simple addition of a certain quantity [emphasis added] of labour, new value is added, and by the quality [emphasis added] of this added labour, the original values of the means of production are preserved in the product. This twofold effect, resulting from the twofold character of labour, appears quite plainly in numerous phenomena" (CI, 309). In turn, value transfer and value creation, the two opposing aspects of the capitalist production process, are externalised in the opposition between constant capital and variable capital. Constant capital, the portion of capital whose value is preserved by being transferred to the final product, represents the concrete side of labour and variable capital the abstract side. Capital is the unity of constant capital (= use value) and variable capital (= value) ${ }^{21}$ and, in this respect, also exhibits a dual nature, which is

\footnotetext{
${ }^{20}$ At this stage, use value and value are only in opposition. Once it develops into a contradiction, the subject-object duality gives way to the struggle between living labour and dead labour. See the sub-section of this chapter titled 'From opposition to contradiction'.

${ }^{21}$ According to Marx (CI, pp. 314-315), labour's function of value transfer is a sort of positive externality to capital:
}

The worker is unable to add new labour, to create new value, without at the same time preserving old values, because the labour he adds must be of a specific useful kind, and 
an externalisation and a developed form of the dual nature of the commodity and labour:

There now appears, as the result of this unity of the production and valorisation process [emphasis added], the product of the process, i.e. capital itself, as it emerges as the product of the process whose precondition it was as a product which is value. (CW28, p. 329)

Another example is the differentiation of constant capital into fixed constant capital and circulating constant capital. Concrete labour inflicts a partial loss of lifetime on a means of production, not least machinery, although this does not mean that there is necessarily any reduction in its use value. For use value under consideration here is indivisible. A machine is consumed over its lifetime, little by little due to wear and tear, but its usefulness does not diminish to the extent that it functions with the same quality and maintains the same throughput. It is useful only as a whole and thus enters the production process as a whole. ${ }^{22}$ It is only after it ceases to function or is replaced by a new, better machine that it loses its (social) use value (other than as potential in terms of changed or different circumstances such as second hand use elsewhere or a surge in demand with limits on capacity to deliver). Therefore, a means of production, especially a machine, is either a use value or a non-use-value - there is nothing in between. From a value point of view, on the contrary, at any moment, the machine is losing its lifetime little by little and is therefore also transferring its value to the final product little by little. Likewise, that different means of production have different lifetimes has economic significance in terms of value, not of use value, ${ }^{23}$ especially when technical change is considered, with the

he cannot do work of a useful kind without employing products as the means of production of a new product, and thereby transferring their value to the new product. The property therefore which labour power in action, living labour, possesses of preserving value, at the same time that it adds it, is a gift of nature which costs the worker nothing, but is very advantageous to the capitalist since it preserves the existing value of his capital.

22 Marx also examines an opposite example (CI, p. 313):

A means of production may enter as a whole into the valorisation process, although it enters only piece by piece into the labour process. Suppose that in spinning cotton, the waste for every $115 \mathrm{lb}$. used amounts to $15 \mathrm{lb}$., which is converted, not into yarn, but into 'devil's dust'. Now, although this amount of waste is normal and inevitable under average conditions of spinning, the value of the $15 \mathrm{lb}$. of cotton is just as surely transferred to the value of the yarn as is the value of the $100 \mathrm{lb}$. that form the substance of the yarn.

${ }^{23}$ As Marx explains, the role of a means of production in the labour process has nothing to do with that in the valorisation process. A means of production, albeit indispensable for use value production, may as well contribute very little to the value of final products: 
means of production with longer lifetimes being more vulnerable to the risk of devaluation. This necessitates the introduction of the economic concepts reflecting a varying lifetime of means of production and its economic consequences, that is, fixed constant capital and circulating constant capital. ${ }^{24}$

\section{From opposition to contradiction}

One important characteristic of the dual nature of the commodity and its development under the capitalist relations is that the two sides in opposition get to engage with each other, developing opposition into contradiction. Either it is resolved by developing into a new form, or it intensifies the struggle between the two sides in contradiction until one prevails over the other, according to Thomas Weston (2012): "For Marx as for Hegel, the main difference between opposition and contradiction is negativity, the internal activity of a contradiction" (p. 13), 25 although Marx does not use the distinction between opposition and contradiction consistently (pp. 14-15). ${ }^{26}$ From this point of view, whereas sale and purchase are in opposition when they are considered as the externalisation of the internal dependence between the two, they are in contradiction as soon as the circulation of commodities is disrupted and there appears a rupture between the two. Similarly, value and use

\footnotetext{
If an instrument of production has no value to lose, i.e. if it is not the product of human labour, it transfers no value to the product. It helps to create use value without contributing to the formation of exchange-value. This is true of all those means of production supplied by nature without human assistance, such as land, wind, water, metals in the form of ore, and timber in virgin forests. (CI, p. 312)
}

The same applies to knowledge although it is a product of human labour, see chapter 3 for more on this.

${ }^{24}$ In addition, due to gradual transfer of its value, the value of fixed constant capital "acquires a dual existence" (CII, p. 243): "A part of it remains tied to its use form or natural form, which pertains to the production process, while another part separates off from this form as money".

25 "Negativity is an abstraction of conflict, not of the absence of something. Both Marx and Hegel generally understand it in this way" (Weston, 2012, p. 13).

26 "His revisions of Capital, Volume 1, for the second edition suggest, however, that he was then taking greater care in distinguishing opposition from contradiction" (Weston, 2012, p. 15). He continues in the footnote (references to Marx's works are removed):

'Widerspruch' [contradiction] and its variants occur two dozen times in the first four chapters (and the Appendix to Chapter 1) of the first edition, the area of the text that has the highest concentration of dialectical terminology. For that edition, Marx deleted two occurrences of 'contradiction' and twice replaced 'contradiction' with 'opposition'. The substantive change here was to drop the assertion that use value and exchange-value are in 'immediate [unmittelbarer] contradiction'. 
value are in opposition in the expression of value, but it develops into a contradiction when commodities are brought into market for exchange, which is resolved by the differentiation of commodities into money and commodities. ${ }^{27}$

Significantly, the struggle between the two sides in contradiction, "contending agencies" (CIII, p. 357), is real as well as conceptual, leading to alterations in reality. ${ }^{28}$ As we have seen earlier, the capitalist production process is the unity of the labour process and the valorisation process. When the introduction of the capitalist relations does not interfere with the labour process, i.e. the "formal subsumption of labour under capital" (CI, p. 645), they are merely in opposition. With the introduction of machinery and large-scale industry, however, the opposition develops into a real contradiction in which the valorisation process is constantly on the offensive, driven by the insatiable desire for valorisation inherent in capital. Consequently, although labour in the stage of large-scale industry remains as both concrete and abstract, it turns out that labour is first and foremost abstract labour, with concrete labour being performed only for the purpose of extracting abstract labour and reconfigured to best suit the need for the extraction of abstract labour, i.e. the "real subsumption" of labour under capital. Not only are human beings degraded into the object of the labour process as well as the valorisation process, but the capitalist form of social production takes precedence over its content, i.e. satisfaction of social needs. Likewise, it is no longer use value but valorisation that is the immediate motive of production. Although use value remains useful for capital in the sense that it allows for valorisation, as long as valorisation can continue, it does not matter to capital whether or not it goes hand-in-hand with use value

${ }_{27}$ "The dual existence [of the commodity as a specific product and as money] in two distinct forms must lead to differentiation, and the differentiation to opposition and contradiction" (CW28, pp. 84-85). According to Weston (2012, p. 13), when referring to oppositions that have yet to develop into contradictions, Marx uses the word complementary. For example, "The possibility of a crisis ... only arises from the fact that the differences in form-the phases-which it [metamorphosis] passes through in the course of its progress, are in the first place necessarily complementary [emphasis added]" (CW32, p. 138). Similarly, "If we say that the simple form of metamorphosis comprises the possibility of crisis, we only say that in this form itself lies the possibility of the rupture and separation of essentially complementary [emphasis added] phases" (p. 139).

28 "As the contradiction undergoes the fullest possible development and nears resolution, this interference is increased to such an extent that the two sides cannot coexist any longer, and one must defeat the other, either by destroying it or by weakening it so completely that it can no longer interfere with the victorious side" (Weston, 2012, p. 24). 
production, as is most clearly expressed in the circuit of interest-bearing capital (MM'). However, even in this extreme case, with interest being indeed a form of surplus value and ultimately requiring use value production by industrial capitalists, use value is not only the means of, but also the prerequisite for, valorisation and thus limits the expansion of value production.

In this assault of the labour process by the valorisation process, and more generally, of use value by value, knowledge plays a critical role. Knowledge is a prerequisite for commodity production and, therefore, also has a dual nature: Knowledge is a factor determining the productivity and complexity of commodity-producing labour, or the value-producing capacity of labour, see Chapter 3 for more on this; Knowledge also determines the use value of a commodity, not only the functional and technical specifications but also the production technologies or technical relations between factors of production. New knowledge, then, in theory, affects both the valorisation process and the labour process; capitalists produce and deploy new knowledge to raise the value-creating capacity of labour and thereby realise extra surplus value or surplus profit, and in doing so, make alterations to the labour process, quantitatively and/or qualitatively.29 Marx analyses in detail three major qualitative changes in the labour process in Chapters 13-15 of the first volume of Capital, simple co-operation, manufacture and large-scale industry based on machinery, respectively. Significantly, through these successive transformations, "the knowledge, judgement and will" (CI, p. 482) are taken away from individual workers and objectified in the means of production, confronting the workers as the power outside workers' control, with the mechanism of its operation being dictated by the capitalists. ${ }^{30}$ For Marx, this transformation culminates in large-scale industry based on machinery, in which workers are degraded into the object of not only the valorisation process but also the

29 "Hitherto, in dealing with the production of surplus value in the above form, we have assumed that the mode of production is given and invariable. But when surplus value has to be produced by the conversion of necessary labour into surplus labour, it by no means suffices for capital to take over the labour process in its given or historically transmitted shape, and then simply to prolong its duration. The technical and social conditions of the process and consequently the mode of production itself must be revolutionised before the productivity of labour can be increased" (CI, pp. 431-432).

30 "If capitalist direction is thus twofold in content, owing to the twofold nature of the process of production which has to be directed - on the one hand a social labour process for the creation of a product, and on the other hand capital's process of valorisation - in form it is purely despotic. As co-operation extends its scale, this despotism develops the forms that are peculiar to it" (CI, p. 450). 
labour process, with "the employment of women and children", "the prolongation of the working day" and "intensification of labour" being key side-effects (CI, Chapter 15):

Every kind of capitalist production, in so far as it is not only a labour process but also capital's process of valorisation, has this in common, but it is not the worker who employs the conditions of his work, but rather the reverse, the conditions of work employ the worker. However, it is only with the coming of machinery that this inversion first acquires a technical and palpable reality [emphasis added]. (p. 548)31

On the other hand, new knowledge constantly raises the productivity of labour, driving down the value of commodities and expanding the scale of production, with more and more use-values being produced per worker in a given period of time. In addition, new inventions and innovations allow for the commodification of new raw materials, parts, sub-assemblies, processes, etc., developing the social division of labour in diversity and in quality as well as in quantity. ${ }^{22}$ Although new value created in the economy for a given period of time $(v+s)$, determined and limited by the number of workers employed by capital, may grow only gradually, the scale and scope of use value production, fuelled by the increasing development of the society's

${ }^{31}$ According to Marx, the inversion of the relation between living and dead labour is clearly a development of the dual nature of the commodity. In Chapter 3 of the first volume of Capital, even before he introduces the concept of capital, he writes (CI, p. 209):

There is an antithesis [Gegensatz], immanent in the commodity, between use value and value, between private labour which must simultaneously manifest itself as directly social labour, and a particular concrete kind of labour which simultaneously counts as merely abstract universal labour, between the conversion of things into persons and the conversion of persons into things [emphasis added]".

In a similar vein, he also writes, "The devaluation of the world of men is in direct proportion to the increasing value of the world of things" (CW3, p. 272).

32 For Marx (CIII, pp. 356-357), an expansion of use value production, in turn, contributes to accumulation (if) indirectly:

The development of labour productivity contributes to an increase in the existing capital value, since it increases the mass and diversity of use values in which the same exchange value is represented, and which form the material substratum, the objective elements of this capital, the substantial objects of which constant capital consists directly and variable capital at least indirectly. The same capital and the same labour produce more things that can be transformed into capital, quite apart from exchange value. These things can serve to absorb additional labour, and thus additional surplus labour also, and can in this way form additional capital. The mass of labour that capital can command does not depend on its value but rather on the mass of raw and ancillary materials, of machinery and elements of fixed capital, and of means of subsistence, out of which it is composed, whatever their value may be. Since the mass of labour applied thus grows, and the mass of surplus labour with it, the value of the capital reproduced and the surplus-value newly added to it grow as well. 
knowledge and not subject to devaluation due to technical changes, grows much faster than those of value production. This raises an important question of whether the explosive growth of the mass of use-values can be absorbed by the market, or the society's consumption power.

\section{Marx's starting point}

Before concluding this section, it is worth elaborating some of the methodological points which have been implicit in our discussion so far. First, Marx's starting point is the commodity, especially its dual nature, not the concept of value. 33 His focus is on commodity as the unity of value and use value and the dual nature's consequences at more concrete and complex levels of analysis; he is not concerned with deriving capital from commodity through money dialectically, as if capital is the culmination of the development of the value form. ${ }^{34}$ In his Notes on Wagner

33 For Postone (1993, p. 139), Marx's choice of commodity as the starting point of Capital reflects his movement from "a transhistorical starting point" to "a historically determinate one". Postone rightly recognises the critical importance of the dual nature of the commodity in Marx's analysis:

The category 'commodity,' in Marx's analysis, does not simply refer to an object, but to a historically specific, 'objective' form of social relations-a structuring and structured form of social practice that constitutes a radically new form of social interdependence. This form is characterised by a historically specific duality purportedly at the core of the social system: use value and value, concrete labour and abstract labour. Proceeding from the category of the commodity as this dualistic form, this nonidentical unity, Marx seeks to unfold from it the overarching structure, of capitalist society as a totality, the intrinsic logic of its historical development, as well as the elements of immediate social experience that veil the underlying structure of that society. That is, within the framework of Marx's critique of political economy, the commodity is the essential category at the heart of capital; he unfolds it in order to illuminate the nature of capital and its intrinsic dynamic. ... In my analysis of Capital, I shall show how this duality, according to Marx, becomes externalised and gives rise to a peculiar historical dialectic.

For critiques of Postone's interpretation of Marx's method, especially of his characterisation of labour as being self-mediating, see McNally (2004) and Aufheben (2007).

34 For value form theorists, the significance of commodity lies mainly in its being the simplest form of value; they apparently prefer starting from value (instead of commodity) and attempt to reconstruct Marx's Capital accordingly. They are, however, keenly aware that the commodity is Marx's unambiguous starting point. Hence, Arthur (2004a, pp. 24-30), endorsing Banaji (1979), instead argues that Capital has a "dual starting point" (p. 29):

The commodity form of the product is the analytical starting point, from which we separate out value and use value, while this value forms the synthetic point of departure for developing more complex relationships in the course of seeking how to ground it as the pure universal essence of the commodity. (p. 30)

Similarly, for Smith (1990, p. 80): "The ordering of the determinations of the value form itself commences with a form of simple unity, i.e. the simplest and most abstract structure 
published in 1880, Marx (CW24, p. 534) says, "For me neither 'value' nor 'exchangevalue' are subjects, but the commodity". ${ }^{35}$ Second, then, Marx's choice of commodity as the starting point is precisely because it is the elementary form of the dual nature, which is in turn commodity's differentia specifica, although Marx does not explicitly say so. ${ }^{36}$ Third, whilst dialectics plays an enormously important role in Marx's analysis, and he often employs a presentational style in which value features as the self-acting subject of dialectical movement, his somewhat idealist exposition should not be taken literally, other than for purposes of presentation. ${ }^{37}$ Equally importantly, for Marx, changes and developments in reality are never the result of conceptual developments. It is the other way around; concepts and theories are the reflection of the changes and developments in reality, only reconstructing the object of study in thought retrospectively..$^{8}$ This by no means denies theories the role of predicting the

[commodity] within which the value form is manifested [emphasis added]". His ordering starts from the commodity, not because it is Marx's starting point but because it is the simplest form of value. Bidet (2007, p. 136) points out that Marx indeed considered starting from value, and quotes from a letter Marx wrote to Lassalle, dated 11 March 1858: "It [the first instalment] contains 1. Value, 2. Money, 3. Capital in General” (CW40, p. 287) although value, the first part, does not seem to be in place of commodity as the three parts, according to the letter, correspond to "the process of production of capital; process of its circulation; the unity of the two, or capital and profit; interest", respectively, and hence "1. Value" and "2. Money" were supposed to cover much more than the first three chapters of the first volume of Capital.

35 "I do not proceed from 'concepts', hence neither from the 'concept of value', and am therefore in no way concerned to 'divide' it. What I proceed from is the simplest social form in which the product of labour presents itself in contemporary society, and this is the "commodity" (CW24, p. 544). He couldn't make it clearer that his starting point is the commodity.

${ }^{36}$ Harvey (2010) deals with the question of Marx's starting point and rightly points out that Marx carefully made his decision. However, he gives no explanation as to why Marx chose the commodity: "The method of descent brought him to the concept of the commodity, but Marx makes no attempt to explain that choice, nor does he bother to argue for its legitimacy. He just starts with the commodity [emphasis added], and that is that" (p. 9).

37 Arthur (2004b, p. 37) argues that "Marx does not derive money as a device to overcome the limitations of barter [emphasis removed]"; Marx's focus is not on deriving money from commodity, but on explaining why commodity exchange is impossible without money, hence the necessity of money. However, Arthur goes further and wrongly states, "[Marx] derives money as the form necessary to constitute value objectively [emphasis added]". See also Arthur (2005, pp. 112-113; 2014).

${ }^{38}$ In the Postface to the second edition of Volume 1 of Capital, Marx famously contrasts his dialectical method with Hegel's (CI, p. 103): 
course of future development, and they may prove to be very powerful in doing so. However, it is important not to confuse the order of explanation (i.e. the concrete and complex being explained on the basis of the abstract and simple) with the order of existence (i.e. the concrete empirical world being the product of abstract concepts).

\section{Concluding remarks}

It has been briefly demonstrated that the first three chapters of Volume 1 of Capital can be interpreted as the logical and historical unfolding of the dual nature of commodities, and Marx's analysis of the capitalist forms of division of labour hinges on that dual nature. We have covered only a small part of the three volumes of Capital in this section, and the scope of our analysis is necessarily limited. But we may conclude that the dual nature is of great significance to understanding Capital (as Marx explicitly said) and applying value theory to issues of contemporary capitalism. In addition, as the development of the dual nature of the capitalist commodity production process - the unity of the labour process and the valorisation process - into the contradiction phase (through the widespread adoption of machinery-based production) shows, knowledge does not sit outside the unfolding of the dual nature, but often plays an important role in the dialectical movement of (capitalist) commodity production.

That contemporary capitalism can be best understood by conceptualising it as the result of the logical and historical unfolding of the dual nature of the commodity is a guiding principle of this thesis. Although this point is not repeated in subsequent

My dialectical method is, in its foundation, not only different from the Hegelian, but exactly opposite to it. For Hegel, the process of thinking, which he even transforms into an independent subject, under the name of 'the Idea', is the creator of the real world, and the real world is only the external appearance of the idea. With me the reverse is true: the ideal is nothing but the material world reflected in the mind of man, and translated into forms of thought.

For Hegel scholars emphasising that Hegel's Idea exists only in and through the empirical world, Marx's labelling of Hegel as an idealist as opposed to a materialist is too simplistic an interpretation. Beiser (2005, p. 69) writes:

According to Hegel's absolute idealism ... the whole dispute between materialism and idealism is misconceived [emphasis added]. The absolute idea is neither subjective nor objective because it is the form or structure that inheres equally in both. We cannot reduce the subject down to the object, as if it were only material, and neither can we reduce the object down to the subject, as if it were only ideal. Both the subjective and objective are equally real, and the opposition between them is apparent from our everyday experience. 
chapters, it is implicit throughout this thesis, especially in the emphasis placed upon making careful distinctions between levels of abstraction (most obvious in the critique of theories failing to do so) and in the incorporation of historical and industry-specific elements into theory when analysing the roles of intellectual property rights. 


\section{New growth theory: Trapped between knowledge and growth}

\subsection{Introduction}

The purpose of this chapter is to assess the development of new growth theory (NGT), focusing on how knowledge is conceived, how knowledge production is incorporated into theory (to generate increasing returns), and the consequences of this. Further, this chapter will examine critically the robustness and flexibility of neoclassical economics in the wake of an increasing focus on knowledge within economics, policy circles and across social sciences, not least the discourses on the knowledge economy 39 in which knowledge is of fundamental importance, with the economy being considered increasingly organised around the production, exchange, dissemination and consumption of knowledge. NGT is the natural choice for this task given that most well-known knowledge-based models of NGT,40 not least the Romer 1990 model, attempt to reconstruct long-term economic growth, generally considered a main feature and strength of the capitalist economy, based solely on the growth of knowledge. It will be shown that too many restrictions are placed upon knowledge in order to bring knowledge into the analysis without abandoning any of the key neoclassical assumptions and, in spite of the compromised conception of knowledge, the link established between knowledge and growth is not strong enough.

This chapter, however, does not provide a thorough literature survey, nor is it

39 Romer says:

My [Romer's] work on growth can be traced back to an attempt to isolate the differences between the information or knowledge-based economy and what came before. My belief is that those differences are important for our understanding of growth. Those distinctions matter to people running firms and they should matter to policymakers. (Kurtzman, 1997, para. 9)

Foray (2004, p. ix) expresses a similar view in the context of economics of knowledge:

Just as industrial economics as a discipline was founded with the advent of industrialisation in around 1820 , so the economics of knowledge developed as knowledge-based economies gradually came into being.

$4^{\circ}$ NGT has evolved to encompass more factors than knowledge, including, but not limited to, regional aspects, political environments, education, etc. For example, Sala-i-Martin (1997) identifies 60 variables correlated to growth, see Fine (2000) for a critique. In this chapter, we use NGT in a narrower sense, as an umbrella term for growth models with endogenised knowledge in which knowledge functions as the sole source of growth in productivity. 
concerned mainly with the critique of NGT. Rather, it primarily deals with modelling choices (and compromises) in a few prominent growth models in terms of incorporating or endogenising knowledge and attempts to understand the reasons for such choices and their implications. For the latter, it is important to lay bare the structural characteristics of the economy (implicitly and explicitly) assumed in these models. With this narrow focus in mind, the choice of growth models to review in this chapter is both selective and strategic.

The remainder of this chapter is organised as follows. Section 2 begins with the Solow model in detail to lay groundwork. This is because the basic structure of the Solow model is reproduced in later models, albeit in different forms. Section 3 then reviews the first generation of endogenous growth models, especially the Romer 1986 model, which relies on positive externalities of R\&D to allow for nonincreasing returns at the firm level with increasing returns at the aggregate level. Much attention is devoted in this section to assessing the adequacy of using externalities to characterise the mechanism of the production and dissemination of knowledge across the economy even if externalities are, to some extent, considered exceptional within mainstream economics other than to explain what is otherwise inexplicable. In section 4 the second generation of endogenous growth models based on monopolistic competition, especially the Romer 1990 model, is examined. Whilst knowledge is incorporated into theory in a more realistic manner, in these second generation models the modelling of knowledge fails to go beyond the heavy restrictions imposed by the neoclassical framework. As a result, the modelling of knowledge in NGT is shown to be unsatisfactory, and so too is that of the mechanism through which new knowledge generates growth. The final section situates such inadequacy of NGT in the context of Marx's distinction between use value and value. As an economics of use value, neoclassical growth theory in general limits the economic role of knowledge to an economy-wide productivity booster and, thus, the endogenisation of knowledge leaves out other important functions of knowledge in the capitalist economy.

\subsection{The Solow model: Competition and growth as two independent aspects of the economy}

NGT and, more generally, neoclassical growth theory assign a crucial role to 
knowledge - the engine of long-term growth, ${ }^{41}$ and it does so on the basis of neoclassical economics' core theoretical framework, not least general equilibrium and (profit and utility) maximising agents, although in simplified forms. More specifically, neoclassical growth theory conceptualises knowledge as the source of increasing returns (in per capita terms) in the presence of non-increasing returns to scale with respect to conventional inputs. Whereas the latter ensures that the economy adjusts towards competitive equilibrium, knowledge carries forward the economy whose growth would otherwise continue to slow down (in per capita terms) despite continuing capital accumulation.

\section{Simple growth model}

This can be easily demonstrated. Suppose that the aggregate production function, $Y=F(L, K)$, has two conventional inputs - labour $(L)$ and capital $(K)-$ and exhibits constant returns to scale. ${ }^{42}$ Then the production function can be rewritten in per capita terms, as $y=f(k)$, where $y$ is per capita output, $k$ is capital per labour and $f(k)=F(1, k)$. Assuming diminishing marginal product of capital, $y$ grows as long as $k$ grows regardless of the reason, but at diminishing rates, with the growth rate of $y$ continually decreasing.

Theoretically, such limitations imposed upon economic growth, stemming from purely technical relations between factors of production and output, can be offset by technical change. Continuing technical change or continuing knowledge growth increases the output level despite diminishing marginal product of capital in the case of Hicks neutral technical change, or keeps $k_{A}(=K / A L)$ from growing in the case of labour augmenting technical change where $A$ is the aggregate knowledge stock. In other words, the continuing increase in the aggregate knowledge stock ensures that per capita output grows indefinitely whilst the economy remains in, or at least approaches, equilibrium.

${ }^{41}$ Prendergast (2010) argues that, before Adam Smith, economic theorists, especially Mandeville, considered economic growth or progress as the result of knowledge accumulation. It is Smith who shifted the focus of later economists towards capital accumulation as the source of economic growth.

42 Constant returns to scale are only a simplifying assumption. Referring to his 1956 model, Solow (1994, p. 48) says, "Notice that I have not mentioned constant returns to scale. That is because the model can get along perfectly well without constant returns to scale. The occasional expression of belief to the contrary is just a misconception". 
Even this very simple formulation of growth reveals the peculiar structural characteristics of neoclassical growth theory. First, growth is only of secondary importance. The economy is designed to be always in or approaching equilibrium regardless of whether the economy grows or not; knowledge can only determine the equilibrium output level, but does not affect, in any way, the formation of competitive equilibrium. Second, by the same token, competitive equilibrium is independent of economic growth. Economic forces that drive the economy towards equilibrium do not generate growth and vice-versa; the economy can grow whilst not moving towards equilibrium and the economy can stay in equilibrium whilst not growing or even contracting. Obviously, this very simple model falls short of a proper growth model, not least because it does not necessarily generate long-term sustained growth. Rather, it opens many different paths for the economy, with the growth rate of the economy at a point of time being determined by the rate of capital accumulation $(\dot{K} / K)$, the growth rate of population $(\dot{L} / L)$ and the growth rate of knowledge $(\dot{A} / A)$. Given that the time paths of these variables and relations between them are not specified yet, that is, they are independent of each other, it is only a coincidence if the economy grows at relatively constant rates over a long period of time.

\section{Solow model with exogenous knowledge growth}

Solow's famous model (Solow, 1956) generates a stable long-term economic growth path. This growth is a necessary outcome of introducing a constraining assumption that a fixed fraction of final output is saved and accumulated as capital in the presence of exponential knowledge growth (i.e. this drives up $k_{A}$ ). This, in combination with constant population growth (i.e. this drives down $k_{A}$ at the growth rate of population, which is exogenously given) and diminishing marginal productivity of capital, induces capital per unit of effective labour of the economy $\left(k_{A}\right)$ to approach a point $\left(k_{A}^{*}\right)$, an equilibrium point which $k_{A}$ will eventually reach regardless of the initial endowment, and in which it will stay once reached. At this steady-state point, by definition, $A L$, effective labour, and $K$ grow at the same rate indefinitely, and so does $Y$ due to constant returns to scale. Consequently, capital per labour $k(=K / L)$ grows exponentially at the same rate as $A$ and so does per capita output $y$. Once the economy has entered the steady state, $y$ grows only if $A$ grows, and its growth rate is determined solely by the growth rate of $A$.

Whilst it is striking that relatively robust and stable outcomes are generated as the 
result of two additional simple assumptions - constant saving rate and exponential knowledge growth - in conjunction with other neoclassical assumptions such as decreasing marginal productivity of capital, one can question the validity of these assumptions. For example, if the saving rate (or the rate of time preference in the case where intertemporal utility maximisation is considered) is not a fixed constant but changes over time, the economy is going to be in endless transition towards ever-changing equilibrium points; whilst the steady-state value of $k_{A}^{*}(t)$ does exist at any point in time $t$, it constantly changes and ends up being a moving target. Although the saving rate does not affect the steady-state growth rate, which is a key policy implication of the Solow model, the economy is unlikely ever to reach a steady state. Further, even a small decrease in the saving rate can immediately result in economic contraction (in per capita terms). 43

The Solow model is an equilibrium model on two different levels. First, the economy is in or approaching equilibrium at any point in time. Any snapshot of the economy shows that all factors are employed and being paid their marginal products and all agents get optimal outcomes, with these working independently of the time path of the economy. This framework of the co-existence of competition and knowledge, of non-increasing returns and increasing returns is at the core of neoclassical growth theory and taken for granted in later endogenous growth models as well. In this respect, the Solow model is not an old, exogenous growth model to be replaced by new models, but rather the main framing of neoclassical growth theory on which many different variations can be written.

Second, assuming that the growth rate of the knowledge stock is exogenously given as constant, the economy is always moving towards, or along, an equilibrium time path, i.e. a balanced growth path. Put differently, long-term sustained growth is shown to be a natural outcome of the economy as it is always driven towards an equilibrium path. Whilst this dynamic equilibrium is distinct from the more fundamental and prevalent static equilibrium in the sense that balanced growth

43 However plausible this critique may be, criticising old growth theory (OGT) on the basis of its simplifying assumptions is not pertinent here when more fundamental simplifications have already been made, not least the use of the aggregate production function, the adoption of the one sector and single agent model, and perfect competition and full employment in all markets. There have been many critiques of neoclassical growth theory on this ground, with the Cambridge capital controversy being the most prominent, see Fine (1980a, Chapter 5), Fine (2006) and Harcourt (1972). These critiques are not to be repeated here as an all-round critique of NGT is not a main concern of this chapter as mentioned earlier. 
paths are no more optimal than the other potential paths of the economy, ${ }^{44}$ it is a salient feature of the Solow model that the (capitalist) economy, by its own nature, not only allocates resources in a Pareto optimal way but is also predetermined to grow in a long-term, sustainable manner as long as the aggregate knowledge stock keeps growing exponentially; the economy featured in this model is inherently stable, efficient and ever-expanding. 45

\section{Endogenisation of knowledge. Is it required?}

Not surprisingly, many have pointed out that the main conclusion of the Solow model - economic growth being solely determined by exogenous knowledge growth - is not satisfactory because this implies the economy grows for non-economic reasons, and hence raises the need for endogenising the changes in knowledge and the steady-state growth rate. Consequently, this has been the main driver of the development of neoclassical growth theory over the last three decades. ${ }^{46}$

44 This is not the case in the Ramsey-Cass-Koopmans model in which the balanced growth path is an outcome of lifetime utility maximisation. It is therefore called an optimal growth model.

45 Solow (2000, p. xii) admits that this is too good to be real: "The connection is a bit too pretty and too interesting and unleashes a standing temptation to sound like Dr. Pangloss, a very clever Dr. Pangloss".

${ }^{46}$ By contrast, the endogenisation of population growth has drawn little interest:

One of the enduring myths about capitalism that continues to be perpetuated in capitalism in mainstream economic textbooks and other pedagogic strategies is that labour supply is somehow exogenous to the economic system. The supply of labour is typically assumed, especially in standard growth theories, to be determined by the rate of population growth, which in turn is also seen as 'outside' the economic system rather than in interplay with it. (Ghosh, 2012, p. ix)

According to Solow (2000, p. 98):

My own 1956 paper did actually show, as an example, how one could allow for a possible dependence of population growth on the current standard of living. But that was intended as a sort of finger exercise ... it seemed best to treat the rate of population growth as exogenous.

For Marx, however, economically active population is an outcome of accumulation, and in this respect, is determined endogenously. As accumulation proceeds, more workers are employed as materials of exploitation. At the same time, due to technical changes, the number of workers required to valorise a given amount of capital decreases over time, producing a relative surplus population:

Simultaneously with impulses towards a genuine increase in the working population, which stem from the increase in the portion of the total social product that functions as capital, we have those agencies that create a relative surplus population. (CIII, p. 357) 
Interestingly, Solow considers endogenisation of knowledge as neither important nor necessary. In his Nobel lecture given in 1987 (it is worth mentioning that Romer's first endogenous growth model was published in 1986) he calls for extending neoclassical growth theory to encompass "medium-run departures from equilibrium growth" (Solow, 2000, p. xxvi),47 but never mentions the need for endogenising knowledge or technical change. For him, it is not a matter of priority, with incorporating deviations from equilibrium paths being more important than developing an endogenous theory of technical change. Rather, Solow is dubious of the need and desirability as well as the feasibility of endogenising knowledge. This is primarily because technical change, in his view, is unlikely to be explained solely in economic terms, and therefore exogenous elements cannot be removed completely. Endogenising technical change is stretching neoclassical growth theory beyond its limits; once knowledge has been endogenised, the model may become more aesthetically pleasing, but probably less plausible. Equally importantly, for Solow, theorising something as an exogenous variable is different from leaving it unexplained. There is no presumption in theorising knowledge as an exogenous variable that knowledge grows exponentially at a constant rate indefinitely, nor that knowledge production is something like a black box, constructing systematic theories of which is not permitted. Rather, Solow's interest lies in understanding "how the path of aggregate output adjusts to the rate of population growth and the rate of technological progress, whatever they happen to be and for however long they persist" (Solow, 2000, p. 98), not in developing theories of how these rates are determined. ${ }^{8}$ Despite his reservations, however, Solow (2007, p. 6) acknowledges that the endogenisation of the changes in knowledge is one of "the two most important innovations to come along in the past 50 years within the framework of neoclassical growth theory".

47 According to Solow (2000, p. xvii):

Growth theory was invented to provide a systematic way to talk about and to compare equilibrium paths for the economy. In that task it succeeded reasonably well. In doing so, however, it failed to come to grips adequately with an equally important and interesting problem: the right way to deal with deviations from equilibrium growth.

This position had been maintained at least for 10 years since the Nobel lecture (Solow, 1996, p. 219).

[New idea] I had in mind [was] the integration of equilibrium growth theory with medium-run disequilibrium theory so that trends and fluctuations in employment and output could be handled in a unified way.

48 "My main interest is the modelling of economic growth, not the modelling of research and development and the source of technological progress" (Solow, 1997, p. 19). 


\subsection{Externality-based endogenous growth models: Growth as exception?}

In the first generation of endogenous growth models, the notion of externalities plays a key role. In these models, 49 the aggregate knowledge stock grows as a byproduct of choices made by profit-maximising firms. More specifically, an increase in conventional inputs by a firm leads not only to an individual output increase but also to an increase in the aggregate knowledge stock through knowledge spillover and, consequently, to an increase in the productivity of all competing firms; no firms are left behind. In more formal terms, the aggregate knowledge stock $R$ is defined as a function of individual knowledge stocks.

$$
R=\sum R_{i}
$$

where $R_{i}$ is firm i's knowledge stock. Then the production function of individual firms, similar to that in the Solow model, is given as:

$$
Y_{i}=R^{\gamma} \cdot F\left(R_{i}, x_{i}\right)
$$

where $x_{i}$ is a set of conventional inputs of firm $i$ and $\gamma$ a constant.50 $R_{i}$ in this model is similar to (physical) capital stock in the sense that it is produced by foregoing consumption, is accumulated and, more importantly, is a factor of production that has decreasing marginal productivity. This is so that a competitive equilibrium is guaranteed to exist, with all individual firms taking $R^{\gamma}$ as constant. The aggregate production function has a slightly different form:

$$
Y=R^{\gamma} \cdot F(R, x)=R^{\gamma+\alpha} \cdot x^{1-\alpha}
$$

The key difference from $R^{\gamma}$ is that $R$ is not taken as constant but determined endogenously as the result of individual profit maximising decisions. Consequently, the aggregate production function exhibits increasing returns to scale with respect to $R$ and $x$. Per capita output grows indefinitely despite non-increasing returns at the individual level as knowledge spillover results in increasing returns at the aggregate level. Significantly, investments into knowledge production or capital accumulation are not completely compensated, as individual firms do not consider

\footnotetext{
49 See Arrow (1962), Romer (1986) and Lucas (1988).

${ }^{50} R_{i}$ is the cumulative physical capital of firm $i$ in Arrow (1962), the knowledge stock in Romer (1986) and the human capital in Lucas (1988).
} 
the external effects on the aggregate knowledge stock when making profitmaximising decisions.

The above is only a simplified description of the externality-based endogenous models, so it is worth mentioning some crucial aspects of, and developments around, these models briefly. First, the Romer 1986 model and the Lucas model were motivated equally by their dissatisfaction with the tendency towards convergence of growth rate across countries which they thought is implied in the Solow model. ${ }^{51}$ The convergence controversy, however, turned out to be both flourishing in weight and somewhat futile in outcome. ${ }^{2}$ Second, the divergence between the social and private optimum in the context of intertemporal utility maximisation and potential policy options (to bridge the gap) are widely discussed. Third, additional constraining assumptions are introduced to generate sustained long-term growth in these models depending on whether factors of production that have externalities have increasing or decreasing marginal productivity: The growth rate of these factors is assumed to be bounded from above so that output does not explode to infinity in the former case (the Romer 1986 model); Zero population growth is ruled out as the production function exhibits decreasing returns with capital accumulation alone (with no population growth) in the latter case (the Arrow model).

Nevertheless, the gist of these models is that positive externalities are indispensable for economic growth. In other words, as long as economic agents ensure that profit and utility are maximised, the economy will manage to reach not only competitive equilibrium but also a stable long-term growth path. This explanation is justified on

${ }_{51}$ "It is useful to ask whether there is anything in the data that should cause economists to choose a model with diminishing returns, falling rates of growth, and convergence across countries rather than an alternative without these features" (Romer, 1986, p. 1008). Lucas is more interested in economic development than in economic growth, which is about "accounting for the observed pattern, across countries, and across time [emphasis added], in levels and rates of growth of per capita income" (Lucas, 1988, p. 3)

$5^{2}$ According to Romer (1994a, pp. 10-11):

The differences between the different researchers concern the inferences about models that we should draw from these facts. As is usually the case in macroeconomics, many different inferences are consistent with the same regression statistics. ... In the end, we have refined the set of alternatives somewhat, but seem to be left in about the same position where we started, with too many theories that are consistent with the same small number of facts.

For a critique of the convergence controversy, see Fine (2000). 
the grounds of common sense observation that knowledge spills over (the Romer 1986 model), knowledge is acquired during the work process (the Arrow model) and the average level of skill affects the productivity of other factors of production (the Lucas model). These models, however, fall short of being systematic theories of knowledge growth (and thus economic growth) for the same reason; they leave unexplained the mechanism through which individual profit- and utilitymaximising decisions bring about the improvements in the aggregate knowledge stock, but take its existence and effects as exogenously given.

\section{The Romer 1986 model}

The Romer 1986 model deserves closer examination though, as it is based on a more plausible explanation that the aggregate knowledge stock grows due to investments into research by individual firms, rather than as a by-product of the accumulation of (physical or human) capital. This model draws a sharp distinction between private and social knowledge, and the differences between the two types of knowledge raise a number of issues. Significantly, private knowledge is considered a conventional rival input with decreasing marginal productivity. This contradicts the received view that knowledge, once acquired, can be used an unlimited number of times. In other words, assuming constant returns to scale, doubling of the output requires doubling of only conventional inputs because knowledge can be re-used as many times as necessary in the production process without incurring additional cost. This means that (private) knowledge should be treated in a different way from conventional inputs, but such need is simply ignored. Equally problematic is the fact that the aggregate knowledge stock is conceived as the total sum of individual knowledge stocks. Suppose that $n$ firms have produced essentially identical set of technologies $(R)$. Although the total sum of individual knowledge stocks - the aggregate knowledge stock according to the Romer 1986 model - increases by $n R$, in this case, knowledge production is severely duplicated across the economy. Given that knowledge necessarily spills over in this model, it is more plausible that the aggregate knowledge stock increases only by $R$, see Olsson (2001) for a similar view. 53 The other extreme, where each firm produces a completely unique set of

53 "However, if the $N$ firms have at least one piece of knowledge in common, which seems to be reasonable given the assumed public good-character of $A$, then summing the knowledge stocks in the above manner means that the same piece of knowledge is accounted for $N$ times, Hence, the measure $T$ [the total sum of individual knowledge stocks] overestimates what is known in society. This logical inconsistency, in part acknowledged by Romer (1994) 
technologies, is simply too unlikely considering that all firms, by definition, produce the same product, have the same cost structure and have access to the same set of technologies.

In short, the modelling of knowledge spillover in this model is both contradictory (private and social knowledge have different characteristics) and casual (no duplication in knowledge production across firms is assumed). Whilst the distinction between social and private knowledge partly reflects the fact that knowledge does spill over, with this unsatisfactory distinction, the Romer 1986 model introduces two extreme (ideal) forms of knowledge: knowledge as a non-rival and non-excludable public good; and knowledge as a (rival and excludable) conventional input. Obviously, such dichotomisation of knowledge is adopted to guarantee the co-existence of increasing returns (economic growth) and nonincreasing returns (competitive equilibrium). 54

\section{Externalities are both exceptional and indispensable in NGT}

Going back to positive externalities, the choice of externalities as the source of economic growth raises a more fundamental issue. One can question why something as essential to the (capitalist) economy as economic growth is explained on the basis of the lack of the market mechanism rather than its presence. It goes without saying that positive externalities are a convenient cost-free solution for generating increasing returns out of non-increasing returns. Suppose instead that a market for knowledge is created such that individual contributions to the aggregate knowledge stock are to be fully compensated, with positive externalities completely internalised. Then incumbents, as collective owners of the existing aggregate knowledge stock, may choose to block potential new entrants from using the knowledge stock and by doing so secure permanent competitive advantage. As a result, competitive equilibrium would cease to exist eventually, with only a few firms dominating the economy, which is an unacceptable result to neoclassical economics;

[1994a], seems to have arisen from a failure to recognise the distinction between the knowing and the known. If total knowledge instead had been thought of as the union of all technological ideas among the $N$ firms ... this problem would have been avoided" (Olsson, 2001, pp. 10-11).

54 Given that "external Marshallian effects have been identified very early on ... one contribution of [externality-based] endogenous growth models is to have resolved ... (mathematical, rather than theoretical) difficulties" (Herrera, 2011, p. 21-22). 
for a growth model to be certified as 'neoclassical' it should exhibit an economy that grows along a path of (competitive) equilibrium points.

Further, and more importantly, there is an unfortunate irony because neoclassical economics treats externalities as exceptions. Externalities, that is to say external effects on someone else's utility or production function, lead either to underprovision or to over-provision. Such suboptimal states are considered to exist only temporarily and to be remedied either by targeted government actions (e.g. taxing and subsidising) or by internalising them through the creation of new property rights (e.g. pollution rights). In other words, in neoclassical economics, externalities are the result of the market economy being not sufficiently extensive. Implicit in this view is that externalities should disappear once the logic of the market economy has penetrated every non-market social relation.

Externality-based endogenous growth models provide a contrasting view, that is, some externalities, not least knowledge spillover, are indispensable for long-term sustained economic growth which is as essential to the market economy as Pareto optimality, and thus they are never to be neutralised or internalised. 55 More generally, the market economy can be sustained only if it does not go beyond its limit and imposes restraints on its incessant drive to subordinate all facets of social life.

These two contradictory views are not necessarily mutually exclusive. Whereas the exception argument is deployed where externalities need to be internalised, the indispensability argument applies to the sphere of innovation, invention, R\&D and learning. However, necessarily, the economy is dichotomised into the realm of Pareto optimality (competitive equilibrium) and the realm of suboptimality (positive externalities and growth). ${ }^{56}$

55 This suggests that externalities should be analysed in a general equilibrium setting. Externalities as exceptional phenomena are often studied in the context of partial equilibrium, see Mishan (1971).

${ }^{6}$ Similarly, Fine (2000, p. 250) says:

As regards the incorporation of market imperfections, endogenous growth theory is essentially cannibalistic. The discipline can plunder itself for the sources of Paretoinefficient outcomes and translate these into sources for growth as opposed to deadweight losses. Not surprisingly, particularly favoured sources are those that concern imperfect competition, since innovation involves temporary monopoly rents, and any capital market imperfections that affect the level, composition or use of savings and investment. 
Significantly, externalities are "pervasive" even where Pareto optimality is supposed to prevail, according to Hunt and d'Arge (1973, p. 345). "In a market economy any action of one individual or enterprise which induces pleasure or pain in any other individual or enterprise and is unpriced by a market constitutes an externality", and "practically any social behaviour results in externalities". This may not be considered a theoretical problem by neoclassical economists; however pervasive externalities may be, they are subject to potential internalisation. In practice, it is almost impossible to create as many taxes, subsidies or property rights as externalities. In addition, the internalisation of an externality would result in the formation of a new externality (Hunt, 1980, p. 244). For example, suppose that a city government introduces congestion charges to internalise the negative externality of congestion and pollution. Whilst many people would give up driving to the city centre during peak time, rich people would continue to drive regardless. Paying congestion charges would then become a sort of symbol of being rich, and therefore congestion charge, a tool of internalisation, would constitute a new externality, a positive externality for those who can afford the congestion charge and a negative externality for those who cannot. In this respect, externalities - a negation of the market mechanism ${ }^{57}$ - are not only pervasive within the market economy, but also constituted by them.

These issues are not taken seriously by neoclassical economists. Instead, externalitybased growth models are criticised mainly for their failure to incorporate the mechanism through which innovations occur and propagate. This is based on the presumption that the growth of the aggregate knowledge stock is not a by-product of the accumulation of (physical or human) capital or knowledge but a result of conscious investment decisions made by profit-maximising firms to create new technologies and improve existing ones.

\subsection{So-called neo-Schumpeterian growth models}

In view of the lack of proper theorisation of knowledge in earlier models, Romer (1994a, pp. 12-13) retrospectively suggests five stylised facts that growth models should address: 1 ) there are many competing firms in a market economy, and they

57 "The Achilles heel of welfare economics is its treatment of externalities (if a theory so utterly indefensible in so many of its facets can be said to have an Achilles heel!)" (Hunt, 1980, p. 244). 
are price-takers; 2) knowledge differs from conventional inputs in that it is nonrival; 3) so production functions with knowledge as a factor exhibit increasing returns to scale; 4) knowledge accumulation is a result of profit-maximising decisions; 5) many individuals and firms have market power and earn monopoly rents on knowledge. The Solow model accommodates facts \#1, \#2 and \#3, but not $\# 4$ and \#5. Externality-based growth models additionally address \#4, but not \#5. Hence, the goal of the next generation of endogenous growth models was to incorporate $\# 5$.

\section{The Romer 1990 model}

In the Romer 1990 model, $5^{8}$ the stylised fact of the existence of monopoly rents is addressed by theorising knowledge as a non-rival but partially excludable good, provided by the firms in the specialised research sector and protected by intellectual property rights. Once a new technology has been produced in the research sector, it is sold to a firm in the intermediate goods sector (property rights change hands) and is used as a blueprint for a new intermediate durable good such as a machine or tool. The new durable good is then rented to firms operating in the final goods sector and used in the production process as a conventional factor of production. In short, knowledge is neither produced nor used in the final goods sector. Instead, knowledge indirectly affects labour productivity in the final goods sector, through embodiment in intermediate goods. It is assumed that all things being equal, the more distinctive technologies are available, the more output is produced. 59 In other

${ }^{8}$ Similar neo-Schumpeterian models include Aghion and Howitt (1992), Grossman and Helpman (1991a, 1991b), Jones (1995) and Young (1998). See Solow (2000) for a neat exposition of these models and Aghion, Akcigit, and Howitt (2013) for a survey of "Schumpeterian growth theory". For a journalistic account of the conception and development of this model, see Warsh (2006). For a critical review of this book, see Mirowski (2007).

59 Suppose that one unit of capital is required to produce one unit of an intermediate good regardless of the type of knowledge used in the production process. Then no matter how many different types of intermediate goods (and thus knowledge) are available, a given amount of capital stock would always be converted into the same number of intermediate goods. For example, 10,000 units of capital would be required to produce 1,000 units of each intermediate good if 10 distinct types of intermediate goods are available (total 10,000 units), and 500 units if 20 types of intermediate goods are available (total 10,000 units). According to the variety model of knowledge, the latter 10,000 units with 20 distinct types would produce more final goods than the former with 10 distinct types as they embody more knowledge. 
words, investments into innovation activities in the research sector necessarily lead to an increase in the aggregate knowledge stock and, thus, in final output by way of the increasing variety of intermediate goods. As innovation or creation of new knowledge drives economic growth in this model, it is often dubbed as a neoSchumpeterian growth model.

This model treats knowledge in a different way from conventional factors. First, knowledge incurs fixed costs only and can be used an unlimited number of times to produce as many intermediate goods as necessary without additional cost. The presence of fixed costs and the unlimited reusability of knowledge (zero marginal cost) demand that the market structure of the intermediate goods sector should be other than perfect competition since the average cost curve would be downwardsloping as long as the fixed costs of knowledge production are high enough to mitigate increasing marginal costs of other physical conventional inputs. Second, access to knowledge is monopolised due to intellectual property rights, and this serves as the source of imperfect competition. Only the rights holder of knowledge is entitled to produce the intermediate good powered by the knowledge. This introduces a contrast between the final goods sector and the intermediate goods sector. Whereas firms in the final goods sector are price takers as in earlier models, firms in the intermediate goods sector are price setters. By the same token, whereas competitive equilibrium exists in the final goods sector, with all conventional inputs including intermediate goods being paid for as much as they contribute to output, firms in the intermediate goods sector are under monopolistic competition. They wield some market power through product differentiation.

In more formal terms, the aggregate production function in the final goods sector is given as

$$
Y\left(H_{Y}, L, x\right)=H_{Y}^{\alpha} L^{\beta} \sum_{i=1}^{A} x_{i}^{1-\alpha-\beta}
$$

where $L$ is labour, $H_{Y}$ is human capital devoted to final-goods production, $x_{i}$ is a number of intermediate good $i$ and $x$ is a list of all intermediate goods used for finalgoods production (by definition, $K=\sum_{i=1}^{A} x_{i}$ ). Firm $i$ in the intermediate goods sector, as the sole provider of an intermediate good $i$, chooses $x_{i}^{m}$ that maximises profit

$$
\pi=p\left(x_{i}^{m}\right) x_{i}^{m}-r x_{i}^{m}
$$

where $p\left(x_{i}\right)$ is the inverse demand function for $x_{i}$, which is equal to the marginal 
productivity of an intermediate good $i$, and $r$ is the interest rate. Finally, the knowledge production function in the research sector is given as

$$
\dot{A}=\delta H_{A} A,
$$

where $A$ is the aggregate knowledge stock, $H_{A}$ is human capital devoted to knowledge production and $\delta$ is a constant.

Assuming $x_{i}=K / A$ for all $i$ (given that all firms in the intermediate goods sector are identical), the aggregate production function can be rewritten as

$$
Y\left(H_{Y}, L, x\right)=\left(A H_{Y}\right)^{\alpha}(A L)^{\beta} K^{1-\alpha-\beta},
$$

which has exactly the same form as the Solow model except that human capital is added as a conventional input. Then, a steady-state satisfies the following conditions. First, $H_{A}$ remains constant so that $A$ grows exponentially at a constant rate; $\delta H_{A}$ is a constant. Second, wages are identical in the final goods sector and the research sector, and consequently, there is no movement of human capital between the two sectors, keeping $H_{A}$ constant. Third, the price of a technology $\left(P_{A}\right)$ is equal to the discounted value of all future monopoly profits. Fourth, $P_{A}$ is equal to the wages paid out to researchers who have invented the technology.

\section{Knowledge in the Romer 1990 model}

All of these factors combined paint an interesting picture of the economy. First and foremost, firms realise no economic profit. Competitive equilibrium exists in the final goods sector; monopoly profits realised in the intermediate goods sector are fully appropriated by the original inventors (monopolistic competition). The price of a new technology - the present value of all future monopoly profits - is exactly as much as needed to compensate human capital for their contribution to knowledge production. And in this respect, fact \#5 - many individuals and firms have market power and earn monopoly rents on knowledge - is not adequately addressed in the Romer 1990 model despite Romer's claim otherwise. Although firms do earn monopoly profits (or monopoly rents), no excess profit is retained since all monopoly profits are paid to researchers. In short, monopoly is no better than competition in terms of profitability. After all, there is no reason why firms would prefer intermediate goods production to final goods production.

Second, and by the same token, firms operating in the research sector do not enjoy 
any excess profit and there is no reason why firms and individuals would choose knowledge production over final goods production. Owners of factors of production - (physical or human) capital and labour - must be indifferent to what to produce, be it knowledge production, intermediate goods production or final goods production. It is only the prospect of earning profits that incentivises firms to move across sectors; arbitrage profits reduce and eventually disappear due to capital movement across sectors.

Third, then, the economy is structured such that resources are allocated to these three pre-existing sectors through profit maximising decisions. ${ }^{60}$ This model, however, does not explain why the economy consists of these three sectors in the first place; their existence is simply taken for granted. In addition, the relation between final goods production and knowledge production is simply accidental, such that final goods production can continue even in the absence of knowledge production although the economy would stop growing. Further, knowledge production (= monopoly and growth) is separated from and even contrasted with final goods production (= competition). As in earlier models, competition is independent of growth; at most, it coexists with growth. ${ }^{61}$

Fourth, intellectual property rights play an essential role in economic growth. Suppose instead that knowledge were freely available for anyone to use. Then no firms in the intermediate goods sector would pay for knowledge and the market for knowledge would disappear. As there would be no incentive for anyone to produce

60 The division between the research sector and the intermediate goods sector is functional rather than structural. The two sectors can be considered as one sector with two functional roles. In other words, a firm can invent a new technology and produce a new intermediate good based on the new technology. This firm would employ human capital to produce knowledge, and physical capital to produce intermediate goods. Economic profit for this firm would be zero as factors of production would be fully compensated for their contribution.

${ }^{61}$ Romer $(1989$, p. 1$)$ traces the tension between growth and competition back to Adam Smith:

With the publication of The Wealth of Nations, Adam Smith put two propositions at the centre of economic theory. The first was that competition allocates the pre-existing stock of productive inputs in a way that is wealth maximising. The second was that savings, the accumulation of capital, is the key process whereby the stock of inputs, and therefore wealth, grew over time.

According to him, economists' interests had been placed upon the first, "not so much because they were convinced that it was wrong, but rather because it seemed to be incompatible with the theoretical apparatus developed to capture the notion of competition". Similarly, Arrow (2000, p. 173) argues that it is due to "a mathematical accident". 
knowledge, no new knowledge would be created, no new intermediate goods would be introduced and, consequently, the economy would stop growing. In other words, full excludability of knowledge in its use for intermediate goods production is a prerequisite for economic growth. Since exclusivity of knowledge requires legal protection for knowledge, we can also conclude that intellectual property rights are a necessary condition for economic growth. Knowledge, as such, is not the sole engine of growth. Institutional arrangements for intellectual property rights are equally necessary. ${ }^{62}$

In addition, the assumption that knowledge is produced only in a specific sector of the economy is arbitrary and unrealistic. Whilst many firms that specialise in knowledge production do exist, not least in the semiconductor and chemical industries (see Chapter 6), Romer abstracts from the sheer reality that firms produce new technologies and make use of them for final goods production in order to gain competitive advantages and market power in the final goods sector, especially by cutting cost. Significantly, this is ignored not for the sake of simplicity, but to produce a sought-for result, i.e. competitive equilibrium. Once differences between firms have been introduced, competitive equilibrium would cease to exist and the economy as a whole would be represented as being dominated by a few monopoly players. ${ }^{63}$ Equally troubling is the characterisation of the economy that a

62 Similarly, Jones (1998, p. 81) says:

Clearly, sustained economic growth is a very recent phenomenon, and this raises one of the fundamental questions of economic history. How did sustained growth get started in the first place? The thesis of Douglass North and a number of other economic historians is that the development of intellectual property rights, a cumulative process that occurred over centuries, is responsible for modern economic growth. It is not until individuals are encouraged by the credible promise of large returns via the marketplace that sustained innovation occurs.

By contrast, for Mirowski (2011, p. 66), intellectual property rights are the basis of the neoliberal transformation of knowledge into commodity, i.e. commodification of knowledge. "The neoliberals had won: Science [and knowledge in general] no longer qualified as a public good".

${ }^{63}$ Solow (1996, p. 233) says, "To judge whether this theoretical enterprise has been a success we need a fairly clear idea of what could legitimately have been expected". NGT is based on, and constrained by, the theoretical apparatus of neoclassical economics including general equilibrium, the one-sector model and profit- and utility-maximising agents. Interestingly, Romer (1989, p. 30) holds a similar view on the weaknesses of earlier models, which reflect "the technical constraints economists faced when they first tried to formulate dynamic equilibrium models", and "theory has advanced to the point that these constraints can now be relaxed". 
firm produces either final goods or knowledge, but not both. A firm may choose to produce both knowledge and final goods, but monopolising the use of new knowledge that it has produced for its own final goods production is strictly prohibited; new knowledge as embodied in a new intermediate good must be available for all firms, according to the Romer 1990 model. It is as if this firm consists of two autonomous and independent divisions, with an insurmountable wall strictly and completely separating the two. Such characterisation of the economy seems simply unreasonable. It is too important and fundamental a fact to be neglected that firms produce both knowledge and final goods and that the purpose of knowledge production is to differentiate (a means of competition). In a similar vein, Nelson (1998, p. 499) asks:

If imperfect competition for some reason has proved attractive or easy to build in, what explains why the understanding that firms differ significantly [emphasis added] in their capabilities and their strategies has proved unattractive or undigestible for the new growth theorists?

Then, it is also questionable whether the Romer 1990 model is sufficiently Schumpeterian. Romer's own view is that it deserves to be called so, as the knowledge stock in his model is designed to grow only if new knowledge is produced, thereby increasing the variety of intermediate goods. Hence, he considers that his contribution lies in modelling production of new knowledge in the monopolistic competition setting. In his words (Romer, 1994b, p. 7):

The modelling innovation in the neo-Schumpeterian models of growth is that they take explicit account of the fixed costs [emphasis added] that limit the set of goods and show that these fixed costs matter in a dynamic analysis conducted at the level of economy. This contrasts with the standard approach in general equilibrium analysis, in which fixed costs are assumed to be of negligible importance in markets of realistic size.

Yet, despite the claims to the contrary, ${ }^{64}$ he argues that NGT, or at least its neoSchumpeterian branch, is new as opposed to OGT, not in terms of theoretical tools deployed, but because NGT is "about newness" (p. 37), allegedly in a Schumpeterian

\footnotetext{
64 For example, Fine (2003, p. 209), taking the example of Arrow's article on learning-bydoing which dates back to 1962, argues that "the ideas underlying NGT are far from new, and there are other precedents in the literature on technical change that anticipate NGT". Herrera (2011, p. 23) goes further and builds a Solowian endogenous growth model "to prove in the technical sphere that a continuity between Solowian and endogenous growth models exists and prohibits consideration of the latter as a new theory".
} 
sense, but see Park (2007) for a critique of the variety model of knowledge. ${ }^{65}$ Similarly, according to Romer (1994b), whereas the distinction between dynamic and static analyses in earlier models is limited in the sense that dynamic analysis in these models is essentially a static one with dated and state-contingent goods (p. 7), NGT is capable of explaining the real dynamic aspect of the economy, which is the continuing introduction of new technologies and new goods. Despite this claim, incorporating fixed costs and new goods and technologies is not sufficient for labelling the Romer 1990 model as Schumpeterian for the following reasons. First, the aspect of destruction is missing in this model. ${ }^{66}$ Second, creativity in this model does not lead to surplus profit; there is no pecuniary incentive for innovation. Third, innovation is seen not as a necessity or a matter of survival, but as a choice or a neutral alternative to final goods production. In reality, on the contrary, firms compete with each other on the basis of different (technical and/or organisational) knowledge in quality and quantity. Differences in knowledge do not necessarily lead to monopoly either, with or without intellectual property rights. Leading players emerge based on new, innovative knowledge, but competitors tend to catch them up eventually. As we will see in Chapter 3, Marx's notion of intra-sectoral competition captures this incessant cycle of innovation and catch-up, in which knowledge is not only compatible with competition, but also the major vehicle of competition, unlike in neoclassical growth models, old and new.

Other aspects of Romer's knowledge production function have also drawn criticism. First, it predicts scale effects. With the knowledge production function given as $\dot{A}=\delta H_{A} A,{ }^{67}$ an increase in population results in a permanent increase in the rate of

65 As the title of Park (2007) succinctly summarises, the key point of his critique of the Romer 1990 model is "homogeneity masquerading as variety" (p. 379). He provides two related explanations. First, although intermediate goods in the Romer 1990 model are qualitatively distinct from each other, they are treated in a symmetric fashion in the final goods production function. Second, all intermediate goods with various types require the same input - physical capital - in quantity and quality and there is the same uniformity issue in designs, given that all designs have the same price:

It turns out that, in a good sample of representative models of horizontal innovation, what in effect contributes to economic growth is the increasing quantity of a homogeneous intermediate good, not the increasing variety of heterogeneous intermediate goods. (p. 391)

${ }^{66}$ Aghion and Howitt (1992) incorporate the notion of destruction although the basic structure of the model is the same as Romer's 1990 model.

${ }^{67}$ As Solow (2000, p. 151) points out, this form of the knowledge production function originates from Lucas (1988). 
knowledge growth, which is easily refuted empirically. ${ }^{68}$ According to Jones (1995, p. 760):

The number of scientists and engineers engaged in R\&D in the United States has grown from under 200,000 in 1950 to nearly 1 million by 1987; per capita growth rates in the United States exhibit nothing remotely similar to this fivefold increase. 69

Second, and more fundamentally, much doubt has been cast on exponential knowledge growth itself. Whilst it does guarantee long-term sustained economic growth, there is lack of microeconomic evidence and theories of innovation supporting its presence, ${ }^{70}$ not to mention the question of whether knowledge "can be

${ }^{68}$ Scale effects are, however, useful for cross-country comparison. According to Romer (1996, p. 204):

In an analysis of American and British growth, the insight that is most relevant concerns scale. By definition, a nonrival idea can be copied and communicated, so its value increases in proportion to the size of the market in which it can be used.

He also argues that scale effects "should be treated in the manner of Adam Smith: as a fundamental aspect of our economic world that follows from the nonrival character of ideas" (p. 206).

69 Jones (1995) proposes an alternative model in which the growth rate of the knowledge stock is determined by the growth rate of population. It can be easily shown that the steadystate growth rate of the knowledge stock and of the final output in this model is $\frac{n \lambda}{1-\phi}$, where $\lambda$ and $\phi$ are constants measuring the negative externalities of $R \& D$ and the degree of knowledge spillover, respectively. Consequently, this model requires exponential population growth $(n)$ to generate sustained long-term growth, which is the same conclusion drawn from the Arrow model. Interestingly, Romer (1987, p. 170) argues that this is the key weakness of the Arrow model as an endogenous growth model:

If the stock of labour is fixed ... diminishing returns to investment in capital will eventually force growth to stop just as it does in the classical case. One way to generate unceasing growth is to allow for exogenous growth in the labour force.

Young (1998) proposes a model without scale effects that exhibits similar features as Romer's 1990 model. According to Jones (1999), however, the Young model manages to remove scale effects only in a special case.

${ }^{70}$ Mirowski (2007, pp. 483-484) quotes widely from leading growth theorists to support his argument that there is no convincing link between research and economic growth although he "venture[s] to guess that none of those economists actually believes that science is not in fact the true first cause of economic growth" (p. 485). For example, a quote from Grossman and Helpman (1994) is as follows: "As yet, no empirical study proves that technology has been the engine of modern day growth" (p. 32). Even the World Bank (2007, p. 7) is sceptical: 
rendered homogenous", and, if it can, whether "there exists any cardinal measure of the single stock of knowledge" (Steedman, 2003, p. 127), but see also Park (2007) for a contrary view..$^{71}$ Therefore, one may wonder whether exponential knowledge growth is a well-established view or a requirement to which the reality must conform to fit the neoclassical framework to obtain a sought-after result. It is a dangerous and weak spot of NGT; if it is shown convincingly that knowledge is not growing exponentially, one should conclude that economic growth would eventually stop. Solow (1994, p. 53) expresses a similar concern:

If an innovation generates a proportionate increase in $A$, then we have a theory of easy endogenous growth. ... But suppose that an innovation generates only an absolute increase in $A$ : then greater allocation of resources to R\&D buys a one-time jump in productivity, but not a faster rate of productivity growth. I do not know which is the better assumption, and these are only two of many possibilities. But merely to adopt the more powerful assumption is no more than to assume the more powerful conclusion.

Third, Romer's knowledge production function suffers from a sort of knife-edge problem, that is, $\phi$ (in a slightly modified form of the knowledge production function $\dot{A}=\delta H_{A} A^{\phi}$,) cannot take any other value but 1. Otherwise either growth will eventually stop as the rate of knowledge growth approaches zero $(\phi<1)$, or the growth rate will increase without a bound to infinity $(\phi>1)$. Obviously, $\phi=1$ is too unrealistic an assumption and raises a robustness issue..$^{2}$

Last but not least and not necessarily to be criticised, positive externalities are required in the knowledge production function. Since exponential per capita output

Using these [endogenous] growth models, however, it continues to be hard to measure the effect of knowledge on economic growth. For example, it is difficult to single out the contribution of knowledge to total factor productivity, which is at the heart of the growth process and can be affected by other parameters such as the more effective utilisation of human or physical capital.

71 "The number of designs is measured in terms of the number of patents granted. Thus this formulation of the production of designs (a form of 'knowledge', broadly defined) apparently satisfies the condition of cardinal measurability of 'knowledge" (Park, 2007, p. 387).

${ }^{72}$ Romer (1994a, p. 18), however, explains that this assumption is taken for the sake of simplicity only:

The mathematical analysis in this more complicated robust model $[\phi<1]$ was much harder than the analysis that is possible when $\phi$ is equal to 1 . The difference between the two models is the difference between studying the phase plane of a nonlinear differential equation system and solving a simple linear differential equation. Once it is clear that we could build a complicated model that is robust, there is every reason to work with the simple special case whenever possible. 
growth requires exponential knowledge growth, knowledge production functions are designed such that the research productivity at any point in time is dependent upon the current knowledge stock. ${ }^{73}$ Consequently, research contributes to final goods production in two ways: by producing new knowledge and thus increasing the aggregate knowledge stock; and by inadvertently increasing the productivity of future researchers. Hence, whereas knowledge must be completely excludable in its use in the production of intermediate goods, it must be completely non-excludable in its use in the production of new knowledge. ${ }^{74}$ If knowledge were fully excludable, the growth rate of knowledge stock would eventually reach zero and so would the growth rate of per capital output. Accordingly, intellectual property rights need to be designed such that knowledge is partially excludable, and in this respect, "excludability is a function of both the technology and the legal system" (Romer, 1990, p. S75).

\title{
2.5. Knowledge-based growth models vs. Marx's value theory
}

As we have seen so far, NGT, or more precisely, knowledge-based new growth models, are not successful as a growth theory with endogenised knowledge production. It is not only that a lot of compromises are made to incorporate knowledge into the neoclassical framework, but the endogenisation of knowledge brings with it more problems such as scale effects and a knife-edge character. As an

73 Whilst it is out of necessity that knowledge should grow exponentially, for Romer, it is also an essential characteristic of knowledge production. He says in an interview (Kurtzman, 1997, para. 11):

\begin{abstract}
One feature of knowledge can be summarised by Isaac Newton's statement that he could see far because he could stand on the shoulders of giants. In other words, his notion was that knowledge builds on itself, which means that as we learn more, we get better and better at discovering new things. It also means that there's no limit to the amount of things we can discover. This is a very important fact for understanding the broad sweep of human history and it is very different from what we are used to thinking about in terms of physical objects, where scarcity is the overwhelming fact with which we have to deal.
\end{abstract}

74 Romer (1990, p. S84) considers this partial excludability of knowledge is consistent with the patent system although there exists no patent regime with the permanent protection of patents:

If an inventor has a patented design for widgets, no one can make or sell widgets without the agreement of the inventor. On the other hand, other inventors are free to spend time studying the patent application for the widget and learn knowledge that helps in the design of a wodget. The inventor of the widget has no ability to stop the inventor of a wodget from learning from the design of a widget. 
economics of knowledge, NGT is inferior to micro-level theories of innovation and technological change, and these models do not add much to the neoclassical understanding of growth. They aspire to be integral models of growth and knowledge, but are instead unfortunately trapped between the two. Put differently, concerned mainly with endogenously generating exponential growth of the knowledge stock, their achievements are both modest and unsatisfactory: modest because nothing fundamentally new is added to the structural characteristics of the economy as conceived in OGT, for example, the co-existence of competitive equilibrium (non-increasing returns) and growth (increasing returns); and unsatisfactory because micro-level innovation theories prove to be difficult to be translated in a way that fits the neoclassical framework.

Whereas OGT is focused on showing how stable a growth path is and how the growth path adjusts to changes in consumer behaviour, population and knowledge, knowledge-based growth models instead try to reconstruct economic growth on the basis of knowledge, and therefore the fate of growth depends on how successfully knowledge production is designed in terms of generating exponential knowledge growth. Unfortunately, assumptions are made too casually in the name of simplicity and too selectively for the obvious reason to generate exponential knowledge growth. Take Romer's knowledge production function as an example, in which the growth rate of the knowledge stock is assumed to be in proportion to human capital devoted to research in the presence of positive externalities of knowledge. Why is this assumption less exogenous than Solow's? As Solow (2000, p. 122) puts it, "some things are exogenous after all, at least exogenous to economics". ${ }^{75}$ Referring to externalities is not an explanation either; it only describes what needs to be explained.

\section{Growth theory, economics of use value}

At a more fundamental level, to some extent, the daunting task of generating exponential knowledge growth is the product of neoclassical economics itself. In neoclassical economics, an economics of use value, growth can be conceived only as an increase in final output regardless of price changes. In addition, all different

75 Mirowski (2011, p. 75) criticises NGT from a similar point of view:

Romer had not truly 'endogenised' technical change, since he still made use of the Solow trick of equating it with shifting the production function, only now linking that shift to yet another unobservable variable dubbed 'human capital devoted to research'. (Romer, 1990, p. S83) 
goods and services are considered homogeneous in that they have utilities, representable by a single use value, as exemplified in the utility function of the consumption goods variety model of Grossman and Helpman (1991b). In this utility function, a consumption index $D$ is defined as,

$$
\left[\int_{0}^{n} x(j)^{\alpha} d j\right]^{1 / \alpha}
$$

where $x(j)$ denotes consumption of good $j$. According to this function, all consumption goods of $n$ distinct types are homogenous with the representative consumption good in quantity $D$, although $D$ may vary depending on the design of the index function. ${ }^{76}$ It is implicit in this model, which none bothers to mention, that real GDP is equivalent to $D$ (or a function of $D$ ), and this, in turn, justifies the use of the aggregate production function (i.e. the one-sector model). For number of goods considered in a model makes no essential difference.

With economic growth being equated with a growth in a single representative use value, and given non-increasing returns to scale with respect to conventional inputs, there must exist something acting as a multiplier or productivity booster for the economy to grow, whatever it is called.77 Brought into the Romer 1990 model as multiplier, the role of knowledge is necessarily limited only to increasing the economy-wide productivity of conventional inputs. And in this limited role, knowledge is not a factor of production; no economic agent can choose how much knowledge to employ in the production of final output. ${ }^{8}$ Nor does the aggregate knowledge stock, determined endogenously or not, affect profit-maximising decisions of individual firms in the final goods sector. Strictly detached from final goods production, knowledge is also stripped of diversity in terms of its production,

${ }^{76}$ This model is a consumption goods variant of the Romer 1990 model.

77 This multiplier encompasses all factors that can cause "any kind of shift in the production function" (Solow, 1957, p. 312). Technical change and knowledge growth are some of the loose terms that refer to increases in this multiplier.

${ }^{78}$ That knowledge does not enter the final goods production as a factor of production is pretty obvious in the Solow model and externality-based growth models. It is also the case for the Romer 1990 model, in which firms in the final goods sector are not involved in knowledge production, but take the aggregate knowledge stock, produced in the research sector, as given. Although there are differences between OGT and NGT in terms of characterisation of knowledge, they equally keep firms in the final good sector out of touch with knowledge. 
consumption and dissemination; knowledge goes through the neoclassical use value filter and comes out as a special thing, as non-rival and partially excludable (and tradable) good and as disembodied knowledge. ${ }^{79}$ Further, no distinction is drawn between firm-level knowledge production, in which knowledge production is aimed largely at reducing production cost, and aggregate-level knowledge production, in which knowledge is only a productivity booster, and the former is simply ignored. It follows that, at the individual level, each firm faces the choice of either knowledge production or commodity production, and the same applies to each worker. At the aggregate level, the economy as a whole should allocate resources between knowledge production and final goods production with the sole aim of determining infinite-horizon output schedule which maximises infinite-horizon utility. Through competition across the two sectors, by way of the equalisation of the wage level, an equilibrium is established between human capital devoted to knowledge production and that to output production, which is seen to strike a right balance between higher current output and higher future productivity (and thus higher future output) and maximises the infinite-horizon utility of the economy by way of long-term sustained per capita output growth.

In sum, NGT starts with the growth of the real GDP per capita and implicitly equates it with a growth in a single use value. From this assumption the need for exponential knowledge growth is derived. For this purpose, knowledge is stripped of all its richness and reduced to a productivity multiplier and, consequently, competition between knowledge production and final goods production comes to the fore as the

79 Mirowski (2009) classifies neoclassical attempts to theorise knowledge into three categories: as a thing; as an inductive index; and as symbolic computation, and criticises that none of these is satisfactory in their "constructions of the epistemology of the agent" (p. 101). For him, knowledge is about cognition, learning, communication and decision-making of the economic agent. For those who theorise knowledge as a thing, to which Romer belongs: cognition is irrelevant; learning is the purchase of a commodity; communication is the same as exchange. It goes without saying that such an epistemology is too simple and sounds almost inhuman: "A thing-like information absolved the theorists of having to confront whatever model of mind was supposedly inherent in the utility function" (p. 116). The epistemology of the agent is, however, not in the scope of the endogenisation of knowledge in the Romer 1990 model and other knowledge-based growth models and, therefore, it is to some extent misleading to impose this line of critique onto these models. In other words, knowledge in these models should be understood in a narrower sense. This understanding corresponds to what Foray (2004, p. 2) calls "a more restrictive conception of the economics of knowledge" which excludes "problems of economic choice in situations of incomplete and uncertain information". 
enabler of long-term sustained growth by optimally allocating resources. However, unfortunately, the bottom-up reconstruction of growth on the basis of knowledge turns out to be no simple matter. The difficulties are augmented further by the lack of empirical evidence that supports the close link between investments into innovation and growth. ${ }^{80}$ This is not to suggest that NGT is necessarily doomed to failure. As Solow (2007, p. 6) puts it: "The most valuable contribution of endogenous growth theory has not been the theory itself, but rather the stimulus it has provided to thinking about the actual 'production' of human capital and useful technological knowledge". Future growth theorists may be able to come up with new modelling techniques that allow growth models to become more successful such that major findings of microeconomic theories on innovation are accommodated.

\section{Marx's value theory, economics of value}

By contrast, in Marx's value theory, an increase in output in terms of use value does not necessarily lead to an increase in value. ${ }^{81}$ Abstracting from individual differences in productivity and sectoral differences in complexity, see Chapter 3 for more on this, the same amount of value is produced for the same period of time regardless of social productivity improvements although more use values are created in quantity and diversity:

Variations in productivity have no impact whatever on the labour itself represented in value. As productivity is an attribute of labour in its concrete useful form, it naturally ceases to have any bearing on that labour [emphasis added] as soon as we abstract from its concrete useful form. The same labour, therefore, performed for the same length of time, always yields the same amount of value, independently of any variations in productivity. But it

80 This is, however, not to deny the fact that average living standards in the capitalist economy have improved significantly due to the rapid development in science and technology. Similarly, Mirowski (2011, p. 77) says:

However, I do not want the reader to leave ... with the impression that, in the real world, scientific knowledge has nothing whatsoever to do with technological change or that science has no causal relationship to economic growth. I would rather hope that the reader would realise that the triad of linear model/public good/growth theory is a badly flawed and expendable set of concepts to structure inquiry into the economics of science. No such simplistic macroeconomic statements concerning science and economic growth have been found to hold up very long.

81 "An increase in the amount of material wealth [use value] may correspond to a simultaneous fall in the magnitude of its value. This contradictory movement arises out of the twofold character of labour" (CI, pp. 136-137). 
provides different quantities of use-values during equal periods of time; more, if productivity rises; fewer, if it falls. (CI, p. 137)

In value theory, then, real GDP is nothing but the price form of the total value created $(v+s)$, not (a function of) the quantity of the representative consumption good, and economic growth is a form of the expansion of accumulation as well as of the capitalist relations of production. The growth in use value production in quantity, quality and diversity is simply a by-product of value production and accumulation. In addition, the problem of generating increasing returns out of nonincreasing returns is non-existent in value theory. For the concept of returns to scale applies to productivity defined in terms of use value, but not to value, in terms of which accumulation is measured (at the aggregate level). Likewise, whilst knowledge is a determining factor of (social and individual) productivity, its effect of boosting social productivity has no significance in terms of total value created.

There are other fundamental differences between economic growth in NGT and accumulation in value theory, not least in the way knowledge is conceptualised and incorporated into the theory, reflecting more fundamental differences between the two theories. First, whereas economic growth in knowledge-based growth models of NGT is the direct result of knowledge growth (despite knowledge production not necessarily being intended to generate economic growth), capital accumulation in value theory does not necessarily depend on knowledge. Accumulation, essentially the conversion of a portion of surplus value into capital, can take place without technical change, ${ }^{82}$ not to mention that technical changes themselves are not a

82 Marx (CIII, p. 372) says:

Yet despite the constant and daily transformation in the mode of production, a greater or smaller part of this total capital, now this, now that, continues to accumulate for a certain period of time on the basis of a given average ratio [emphasis added] of these [organic] components, so that its growth does not involve any organic change and is thus no cause for a fall in the rate of profit.

Similarly, He also says that even simple reproduction (in which there is neither accumulation nor technical change) is a part of accumulation:

Simple reproduction on the same scale seems to be an abstraction, both in the sense that the absence of any accumulation or reproduction on an expanded scale is an assumption foreign to the capitalist basis, and in the sense that the conditions in which production takes place do not remain absolutely the same in different years (which is what is assumed here). The supposition is that a social capital of a given value supplies the same mass of commodity values and satisfies the same quantity of needs in both the current year and the previous year, even if the forms of the commodities may change in the reproduction process. But since, when accumulation takes place, simple reproduction still remains a part of this, and is a real factor in accumulation [emphasis added], this can also be considered by itself. (CII, pp. 470-471) 
continuous process; it is possible to continue accumulation without adopting new technologies, by extending the working day and/or increasing the intensity of labour.

Second, in contrast to these models in which knowledge growth causes economic growth, in value theory, accumulation explains knowledge growth and vice-versa. ${ }^{83}$ Capitalists with varying levels of technical knowledge co-exist and compete against each other, meaning there is a minimum productivity requirement for individual capitalists to continue their business operations for a foreseeable period of time whilst making no profit or even sustaining losses; (a certain level of) knowledge is a prerequisite for accumulation. In addition, given that capitalists with higher productivities than the sectoral average can realise extra surplus value or surplus profit, individual capitalists strive to strengthen and deepen their knowledge base; knowledge production is driven by the desire to accumulate more and faster. Last, at the economy-wide as well as the sectoral levels, individual capitalists' knowledge production leads to the growth of social knowledge by way of knowledge transfer and (partial) spillover. In short, the capitalist mode of production, where production is primarily for accumulation, drives the growth of social knowledge through competition.

Third, the relations between knowledge and accumulation in value theory are multifaceted, encompassing different spheres and multiple layers of abstraction, and are therefore much more complex than the simple one-way and accidental relationship between the two demonstrated in NGT. As well as being the result of accumulation, knowledge production shapes the trajectory of accumulation, often generating contradictory tendencies. For example, on the one hand, a rise in productivity drives down the profit rate by raising the organic composition of capital, weakening the impetus to accumulation. On the other hand, at a more complex level of analysis, it increases the profit rate by increasing the rate of exploitation and thereby accelerates accumulation. In addition, a fall in the profit rate, in turn, intensifies competition, expanding the scale and scope of knowledge production and further accelerating (by increasing the profit rate) and decelerating

\footnotetext{
83 Marx introduces the concept of capital and the transformation of surplus value into capital in Chapter 4 of the first volume of Capital. Then he analyses the production of absolute surplus value which does not involve technical change, in Chapter 10. Knowledge only first appears in Chapter 12 where he discusses competition between individual capitalists centred on productivity and the production of relative surplus value.
} 
(by decreasing the profit date) accumulation. As knowledge and accumulation have effects on each other in diverse and often contradictory ways, no mathematical correlation between them can be established, let alone a causal relation, as in NGT.

All in all, metaphorically speaking, whereas knowledge in NGT is the engine of (mechanical) economic growth, in value theory, it is an enzyme produced by the capitalist economy (as an organism) functioning as the catalyst for accumulation and accompanying tendencies and counter-tendencies.

\subsection{Concluding remarks}

As we have seen in the previous section, NGT is not successful in explaining growth on the basis of knowledge despite many theoretical compromises it makes whilst bringing knowledge into the analysis on the basis of a neoclassical framing. This is not to deny the need for growth theory. It is not only that understanding the longterm path of real GDP per capita is important in and of itself, but most economic policy discourses are organised around GDP growth. There is, then, an imperative to develop an alternative growth theory on the basis of Marx's value theory, taking its distinction between value and use value being a solid foundation. ${ }^{84}$

In developing such a theory, the top-down approach of NGT should be avoided because no such role as productivity booster is deduced from the growth of real GDP per capita in value terms. By contrast, it is necessary to take a bottom-up approach, the first step of which is to explore why knowledge is produced in the capitalist economy in the first place. The short answer to this question is the forces of competition among capitalists driven and imposed by productivity differences within sectors and complexity differences across sectors, which is a form through which an immanent law of capitalism is asserted (compare this with NGT which takes the existence of the research sector for granted). In the next chapter, we will

84 This thesis is not concerned with developing a theory of real GDP per capita on the basis of Marx's value theory. However, here are some guiding principles for future research: at the very abstract level, the growth in real GDP per capita should be understood as the growth in total work hours of the economy; at more concrete and complex levels of analysis, the following will need to be considered: 1) the division of the total work hours between productive labour and unproductive labour; 2) the existence of temporary surplus profit within and across sectors; 3 ) the existence of false social value in the agricultural sector due to barriers to capital movement; 4) trade, capital flow, productivity differences across countries. 
also show that knowledge can be incorporated into value theory in a consistent and coherent manner albeit in a different context. Suffice for now to conclude this chapter by noting that neoclassical economics has turned out to be neither robust nor flexible enough to accommodate knowledge, at least in the context of growth. 


\section{Knowledge in value theory: Virtual multiplication of labour}

\subsection{Introduction}

We have seen in the previous chapter that too many simplifying assumptions are imposed on knowledge to incorporate it into growth models without altering the core elements of neoclassical economics. Consequently, the theory of knowledge underpinning NGT is shallow and little is added to the neoclassical understanding of economic growth. Neoclassical growth theory has yet to pass the test of incorporating knowledge either anywhere approaching fully, let alone coherently.

In addition, it is an irony that the continuing and rapid development of social knowledge, a systemic characteristic of capitalism, is seen as undermining the validity of value theory by some groups of theorists, not least the proponents of cognitive capitalism theory (see Chapter 4 for extensive consideration). The presumption is that, with the putatively decreasing role of labour in the production process, the validity of treating labour as the sole source of value is also being eroded, to the extent that labour gives way to knowledge as the source of value. Instead of incorporating the role of knowledge into value theory, the seeming dominance of knowledge (in some sectors) in contemporary capitalism is taken as the reason to reject value theory altogether.

To the contrary, as argued here, knowledge can be incorporated into value theory. First, it can be demonstrated that the labour theory of value is compatible with labour-saving, knowledge-using technologies. Second, value theory can be put to the test of knowledge to prove its consistency, coherence and flexibility.

For this purpose, the South Korean controversy on the value and price of information commodities ('Controversy') such as computer software and digital music is of great importance. ${ }^{85}$ It is not only that the Controversy is instrumental in identifying issues discussed in this chapter, especially those around the relationship between knowledge and commodity in value production, but it is instrumental for a more concrete analysis in Chapter 6, through the consideration of the distribution of surplus profit in the form of royalty payments and licence fees to the rights holders.

85 The Controversy started in 2002 and is drawing to a close in terms of number of publications; since 2014, only two papers (Ahn, 2014; Ha, 2015) have been published. 


\section{Source vs. Copy}

The Controversy is concerned mainly with the puzzle that the (re-)production of a software commodity requires very little, if any, labour, but it is being sold at a high price. This raises the question of whether value theory is applicable to software and, more generally, to information commodities. Answering this question requires, above all, the analysis of the software production process, which broadly consists of two phases.

First, the source code ('source') of software is produced. Like any other products of labour, the production of a source, also known as coding, requires both means of production (e.g. a computer) and labour. This step includes feature requirements definition, user experiences (UX) design, visual design, software architecture design, programming and testing and, therefore, different types of labour with qualitatively distinct skill sets are needed. Second, install packages of the software ('copy') are produced by compiling the source code and replicating the first copy, ${ }^{86}$ even at the point of sale, especially when a copy is delivered via the Internet. As the second step requires little human involvement, most workers in software companies are devoted to the first step.

In neoclassical terms, then, computer software and other information commodities such as digital music, e-book and mobile apps - the most prominent examples of information commodities at time of writing - have a cost structure with a high fixed cost and very low constant marginal cost. In other words, whereas the production cost of the first copy, which includes the production cost of the source, is very high, subsequent copies cost very little to produce. For these goods, competitive equilibrium does not exist because average cost curves are downward sloping, with profit per unit increasing as supply grows. This is why information goods markets have often been analysed on the basis of the theory of imperfect competition in mainstream economics, with knowledge producers realising monopoly profit in partial equilibrium settings. However, although it is acknowledged that information commodities are special cases, the consensus is that they do not warrant a new economic theory. The received view is that "forces that were relatively minor in the industrial economy turn out to be critical in the information economy" (Varian,

${ }^{86} \mathrm{All}$ copies are not necessarily identical. It is often the case that a customer-specific identity verification code is embedded into each copy to make sure it can be used only by the customer who has bought the product. 
Farrell, \& Shapiro, 2004, p. 3), for example, "pricing, switching costs, scale economies, transaction costs, system coordination and contracting" (p. 4). In other words, information commodities do not pose any fundamental challenges to mainstream economics.

By contrast, the Controversy has yet to reach a consensus. This is mainly because different approaches reflect different interpretations of Marx's value theory, especially on such key concepts of value theory as extra surplus value and rent. The Controversy has necessarily evolved to become about value theory. ${ }^{87}$

The next two sections ( 2 and 3), then, are devoted to critically reviewing the two contending approaches of the Controversy, the 'cost approach' and the 'monopoly price approach', focusing on how each approach theorises the role of the source code of computer software in the determination of the value of a software copy. Although both the strengths and weaknesses of each approach are highlighted, both are rejected for inadequately theorising the relations between source and copy. It is shown and criticised, that the source code is considered as means of production in the cost approach and having nothing to do with the production of the value of software copies in the monopoly price approach. In Section 4, the debate is taken to a more general level by introducing a structural distinction between knowledge (source) and commodity (copy) and their internal relations in the production process are analysed. In addition, given that such a distinction is present in commodity production in general, the notion of information commodities as the object of analysis is questioned. On the basis of this, in Section 5 , an alternative approach, called the virtual multiplication approach, is put forward. It is argued that knowledge (source) should be seen as taking part in the determination of the value of commodities (copies) by determining the productivity and complexity of commodity-producing labour, i.e. the virtual multiplication of commodityproducing labour.

\footnotetext{
${ }_{7} 7$ The following has been fiercely discussed in the Controversy: whether labour expended to produce a source contributes to the value of a copy; the nature of the price of a copy, whether it is determined by the value of the copy or it is a monopoly price, etc.; and the role of intellectual property rights in the determination of the value and price of information commodities.
} 


\subsection{The 'cost approach'}

Namhoon Kang, who initiated the Controversy by publishing a book on the value and price of information commodities in 2002 (N. Kang, 2002), introduces a crucial distinction between the source and the copies of software. For him, this distinction is the key to understanding the outstanding divergence between the high price of a copy and its low marginal production cost, which is a defining characteristic of information commodities. ${ }^{88}$ Significantly, he suggests that the source should be considered as an information commodity:

The value of an information commodity is the labour time required to reproduce the source rather than a copy. ${ }^{89}$ (N. Kang, 2002, p. 99)

The value of the source is realised by selling multiple copies ... Whether or not the value of an information commodity [source] is properly realised depends upon the price of a copy and total number of copies sold. If the value of the source is properly realised, the information commodity will be reproduced without any problem.

In other words, the high price of a copy is not determined by the value of a copy in isolation, but rather by (incorporating a fraction of) the value of the source. This is to avoid the inevitable conclusion of taking copies as commodity that the value of information commodities is approximately zero, which, then, is at odds with their high price (p. 98).

Although the distinction between source and copy that N. Kang first introduced has been an important contribution, it is hard to justify the argument that source is a commodity. Commodity production is mass production and "from the beginning, replica production" (C.-O. Lee, 2005, p. 155), ${ }^{\circ 0}$ but apparently a source is never

88 "Information commodities have characteristics that are quite different from other commodities. ... From a production point of view ... the marginal cost of software is approximately zero" (N. Kang, 2002, p. 47). All translations from Korean sources are my own.

${ }^{89}$ Similarly, K. Lee (2004) argues that 'algorithm' rather than the entire source code, which consists of multiple algorithms, is an information commodity. What should be considered as an information commodity, source or copy, has been one of the major debating points. We do not, however, cover this point in detail.

${ }^{90}$ Chae (2004a), N. Kang (2004, 2005), K. Lee (2004), C.-O. Lee (2005), Rieu (2005) are reprinted in N. Kang et al. (2007). Page references for these papers are from N. Kang et al. (2007). 
mass produced. For example, mass produced automobiles are replicas of the first automobile produced based on the design of an automobile model, where the design corresponds to the source and mass produced automobiles are (commodity) copies. Information commodities are extreme cases in which the replication cost of copies is approximately zero, but this does not justify the selection of source as commodity.

N. Kang's view is a variant of what I call the 'cost approach' in which both Research and Development labour ('R\&D labour') that produces source and 'copy labour' that produces copies are considered as producing value. Whilst, for N. Kang, R\&D labour produces the value of the source and copy labour that of copies, for those who view a copy as commodity, the value of a copy is the sum of the direct labour time expended for copy production and (a fraction of) the indirect labour time expended for source production, leaving value transfer from the means of production (e.g. electricity) during copy production aside. For example:

The value of every commodity is determined by embodied labour time, which is the sum of direct labour time and indirect labour time. If we view a copy as an [information] commodity, the production cost of the source [per copy] is indirect labour time that decreases as the number of produced copies increases. The indirect labour portion of the total embodied labour decreases as the number of produced copies increases. (C.-O. Lee, 2005, pp. 157-158)

There is no reason why we cannot say that $\mathrm{V} / \mathrm{n}$ [the value of the source divided by the number of sold copies] is the value of copy. (Rieu, 2005, p. 173)

Producing 10 million Windows XP copies requires not only copy labour but also R\&D labour. Hence, by summing up all these labour times [of copy labour and R\&D labour] and dividing the total labour time by 10 million, we can easily get the value of a Windows XP copy. (Kim, 2008, p. 266)

There is no reason why the labour of researchers producing [a new] model [design] should be distinguished from the labour performed at the assembly lines. (Jo, 2008, Section 1, para. 5)

However, the proponents of the cost approach do not explain why there should be no distinction between source-producing labour and copy-producing labour other than that the former is indirect labour and the latter direct labour. In addition, the cost approach is inconsistent with Marx's value theory in four respects. First, according to this approach, the value of a copy is determined ex post facto. For the value to be determined, copies should stop being sold in the market so that the number of produced/sold copies is finalised. If more copies are sold after this point for any reason, the value of a copy falls, even without any changes to the conditions 
of production (e.g. productivity). Such a view turns socially necessary labour time, determined through the economic and social reproduction associated with the total circulation of capital and given before production, into average cost of production. Second, whilst R\&D labour is considered to be indirect labour for the production of copies and the source as fixed constant capital, in practice, no value can be transferred from source to copy because no changes are made to the source, especially in terms of its lifetime, before or after the production of copies. According to Marx, means of production transfers value to a final output little by little because production results in its "deterioration" (CI, p. 312). However, a source, once produced, can be used for the production of copies an unlimited number of times, and no deterioration is inflicted on its use value and value during the production process, except through technical changes. Third, for N. Kang, who maintains that source is a commodity, the realisation of the value of a source is the result of the sale of copies, not of the source. Consequently, the source can continue to be held by the owner even after its value has been fully realised. His point is that, once the final copy has been sold, the source would be useless by definition and thus would have no value. However, this is simply wrong. Last, this approach ends up blurring the distinction between source and copy. Although it is acknowledged that R\&D labour and copy labour have different roles in use value production of software copies, there is no essential difference between R\&D labour and copy labour in terms of value production.

\subsection{The 'monopoly price approach'}

In an opposing approach to the cost approach, Chae and S. Kang argue that R\&D labour does not contribute at all to the value of copies. The key argument of the monopoly price approach is that, although the source is indispensable for copy production, it is not a means of production and does not transfer value during the production process of copies. Consequently, as "virtually no labour time is needed" (Chae, 2004b, para. 3) to produce a copy, the value of a copy is approximately zero, provided that the use of electricity and the wear and tear of computer systems incurred by copying and compiling are negligible in terms of value transfer.

Given the price of a copy is much higher than the value of a copy which is approximately zero, it follows that the value of a copy does not determine its price. Rather, the high price is argued to be a monopoly price that can only be sustained due to intellectual property rights, see Chapter 5 . It follows that, if no intellectual property rights had existed, the commodification of software and information 
commodities would not have been possible, because the price of a copy would then haven been determined by the value of a copy, and thus would also be approximately zero.

According to this approach, the value of a copy is determined by the new value created by direct copy labour alone. Source and R\&D labour do not have any role in the determination of the value of a copy. S. Kang (2008a, p. 64) argues that R\&D labour "never produces value" although he takes a more eclectic view in his later works, as we will see later.

Our critique of this approach is twofold. The first line of this critique focuses on the fact that concrete labour time expended to produce a copy is considered to be not much different from, if not directly equal to, socially necessary labour time. There is no doubt that the concrete labour time required to create a copy of software (for individual capitalists) is approximately zero. But it is wrong to derive from this that socially necessary labour time to create a copy is also approximately zero. Because value - socially necessary labour time - is socially determined, there is no preexisting fixed conversion ratio between concrete labour time and social labour time. It depends on the social circumstances under which the specific concrete labour is performed. Significantly, the same (concrete) labour time can create different magnitudes of value under different circumstances (in a given period of time). First, the more productive is labour, the more value it creates. Suppose that worker A produces two chairs per hour and worker B only one chair due to different levels of personal skill. As all chairs have the same value due to "the law of market value" (CIII, p. 799), worker A creates twice as much social value as worker B for the same period of time. Put differently, the value-creating capacity of worker A is twice as much as that of worker B. Second, labour performed under better (individual) conditions of production creates more value. Suppose that now worker A moves to a new workplace that makes use of more advanced production methods and is, therefore, able to produce three chairs per hour. In this case, different valuecreating capacities of the same worker arise from different conditions of production that are more or less independent of workers' skill and knowledge. Third, more complex labour creates more value than simple average labour. Marx gives an example of the labour of a jeweller and the labour of a spinner (CI, pp. 305-306), in which the former is complex labour and the latter simple labour. Setting aside the question of how complexity is determined, and how complex labour is reduced to simple labour, the labour of a jeweller creates more value than the labour of a spinner because the former is more complex. In sum, the same amounts of concrete 
labour time can be converted into different social labour times under different circumstances. In the monopoly price approach, however, there is only one predetermined conversion scenario between concrete labour time and social labour time; concrete copy labour time of approximately zero is considered to be equal to social labour time of approximately zero. It is implicit in this approach that the value-creating capacity of copy labour is fixed no matter what are the conditions of production. In other words, it ignores the variability of the value-creating capacity of concrete labour.

The second line of our critique of the monopoly price approach is that it presumes information commodities are inherently different from more tangible (noninformation) commodities in such a way that they deserve special consideration. For the proponents of the monopoly price approach, information commodities are unique in that the price of information commodities is a monopoly price that is determined without consideration of the value of information commodities. Instead, intellectual property rights play a decisive role in the determination of price. Although it is acknowledged that monopoly pricing as such is not specific to information commodities, S. Kang (2008a, pp. 108-109) argues that the monopoly price of information commodities is unique in the sense that it cannot be sustained without intellectual property rights: "Given that the monopoly price of software originates from the unique characteristics of software [emphasis added], the monopoly price of software is distinct from that of other commodities. The latter is sustained due to the market power of monopoly firms". ${ }^{91}$

${ }^{91}$ As a surprising turn of events, the proponents of the monopoly price approach changed their views on R\&D labour. According to their most recent contributions (Chae, 2008; S. Kang, 2008b), R\&D labour does produce value, although R\&D labour is still seen not to contribute to the value of software copies. Apparently, this was to address the ambiguity around whether R\&D workers are exploited by capitalists or not. According to Chae (2008), "System engineers and programmers employed by capital create value, and thus must be exploited by capital [emphasis added]" although he does not explain why and how R\&D labour produces value. Likewise, S. Kang (2008b, p. 282) argues that "R\&D labour subsumed under the capitalist production is a productive labour in the sense that it produces both use value and value". He also gives a similar but slightly different account: "R\&D labour expended to produce the first copy of software - source - is, of course, subsumed under the capitalist production aimed at producing surplus value. Therefore it is productive labour that creates value" (S. Kang, 2009, p. 97). However, he does not explain why R\&D labour creates value other than that $R \& D$ labour is subsumed under the capitalist production. He also changes the definition of $R \& D$ labour to incorporate the labour expended to produce the first copy as well as the source: "R\&D labour which is expended to produce the first copy creates 


\subsection{Knowledge and commodity}

In light of the deficiencies and flaws of both the cost approach and the monopoly price approach, we put forward an alternative view on the value and price of (information) commodities. The key differences from the two approaches are as follows.

First, the presumption is that there is no need for a special theory of information commodities; its position is similar to the view of mainstream economic theories that information commodities are, at best, extreme cases in which features that are minor in the case of non-information commodities come to prominence, especially in the so-called knowledge economy. ${ }^{92}$ Second, then, the outstanding divergence between the high price and very low marginal cost of information commodities is also considered to be present in non-information commodities, albeit on a much less

the value of the first copy, but it never creates the value of subsequent copies" (S. Kang, 2009, p. 100). In other words, R\&D labour or knowledge labour contributes to the value of the first copy or the first commodity, but does not create the value of subsequent copies or commodities. An unfortunate consequence is that the value of the first copy would be much higher than that of the subsequent copies although nobody would be able to distinguish the first copy from the rest because they are identical. According to this interpretation, value bifurcates into the value of the first copy and the value of the rest.

92 The category of information commodities is not well-grounded. First of all, information commodities do not comprise a sector of the economy. A sector in value theory is composed of individual capitals that produce commodities with the same use value, not of those who use the same production technologies or materials, for example, digital technologies in the case of information commodities. Apple's Mac OS X competes with Microsoft Windows, but not with nytimes.com although all of them are information commodities. Dictionary applications for personal computers compete not only among themselves, but also with dictionaries in book form, and in this respect, digital dictionaries and physical dictionaries belong to the same sector. Surely, then, there are more factors involved in the determination of the value of digital dictionary copies than their being information commodities, and for this reason, the value of a digital dictionary copy would be higher than zero even if concrete labour time expended to produce it is almost certainly approximately zero, because their value should not deviate too much from the value of a physical dictionary. In short, the call for a special theory of information commodities is ill-conceived. Information commodities exist in digital form and are consumed using digital devices such as personal computers and mobile phones. In other words, their key characteristics are described on the basis of the common production and consumption technologies, rather than of their use values. Although information commodity is a widely used umbrella term cutting across many different sectors of the economy, its analytical significance is not thereby established. It is difficult from such a concept to derive the structures, processes and tendencies that are specific to the capitalist mode of production. 
prominent scale, because the marginal cost of non-information commodities is usually higher than zero. After all, there is no essential qualitative difference between information commodities and non-information commodities. Mass production of commodities presupposes knowledge, for example, design, blueprint, specifications, and in the case of information commodities, the source code. In other words, for commodities of any kind, knowledge production has to precede commodity production. An inherent aspect of production in general - the production cost of the first unit is higher than that of subsequent units because it includes the production cost of knowledge - manifests very prominently in the case of software, in which source corresponds to knowledge and copy to commodity. ${ }^{93}$ Likewise, the question of the role of R\&D labour in the determination of the value of copies is generalised into that of the role of knowledge labour in the determination of the value of commodities. It is not until the latter question is clarified that the former can be answered properly. It is in this respect that N. Kang's distinction between source and copy is of great significance and importance.

\section{Labour presupposes knowledge}

In Chapter 7 of the first volume of Capital, in which Marx demonstrates that the capitalist production process is the unity of the labour process and the valorisation process, we can find a trace of Marx's views on knowledge and its relation to the commodity. According to Marx, what distinguishes the labour of humans from the labour of animals is that the result of human labour already exists, if only ideally, before the exercise of labour itself: "The architect builds the cell in his mind [emphasis added] before he constructs it in wax" (CI, p. 284) and "at the end of every labour process, a result emerges which had already been conceived by the

93 For Arora, Fosfuri, and Gambardella (2001, p. 53), there are similarities between software and knowledge:

Software shares a key characteristic of technology, namely that production is characterised by a high fixed cost of producing the first unit and a low marginal cost of reproducing it. Moreover, software is typically licensed rather than sold, resembling the manner in which technology is transferred. In some cases, however, the resemblance is only superficial and licensing reflects merely the extremely low marginal cost of reproduction compared to the fixed costs of development. In other cases, software represents technology embodied in code. It can therefore be seen as one form (and an increasingly important one) in which knowledge is held and transferred.

While software does embody knowledge or technologies in various forms, it is hard to make a distinction between software as embodied knowledge and software as a product (sold to other companies or the final users) or component (sold to other companies and embedded in larger and more complex systems). 
worker at the beginning [emphasis added], hence already existed ideally". In the same vein, he also says, "this activity [commodity-producing labour] is determined by its aim, mode of operation, object, means and result" (CI, p. 132), each of which is a specific type of knowledge. From a slightly different angle, the production of an idea (or knowledge) is "an expression of [human's] own nature" (CW34, p. 136).94 He says, "Milton produced Paradise Lost for the same reason as a silkworm produces silk". Paradise Lost, a product of Milton's own nature, was produced in manuscript form before it started being mass produced as commodities by factory labour. Milton's (knowledge) work was the precondition for the factory labour. 95

In other words, the labour process presupposes knowledge, the goal of the labour (i.e. what to produce) on the one hand and the technical methods and modes of cooperation to realise the goal (i.e. how to produce) on the other hand. ${ }^{96}$ Commodity production requires not only commodity-producing labour in the labour process, but also labour of a different kind that produces knowledge, which would enter into the labour process, as objectified in means of production, as the productive powers of individual labour as well as social labour, or more realistically, as combinations of

94 Marx often mentions science and art together and he associates them with the activities in surplus time or disposable time: "In relation to the whole of society, the production of disposable time [can] also [be considered] as the creation of time for the production of science, art, etc." (CW28, p. 328). See also Marx (CW30, p. 190; CW31, p. 27). Science and art in capitalism, however, are means of increasing surplus labour time in capitalism: "[Capital] increases the surplus labour time of the masses by all the means of art and science, because its wealth consists directly in its appropriation of surplus labour time; for its direct aim is value, not use value" (CW29, pp. 93-94).

95 Milton's example shows that Marx draws a distinction between the final manuscript (knowledge) and books (commodities). Similarly:

\begin{abstract}
Productive labour is labour which produces commodities, material products, whose production has cost a definite quantity of labour or labour time. These material products include all products of art and science, books, paintings, statues, etc., in so far as they take the form of things [emphasis added]. In addition, however, the product of labour must be a commodity in the sense of being 'A VENDIBLE COMMODITY', that is to say, a commodity in its first form, which has still to pass through its metamorphosis. (CW31, p. 27)
\end{abstract}

Carchedi (2011, p. 186) argues that knowledge has always been a commodity in capitalism, "starting from the production and popularisation of the printed book". This, however, ignores the essential, ontological difference between knowledge and commodity. A commodity is produced on the basis of knowledge, no matter how much knowledge is embodied into the commodity during the production process.

${ }_{96}^{6}$ For Marx (CW34, p. 323), knowledge "determines the material process of production more or less directly". 
both. 97

There is, then, a separate process dedicated to knowledge production. We call this the 'knowledge production process', in which labour produces knowledge of a variety of types, each with its own specific use, for example, product specifications (e.g. colour, size, features, blueprint, etc.), technical design, production line design, production technologies, the skill of individual workers, modes of co-operation and many others. Further, knowledge exists in many different forms. Whereas the skill of individual workers exists as objectified in the workers' brains and bodies and thus cannot be separated from them, designs and blueprints do not necessarily require human embodiment. ${ }^{8}$ More importantly, knowledge is inherently different from commodities in that knowledge can be used an unlimited number of times for the production of commodities, unlike means of production, because use of knowledge never causes wear and tear although it can become obsolete due to technical advance, in a similar way as moral depreciation. ${ }^{99}$

Knowledge production involves not only living (knowledge) labour but also diverse types of means of production, as does the labour process. For example, the visual design of a new automobile model requires pencils, sketchbooks and computers (means of production) as well as visual designers (workers). To produce a new automobile model, trial products go through intense testing. The labour expended in testing - which is more or less simple, average labour compared with design labour - is also knowledge labour because it is labour that contributes to the production of knowledge, an automobile model in this case. ${ }^{100}$ Contrary to popular belief,

${ }^{97}$ In a slightly different context, Marx (CW28, p. 113) acknowledges the distinction between knowledge and commodity: "Because in its preparation nature undertook the work of art [emphasis added], and for its first discovery only ROUGH LABOUR [emphasis added], neither science nor developed instruments of production, required".

${ }^{98}$ The distinction between human and non-human forms of knowledge is reflected in the mainstream distinction between tacit knowledge and codified knowledge, drawn ultimately on the basis of reproduction cost, with the reproduction cost of perfectly codified (and codifiable) knowledge being (potentially) zero.

${ }_{99}$ See also Carchedi (2011, p. 186).

${ }^{100}$ Then the distinction between knowledge labour and commodity-producing labour has nothing to do with the more popular distinctions between intellectual labour and manual labour and between material labour and immaterial labour, which are based on either the human faculties utilised in labour or the materiality of final output, whereas the distinction between knowledge labour and commodity-producing labour draws from the division of the 
knowledge labour is not necessarily complex, nor is it only a mental process. Furthermore, considering that the skill of individual workers is also a type of knowledge, training and education are essential components of knowledge production. When a worker produces commodities in the labour process, he or she performs commodity-producing labour. When the same worker learns and practices new production techniques, he or she performs knowledge labour. The worker may acquire skills whilst producing commodities, i.e. learning-by-doing. In this instance, the worker performs both commodity-producing labour and knowledge labour at the same time. ${ }^{101}$

\section{The knowledge production process: Examples of software and automobile}

As implied earlier, the distinction between source and copy is a particular and extreme case of the distinction between knowledge and commodity. R\&D labour is knowledge labour and copy labour is commodity-producing labour (Figure 1).

production process into the knowledge production process and the commodity production process.

Tsogas (2012, p. 383) criticises the distinction between knowledge and commodity in Jeon (2011) that it reproduces the distinction between intellectual and manual labour:

This interpretation re-creates for knowledge and commodity the antithesis between intellectual labour and manual labour. In fact, it is the idealistic presumption of a distinction between intellectual labour and manual labour that creates an equally idealistic ontological distinction between knowledge and commodity, where knowledge can affect commodity production (i.e. knowledge directs and organises commodity production and exchange), but it remains separate and unaffected by it. That is, knowledge is acquired somewhere else or pre-exists and is external to production, like the Kantian categories a priori are external to thought. It is this idealism that SohnRethel wants to shutter - and we concur - by advocating the ontological unity of knowledge and commodity.

This critique is misleading in two respects. First, as we mentioned earlier, knowledge labour has both intellectual and manual aspects, and so does commodity-producing labour. Second, although knowledge precedes commodity production, there is no presumption that the relation between them is uni-directional. Major improvements of the production methods are often suggested by commodity-producing workers; there is a feedback loop between knowledge production and commodity production.

${ }^{101}$ Marx (CW34, p. 323) points out that the skill of workers costs capitalists nothing:

The natural growth of population is one of the results of reproduction; it is firstly itself accumulation (of human beings) and secondly the prerequisite of the process of accumulation (WITHIN CERTAIN LIMITS). It costs the capitalist nothing, no more than does the skill accumulated (piled up) by the working class through practice alone [emphasis added] and TRANSMITTED as a result (advantages of labour) to its remplaçants [replacements]. 


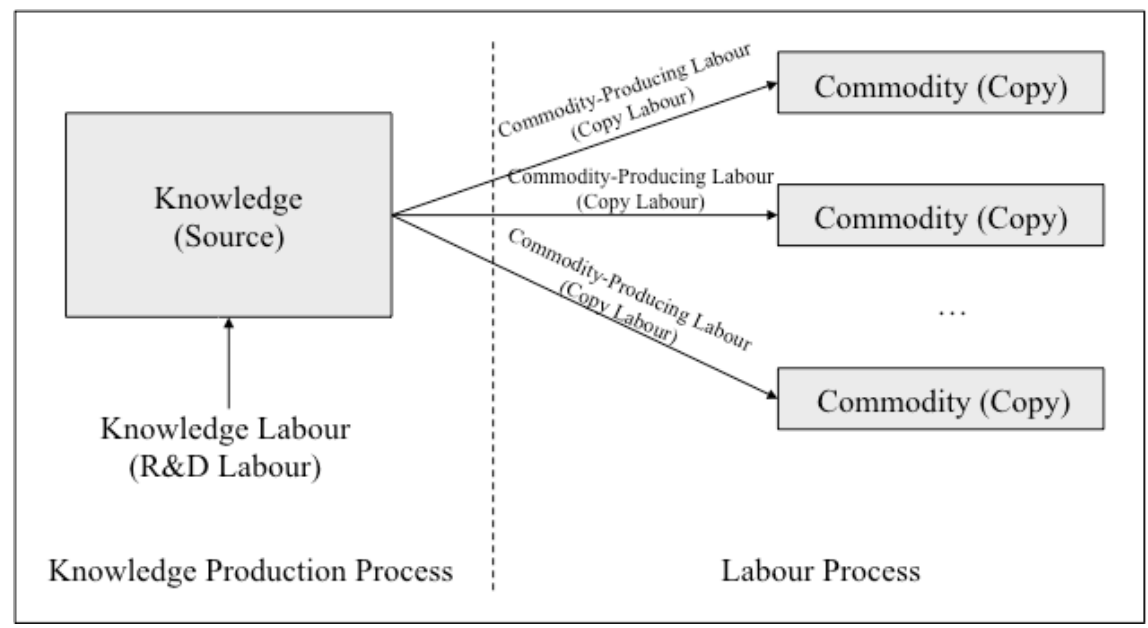

Figure 1. Knowledge production process and labour process (software)

Let us look into the knowledge production process of software such as Microsoft Windows in more detail. Different types of labour are needed to produce the source code of Microsoft Windows. Those who understand both market requirements and technical details of computers write feature specifications. On the basis of the specifications, architects design the software architecture and programmers write code. Quality assurance (QA) engineers write test cases and run unit tests, regression tests, integration tests, and acceptance tests to verify that the source code is being developed in accordance with the specifications and to determine that the final product is fit for use. ${ }^{102}$ All these workers, regardless of the content of their job role, are doing knowledge labour. They are knowledge workers not because their labour requires a higher level of knowledge than workers who are engaged in relatively simple and repetitive labour, but because they work to produce knowledge (i.e. the source code of Windows). This conception of knowledge labour is different from that found in the theories of the knowledge economy, where knowledge labour is more or less a classificatory concept based on education level, industry, and occupation. ${ }^{103}$

Once knowledge production, including the definition of requirements, design, coding and testing, has been completed, copies are mass produced based on the source code, i.e. knowledge. This mass production process is the labour process

102 This, however, should not be understood as a linear, waterfall type of process; there is a feedback loop in the software development process. For example, test cases are often defined before coding starts.

103 For example, see Machlup (1962). 
whereby copies of Windows are produced, in which very little, if any, living labour is expended, in this case, for replicating the first copy which is produced by compiling the source code.

Knowledge production is also required for other more tangible commodities. Take the example of the production of a new automobile model (Figure 2).

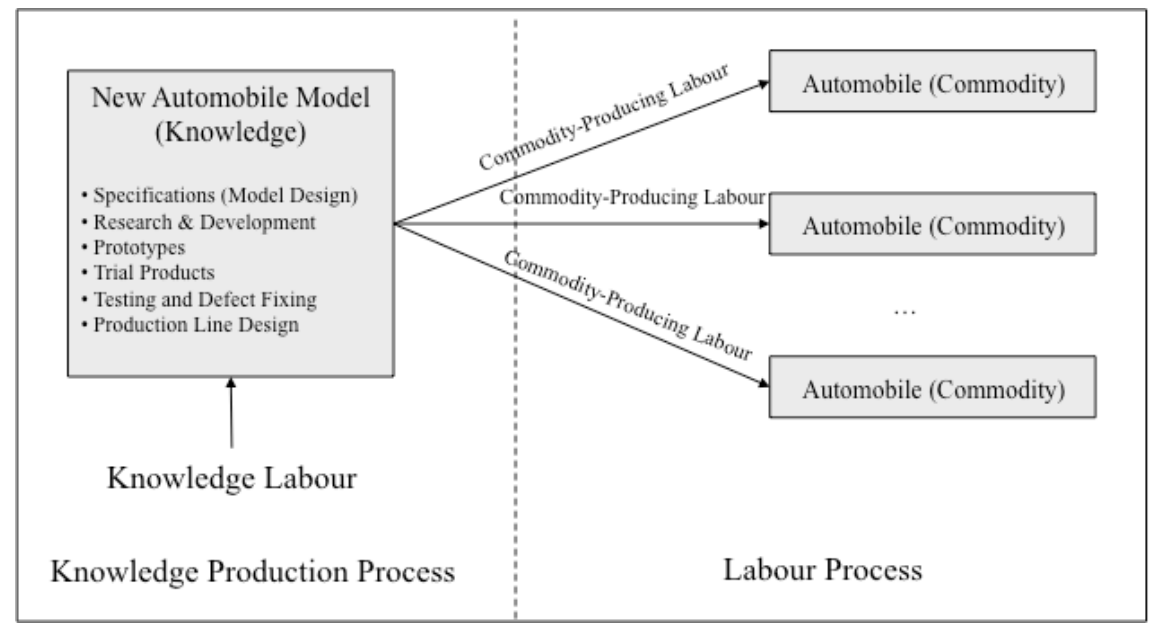

Figure 2. Knowledge production process and labour process (automobile)

As in the example of software, mass production of automobiles can begin only after a new automobile model has been produced, which involves various types of tasks and processes. First, the product concept and initial design are created (design phase). This requires both engineering and visual considerations. Second, prototypes are built based on the design (prototyping phase). A prototype requires much more labour time to build than each mass-produced automobile as no automated production process exists for prototypes yet. Prototyping usually involves close collaboration between the design group and the development group, and goes through multiple iterations. Any flaws found in this phase are instrumental for fixing and improving the initial design. Third, once a prototype has been selected, various types of testing are performed (testing phase). Depending on the severity of the defects found at this stage, the prototype may be rejected, and even design changes can still occur; again, the whole process should not be understood as linear. This cycle of design, build and test is repeated until a prototype passes the quality gate and it is only after this that the prototype, now a new model, can be mass produced. As is the case with software, all labours expended to produce the new model, and the design of a new assembly line for mass production, are knowledge labour, regardless of type, complexity and importance. 


\subsection{An alternative approach: The virtual multiplication of commodity-producing labour}

Production in capitalism is, then, the unity of knowledge production and commodity production, with the latter being the unity of the labour process and the valorisation process. There is a clear distinction between the two, but at the same time they are internally related; knowledge production in capitalism is mainly for the production of surplus value by way of commodity production, and commodity production, in turn, requires knowledge production. Therefore, whilst each should be analysed separately from the other, their interdependence should never be forgotten. ${ }^{104}$

Now that the relation between knowledge and commodity in terms of use value production is firmly established, we should also question the nature of their relation in terms of value production. As mentioned earlier, use of knowledge in the labour process never results in wear and tear of the knowledge, so that it can be used an unlimited number of times. ${ }^{105}$ This means that, whether or not knowledge has

104 Although Ross (2013) provides an excellent exposition of the role of free and open source software (FOSS) in the software industry and in capital accumulation, he fails to distinguish between knowledge labour and commodity-producing labour and instead raises the problem of the measurability problem of knowledge labour (drawing from the concept of immaterial labour), which, from our point of view, is misplaced, because knowledge labour as such does not create value, regardless of whether it is measurable or not:

The fact that the immateriality of the creative and knowledge-work labour processes prevents the accurate apprehension of the ratio of surplus value to variable capital means that the rate of surplus value $\left(s^{\prime}=\frac{s}{v}\right)$, and therefore the rate of profit $\left(p^{\prime}=\frac{s}{c}\right)$, cannot be anticipated. (p. 206)

Similarly, May (2002, p. 44) also puts more emphasis on similarities between knowledge labour and commodity-producing labour:

The relations between knowledge capitalists and knowledge workers remain essentially the same as between their predecessors under 'modern' capitalism. Capitalists control and deploy the knowledge outputs in a similar way to the products of their more materially oriented workers.

105 Marx also points out that the use of knowledge costs little (if any) to reproduce:

Once discovered, the law of the deflection of a magnetic needle in the field of an electric current, or the law of the magnetisation of iron by electricity, cost absolutely nothing. But the exploitation of these laws for the purposes of telegraphy, etc., necessitates costly and extensive apparatus. (CI, pp. 508-509)

A constant accumulation of the worker's personal skill takes place, through practice, and through the TRANSFER of acquired skill to the new generation of workers which is growing up. This accumulation costs capital nothing although it plays a role of decisive importance in the reproduction process. The accumulation of scientific knowledge should also be added here, in so far as it is applied to the material production process. This accumulation is continuous reproduction on a continuously expanding scale. The 
value, ${ }^{106}$ knowledge does not transfer value to the commodities produced based on it. Consequently, knowledge labour never contributes to the value of commodities either directly or indirectly. ${ }^{107}$ Nevertheless, this does not mean that knowledge (labour) has nothing to do with the production of the value of commodities. On the contrary, knowledge (labour) plays an important role in the determination of the value of commodities, by determining the productivity of commodity-producing labour within a sector and the complexity across sectors. In this section, we incorporate the role of knowledge into value theory in a consistent and coherent manner, by making use of the abstract concepts that Marx deploys in the first volume of Capital, especially complex labour, the collective worker and individual/social value.

\section{Different levels of knowledge within a sector and the productivity of commodity- producing labour}

For Marx, the productivity of labour is always "the productivity of concrete useful labour" (CI, p. 137). It "determines only the degree of effectiveness of productive activity directed towards a given purpose [emphasis added] within a given period of time". The comparison between labours in terms of productivity is, in principle, only possible when they produce the same commodity, that is, when they belong to the same sector.

results of knowledge achieved are taught and reproduced as the elements of knowledge, and worked on further by the learners as elements of knowledge. Here the cost of reproduction never stands in proportion to the original cost of production. (CW34, p. 228)

Scientific knowledge is the branch of objectified labour in which reproduction-the labour time necessary to 'appropriate' it-stands in the lowest ratio to the labour time required originally in production. (p. 323)

${ }^{106}$ Knowledge is not a commodity and therefore it does not have value. It is a fictitious capital and has price (arising from the capitalisation of surplus profits).

107 Compare this with Carchedi (2011, p. 221):

The use value of knowledge is a mental use value. Accordingly, new knowledge (a mental transformation) is, by definition, a new mental use value, because, by transforming our perception, theorisation and comprehension of objective reality, it transforms the use to which new knowledge can be put ... It follows that any production of knowledge is at the same time the production of a new mental use value and, if performed by mental labourers for the capitalists, is production of value and surplus value [emphasis added] as well.

In other words, for him, knowledge is a use value instead of a factor contributing to the determination of the use value of commodities. In addition, he does not explain how the mental use value is commodified and traded in the market. 
Suppose that two individual capitalists, or more precisely, workers employed by two capitalists, produce the same commodity, but their productivities are different. This can be due to either or other, or more likely, both of two reasons. First, when workers are identical, they make use of different production methods, embodying different levels of knowledge. The more advanced is the production method or design (e.g. through the use of machines with better quality) that commodityproducing labour makes use of, the higher is the productivity of labour, that is, a greater number of commodities are produced within a given period of time. Such knowledge, which is often objectified into machinery, exists independently of commodity-producing workers, although they need to learn how to use new machinery and techniques. Second, workers themselves have different levels of knowledge or, more specifically, of skill, intelligence, resilience, etc. Under such circumstances, although workers make use of the same production method or design, the labour productivity across workers varies. Considering these two differentiating aspects, Marx (CI, p. 130) says:

This [productivity of labour] is determined by a wide range of circumstances; it is determined amongst other things by the worker's average degree of skill, the level of development of science and its technological application, the social organisation of the process of production, the extent and effectiveness of the means of production, and the conditions found in the natural environment.

For Marx, however, personal differences among workers do not attract much attention; we too will also focus on the first element - that of different production methods.

Significantly, that individual capitalists in a sector usually have and use different levels of knowledge is a systemic feature of capitalism. Individual capitalists, under the pressure of competition, ceaselessly attempt to increase the productivity of labour. ${ }^{108}$ Given a (social) value, an increase in the productivity of an individual

${ }_{108}$ The pace of the development of productivity varies across sectors. According to Marx (CIII, pp. 368-369):

Since the development of labour productivity is far from uniform in the various branches of industry and, besides being uneven in degree, often takes place in opposite directions, it so happens that the mass of average profit (= surplus value) is necessarily very far below the level one would expect simply from the development of productivity in the most advanced branches. And if the development of productivity in different branches of industry does not just proceed in very different proportions, but often also in opposite directions, this does not arise simply from the anarchy of competition and the specific features of the bourgeois mode of production. The productivity of labour is also tied up with natural conditions, which are often less favourable as productivity rises - as far as 
capitalist through the use of more advanced knowledge (especially technical and practical applications of scientific discoveries) would result in a decrease in the individual value of the commodities. This is due to the fact that less labour time is required to produce the same commodity. As the new individual value is lower than the social value, the capitalist can realise extra surplus value. Put differently, knowledge (labour), by increasing the productivity of commodity-producing labour, makes it act as potentiated or multiplied labour: "The exceptionally productive labour acts as intensified labour [potentiated labour; potenzierte Arbeit]; it creates in equal periods of time greater values than average social labour of the same kind" (CI, p. 435). ${ }^{109}$ In other words, knowledge contributes to the production of the value of commodities by virtually potentiating or multiplying commodity-producing labour, and, consequently, capitalists with higher productivities than the sectoral norm, through the virtual multiplication of labour arising from a higher level of knowledge, accrue extra surplus value. ${ }^{110}$

Kim (2008) criticises the notion of the virtual multiplication of labour. From his point of view, it "can lead to the conclusion that the source of extra surplus value is not labour but productive power itself [emphasis added]" (p. 280). ${ }^{111}$ This is based

that depends on social conditions. We thus have a contrary movement in these different spheres: progress here, regression there.

109 'Intensified labour', used in both the Fowkes translation and the first English edition of Capital, is not a good translation of potenzierte Arbeit (potentiated labour) because it gives the false impression that the intensity of commodity-producing labour increases due to the use of better knowledge than the social average. Intensity of labour increases only when labour becomes more intense, for example, by increasing the degree of control and monitoring, and by reducing breaks. Although an increase in productivity has the same effect as an increase in intensity in the sense that both result in more output in a given period of time, the role of knowledge in the determination of value should be distinguished clearly from that of intensity of labour. Throughout this thesis, we use 'multiplied labour' as the translation of potenzierte Arbeit. Interestingly, according to Bidet (2007, p. 21), in the French edition of Capital, potenziert is translated as complexe [complex], which is unfortunate because this blurs the distinction between productivity and complexity. Bidet himself mixes up complexity with productivity and "propose[s] to show that, in the theory of the capitalist mode of production, skilled [complex] labour can only be tackled in the context of 'more productive' labour [emphasis added]". Similarly, Saad-Filho (2012, p. 57) argues that "differences or changes in the intensity or complexity of labour, and differences or changes in the level of education and training of the workforce, have identical effects on value production".

${ }^{110}$ See also Ebert and Zavarzadeh (2014, p. 409).

${ }^{111} \mathrm{He}$ also says: "That labour with a higher productive power produces more value [for a 
on the presumption that individual values are created first and then distributed among capitalists based on productivity to form the social value. Extra surplus value is viewed as the result of the value transfer from the capitalists with relatively low productivities to those with relatively high productivities although he does not explain the real processes by which value is transferred among capitalists in the same sector. ${ }^{112}$

The category of extra surplus value presupposes that there is a multiplicity of individual capitalists with varying productivities of labour, which is in fact the specific character of Marx's theory of competition within a sector. That is, despite the fact that the individual productivity of labour and the individual level of knowledge vary and precisely because of that, a single social value is formed out of competition within a sector (without involving value transfer within the sector); with no productivity difference (as in perfect competition), no competitive pressure would be systematically generated. In Marx's theory, competition within a sector is centred on productivity, although there are many other factors affecting competition

given period of time] means productive power itself produces value. If this were true, the labour theory of value would collapse" (Kim, 2008, p. 290).

${ }^{112}$ Kim (2008, pp. 291-294) argues that Marx's example in Chapter 12 of the first volume of Capital (CI, pp. 433-435) substantiates his claim that value transfer occurs among capitalists within a sector due to productivity differences. Without going into too much detail, his interpretation of the example can be summarised as follows: 1) there are two individual capitalists in a sector. 2) there is no difference in productivity between the two capitalists, and they produce the same number of commodities. Consequently, all commodities produced in this sector have the same individual and social value, which is $12(6 c+3 v+3 s)$; 3 ) the productivity of a capitalist is doubled, whereas the productivity of the other capitalist remains the same. The former employs the same number of workers, so its output is also doubled and the individual value of commodities this capitalist produces goes down to 9 (6c $+1.5 \mathrm{v}+1.5 \mathrm{~s})$; 4) the social value is adjusted to 10 , the total sum of all individual values divided by the number of commodities $(12 * 1 / 3+9 * 2 / 3)$, and this is the result of value transfer from the capitalist with the lower productivity to the capitalist with the higher productivity; 5) the choice of 10 as the new social value by Marx, then, is not arbitrary. This interpretation is flawed in at least three respects. First, Marx never mentions that there are two capitalists in this sector. Second, the choice of 10 is apparently arbitrary. His point is that for the capitalist with a higher productivity to "command a more extensive market" (CI, p. 434), the price (not value) should be "above their individual but below their social value, say [emphasis added] at 1od. each". Third, there are cases where the social value of a commodity is determined by the worst production condition (e.g. agricultural products). In these cases, no value is transferred even from the capitalists with the lowest productivity; social value is not the result of value transfer between individual capitalists. 
(e.g. proximity to the market) driving each capitalist to innovate either to accrue extra surplus value or to catch up with first-movers. ${ }^{113}$ The first-movers' better production methods eventually become universal, and consequently, their extra surplus value is eroded. In addition, through the constant repetition of differentiation and equalisation the social average level of knowledge within a sector grows. ${ }^{114}$

\section{Different levels of knowledge across sectors and the complexity of collective commodity-producing labour}

Different levels of knowledge among sectors also affect the production of value. In this case, knowledge takes part in the production of the value of commodities by determining the complexity of commodity-producing labour. That is, if the sectoral average level of knowledge is higher than the economy-wide average level of knowledge, all commodity-producing labours (average simple labour) in this sector act as if they are complex (or complicated) labour, "intensified [potentiated; potenziert], or rather multiplied [multipliziert] simple labour" (CI, p. 135), ${ }^{115}$ which is in addition to the virtual multiplication of labour within a sector. Consequently,

${ }_{113}$ "The development of the natural sciences themselves //and they form the basis of all knowledge// as also the development of all knowledge with regard to the production process, itself takes place on the basis of capitalist production, which generally first produces the sciences' material means of research, observation and experiment. In so far as the sciences are used as a means of enrichment by capital, and thereby become themselves a means of enrichment for those who develop them, the MEN OF SCIENCE compete with each other [emphasis added] to discover practical applications for their science. Moreover, invention becomes a métier by itself. With capitalist production, therefore, the scientific factor is for the first time consciously developed, applied, and called into existence on a scale which earlier epochs could not have imagined" (CW34, p. 34).

${ }^{114}$ It is worth noting that Marx introduces the concept of extra surplus value in the context of the production of relative surplus value. It is one of the "immanent laws of capitalist production" (CI, p. 433) and these laws "manifest themselves in the external movement of the individual capitals". The "external movement" refers to the above process of innovation and catch-up, which results in the continual fall in the social value of commodities. The fall in the values of consumer goods in turn brings about the fall in the value of labour power and the portion of necessary labour time in the working day. As a result, more (relative) surplus value is appropriated by capitalists.

115 Marx explains the distinction between complex labour and simple labour by way of an analogy with job hierarchy: "Just as, in civil society, a general or a banker plays a great part but man as such plays a very mean part, so, here too, the same is true of human labour" (CI, p. 135). 
capitalists in the sector with a higher average level of knowledge than the economywide social average accrue surplus profit, in the sense that the 'sectoral value' of commodities produced in this sector, simply defined as the weighted average of individual values of the sector, is always lower than the social value. In other words, virtual multiplication applies at two different levels, within and across sectors, respectively. It is the source of two different types of surplus profit related to knowledge: higher level of individual knowledge than the sectoral average level and higher level of sectoral knowledge than the economy-wide social average level. ${ }^{116}$

Marx analyses complex labour in Capital only briefly. ${ }^{117}$ First, in Chapter 1 of the first volume of Capital, the discussion does not go beyond the statement that complex labour is reduced into multiplied simple labour: ${ }^{118}$

Experience shows that this reduction is constantly being made. A commodity may be the outcome of the most complicated labour, but through its value it is

${ }^{116}$ Virtual multiplication is an important part of the normalisation (within a sector) and homogenisation (across sectors) of labour. For more on normalisation and homogenisation, see Saad-Filho (2002, Chapter 5).

117 We do not review the reduction problem in this chapter because, for our purpose, it is sufficient that complex labour is being reduced to multiplied simple labour in reality (fortunately, the reduction is not a technical process taking place in the head of accountants, but is the result of real social processes) and therefore the complexity of different labours and the value-creating capacity of different types of labour vary. For more on the reduction problem, see C.-O. Lee (1990, pp. 101-139; 1993, pp. 471-476), Rosdolsky (1977, pp. 506520), and Bidet (2007, Chapter 2).

118 In terms of scope, the first chapter of David Ricardo's Principles of Political Economy and Taxation is similar to the first section of Chapter 1 of Volume 1 of Capital. In this chapter, Ricardo draws a distinction between value and utility; argues that the value of a commodity is determined by its scarcity and the relative quantity of labour necessary for its production; mentions that commodities which are not useful are not values; and labours with different skills get differently rewarded. Especially, on the last point related to complexity and skill, he says:

We may fairly conclude, that whatever inequality there might originally have been in them, whatever the ingenuity, skill, or time necessary for the acquirement of one species of manual dexterity more than another, it continues nearly the same from one generation to another; or at least, that the variation is very inconsiderable from year to year, and therefore, can have little effect [emphasis added], for short periods, on the relative value of commodities. (Ricardo, 1817, 1.27)

The words emphasised in the above is similar to Marx's view that "the various proportions in which different kinds of labour are reduced to simple labour ... appear to the producers to have been handed down by tradition" (CI, p. 135). For Marx's summary and defence against Bailey of Ricardo's view on complex labour, see Marx (CW32, p. 350). 
posited as equal to the product of simple labour, hence it represents only a specific quantity of simple labour. The various proportions in which different kinds of labour are reduced to simple labour as their unit of measurement are established by a social process that goes on behind the backs of the producers; these proportions therefore appear to the producers to have been handed down by tradition. (CI, p. 135)

He, then, immediately suggests that complex labour be ignored: "In the interests of simplifications, we shall henceforth view every form of labour power directly as simple labour power; by this we shall simply be saving ourselves the trouble of making the reduction".

Second, in Chapter 6, in which he discusses the value of labour power, Marx (CI, pp. 275-276) argues that the value of labour power with a relatively higher complexity is higher than that of ordinary labour power due to education and training costs. In other words, education and training costs are part of the reproduction costs of the labour power of a higher sort: ${ }^{119}$

In order to modify the general nature of the human organism in such a way that it acquires skill and dexterity in a given branch of industry, and becomes labour power of a developed and specific kind [emphasis added], a special education or training [emphasis added] is needed, and this in turn costs an equivalent in commodities of a greater or lesser amount. The costs of education vary according to the degree of complexity of the labour power required. These expenses (exceedingly small in the case of ordinary labour power) form a part of the total value spent in producing it.

Third, at the end of Chapter 7, whilst emphasising that workers are exploited regardless of their skills, he gives an example of complex labour, the labour of jewellers, as opposed to the labour of spinners. Complexity of labour, then, unlike productivity of labour, is a concept for the comparison of the value-creating capacity between different types of concrete labours. ${ }^{120}$ Whereas two individual labours

119 It is unfortunate that knowledge production - education and training - is mixed up with other consumer goods. Skills acquired through education and training can be re-used without re-training and re-education in principle, so they don't have to be reproduced every time labour power is reproduced. For this reason, education and training are not part of the reproduction costs, but is rather a multiplier. This does not mean that differences in the value of labour power across sectors can be explained exclusively on the basis of training and education. For critiques of the reduction of complex labour based on education and training costs, see Saad-Filho (2002, p. 58) and Fine (1998, pp. 186-187).

120 Saad-Filho (2002, p. 57) does not distinguish complexity from productivity: 
producing the same type of commodity can have different productivities, two individual labours producing two different types of commodity can have different complexities. ${ }^{121}$ In addition, he states that complex labour is what it is due to labour power being complex:122

All labour of a higher, or more complicated, character than average labour is expenditure of labour power of a more costly kind, labour power whose production has cost more time and labour than unskilled or simple labour power, and which therefore has a higher value. This power being of higher value, it expresses itself in labour of a higher sort, and therefore becomes objectified, during an equal amount of time, in proportionally higher values. (CI, p. 305)

Again, however, instead of further elaborating the concept of complex labour, he suggests that the complexity of labour and labour power be ignored: "We ... save ourselves a superfluous operation, and simplify our analysis, by the assumption that the labour of the worker employed by the capitalist is average simple labour" (p. 306).

Fourth, although Marx does not mention complex labour in the second volume of Capital, he does refer to complex labour in the third volume as a reason why the

All else constant, more intense or complex labour, and better educated and trained workers, generally create more use values and, consequently, more value per hour. The quantitative difference depends upon the relationship between individual and social productivity [emphasis added] in each branch, that is known precisely only ex post.

${ }^{121}$ Similarly, according to C.-O. Lee (1993, p. 474):

The reduction problem of skilled, complex labour to unskilled, simple labour must not be mixed up with the question of finding a social-average of different individual labours. One relates to inter-sectoral production while the other relates to intra-sectoral production.

122 Then, the value of labour power can vary across sectors. As Fine (2012a, p. 124) says:

The moral and historical element in the value of labour power should not be understood as an average across all workers. Rather it reflects differentially determined and differentially distributed norms of consumption and labour market conditions, across both monetary remuneration and the levels and composition of use value consumption. This is reflected in different food, health, pension, housing and transport systems and so on, each deeply and uniquely rooted in different ways and to a different extent in capitalist production and exploitation. And labour markets are also differentially organised and rewarded according to the ways in which the labour process within and across different workplaces have been integrated into economic and social reproduction. This is not to deny the significance of class struggle and organisation at the point of production (and elsewhere) nor the validity of the value of labour power as a concept. Rather, it is to locate and reconstruct such concepts at more concrete levels in conformity to the more complex material functioning of capital itself.

See also Fine (1998, Chapter 7), Fine (2008) and Saad-Filho (2002, pp. 48-53). 
level of wages can vary among workers:

Other distinctions, for instance in the level of wages, depend to a large measure on the distinction between simple and complex labour ... and although they make the lot of the workers in different spheres of production very unequal [emphasis added], they in no way affect the degree of exploitation of labour in these various spheres. (CIII, p. 241)

This suggests that the complexity of labour power in a sector is one of the factors determining the wage level of the sector, although complexity is not reduced to wage differentials or vice-versa (Saad-Filho, 2002, p. 57). Rather, given that wage is the price form of the value of labour power, wage differentials across sectors should be reproduced as a concrete form of the differences in the value of labour power across sectors.

For Marx (CIII, pp. 241-242), however, again, the distinction between complex and simple labour does not affect the general analysis, so it can be ignored:

If the work of a goldsmith is paid at a higher rate than that of a day-labourer, for example, the former's surplus labour also produces a correspondingly greater surplus value than does that of the latter. And even though the equalisation of wages and working hours between one sphere of production and another or between different capitals invested in the same sphere of production, comes up against all kinds of local obstacles [emphasis added], the advance of capitalist production and the progressive subordination of all economic relations to this mode of production tends nevertheless to bring this process to fruition. Important as the study of frictions of this kind is for any specialist work on wages, they are still accidental and inessential as far as the general investigation of capitalist production is concerned and can therefore be ignored [emphasis added]. In a general analysis of the present kind, it is assumed throughout that actual conditions correspond to their concept, or, and this amounts to the same thing, actual conditions are depicted only in so far as they express their own general type.

In sum, for Marx, complex labour is not a very important concept since the general laws of capitalism can be derived and explained without reference to this concept. In addition, there is a tendency towards equalisation and simplification of labour in capitalism, especially in the stage of large-scale industry based on machinery, although new skills do arise with the development of the social division of labour. ${ }^{123}$

${ }_{123}$ "Admittedly, a small class of higher workers does take shape, but this does not stand in any proportion to the masses of 'deskilled' workers" (CW34, p. 34). 
However, the notion of complexity is still useful for analytically capturing the differences in the value-creating capacity of simple labour across sectors. In the specifically capitalist mode of production, knowledge and skills once possessed by skilled workers are systematically separated from workers and come to be objectified in the means of production, especially machinery, and the labour process. In other words, production based on machinery and large-scale industry separates "the intellectual faculties of the production process from manual labour" (CI, p. 548) and deprives "the work itself of all content". At the same time, however, even if machinery dominates individual workers in the labour process, workers still use machinery as instruments of production at the collective level. Marx, quoting Ure, describes these two seemingly contradictory aspects of the factory as a whole, "a form of social labour organised on the material basis of machinery" (CW34, p. 123) as below (CI, pp. 544-545):

Dr Ure, the Pindar of the automatic factory, describes it, on the one hand, as 'combined co-operation of many orders of work people, adult and young, in tending with assiduous skill a system of productive machines continuously impelled by a central power' (the prime mover); and on the other hand as 'a vast automaton, composed of various mechanical and intellectual organs, acting in uninterrupted concert for the production of a common object, all of them being subordinate to a self-regulated moving force'. These two descriptions are far from being identical. In one, the combined collective worker appears as the dominant subject [übergreifendes Subjekt], and the mechanical automaton as the object; in the other, the automaton itself is the subject, and the workers are merely conscious organs, co-ordinated with the unconscious organs of the automaton, and together with the latter subordinated to the central moving force. The first description is applicable to every possible employment of machinery on a large scale, the second is characteristic of its use by capital, and therefore of the modern factory system. ${ }^{124}$

At the collective level, then, knowledge separated from individual workers and instead embodied in machinery, ${ }^{125}$ appears as the knowledge of the collective

124 Similarly, "Capital now appears both as the collective power of the workers, their social power, and as the unity which binds them together and thereby creates this power" (CW28, p. 507).

125 "This process of separation starts in simple co-operation, where the capitalist represents to the individual workers the unity and the will of the whole body of social labour. It is developed in manufacture, which mutilates the worker, turning him into a fragment of himself. It is completed in large-scale industry, which makes science a potentiality for production which is distinct from labour and presses it into the service of capital" (CI, p. 
worker, hence the expression, the productive power of social labour. The collective worker is "formed out of the combination of a number of individual specialised workers" (CI, p. 468) and exists as "individualised in particular workers or groups of workers" (p. 469). Therefore, when individual workers perform simple average labour, knowledge objectified into the labour process, especially machinery, can make the labour of the collective worker act as complex labour, depending on the average level of knowledge in the sector embodied in the machinery, compared with the social average (across sectors). ${ }^{126}$

The collective worker arises from simple co-operation which is "the fundamental form of the capitalist mode of production" (p. 454). Marx's analysis of the capitalist forms of co-operation includes both logical and historical elements: the former is concerned with the formation of the level of collectivity in general and collective labour or combined labour in particular; the latter focuses on the distinctions between the capitalist forms of co-operation and the historical processes of the becoming-autonomous of knowledge production - the historical externalisation of the internal opposition between knowledge production and commodity production, see Chapter 6.

First, the collective worker is formed out of co-operation as such. When individual workers collaborate, they work together to achieve common goals. Under cooperation, individual workers not only perform individual labours but also function as organs of the collective worker. Importantly, the productivity and complexity of collective labour exceeds the sum of individual contributions both quantitatively (i.e. how much) and qualitatively (i.e. what can be achieved). Second, in its simplest form, co-operation can take place by simply gathering workers together; but in most cases, co-operation involves the co-ordination, organisation and supervision of the labour process and shared means of production (e.g. machinery). This means that knowledge also becomes collective as labour becomes collective. ${ }^{127}$ This gives rise to

482).

${ }^{126}$ Although for Marx the complexity of labour is the concept that captures the different value-creating capacities of individual workers due to different levels of individual knowledge, we are concerned here with the complexity of the collective worker.

${ }^{127}$ Collective knowledge, or the productive powers of social labour, consists of the knowledge embodied in the labour process (including but not limited to machinery and knowledge for co-ordination, organisation and supervision) and skills of individual workers. The notion of collective knowledge is crucial for explaining why complex labour is of little importance to 
a group of workers more or less dedicated to the production of such collective knowledge, which is separated from commodity production (within a firm). Marx mentions the emergence of overseers in this context, but knowledge work as such is not identified. Third, the historical separation of knowledge production and commodity production "is completed in large-scale industry, which makes science a potentiality for production which is distinct from labour and presses it into the service of capital" (CI, p. 482). ${ }^{128}$ Unlike in manufacture, which is based on handicraft and "excludes a really scientific division of the production process" ( $p$.

Marx; it is because knowledge of the collective worker increasingly takes the form of machinery. Similarly, Bidet (2007, p. 29) says:

It is significant, moreover, that Part Five of Volume One [of Capital], which deals systematically with the factors determining the amount of surplus value (and thus value) produced, introduces in place of the former triptych productivity/intensity/skill (factors that weight the average social duration that defines value), a new problematic of duration/productivity/intensity, marked by the absence of any category such as skill or specialisation [emphasis added]. This absence flows logically from the development of Part Four, which shows that the commodity, in terms of both exchange-value and use value, is the fruit of collective labour.

${ }^{128}$ The collective worker, the concept first introduced in Marx's discussion of manufacture, is applicable also to the stage of large-scale industry. For example:

A fundamental transformation takes place in the composition of the collective labourer [emphasis added] or, in other words, the combined working personnel. In contrast with the period of manufacture; the division of labour is now based, wherever possible, on the employment of women, of children of all ages and of unskilled workers, in short, of 'cheap labour', as the Englishman typically describes it. (CI, p. 590)

With the progressive accentuation of the co-operative character of the labour process, there necessarily occurs a progressive extension of the concept of productive labour, and of the concept of the bearer of that labour, the productive worker. In order to work productively, it is no longer necessary for the individual himself to put his hand to the object; it is sufficient for him to be an organ of the collective labourer [emphasis added], and to perform any one of its subordinate functions. (pp. 643-644)

Similarly, Marx says elsewhere:

The social productive powers of labour, or the productive powers of directly social, socialised (common) labour, are developed through cooperation, through the division of labour within the workshop, the employment of machinery, and in general through the transformation of the production process into a conscious application of the natural sciences, mechanics, chemistry, etc., for particular purposes, technology, etc., as well as by working on a large scale, which corresponds to all these advances, etc. //This socialised labour alone is capable of applying the general products of human development, such as mathematics, etc., to the direct production process, just as, conversely, the development of the sciences presupposes that the material production process has attained a certain level. (CW34, pp. 428-429)

Since with the development of the real subsumption of labour under capital or the specifically capitalist mode of production it is not the individual worker but rather a socially combined labour capacity that is more and more the real executor of the labour process as a whole. (p. 443) 
458), ${ }^{129}$ in machinery-based production, the human portion of the collective skills tends to become marginalised. ${ }^{130}$ Science is incorporated into the labour process "as an independent power" (CI, p. 799), and this is reflected in Marx's distinction between "universal labour" and "communal labour" (CIII, p. 199). Whereas the former corresponds to (scientific) knowledge labour, the latter is another name for collective labour:

We must distinguish here, incidentally, between universal labour and communal labour. They both play their part in the production process, and merge into one another, but they are each different as well. Universal labour is all scientific work, all discovery and invention. It is brought about partly by the co-operation of men now living, but partly also by building on earlier work. Communal labour, however, simply involves the direct co-operation of individuals.

In sum, in capitalism where production is based on co-operation and collaboration, "useful knowledge" for commodity production (Mokyr, 2002, pp. 1-27), bifurcates into the knowledge of individual workers and the knowledge objectified in the labour process in general and the means of production in particular, with increasing

129 Marx (CW30, p. 255) equates machinery with "the application of SCIENTIFIC POWER".

130 "Such polarisation of conception and execution, and its impact on waged work, have been the main theme of labour process theory. Braverman's (1974) notion of deskilling suggests that there is a tendency in capitalism to deprive workers of skills, fragmenting and subdividing work into a set of functions. 'Semi-artistic' workers in simple cooperation are transformed into partially skilled workers in manufacture (CI, p. 504), and into versatile, unskilled workers in machinery-based production, 'to the level of an appendage of a machine' (p. 799). The deskilling thesis, however, has been criticised from a number of perspectives: that in some cases, it goes hand-in-hand with the emergence of new jobs requiring different kinds of skills than those of craft workers; that the notion of skill in Braverman is partial and takes craftworkers as ideal; that the broader social determination and construction of skills are neglected; that Braverman ignores the importance of consent and autonomy, as opposed to contestation, as part of capitalist and worker strategies; and that the corresponding role of subjectivity of workers and class struggle in the formation of the labour process is overlooked (Wardell, 1999; Meiksins, 1994). Marxist labour process theorists have argued that deskilling is a tendential law, inherent in the capitalist mode of production as an underlying force (Hassard \& Rowlinson, 1994 and 2000; Spencer, 2000). Capital does mechanise and systematise skills in an attempt to increase labour productivity and to minimise the risk of sabotage. Not only is the separation between conception and execution never absolute, but it is continuously evolving and redefining what is and what is not recognized as skill, including the articulation with the specifically value-producing requirements of capitalism, from command in the workplace through to the attempts to ensure realisation in the sale of commodities" (Fine et al., 2010, pp. 77-78). 
emphasis upon the latter. With the development of science and its technological applications on an unprecedented scale, knowledge also tends to become autonomous, within and across firms, albeit not completely detached from commodity production. ${ }^{131}$

\section{The Value of information commodities}

As we have seen so far, knowledge allows for virtual multiplication both within and across sectors (Figure 3), which is one of the social processes that go on "behind the backs of producers" (CI, p. 135), determining the productivity and complexity of commodity-producing labour and thereby the value of commodities, ${ }^{132}$ although productivity and complexity cannot be reduced to the effect of knowledge alone. An example of other factors determining the value-creating capacity of commodityproducing labour is economy of scale through centralisation, which does not necessarily involve new knowledge. Knowledge production itself is also determined by a multiplicity of factors. For example, an expansion of the market can spur capitalists on to a greater investment into $\mathrm{R} \& \mathrm{D}$.

${ }_{131}$ "Exploitation of science, of the theoretical progress of humanity. Capital does not create science, but it exploits it, appropriates it to the production process. There is at the same time a separation of science, as science applied to production, from direct labour, whereas at earlier stages of production the restricted measure of knowledge and experience is directly linked with labour itself, does not develop as an autonomous power separated from labour, and therefore in general never goes beyond a collection of procedures carried on traditionally and only expanding very slowly and little by little. (Learning by experience of the MYSTERIES OF EACH HANDICRAFT.) No separation of hand from brain" (CW34, p. 33).

${ }_{132}$ Value is the category that expresses the homogenisation of qualitatively distinct concrete labours. By the same token, the role of knowledge, the virtual multiplication of labour, expresses the homogenisation of different types of knowledge in capitalism, as the result of the subsumption of knowledge under the value dimension. Qualitatively different types of knowledge are reduced into homogeneous abstract knowledge, with quantitative differences. 


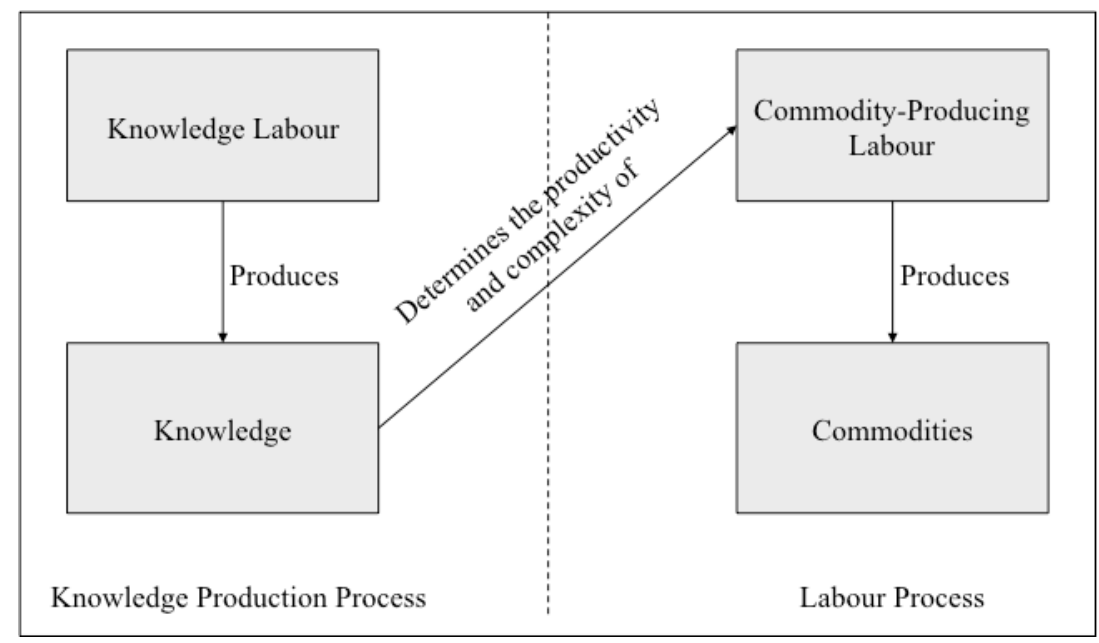

Figure 3. The determination of the productivity and complexity of commodity-producing labour

Going back to information commodities, we can draw the following conclusions. First, the source of software corresponds to knowledge and the copies to commodities. Second, R\&D labour that produces the source is knowledge labour. It does not contribute to the value of the copies directly or indirectly (as constant/fixed capital). Third, R\&D labour can virtually multiply copy labour. The extent of virtual multiplication depends upon 1) the difference between the level of individual knowledge and the sectoral norm and 2) and the difference between the sectoral average level of knowledge and the economy-wide social average. At this abstract level of analysis, we can only conclude that the value of information commodities can be, but not necessarily, higher than zero despite very little concrete labour required in copy production itself.

This is consistent with Marx's view:

The specific productivity of labour in one particular sphere [emphasis added], or in one individual business in this sphere [emphasis added], concerns the capitalists directly involved in it only in so far as it enables this particular sphere to make an extra profit [Extraprofit] in relation to the total capital, or the individual capitalist in relation to his sphere. (CIII, p. 300)

Although Marx refers to productivity differences between sectors rather than complexity differences, he clearly recognises two separate processes, within and across sectors, of determining the value-creating capacity of labour.

This approach is distinct from both the cost approach and the monopoly price approach. First, the cost approach argues that R\&D labour is productive labour that creates the value of either source or copy. In the latter case, source is considered a 
means of production that contributes to the value of the final products in a piecemeal fashion. This is wrong; knowledge (i.e. source) is qualitatively different from commodities and does not have value. Second, although the monopoly price approach rightly argues that $R \& D$ labour does not create value, it is wrong in the sense that R\&D labour is considered as having nothing to do with the determination of the value of copies.

\subsection{Concluding remarks}

Drawing on the structural distinction between knowledge and commodities, we have clarified the role of knowledge in value production. On this basis, we have also shown that it is possible to extend value theory to incorporate knowledge at a relatively abstract level of analysis without abandoning or compromising any of the core elements of value theory, which demonstrates the consistency, coherence and strength of value theory, and not least in allowing for a favourable comparison with the shallowness and inconsistencies of NGT.

The social processes of virtual multiplication are, however, only a starting point for the development of more complex and concrete analyses. In this respect, although motivated by, and developed under heavy influence of, the Controversy, this approach does not attempt to offer conclusive arguments as to the nature of the value and price of information commodities, for example, whether the price of information commodities is monopoly price or not, whether the value is close to zero or not, and whether the value includes extra surplus value or not in case price is significantly higher than zero.

First, dissecting the determinants of the value, if not price, of a particular information commodity (e.g. Microsoft Windows) is not a simple task, involving detailed and concrete analysis of the social structures and processes attached to the production of the information commodity at various levels of abstraction: the sector to which the information commodity belongs should be identified; competitive dynamics (mainly around knowledge production) within the sector and across the value chain should be analysed; the average knowledge level of the sector should be determined; finally, the sectoral average level of knowledge should be compared with the social average. For this purpose, horizontal categories such as extra surplus value are not sufficient and should be complemented by the analysis of social structures and processes specific to the commodity and sector in question. 
Second, relatively simple applications or impositions of horizontal categories as in both cost and monopoly price approaches cannot go beyond static analysis and tend to collapse different levels of abstraction. Whereas there are only two levels of abstraction - value and (monopoly) price - in the monopoly price approach, the price is reduced to the total sum of its components in the cost approach, see Chapter 5. Instead, Marx refines the concept of value and introduces more concrete and complex concepts, e.g. extra surplus value, price of production and rent, step-bystep, as the analysis moves from the abstract to the concrete. In doing so, Marx also introduces a concept pertaining only to a specific sector, i.e. ground rent.

In subsequent chapters, these points will be further developed, by extending our critique of the two approaches in the Controversy for their inadequate theorisations of intellectual property rights (Chapter 5) and by providing sketches of industryspecific theories of intellectual property rights (Chapter 6). 


\section{Cognitive capitalism theory: Cognitive capitalism or cognition in capitalism?}

\subsection{Introduction}

One question that has drawn much interest among theorists is how to characterise the economic importance ascribed to knowledge and technological development. On the one hand, knowledge and technological development are seen to be always essential for the economy. According to this view, the lack of accounts of knowledge in economic theories is considered as a flaw, which needs to be fixed by properly incorporating the role of knowledge in a consistent and coherent manner, as attempted in Chapter 3 for Marx's value theory (and by new growth theorists less than successfully for neoclassical growth theory as demonstrated in Chapter 2). On the other hand, in some theories and discourses, the recent recognition of the central role of knowledge in the economy is viewed as reflecting a new underlying reality. It is argued that, whilst knowledge has always been important, qualitative changes that the capitalist economy is undergoing have elevated the practical and theoretical significance of knowledge and technology to a far higher level. Such theories face the task of identifying and analysing the essence of the new reality.

Cognitive capitalism theory (CCT) is one such theory which asserts that recent changes represent a fundamental transformation in capitalism. Proponents of this theory argue that capitalism is in transition to a new stage of development, although the extent of the transformation is not so extreme that these changes do not entail the emergence of a new mode of production.

According to Paulré (2004, para. 11), the objective of CCT is "to address the role of knowledge in understanding the evolution and transformation of contemporary capitalism". ${ }^{133}$ The new stage of capitalism, called cognitive capitalism, is, then, characterised by the appropriation by workers of the cognitive aspect of work and the mutation of the power relations between capital and labour (around knowledge), more favourably to labour. Cognitive labour ${ }^{134}$ is a type of labour that produces

133 All translations from Italian and French sources are my own.

${ }^{134}$ Note that the term cognitive has nothing to do with cognitive science, a study of mental operation or thought. It is used "simply as an adjective derived from knowledge" (Paulré, 2004, para. 4). 
knowledge, co-operation and communication and it is suggested as the hegemonic form of labour in the stage of cognitive capitalism. Consequently, this leads to the argument that the determination of the value of commodities by socially necessary labour time is rendered dubious because cognitive labour (or knowledge-producing labour) is immeasurable by labour time. By contrast, capital is seen to be increasingly becoming parasitic, playing no meaningful roles in the production process. According to this view, whilst capital still appropriates part of surplus products created by labour, it does so only through legal means, not least intellectual property rights. Consequently, profit as an economic category is disappearing and becoming like rent (see Chapter 5). In sum, it is argued that Marx's labour theory of value suffers a crisis of validity in the wake of cognitive capitalism.

The significance of CCT lies in the fact that it is one of the few, if not the only, leftist accounts of contemporary capitalism from a viewpoint of knowledge. This is contrasted with the flourishing development of knowledge-based economy theories based on mainstream economics, supported by governments of advanced countries and international organisations such as the World Bank and the OECD. Further, whilst Marxist political economy is actively engaged with contemporary capitalism, its focus is placed upon neo-liberalism, globalisation and financialisation. We see a clear need to develop and refine Marxist accounts of the knowledge economy in order to fill this theoretical vacuum, to which CCT has obviously contributed. This scarcity, however, ironically requires us to critically engage with CCT. First, any Marxist theory of the knowledge economy or technological development in contemporary capitalism cannot avoid being evaluated in light of CCT. Second, the influence of CCT is clearly increasing. It has drawn attention from many theorists and activists to the extent that the term 'cognitive capitalism' is being used in much the same way as the knowledge economy. Indeed, it is used casually without much theoretical consideration and reflection. For example: "Contemporary 'cognitive' or 'informational' [references removed] capital is ever more dependent on social production to generate value and profits" (Arvidsson, 2009, pp. 16-17); "Adaptation to participatory modes of innovation, to open models of intellectual property (IP), is antithetical to both the industrial and cognitive modes of capitalism" (Bauwens, 2009, p. 132). Third, and most importantly, whilst it is argued to be based on Marx's methods, CCT misrepresents Marx's theory of capitalism, in general, and value theory, in particular, as we will show later. 


\section{Focus of the critique}

Whilst we are observing changes such as the rapid adoption and diffusion of information and communication technologies, we can still claim that they represent no fundamental change in the essence of capitalism, but comprise only new appearances through which more or less the same essence manifests. This type of critique, on the basis of empirical facts and numbers, is simple, but can also prove to be effective. If we can convincingly demonstrate that the core of capitalism still remains intact, the claimed need to develop a new value theory can simply be discarded. For example, many have shown that traditional industrial labour still accounts for a significant portion of total work hours as opposed to the alleged hegemony of cognitive labour, rejecting one of the core arguments of CCT empirically. In addition, the relative and continuing growth of the service sector in terms of share of total employment or GDP, in which cognitive labour is believed to be dominant, may be interpreted in different ways (Huws, 2003, pp. 129-131). All these are suggested as evidence by opponents that nothing has really changed. Their arguments are neither flawed nor insufficient, but not so entirely successful in outcome. For proponents of CCT always respond by arguing that the transition is still ongoing and that what matters is not the current status of capitalism, but the tendencies towards a new stage of capitalism. They suggest that cognitive labour is the hegemonic form of labour under cognitive capitalism only as a tendency, not as yet an established fact. ${ }^{135}$

An alternative approach is to focus on the way the major arguments of CCT are derived, criticising assumptions and methods deployed in the analysis rather than the final outcome as such. Our critique will take this approach, actively and critically engaging with the interpretation of Marx's value theory by cognitive capitalism theorists, on the basis of the virtual multiplication approach we put forward in Chapter 3. We focus on showing that their interpretations of Marx's value theory are flawed. By doing this, the call for a new theory on this basis can be disregarded. Therefore, we do not question whether or not capitalism is transitioning to a new phase, but instead attempt to demonstrate and criticise how this conclusion is drawn; in this approach, then, the analysis of facts and numbers is not of primary concern. Rather, the focus is placed upon the (alleged) essential differences between

135 For critiques of CCT from this perspective, see Camfield (2007), Wright (2005) and Husson (2003 and 2007). For responses, see Vercellone (2004) and Hardt and Negri (2004, pp. 140-152). 
cognitive capitalism and industrial capitalism, most notable among them being the change of the hegemonic form of labour from industrial labour to cognitive labour and labour's appropriation of the role of knowledge production. Significantly, these changes are considered to be essential, not in themselves, but because value theory is seen to be unable to address them.

The remainder of this chapter is organised as follows. Sections 2 and 3 summarise the key arguments of CCT, especially in its relation with other similar theories. Section 4 demonstrates that the interpretations of Marx's value theory by the proponents of CCT are fundamentally flawed. The presumption in CCT is that abstract labour is an ahistorical, naturalistic and physiological category which became the substance of value as the result of the imposition of the industrial form of the division of labour (the separation between conception and execution). This not only reduces the concept of commodity-producing labour into simple, repetitive manual labour but also bypasses the role of knowledge in value production. Therefore, it is this weakened version of value theory that is rejected by the proponents of CCT. Section 5 criticises the interpretation of the concept of the general intellect in CCT, allegedly the dominant form of the division of labour in contemporary capitalism. Section 6 concludes the chapter.

\subsection{The regulation approach, post-Workerism and the knowledge economy}

Before embarking on our critique, it is necessary to trace the origin of CCT, focusing on its similarities with, and differences from, the regulation approach, knowledgebased economy theories and post-Workerism. This will help situate our critique in a proper context.

Whilst the origin of CCT dates back to early 1990s (Toscano, 2007, p. 5), its development as a separate research stream started when the thesis of cognitive capitalism was drafted during a symposium held in Amiens in 1999 (Paulré, 2004). Major contributors include Antonella Corsani, Patrick Dieuaide, Andrea Fumagalli, Maurizio Lazzarato, Jean-Marie Monnier, Yann Moulier-Boutang, Bernard Paulré, and Carlo Vercellone. ${ }^{136}$ The early thoughts are summarised in the document ('Draft') which describes the cognitive capitalism research program of MATISSE

${ }^{136}$ Since then, quite a few varied views have emerged even if they do not differ from each other to the extent that they have to be considered as alternatives (Paulré, 2008, p. 79). 
(Modélisations Appliquées, Trajectoires Institutionnelles, Stratégies SocioÉconomiques) - 'Le capitalisme cognitif comme sortie de la crise du capitalisme industriel (Cognitive Capitalism as an exit from the crisis of industrial capitalism)' (Corsani et al., 2001).

\section{The regulation approach, knowledge-based economy and the like}

The Draft shows that the thesis of cognitive capitalism has been developed under the significant influence of the French regulation school. This is more than evident in the use of such concepts as regime of accumulation and mode of development; cognitive capitalism is suggested as a new regime of accumulation that arises out of the crisis of Fordist regime of accumulation. In the same vein, Paulré (2004, para. 12) defines cognitive capitalism as a new "system of accumulation" in which the accumulation is centred on knowledge production, especially science and technology. However, the concept of cognitive capitalism goes beyond the regulation approach in the sense that the transition to cognitive capitalism involves discontinuity or rupture from the Fordist regime of accumulation. Nor is CCT a theory of post-Fordism. The transition is considered as an exit, not only from the crisis of Fordism but also from that of industrial capitalism as a whole, which encompasses both Fordism and post-Fordism. ${ }^{137}$ CCT therefore occupies "a unique position" (Corsani et al., 2001, p. 4) within the regulation approach. Braudel's study of the long dynamic of capitalism inspired this view on the transition from one stage of capitalism to another, with industrial capitalism being one of them. ${ }^{138}$

CCT also draws from other contemporary economic and social theories that attempt

137 Paulré (2004, para. 13) says, "We believe that the crisis of Fordism in fact disguises or indicates that of industrial capitalism". For Lucarelli and Fumagalli (2008, p. 77), postFordism indicates only "the passage from Fordism to CC [cognitive capitalism]".

138 Vercellone (2007, p. 14) also says:

It is necessary to note that the notion of cognitive capitalism has also been developed as a response to the insufficiency of the interpretations of the current mutation of capitalism in terms of the transition from a Fordist to a post-Fordist model of flexible, or what is sometimes referred to as 'Toyota-ist', accumulation. ... Theories of post-Fordism, while capturing some significant elements of rupture, often remain bound to a factoryinspired vision of the new capitalism seen as a further development of the Fordistindustrial logic of the real subsumption of labour by capital. For these reasons, the category of post-Fordism appears to us to be inadequate for comprehending the profound transformation of the antagonistic relation of capital to labour related to the development of an economy founded on the driving role of knowledge and the figure of the collective worker of the general intellect. 
to capture the mode of development or "dynamic efficiency" of capitalism as opposed to "static efficiency" represented by the general equilibrium framework (Antonelli, 2007, p. 13). Such theories include knowledge economy theories, NGT, economics of innovation, evolutionary economics and theories of post-industrial society and network society. ${ }^{139}$ For the proponents of CCT, they are useful and instrumental for stimulating debate on the role of knowledge in contemporary capitalism. In addition they provide raw materials for CCT; for example, the role and nature of knowledge, the effects of the diffusion of information and communication technologies, public policy on education and intellectual property rights, to name just a few. These theories focus on the special aspects of knowledge as compared with material goods, especially its role and its peculiar way of production and diffusion in the broader economy. However, they do not go further to ask if these changes are linked to more fundamental transformations. CCT takes the phenomenal changes identified by them as a given, but attempts to provide an alternative interpretation. Whilst cognitive capitalism shares the same characteristics with the knowledge economy or the information society where knowledge is seen to play a central role, CCT criticises these for being technologydeterministic, ahistorical, positivist and non-confrontational in lacking social and historical analyses and unduly focusing on the rapid technological development as the source of social and economic changes (Vercellone, 2004). Vercellone (2005, p. 2) also argues:

The interpretation provided by neo-classical theories of endogenous growth and the knowledge-based economy take into account neither the antagonism between capital and labour nor the conflicts between knowledge and power investing the transformations of the division of labour.

In short, in cognitive capitalism, "there is antagonism, but it is new" (MoulierBoutang, 2006, para. 25). Although the quantitative growth of knowledge sectors and/or knowledge workers is certainly a notable development, knowledge alone is not considered sufficient to substantiate the establishment of a new (knowledge) economy, considering that knowledge has always been important for the economy (Paulré, 2004).

139 For details, see Corsani et al. (2001). Moulier-Boutang (2002) suggests 14 features of cognitive capitalism, some of which, for example, the emergence of network form, knowledge as public good, expansion of the scope of positive externalities, and importance of tacit knowledge, are well known as the features of the knowledge economy. 
By contrast, the notion of cognitive capitalism aims to capture the qualitative changes of the underlying social forces. It is suggested that a new form of the conflictual capital-labour relation, marked by the hegemony of cognitive labour and the rise of rent as the central category, represents such fundamental qualitative changes. In the same vein, technological determinism is rejected: "The emphasis on technology should not be interpreted as meaning the determining role of technology as an exogenous causal factor" (Corsani et al., 2001, p. 8); "Cognitive capitalism cannot simply be equated with a society characterised by the development of the new ICT (information and communication technologies)" (pp. 11-12); "Investments in the information and communication technologies in the material sense of the term, on which economists often focus their attention, are rather a symptom or a signal of ongoing changes" (Paulré, 2004, para. 18). Monnier and Vercellone (2014, p. 62) summarise the difference between the knowledge economy and cognitive capitalism as follows:

\begin{abstract}
It can be asserted that the difference and the contradiction between knowledge-based economy and cognitive capitalism refer to the Marxian contradiction between productive forces and social relations of production. Cognitive capitalism tries to set limits and submit to the logic of profit and of commodification a dynamic of knowledge economy that contains in itself the possibility of a transition to a society based on non-market primacy. In that spirit, the concept of cognitive capitalism allows to emphasise on the historical dimension and the conflictual relationships between its two components.
\end{abstract}

\title{
Post-Workerism
}

It is especially in the respect of the centrality of class struggle in method, that CCT owes much to post-Workerism, a major strand of Autonomist Marxism. ${ }^{140}$ Major proponents of post-Workerism include Antonio Negri, Michael Hardt and Maurizio Lazzarato. They have much contributed to a French journal, Futur Antérieur and its sequel, Multitudes, ${ }^{141}$ central themes of which include Autonomist Marxism, in general, and post-Workerism and CCT, in particular.

Notably, Vercellone, a proponent of CCT, co-wrote an article about cognitive capitalism with Negri (Negri \& Vercellone, 2007), which indicates that post-

\footnotetext{
${ }^{140}$ See Wright (2002 and 2008) for a history of Autonomist Marxism, focusing on its diversity. See also Dyer-Witheford (1999).

${ }^{141}$ Multitudes was founded by a proponent of CCT, Yann Moulier-Boutang.
} 
Workerism and CCT were converging. ${ }^{142}$ Further, in his later book in English, Reflections on Empire, Negri (2008, pp. 63-64) explicitly reveals the affinity between CCT and post-Workerism:

Today, we find ourselves in a way of life and in a way of producing that are characterised by the hegemony of intellectual labour. It has been said that we have entered the era of cognitive capitalism. ... The originality of cognitive capitalism consists in capturing within a generalised social activity, an innovative element which produces value.

Indeed, post-Workerism and CCT share crucial aspects of methodology and similar views on class struggle, history, and Marx's value theory. Thus, many of the strengths and weaknesses of post-Workerism are also present in CCT. Due to such similarities, it is difficult to distinguish CCT from post-Workerism clearly, and our critique of the former partly takes the form of critique of the latter. It is therefore important and instrumental to summarise briefly some of the key arguments of post-Workerism.

First, post-Workerism views capitalism as consisting of several stages, each of which is characterised by a distinct class subject, class antagonism and dominant form of labour. Transition from one stage of capitalism to another is driven by class struggle.

Second, contemporary capitalism is allegedly the third stage of capitalism or the third cycle of struggle between labour and capital. Post-Workerism, which is built upon the collapse of Workerism corresponding to the end of the second cycle of class struggle represented by the mass worker ${ }^{143}$ and the social factory, attempts to capture the essence of the third stage through the concept of immaterial labour (Lazzarato, 1996) and social (or socialised) worker. Similarly, the mass worker emerged from the crisis of the first cycle of class struggle as a new class subject, responding to the attempts of capitalists to subordinate the previous class subject the professional worker - by way of the automation of the production process and the introduction of assembly lines. Struggles of the mass worker against capital took the forms of sabotage, refusal to work and worker-student alliance, and the class subject was redefined through this mass movement as a more creative and flexible

${ }^{142}$ It is worth mentioning, however, that there is no mention of cognitive capitalism in Hardt and Negri's (2009) Commonwealth, published after Negri and Vercellone (2007).

${ }_{143}$ Mass workers are deskilled workers doing repetitive/manual work in assembly lines which “meets Marx's definition of 'abstract labour" (Bowring, 2004, p. 106). 
labour power.

Third, the transition to the third cycle of struggle - the age of Hardt and Negri's (2000 and 2004) Empire and Multitude - which is still underway, started with the formation and struggle of the mass worker against capital. In the face of sabotage and the mass worker's refusal to work, capitalists had to adopt different strategies in order to reconfigure class composition. Globalisation of production sites, offshoring, shift to service work, outsourcing and adoption of flexible production methods are some of the countering strategies adopted by capitalists. More specifically, capital had to give up the production mechanism represented by Fordism and assembly lines to cope with this new class subject: "Capital had to abandon the large scale factory, its linear production, its inflexible working day and its mechanistic logic and employ open networks and flexi-time and give space to creativity" (Aufheben, 2006, p. 29); "Capital was forced to move into immaterial production to dominate a new labour power that had redefined itself, autonomously, as creative, communicative and affective" (p. 27). Similarly:

If there had not been worker and student revolts in the 1960s, if there had not been 1968 and the second wave of the women's movements, if there had not been the whole series of anti-imperialist struggles, capital would have been content to maintain its own arrangement of power, happy to have been saved the trouble of shifting the paradigm of production! (Hardt \& Negri, 2000, p. 275)

Fourth, with the collapse of class struggle represented by the mass worker, what used to be rigid is now replaced by what is flexible. Labour becomes increasingly immaterial and so does capitalist control. Labour is involved more in the production of images, meanings and cultural elements of material goods which, in the previous stage, was monopolised by capitalists or a group of specialised workers. The mass refusal was "not only a negative expression but also a moment of creation" (p. 274). Capital has to become flexible accordingly. As "the truly creative moment had already taken place [emphasis removed]" (p. 276), capital needs to appropriate this moment, rather than creating it anew.

Fifth, immaterial labour ${ }^{144}$ is suggested as becoming the hegemonic form of labour in the third cycle of class struggle. ${ }^{145}$ Immaterial labour is not measurable, and in its

\footnotetext{
${ }^{144}$ For a critical review of the concept of immaterial labour, see Haug (2009).

145 For Lucarelli and Vercellone (2011, pp. 87-88), the growth of intangible capital, both in
} 
nature, cooperative, flexible, communicative and affective, ${ }^{146}$ encompassing both intellectual work and service labour. ${ }^{147}$ Immaterial labour or biopolitical labour is immeasurable because being measured means being imposed, which is in diametrical opposition to its being flexible, creative and communicative. Labour, then, becomes life itself. ${ }^{148}$

Sixth, despite the immeasurability of immaterial biopolitical labour, labour is still seen as the source of value. According to Hardt and Negri, "what is different today, however, in the era of biopolitical production, is that intellectual and/or affective invention has become the primary source of value and wealth in society" (Brown \& Szeman, 2005, p. 383). However, no account of the new immaterial labour theory of value is provided.

\subsection{Cognitive capitalism theory}

Whilst sharing many crucial aspects with post-Workerism, especially those of methodology, CCT is distinguished from post-Workerism in several respects. The key difference lies in its focus on the central role of knowledge. In place of immaterial labour, cognitive labour, a type of immaterial labour, ${ }^{149}$ is suggested as the hegemonic form of labour in cognitive capitalism. Likewise, class struggle between capital and labour is viewed as centred on the role of knowledge production, instead of encompassing all aspects of life as implicit in the category of biopolitical labour. In addition to narrowing down the focus onto knowledge, CCT attempts to conceptualise the new reality at a more logical and abstract level than

absolute and relative terms, to the extent that it "has exceeded the portion of physical capital in the global capital stock and it now represents the main factor for economic growth and competitiveness", expresses the transition from "the Taylorist division of labour" to "a cognitive division or organisation of labour".

${ }^{146}$ See Hardt (1999) for more on affective labour.

147 This aspect of immaterial labour is crucial for distinguishing cognitive labour from immaterial labour. For Vercellone (2007 and 2011), cognitive labour and immaterial labour are similar concepts, with cognitive labour being more specific. Monnier and Vercellone (2014, p. 65) suggest that cognitive labour can be either material or immaterial labour.

${ }_{148}$ Caffentzis (2005, p. 97) criticises Negri and Hardt that they "willfully ignore the well known ontological distinction between labour and action".

149 According to Hardt and Negri (2004, p. 108), "conventional terms such as service work, intellectual labour, and cognitive labour all refer to aspects of immaterial labour". 
post-Workerism, such that its analysis of the economic aspect of contemporary capitalism is more advanced and sophisticated than that of post-Workerism: "Of course, this problem will basically be addressed from the viewpoint of economists" (Paulré, 2004, para. 2).

Cognitive capitalism theory, as the nomenclature suggests, is also based on the view that capitalism consists of several stages even though CCT and post-Workerism periodise capitalism in different ways. Whereas post-Workerism tries to periodise "the history of real subsumption of labour under capital" (Bowring, 2004, p. 105) by identifying three successive stages of capitalism whose first stage dates back only to 1848, CCT shares Braudel's view that capitalism has a long history, which came into being far earlier than the industrial revolution (Moulier-Boutang, 2002). ${ }^{150}$ In CCT, cognitive capitalism is the third stage of capitalism, preceded by industrial capitalism which started with the first industrial revolution. ${ }^{151}$ In this respect, and as mentioned earlier, the transition to cognitive capitalism is called a rupture, not a transition within industrial capitalism from Fordism to post-Fordism. The transition to cognitive capitalism is seen to be so profound that Moulier-Boutang (2002, p. 3) puts it as a "grand transformation" in a Polanyian sense. We therefore need new theories for the new capitalism: "It makes us leave behind the political economy born in the eighteenth century" (Moulier-Boutang, 2006, para. 23).

The originality of CCT lies in conceptualising the succession of stages of capitalism as the logical and historical development of the capitalist division of labour. ${ }^{152}$ According to Vercellone (2007, p. 19), the three stages of capitalism correspond to three successive forms of the capitalist division of labour - formal subsumption,

150 "It is a confirmation of one of the lessons of Braudel who, in opposition to approaches assimilating too early the essence of capitalism to its industrial configuration, reminds us that capitalism is an 'old history"' (Corsani et al., 2001, p. 14).

${ }^{151}$ In its first stage, capitalism was mercantilist capitalism "based on the models of production of the putting-out system and of centralised manufacture" (Vercellone, 2007, p. 15).

${ }^{152}$ No one except Vercellone and Moulier-Boutang explicitly associates the periodisation of capitalism covering all the three stages of capitalism with the evolution of the capitalist division of labour. However, considering that this view is already present in the Draft, we may conclude that others' silence on this matter does not mean rejection of this view, but implicit approval. There is at least a general agreement among theorists that the emergence of cognitive labour and a new form of the capitalist division of labour is a necessary condition of the transition to cognitive capitalism. 
real subsumption and the general intellect, respectively, all of which are discussed in Marx's works. Each form of the division of labour is distinguished from the others by its distinctive configuration of production and appropriation of knowledge. In this view, whereas knowledge was originally produced, owned and controlled by workers in the stage of formal subsumption or mercantilist capitalism, the role of knowledge production was systematically detached from workers and centralised to a small group of specialised workers during the stage of industrial capitalism, with (scientific and/or technological) knowledge mainly objectified in fixed capital. In this form of the division of labour, commodity-producing workers are seen to play a passive role, and are under real subsumption to capital. It is argued that the situation is being reversed in the transition to cognitive capitalism or the stage of the general intellect, in which the role of knowledge production or conception is being re-appropriated by workers. In this stage, "the traditional terms of the opposition between 'dead labour' and 'living labour' of industrial capitalism gives way to a new antagonism between the 'dead knowledge' and 'living knowledge"' (Corsani et al., 2001, p. 19). Social knowledge exists as a "mass intellectuality" (Virno, 2007, p. 6) or a "diffuse intellectuality" (Vercellone, 2007, p. 16) within living labour as opposed to fixed capital. Moulier-Boutang (2002, p. 8) also speaks of "the centrality of living labour which is not reduced to dead labour in machinery".

The evolution of the capitalist division of labour is certainly not simply a technical process. As is the case in post-Workerism, it is seen as the terrain, as well as the result, of class struggle. Technological determinism is clearly rejected. Rather, knowledge production and its technological application are understood as a means of undermining and containing the resistance of the working class. In the stage of industrial capitalism in particular, capital incessantly attempted to introduce new production technologies in order to subordinate labour to capital and to empty workers of traditional production knowledge. As this involves deskilling and degradation of work, "the labour process remains irreducibly conflictual" (Vercellone, 2007, p. 17), and "the analysis of technical progress as an expression of a relation of forces concerning knowledge is everywhere present in Marx's work" (p. 18). Further, in the tradition of Autonomist Marxism, technological development is understood primarily as a weapon for capital against the working class. As Aufheben (2006, p. 29) puts it, "this [deskilling] is class struggle which appears, post facto, crystallised in the objective laws of capital or in the objective rationale of innovation, progress and development of capitalist production".

In sum, the conflictual relation centred on knowledge is the defining feature of the 
capital-labour relation in cognitive capitalism, with cognitive capitalism itself essentially resulting from the class struggle around knowledge production. Based on this view of the determining role of class struggle in historical development, Vercellone (2007) goes further and argues that the re-appropriation of knowledge by workers was possible by the expansion of public education, which is also a result of the struggle between labour and capital in industrial capitalism, or, more specifically, in Fordism.

\subsection{Misinterpretations of Marx's value theory in cognitive capitalism theory}

Having reviewed key aspects of cognitive capitalism theory, we are now ready to move on to our critique. As mentioned earlier, we will focus on demonstrating that value theory is misinterpreted in CCT, which leads to the equally misleading bold argument that value theory is no more valid in contemporary capitalism. In short, the marginalisation of direct labour time in the knowledge-intensive sectors is viewed in CCT as representing the demise of value theory on the basis of a (mis)interpretation of value theory. 153

Our critique begins by drawing attention to the argument that value theory, or the law of value, presupposes a specific form of the division of labour and is therefore valid only in a specific stage of capitalism. In this sense, value theory, being a theory of industrial capitalism, is taken by CCT as a barometer of the status of industrial capitalism: as long as new changes can be explained by value theory, capitalism remains to be industrial capitalism; conversely, such phenomena that seemingly contradict value theory are taken to indicate that fundamental mutations are taking

153 Leaving aside the problem that CCT proposes no alternative value theory replacing Marx's labour theory of value, the notion that value theory can be rejected because of some new phenomena that seem to contradict value theory is at odds with Marx's own view. Marx (CW43, pp. 68-69) criticises such a notion, by saying that:

Even if there were no chapter on 'value' at all in my book, the analysis I give of the real relations would contain the proof and demonstration of the real value relation. The chatter about the need to prove the concept of value arises only from complete ignorance both of the subject under discussion and of the method of science. ... Where science comes in is to show how the law of value asserts itself. So, if one wanted to 'explain' from the outset all phenomena that apparently contradict the law, one would have to provide the science before the science. It is precisely Ricardo's mistake that in his first chapter, on value, all sorts of categories that still have to be arrived at are assumed as given, in order to prove their harmony with the law of value. 
place behind them. ${ }^{154}$ Significantly, this argument is based on a naturalistic interpretation of value theory. This interpretation views abstract labour as pure expenditure of human energy, which comes to the fore under a specific form of the division of labour where the role of knowledge production, or conception, is deliberately separated from workers and is monopolised by capitalists. It is argued that simple commodity-producing execution work prevailing in industrial capitalism approximates abstract labour, not the abstract aspect of labour, but labour being stripped of its concrete aspect and becoming pure expenditure of human (physical) energy. In this sense, the separation between conception and execution is implicitly considered to be a defining aspect of the category of value, not a consequence of it.

Second, related to the first point, that abstract labour and value are social categories, expressing equivalence between human labours, is neither acknowledged nor recognised in CCT. Simple execution work is seen as directly abstract labour and quantitative relations between human labours are ignored, despite varying productivity and complexity of labour. In other words, the quantitative conversion of concrete labour time into abstract labour time is not studied and social processes involved in this conversion are short-circuited, within which knowledge plays an important intrinsic role of virtual multiplication as we have seen in Chapter 3 . Knowledge is seen to be produced solely by capitalists and to contribute nothing at all to value production. Not surprisingly, then, in taking the view of the predominant role of knowledge under the stage of cognitive capitalism, value becomes a redundant category.

Third, and more fundamentally, such misinterpretation is based on a specific view of the relation between conception (knowledge-producing labour) and execution (commodity-producing labour). Different roles of conception and execution in the production of use value and value in capitalism are not analysed in CCT. Instead, although both are indispensable parts of the production process as a whole, labour is seen to create wealth as either execution alone (in industrial capitalism) or conception alone (in cognitive capitalism). Not only are execution (or industrial labour) and conception (or cognitive labour) contrasted with each other, but the two

\footnotetext{
154 For the proponents of CCT, however, this does not mean Marx is wrong. Given that the object of value theory is believed to gradually give way to a new reality, for them, it is compatible with Marx's method and his historical materialism to reject the validity of value theory in the stage of cognitive capitalism. The presumption is that with the emergence of a new reality, new theories should be developed, and that is what Marx's method requires.
} 
are seen to mutually exclude each other. Put differently, the one is viewed as the negation of the other and no inter-relation between them is analysed. In this interpretation, Marx's value theory is degraded into an execution-labour theory of value where no consideration of conception (or knowledge) is present. In addition, what holds for the old theory (the execution-labour theory of value) is considered obsolete in the new theory (the conception-labour theory of value). For example, in cognitive capitalism, the presence of the single measure of wealth is seen to be dubious, and the distinction between material wealth and wealth in general (in value terms) is absent.

\section{Abstract labour and value in cognitive capitalism theory}

In CCT, abstract labour is first and foremost a naturalistic category. According to Hardt and Negri (2004, p. 144), all the qualitatively different (concrete) industrial labours are "equivalent or commensurable because they each contain a common element, abstract labour, labour in general, labour without respect to its specific form". Conceptualised in this way, abstract labour is measured by one of the "natural units of measure" (p. 156). Whilst there is nothing wrong with this definition of abstract labour, it is not sufficient. ${ }^{155}$ For the social and historical aspects of abstract labour, which are more fundamental than the physiological aspect, are neither acknowledged nor recognised. According to this interpretation, Marx's labour theory of value belongs to the "energy and entropy paradigm of labour" (Moulier-Boutang, 2012, p. 53; see also p. 117 and Moulier-Boutang, 2002). ${ }^{156}$ Similarly, Lebert and Vercellone (2011, p. 8) say:

155 "'Physiological' definition derives from a mental generalisation across all types of concrete labour. Although simple and often adequate, it may be insufficient for two reasons. First, it is excessively general; several forms of purposeful energy expenditure are not generally considered labour, for example those activities directly related to the upkeep and reproduction of the individual and the household, leisure and self-expression, and the arts. Second, this transhistorical definition is analytically sterile. Inspection of reality shows that certain types of labour, for example cooking, design, management, or personal services, can vary significantly over time and place in terms of the work process and the circumstances in which these activities are performed. In spite of the importance of these features of human labour, the physiological definition of labour cannot be developed systematically in order to explain them" (Saad-Filho, 2002, pp. 10-11).

${ }^{156}$ Moulier-Boutang (2004, para. 2) also argues that the energy paradigm does not hold in cognitive capitalism: "The source of value becomes the cooperation between brains and not just the use of the force of muscular work and energy expenditure [emphasis added]". 
At the heart of this transformation [in the laws of functioning of the economy] is the transition of the energy paradigm [emphasis added] of work in industrial capitalism towards a new social organisation of production, based on the rise of cognitive and immaterial dimensions of work, but, more generally, that of the role of knowledge.

For Marx, by contrast, abstract labour is primarily a social category. In the first volume of Capital, immediately after he suggests abstract labour as the common element of various concrete labours, he refers to it as "social substance" (CI, p. 128). ${ }^{157} \mathrm{He}$ does so before he introduces more complex concepts such as money and capital. His interest is in laying bare the social dimension underneath generalised commodity production and exchange, and apparently, the physiological understanding of abstract labour, that all commodities are the outcome of human energy expenditure, which is true at anytime and anywhere, falls short for this purpose. Simply, it is not a good foundation on which to reconstruct (in thought) a historically specific mode of (social) production. Abstract labour, for Marx, above all, expresses the equivalence between human labours, which is a historical product, ${ }^{158}$ as is shown by the example of Aristotle who failed to recognise human labour as the common element contained in two different commodities in exchange due to the necessarily historical limitations of his perspective (CI, pp. 151-152).

Significantly, for the proponents of CCT, abstract labour, an ahistorical and naturalistic category for them, became the substance of value in (industrial) capitalism. From this point of view, contrary to the previous mode of production, where measuring labour by time had little social significance (in fact, it was the other way around), labour time was elevated to become the measure of labour as the

157 Cremin and Roberts (2011, p. 184) also criticise Hardt and Negri's physiological understanding of abstract labour. They attribute Hardt and Negri's misinterpretation to their privileging of the very beginning of the first volume of Capital:

\begin{abstract}
By insisting that the first few pages of Capital do in fact faithfully represent Marx's main arguments on value, Hardt and Negri ignore ... [a] more rigorous and developed analysis and simply reduce Marx's value theory to a statement about the collective amount of individual concrete labour that taken as a whole across production constitutes social and abstract labour. In other words, Hardt and Negri attribute a rather simplistic theory of value to Marx which can be termed an 'embodied theory of value'. This theory of value is based on the idea that everyday concrete labour is recognized as physiological labour embodied in commodities during production.
\end{abstract}

158 "The secret of the expression of value, namely the equality and equivalence of all kinds of labour because and in so far as they are human labour in general, could not be deciphered until the concept of human equality had already acquired the permanence of a fixed popular opinion" (CI, p. 152). 
result of the systematic separation of the cognitive aspect of labour from workers. Whereas capitalists were responsible for knowledge production, workers were increasingly forced to perform simple labour, at the rhythm and pace dictated by capitalists, such that commodity-producing labour was transformed to be primarily about the (measurable) expenditure of human energy. Especially with the introduction of machinery to the production process and the establishment of largescale industry, labour became "ever more abstract, not only under the form of exchange-value, but also in its content, emptied of any intellectual and creative quality" (Vercellone, 2007, p. 24). In short, in CCT, (industrial-)value, of which abstract labour is the substance, is the result of the separation between conception (knowledge-producing labour) and execution (commodity-producing labour).

For Marx, by contrast, time is the measure of labour and value at a more abstract level. Whereas generalised commodity production and exchange and the division of labour are presupposed in his analysis of value, capital is brought into the analysis after commodity, value, and money. Value and abstract labour also precede more complex concepts such as the division of labour (within a workplace) and the separation between conception and execution, logically, if not historically. Therefore, Marx's analysis of labour in Chapter 1 of the first volume of Capital does not mention the separation between conception and execution; on the contrary, labour is seen as the unity of conception and execution: "Tailoring and weaving, although they are qualitatively different productive activities, are both a productive expenditure of human brains [emphasis added], muscles, nerves [emphasis added], hands etc., and in this sense both human labour" (CI, p. 134). ${ }^{159}$ Law-like tendencies, not least the tendency of deskilling, are also the results of, not preconditions for, value. Likewise, a specific form of the division of labour cannot be taken as a prerequisite for the validity of value theory, nor for the real existence of value.

159 Similarly, Marx (CW30, p. 168) says, "It [the capitalistic production] is a greater spendthrift than any other mode of production of man, of living labour, spendthrift not only of flesh and blood and muscles, but of brains and nerves [emphasis added]". Lucarelli and Vercellone (2014) also acknowledge that labour, for Marx, is the unity of conception and execution although their emphasis is on the immeasurability of labour and worker's resistance to control due to the cognitive aspect of labour:

It is important to recall that for Marx, labour as a cognitive activity - understood as the inseparable unity between thought and action - is the very essence of man (see Capital Book I, ch.7). It seems to us that the crucial point is the following: if the cognitive dimension of labour is the very essence of human activity, awareness of this might be understood as an impediment to the capitalist control of production and, therefore, accumulation (p. 8; page reference is from an early draft). 


\section{Cognitive labour and industrial labour as two independent forms of labour}

Cognitive capitalism theory takes it the other way around. For the proponents of CCT, it is precisely through the separation between conception and execution that time became the measure of execution labour which is physiologically and ahistorically abstract, and abstract labour the substance of value. In the sense that value is the result of the historically specific form of the division of labour, contrary to abstract labour, it is both a social and historical category although it is also a directly social category, with the separation between conception and execution, a class relation, being imposed from without. ${ }^{160}$

Significantly, it is seen that, under the industrial form of the division of labour, labour is either cognitive labour or execution labour and it is only the latter that creates (industrial-)value. In addition, whilst labour is viewed as the source of wealth both in industrial and cognitive capitalism, labour is understood to create value either in its industrial form alone or in its cognitive form alone. Industrial labour and cognitive labour are contrasted with each other, to the extent that they appear to mutually exclude each other: the former is repetitive, pure consumption of human energy and the latter is creative, cooperative and intellectual; the former is measured by time and the latter is immeasurable by time; the former is expended in the labour process as dictated by capital and the latter organises and co-ordinates itself; the former produces commodities according to knowledge objectified in fixed capital or machinery and the latter produces such knowledge. It is as if one is the pure negation of the other; cognitive labour is labour which is not industrial labour; industrial labour is labour which is deprived of its cognitive aspect. ${ }^{161}$

160 "The imposition of work as imposition of abstract labour thus represents capital's attempted transformation of the multi-dimensionality of life into the one-dimensionality of work. The potentially boundless and qualitatively distinct forms of human activities and human relations are turned into the potentially boundless different forms of the same thing: work" (De Angelis, 1995, p. 113).

${ }^{161}$ It is worth noting that the distinction between knowledge labour (conception) and commodity-production labour (execution) is different from the distinction between material and immaterial labour. Knowledge labour can create material products and commodityproducing labour immaterial products. For the latter, Marx (CW34, p. 144) gives examples of "artists, orators, actors, teachers, doctors, clerics, etc.":

With non-material production, even when it is conducted purely for exchange, hence produces commodities, two things are possible: ... 2) The product is not separable from the act of producing, as with all executant artists, orators, actors, teachers, doctors, clerics, etc. ... E.g. teachers in educational institutions may be mere wage labourers for 
Any type of the division of labour involves a separation between conception and execution to some extent. However, as long as both forms of labour are required and indispensable for commodity production, their different roles in value production as well as in use value production should be recognised and analysed. Execution alone cannot produce commodities and thus alone cannot produce (industrial-)value either. In other words, execution cannot stand on its own without conception and vice-versa. This internal relation may appear in many different forms which change and develop historically. For example, in contemporary capitalism, the separation between conception and execution has been developed to the extent that knowledge can be bought and sold. In addition, knowledge production is not only for internal use to enhance the productivity and complexity of commodity-producing labour or to develop new products, but also for making profit by way of knowledge licensing, although conception and execution can be detached only imperfectly from each other. This can and should, however, be theorised on the basis of the internal relation between conception and execution at the abstract level, as a form of its externalisation. In sum, for Marx, commodity production and, thus, value production, are anchored firmly in the unity of conception and execution.

The contrary is the case in CCT, in which the internal relation between conception and execution is lost. They are seen to be independent of each other, as if one can exist irrespective of, and/or prevail over, the other. Likewise, Marx's value theory is understood as an execution-labour (or industrial-labour) theory of value in which there is no place for conception or knowledge-producing labour. Knowledge production monopolised by capitalists is seen as a technological means of domination, which forces workers to perform abstract labour, and as a tool to

the entrepreneur who owns the institution; there are many such education factories [emphasis added] in England. Although they are not productive workers vis-à-vis the pupils, they are such vis-à-vis their employer. He exchanges his capital for their labour capacity, and enriches himself by this process. Similarly with enterprises such as theatres, places of entertainment, etc. Here the actor's relation to the public is that of artist, but vis-à-vis his employer he is a productive worker. All the phenomena of capitalist production in this area are so insignificant in comparison with production as a whole that they can be disregarded entirely. (CW34, pp. 143-144)

Similarly:

The material determination of labour, and therefore of its product, in itself has nothing to do with this distinction between productive and unproductive labour. For example, the cooks and WAITERS in a public hotel are productive labourers, in so far as their labour is transformed into capital for the proprietor of the hotel. These same persons are unproductive labourers as MENIAL SERVANTS, inasmuch as I do not make capital out of their services, but spend revenue on them. In fact, however, these same persons are also for me, the consumer, unproductive labourers in the hotel. (CW31, p. 15) 
increase relative surplus value, without affecting the production of value. In conclusion, by reducing Marx's value theory into an execution-value theory of labour, CCT not only misinterprets but also narrows the applicability of value theory, and on this basis, rejects the validity of value theory in contemporary capitalism. ${ }^{162}$ CCT takes a dialectical unity in labour between conception and execution, and dehistoricises it to allow for certain tendencies, of deskilling and the like under capitalism, to be realised as absolute in separating the two in industrial capitalism and, further, conversely, for labour to appropriate conception in cognitive capitalism.

\section{Law of value in crisis and the emergence of cognitive labour as the source of material wealth}

With cognitive labour becoming the hegemonic form of labour in cognitive capitalism, it is argued that the law of value is in crisis because cognitive labour is, by its nature, difficult to measure. As Caffentzis (2005, p. 89) points out,

162 Lebert (2011, p. 106) criticises this line of critique of CCT in Fine et al. (2010) as being "Ricardian Marxist (marxo-ricardienne)" in the sense that "it apprehends the law of value primarily as a law of the (universal) measure of the magnitude of value, not as a historical product of the law of surplus value", although he does not define "the law of surplus value". He continues:

[The] distinction is, however, explained in the passages of The Poverty of Philosophy on 'automatic shop', the result of socio-historical process of 'subordination of man to the machine'. And Marx considers labours that are not reducible to this logic - immaterial labours with high professional autonomy - and notes that these labours in his time concern a very small part of the use of labour power. What would happen if, historically, this share was gaining importance in the capital accumulation process? The model of the automatic workshop would be called into question, and with it the abstract labour time standard that enables the measurement and comparison of labour. This is the starting point of the criticism of the theory of the labour time value [la théorie de la valeur temps de travail] in the approach of cognitive capitalism.

In other words, he argues that like Marx who ignored conception since it was negligible in his time, CCT should ignore execution, as it is increasingly becoming marginalised in contemporary capitalism. It is argued, however, that this does not amount to the rejection of the validity of the law of value:

To put it otherwise, in the approach of cognitive capitalism, the separation between conception labour and execution labour is to understand it [the law of value] as the result of the historical process leading to the real subsumption of labour to capital during industrial capitalism, the process (never completely finished) which finds a form of culmination during the Fordist period; it is by no means a premise from which this approach [of cognitive capitalism] would base a radical critique of the notion of the "Marxist" law of value that would serve to provide a disconnected alternative. It is only the interpretation [of the law as] "the theory of the labour time value" which is disputed in a setting where, by nature, and as contemplated elsewhere in Fine et al. (2010), the inseparability between cognitive and physical forms of work becomes the norm. 
interestingly, "the 'Law of value' is not explicitly defined in Marx's work". Nor is the law defined in the works of cognitive capitalism theorists. Notably, however, Negri and his followers have been using this term frequently since as early as $1978 .{ }^{163}$ Hardt and Negri (2004, p. 145), for whom the law of value is first and foremost about imposing a measure, ${ }^{164}$ say:

According to this law of value [emphasis added], which defines capitalist production, value is expressed in measurable, homogeneous units of labour time. ... This law, however, cannot be maintained today in the form that Smith, Ricardo, and Marx himself conceived it. The temporal unity of labour as the basic measure of value today makes no sense.

For Corsani et al. (2001, p. 16), the law of value is at the core of Marxist political economy, and therefore the crisis of the law of value reveals a more fundamental crisis, the crisis of the entire political economy (based on the law of value): "The categories of political economy (trade, value, ownership, production, consumption, labour, etc ...) are in crisis".

Despite the lack of definition, an example provided by Vercellone (2007, pp. 33-34) suggests that the law of value, ${ }^{165}$ for the proponents of CCT, refers to the determination of value by labour time and the determination of price by value:

The time of labour directly dedicated to the production of commodities intensive in knowledge becomes insignificant; or, to put it in the language of neoclassical economy theory, where the marginal costs of reproduction are practically nothing or extremely low, these commodities should be given for free.

In this example, the value of commodities in a knowledge-intensive sector is considered to be close to zero because the labour time expended to produce each commodity is very little as is the case with information commodities (see Chapter 3 ).

${ }^{163}$ For example, Negri (1991, p. 24) speaks of "money as the crisis of the law of value". According to Caffentzis (2005, p. 91), "the phrase [the law of value] is not in common use outside of the pages of post-Marx Marxist and Soviet-era economists".

164 On the other hand, "The law of value also takes a ... form, which regards the value of labour as a figure of antagonism, as the subject of an open and ever present rupture in the system rather than an element of equilibrium" (Hardt \& Negri, 2009, p. 314).

165 Vercellone (2007, p. 16) uses "the law of value-labour" instead, to distinguish the value created by commodity-producing labour in industrial capitalism from the new value created by cognitive labour in cognitive capitalism (value-knowledge). In this chapter, we use industrial-value (old value) and cognitive-value (new value). 
In reality, however, such commodities as software ${ }^{166}$ and microprocessors are sold at the price far higher than their marginal cost or direct labour time expended per output. Such divergence is seen as revealing that the law of value is in crisis in the sense that value no longer governs the determination of price. ${ }^{167}$

Despite the putative crisis of the law of value due to the expansion of the role of knowledge in commodity production, value remains a central category of cognitive capitalism and labour the source of wealth, even if value and wealth in cognitive capitalism cannot be taken as the same value and wealth in industrial capitalism: "Labour does remain the fundamental source of value in capitalist production, that does not change" (Hardt \& Negri, 2004, p 145); "Labour, particularly in the form of knowledge, remains nevertheless the principal source of the creation of wealth, but it can no longer be measured on the basis of labour time directly dedicated to production" (Vercellone, 2007, p. 30); "The main source of value now lies in the creativity, versatility and strength - invention of employees - and not in capital assets and in the work of execution" (Negri \& Vercellone, 2007, para. 32); MoulierBoutang (2012, p. 4) asks, "Are we ... going to remain obstinately stuck to the perspective of the value of working time, of the utility or scarcity of resources, in order to measure a wealth that depends on the time of life and on the superabundance of knowledge?" It goes without saying that labour time is not a good measure of knowledge, the product of cognitive labour. First, the distinction between labour time and non-labour time is becoming unclear in knowledge labour. Ideas flash through mind and workers can continue to think at home. Second, and more importantly, a given amount of labour time can lead to either a useless idea or an epoch-changing idea. Whilst it is more likely that better and/or more knowledge is produced if more cognitive labour-time is expended, labour time is not a decisive factor in evaluating the economic benefit of knowledge. ${ }^{168}$ Consequently, in cognitive

${ }^{166}$ For Moulier-Boutang (2012, p. 68), software production is on the basis of "a cognitive division of labour":

In as much as it is a production of knowledge through knowledge that has been acquired, interpreted and contextualised, the development of software (for example) derives from a cognitive division of labour and not from a Smithies division of labour.

167 In this respect, Vercellone's view has some affinity with the monopoly price approach. 168 Similarly, Moulier-Boutang (2012, p. 165) says:

In a society where production operates through the living and is geared to creating the living (bio-production and biopolitics) and living knowledge by means of the activity of living knowledge, the measuring of working time goes into crisis. Doubly so, in fact. On the one hand, the classic system of working time has now become largely porous. The 
capitalism, either a new measure of cognitive-value is required or the notion of measure should be abandoned. ${ }^{169}$

Unfortunately, however, CCT only demands that a new value theory be developed, but does not take on this task itself. In addition, the quantitative aspect of the new cognitive-value is simply ignored. It is not only that the determination of the magnitude of cognitive-value is not explained, but it is even unclear if the new cognitive-value, or the value of the 'common' in the language of Hardt and Negri, determines the price of commodity and/or knowledge. Furthermore, the qualitative equivalence between different types of cognitive labour and of knowledge is not questioned. ${ }^{170}$ For the proponents, this is not a weakness because homogenisation is seen to be unnecessary. Given that social wealth in cognitive capitalism is represented by the abundance of use values, different types of cognitive labour and different types of knowledge do not have to be homogenised. Nor do their magnitudes have to be expressed by a single intrinsic measure. Negri and his followers are even hostile to the notion of measure. For example, Hardt and Negri (2004, p. 153) criticise that "economics has evolved as a theory of the measure", being "really completely fixed and static". Measure is also seen to be impossible: "One can no longer hope to find any natural units of measure" (p. 156). This point is repeated most clearly by Virno (2007, p. 6) who says, "[the models of social knowledge] are not units of measure; they constitute the immeasurable presupposition of heterogeneous operative possibilities". According to Caffentzis

labour code is felt by employers (and sometimes even by employees) as simultaneously too restrictive and too lax. What does it mean to do 35 hours of mental work per week? What is the meaning of a system that measures productive output only in terms of the final product and does not measure it in relation to the products of an activity that requires continuous preparation, updating and training, and a joint sharing of things?

169 Hence, it is argued that capital strives to impose a new measure:

Contemporary attempts to reinvent measure in terms of market values, goodwill, intangible assets, and the like demonstrate the inadequacy of the law of value for measuring productivity, but they do indicate a real change in the nature of productive power, which is still based on labour. (Hardt \& Negri, 2009, p. 316)

170 Virno (2007, p. 6) mentions abstract knowledge: for example, "the fact that social relations are ordered by abstract knowledge rather than the exchange of equivalents". However, he neither defines abstract knowledge nor analyses real social processes that establish a qualitative equivalence between different (concrete) knowledges. The scale and scope of knowledge trade, which is distinct from commodity exchange, is certainly rapidly increasing, and we may say that abstract homogenous knowledge is formed out of this generalised knowledge exchange, with the economic value of knowledge being expressed in the money form. 
(2005, p. 96), "the value they [Hardt and Negri] cherish and refer to ... is both immeasurable and beyond measure". In short, for the proponents of CCT, labour remains the source of wealth in cognitive capitalism, but in fundamentally different ways than in industrial capitalism.

This suggests that (cognitive-)value in cognitive capitalism is more similar to use value than to (industrial-)value. According to Vercellone (2007, p. 34), wealth in cognitive capitalism is based on "abundance and use value [emphasis added], and therefore on free appropriation". In addition, social knowledge, collaboration and co-operation are seen to play a far more important role in wealth creation than commodity-producing labour in cognitive capitalism. In the same vein, Hardt and Negri (2004, p. 150) argue, "we must understand the production of value in terms of the common [emphasis added]". ${ }^{171}$ Monnier and Vercellone (2014) attempts to redefine and extend the concept of productive labour accordingly: ${ }^{172}$

\begin{abstract}
The concept of productive labour as labour that produces use value, a wealth that escapes market logic and wage relations subjected to capital [emphasis added]. In short, it regards questioning the assimilation of the concept of labour and the concept of employment and strongly affirming that labour can be unproductive in terms of capital while producing non-market wealth and therefore giving rise to income that is in turn, economically and socially significant. (p. 67)
\end{abstract}

With the focus of analysis being placed on use value, a lot of factors contributing to the (re)production of use value including labour power are necessarily brought into

${ }_{171}$ "We define the common as the potential of expanding social cooperation which attends the paradigmatic transformation of productive forces and the prominence of new forms of labour in contemporary capitalism such as the increasingly socialised production of knowledge [emphasis added]. Consequently the common is not relegated to specific common goods such as water, for example. Conversely the naturalistic approach leads to a subordinate position that is not able to overcome the public-private dichotomy. In Toni Negri's recent writings, the common refers to a form of socialisation that breaks down the former divisions between work and life, between production and reproduction, and between material and immaterial" (Lucarelli \& Vercellone, 2011, p. 79).

${ }^{172}$ Similarly, Morini (2007, p. 44) says:

In areas where there is a greater diffusion of cognitive capitalism our comprehensive action becomes, ever more glaringly, productive labour. A characteristic peculiar to current production is indeed the use of our ability for creation, reaction and relationships. These are the linguistic and cooperative exchanges: the precarious person becomes part of a network of relationships and in fact has no sense of consistency outside of these. Personal, social and communicational identities identify with each other in a sort of short circuit. 
the analysis, not least unpaid life activities of men, often called free labour, especially in the context of housework: "Life itself is put to work and the role of working relations is emphasised, directly incorporated within the productive activity. Thus, economic management assumes as its object living life rather than static life" (Morini \& Fumagalli, 2010, p. 236). Consequently, in the stage of "biocapitalism" (p. 235), ${ }^{173}$ which is "a process of accumulation that not only is founded on the exploitation of knowledge but of the entirety of human faculties, from relational-linguistic to affective-sensorial", the distinction between labour and non-labour becomes even more loose and the question of remuneration of such activities is raised.

The expansion of free labour goes hand in hand with its subordination to value-producing social labour since these tendencies push toward a blurring of the separation between labour and non-labour as well as blurring the sphere of production and that of reproduction. (Monnier \& Vercellone, 2014, p. 67)

In addition, inevitably, there is now a multiplicity of theories of (use) value: ${ }^{174}$

It is necessary to subdivide the analysis in three phases: value generated by the diffusion of knowledge, namely linguistic-cognitive labour (knowledge theory of value); value generated by affective and reproductive labour (affect theory of value); value generated by symbolic and imaginary labour,

173 Biocapitalism also entails "the shift from a production of money by means of commodity (M-C-M') to a production of money by means of the commodification of bios [M-C(bios)-M'] has modified the mode of production and the process of exploitation" (Morini \& Fumagalli, 2010, p. 239).

174 It is striking that Lucarelli and Fumagalli (2008) refers to economies of scale and increasing returns to scale, defined in terms of use value, whilst discussing the role of knowledge:

Cognitive capitalism (CC) has generated two new economies of scale [emphasis added] that have a positive impact on the nature of production returns and therefore on productivity. On the one hand we have dynamic economies of learning (learning by doing, learning by using, etc.) strictly depending on the characteristics of information and communication technologies; on the other, we have new spatial economies, related to the existing network and capabilities that affect a given territory and are able to increase diffusion of knowledge. (p. 78)

Due to the fact that it is not exhausted by consumption, the cumulativeness of knowledge and the speed of its diffusion necessarily imply increasing returns to scale [emphasis added].

By contrast, "In the Fordist context, the evolution of productivity depends upon the evolution of the techniques of production, on the investment flow, and on the presence of static (size) scale economies [emphasis added]" (p. 75) 
especially in the process of branding (image theory of value). (Morini \& Fumagalli, 2010, p. 241)

There is no reason why there should and can be only three theories of value. ${ }^{175}$ Each and every aspect of life contributes to the production of wealth in its own peculiar way, each requiring a specific theory of value. Where homogenisation is considered unnecessary and even impossible, the categorisation of essentially heterogeneous activities into knowledge, affect, image, and many more is meaningless. Then, despite the narrower and more economic focus of CCT, it is back to Hardt and Negri's original conception of biopolitical society.

In addition, in terms of use value production, everything contributes to the production of everything else, either directly or indirectly, and either positively or negatively. Hence, for the proponents of CCT, drawing a solid line between factors of production which are remunerated and life activities which are not is doomed to failure. As Hardt and Negri (2009, p. 317) argue, "In the biopolitical context, value overflows any threshold of political and economic control ... [biopolitical exceeding] overflows the barriers that the tradition of modern political economy built to control labour power and the production of value". Whilst they suggest that a new theory of value is required, they therefore ask themselves, "will it really be a theory of value?" (p. 316). ${ }^{176}$

\subsection{The general intellect}

Although not directly related to the (mis)interpretation of value theory in CCT, we touch upon the topic of the general intellect in this section, not least because it is argued to represent the new form of the capitalist division of labour in cognitive capitalism. In particular, this section is concerned with the argument that the general intellect which Marx presents (for the first and only time) in the Grundrisse anticipates the re-appropriation of the role of knowledge production by workers, often suggested as strong evidence that Marx shares the CCT view and anticipates

\footnotetext{
175 Fumagalli (2010, p. 53) also speaks of "bio-economic value”.

${ }_{176}$ As Toms (2008, p. 435) observes:

Without a theory of profit creation, there can also be no theory of profit distribution. Without a theory of profit, there can be no theory of rent, nor a theory of price or market competition. Of course, immeasurability implies that all these theories are now surplus to the requirements of a value theory that only requires us to acknowledge there is a power to act and with it comes an associated excess or social surplus.
} 
the advent of cognitive capitalism. ${ }^{177}$

We will criticise this argument by showing that the general intellect refers to social knowledge in general, if not in a narrower sense, knowledge objectified in fixed capital. We will briefly review some passages of the Grundrisse related to the general intellect, also known as the Fragment on machines ('Fragment'), which is a misnomer according to Haug (2010). The aim is both to summarise the interpretation of these passages in CCT, and criticise it.

In the Fragment, Marx argues that with the rapid development of science and technology, at some point, labour time can cease to be the measure of value:

In the degree in which large-scale industry develops, the creation of real wealth becomes less dependent upon labour time and the quantity of labour employed than upon the power of the agents set in motion during labour time. And their power-their POWERFUL EFFECTIVENESS-in turn bears no relation to the immediate labour time which their production costs, but depends, rather, upon the general level of development of science and the progress of technology, or on the application of science to production. (The development of science itself, especially of natural science, and with it of all the other sciences, is, in turn, related to the development of material production.) E.g. agriculture becomes mere application of the science of the exchange of matter-in terms of how that exchange can be regulated to the maximum advantage of the social body as a whole ... Once this transformation has taken place, it is neither the immediate labour performed by man himself, nor the time for which he works, but the appropriation of his own general productive

177 For Heinrich (2013, p. 203), however, "the path from the Grundrisse to Capital witnesses not only transformations of individual aspects, but also of the fundamental conceptual questions". He argues that Marx's analysis, in the Grundrisse, of the decreasing role of labour in the production of real wealth, of the growing contradiction between real wealth production and value production pointing to the eventual collapse of capitalism, and of the notion of the general intellect, was superseded by the concept of relative surplus value in Capital (pp. 212-213):

In the treatment of the 'concept of relative surplus value' in Chapter Twelve [of the first volume of Capital], Marx speaks of the 'riddle' with which one of the founders of political economy, Quesnay, had tormented his opponents and for which they owed him an answer: namely, the fact that, on the one hand, capitalists were only interested in exchange value; but that, on the other hand, they constantly sought to lower the exchange value of their products. Marx also could not provide an answer to this riddle in the Grundrisse. There, he had effectively named the contradiction nominated by Quesnay. But rather than resolving it, he had comprehended it as a contradiction of capital. ... In the Grundrisse, Marx had ascribed to this 'contradiction' a potential to overthrow the capitalist mode of production. In Capital, against the background of the analysis of the production of relative surplus value, this contradiction is resolved: the capitalist is not interested in the absolute value of the commodity, but rather, merely in surplus value contained within it and able to be realised by means of sale. 
power, his comprehension of Nature and domination of it by virtue of his being a social entity-in a word, the development of the social individual-that appears as the cornerstone of production and wealth. (CW29, pp. 90-91)

Consequently:

Production based upon exchange value collapses [emphasis added], and the immediate material production process itself is stripped of its form of indigence and antagonism. Free development of individualities, and hence not the reduction of necessary labour time in order to posit surplus labour, but in general the reduction of the necessary labour of society to a minimum, to which then corresponds the artistic, scientific, etc., development of individuals, made possible by the time thus set free and the means produced for all of them. (p. 91)

Given that it is capital which strives to develop science and technology without limit, and therefore reduces the role of labour in the production of real (material) wealth, "capital itself is a contradiction-in-process" (p. 91). Put differently, capital, as the productive powers, "make the creation of wealth (relatively) independent of the labour time" (p. 92), on the one hand, ${ }^{178}$ and, as the relations of production, it tries "to confine them within the limits necessary to maintain as value the value already created", on the other hand. The productive powers and the relations of production, "two different aspects of the development of the social individual", and hence a developed form of the dual nature of the commodity, necessarily clash with each other; "they are the material conditions for exploding that basis".

Once this well-known conclusion is drawn, Marx steps back and considers the meaning of the development of fixed capital.

The development of fixed capital shows the degree to which society's general science, KNOWLEDGE, has become an immediate productive force, and hence the degree to which the conditions of the social life process itself have been brought under the control of the GENERAL INTELLECT and remoulded according to it. It shows the degree to which the social productive forces are produced not merely in the form of knowledge but as immediate organs of social praxis [emphasis added], of the actual life process. (CW29, p. 92)

The passage quoted above makes it abundantly clear that Marx equates the

${ }^{178}$ For Caffentzis (2008, p. 61), because of this, which he calls the "incommensurability tendency", "the labour theory of value is increasingly falsified". He also argues that the incommensurability tendency is interconnected with the law of the tendency of the rate of profit to fall (LTRPF). 
development of fixed capital with the appropriation of knowledge, especially science and technology, by capitalists, for the purposes of commodity production. Knowledge, produced by the general intellect, increasingly takes the form of fixed capital, "immediate organs of social praxis" and therefore becomes an "immediate productive force" of social labour. Marx's emphasis is, then, on knowledge becoming increasingly associated with commodity production.

For the proponents of CCT, by contrast, the general intellect is the totality of living knowledge. For Vercellone (2007, p. 33), "living knowledge" clashes with "dead knowledge" in cognitive capitalism, in which the capitalist division of labour takes a new form, "the historical emergence of the figure of the collective worker of the general intellect" (p. 30). He also speaks of the "overturn[ing of] the relation of subordination of the living knowledge incorporated in labour power to the dead knowledge incorporated in fixed capital" (p. 18) and argues that with the general intellect, "Marx announces the advent, after the stages of formal and real subsumption of labour to capital, of a new stage of development of the division of labour" (p. 19). Virno (2007, p. 6) suggests mass intellectuality, "the entirety of postFordist living labour", as "the prominent form in which the general intellect is manifest today". Similarly, Hardt and Negri (2009, p. 267) say, "In today's economy, in contrast, knowledge that is widespread across society-mass intellectuality-is becoming a central productive force, out of reach of the system of control, and this shift undermines the industrial paradigm". Whilst Moulier-Boutang (2012, p. 162) rightly associates the general intellect with "the development of science becom[ing] the force of production par excellence", but his focus is not on science as the force of production, but on "exploitation of the inventive force of living labour [emphasis added]". ${ }^{179}$ For Morini and Fumagalli (2010, p. 238), "This general intellect is the new source of (surplus) value ... Every singularity becomes a 'knot' in the network of collective intelligences, that organically connect economic and desiring flows".

Such interpretation of the Fragment in which the general intellect is equated with living knowledge vis-à-vis knowledge objectified in fixed capital, or dead knowledge, is highly questionable. Clearly, as we have seen, with the concept of the general intellect, Marx draws attention to the increasing (free) appropriation of knowledge by capital for commodity production in the form of fixed capital. Virno $(2007$, p. 5)

179 For more on the interpretations of the general intellect within cognitive capitalism theory, see Haug (2010). 
also admits this point: "According to Marx, the general intellect - that is knowledge as the main productive force - fully coincides with fixed capital, that is the 'scientific power' objectified in the system of machinery". ${ }^{180} \mathrm{He}$, however, suggests going beyond Marx by extending the concept of the general intellect to encompass "formal and informal knowledge, imagination, ethical inclinations, mentalities and 'language-games", although his emphasis is on informal knowledge embodied in living labour. Hence, "General intellect needs to be understood literally as intellect in general: the faculty of thought, rather than the works produced by thought (a book, an algebraic formula, etc.)" (p. 6).

In the Fragment, instead, Marx envisions a society where labour remains to be necessary for the creation of real wealth although playing only a minor role. ${ }^{181} \mathrm{In}$ such a society, production of real wealth, i.e. use values, will be dependent more on the state of science and technology rather than on total direct labour time. The Fragment is, then, about the contradiction between the powers of production and the relations of production in capitalism. He argues that capital pushes the development of the powers of production to the limit to the extent that it comes into conflict with the capitalist relations of production. Marx does not, however, mention counter-tendencies which are also consequences of the development of the productive powers (e.g. the expansion of commodity production in diversity) in the same passages. Further, with his focus on knowledge objectified in fixed capital, Marx does not give much attention to knowledge of workers, which is formed out of the mutually contradictory processes of deskilling and re-skilling. ${ }^{182}$ As is the case

${ }^{180}$ Vercellone (2007, p. 27) disagrees with Virno: "Our interpretation diverges from that of Paolo Virno, according to which Marx identifies the general intellect with fixed capital in toto, in contrast to the way that the same general intellect presents itself as living labour".

${ }^{181}$ According to Smith (2013, p. 7): "Marx ... expected that the general intellect could develop to this point only within communism. He did not foresee capitalism's transformation into a system in which the 'principal productive force' was the general intellect in the form of mass intellectuality".

${ }^{182}$ In the same vein, Smith (2013, pp. 15-16) says:

Virno and Vercellone are correct to stress the tendency to reduce workers to mere appendages of machine systems in the period from Marx's day through Fordism, and the resulting tendency for individual workers to be alienated from the scientific-technical knowledge embodied in them. These tendencies are objective material realities, experienced as such by individual workers. But the account in Capital also implies that the workforce as a whole simultaneously developed new capacities and new forms of knowledge in the course of its practical experience. An exclusive focus on 'deskilling' in this period oversimplifies Marx's position. Such an exclusive focus understates the extent 
with the nature of tendencies in the LTRPF (and counteracting tendencies), it is not possible to predict the outcome of the interplay of such contradictory tendencies. ${ }^{183}$

\subsection{Concluding remarks}

For the proponents of CCT, the dual nature of the commodity is the result of the separation between conception and execution, the imposition of time as the measure of labour. In other words, commodities are use values regardless of time and place, upon which social relations, organised around the division of labour in terms of knowledge production, can be imposed or not. For this reason, the struggle over knowledge is essentially the struggle over power (Vercellone, 2007, pp. 13-14). Knowledge is, then, the epicentre of class struggle.

The proponents argue that with the emergence of cognitive capitalism as the hegemonic form of labour, the role of knowledge production is being appropriated by workers, and capitalists are therefore required to devise new mechanisms of class struggle, e.g. intellectual property rights, to continue to appropriate surplus products, although in a different form to surplus value. ${ }^{184}$

This, then, raises the question of how to define surplus and the extent of the new type of exploitation. Dispensing with the value dimension, cognitive capitalism theorists face a daunting task: they must either discard the need for an economic theory given the alleged immeasurability of cognitive labours, or develop a new value theory on a par with Marx's value theory, essentially a social theory in the

to which the general intellect was already 'diffused' at the time of the industrial revolution, that is, not monopolised by a small group of scientific-technological experts.

183 Caffentzis (2008) seeks to explain the relation between "the incommensurability tendency" and the LTRPF, but mistakenly equates the former with the transformation of commodity values into prices of production:

In the transformation of commodity values into prices of production the incommensurability thesis is preserved and finally made compatible with the falling rate of profit tendency. If the value-to-price-of-production transformation did not occur, the high organic composition industries would suffer from inadequate profit rates and would be unable to develop into a hegemonic presence in production. Indeed, the transformation makes it possible for there to be electricity-generating nuclear power plants that successfully realise an average rate of profit (on the basis of an enormous investment in fixed and circulating capital) even though the workers within them create a tiny fraction of the surplus value created by workers in a typical sweatshop. (pp. 63-64)

${ }^{184}$ As long as the relations between capital and labour are expressed through wage and profit, the new form of the division of labour is within capitalism (Monnier \& Vercellone, 2014, p. 62). 
form of an economic theory. In case of the former, the economic analysis of social reproduction would no longer be possible, which is not an option, given that CCT aspires to be an economic theory of contemporary capitalism. On the other hand, it looks, however, very unlikely that the latter can be achieved unless they manage to find a common element with which all things in the world can be brought into a single quantitative dimension, other than the concept of utility in neoclassical economics. In short, cognitive capitalism theory, with its rejection of the validity of Marx's value theory in contemporary capitalism, has no option but reverting back to an economics of use value.

However, unfortunately, they are caught in their own snare: with the prevalence of becoming common, everything is related to everything else, rendering the task of identifying factors contributing to a product and, therefore, developing a consistent and coherent theory of the formation of price, let alone value and price theory themselves, almost impossible. Considering the flourishing of publications related to cognitive capitalism, they seem to bypass all these difficulties by simply focusing on intellectual property rights and basic income (see the next chapter). But this should not be viewed as indicating that their theoretical adventure is successful. 


\section{Intellectual property rights and rent theory}

\subsection{Introduction}

Marshall (1920, Book V, Chapter IX) explains the difference between rent, quasi rent, and interest by way of supposing an imaginary meteoric stone which is "harder than diamonds" (V.IX.8). ${ }^{185}$ When this stone is used for the production of commodities requiring cutting of metal or stone, the productivity of labour is significantly higher than when using diamonds which is the second best production method in terms of productivity. Marshall considers three cases.

First, a few thousand stones fall from the sky and they are all picked up at once by a few people. They are so hard and not affected by wear and tear, so that they can be used an unlimited number of times for the production of commodities. The owners of the stones benefit from a permanent increase in productivity and producer surplus. Alternatively, they can loan the stones to other firms and charge as much as the reduced production cost per unit (rent).

Second, not all stones are recovered at once but "scattered over the surface of the earth on public ground, and that a laborious search might expect to be rewarded by finding one here and there" (V.IX.13). The stones are hard enough and use of them in production does not cause wear and tear as in the first case. Those who put efforts into searching for the stones and manage to recover some would see their productivities go up (as long as the expected cost reduction per unit is greater than the search cost per unit) although the increase in productivity will eventually be generalised once all firms make use of the stones. As in the first case, the stones can alternatively be obtained from existing owners (quasi rent).

Third, the stones are not hard enough and are soon destroyed once used in production. In addition, there is "an inexhaustible store" (V.IX.14) of these stones, so supply is unlimited and the price of the stones is kept constant (interest or normal profit). Given that the stones are better than diamonds, all competing firms have no choice but to use the stones unless the stones are too expensive. However, none of them would enjoy any competitive advantage by using the stones as everybody has access to this advanced technology.

185 See also Dooley (1991). 
Marshall uses this analogy to consider the effects of the presence of fixed cost and fixed supply on the price of a means of production. Without going into detail, however, suffice it to say that the stones in the three cases correspond to land, capital goods with a fixed supply in the short term and raw materials, and yield rent, quasi rent and interest (normal profit), respectively.

These three cases provide a neat framework to assess different types of benefit which knowledge can bring to its producer. First, as we have seen in Chapter 3, knowledge allows for the virtual multiplication of commodity-producing labour. A capitalist making use of better knowledge than the sectoral average realises an extra surplus value, and if imitation of knowledge is strictly prohibited, and thus the knowledge is monopolised, the extra surplus value is perpetuated as long as the knowledge is not rendered obsolete by new knowledge. The capitalist can also choose to license the knowledge to his competitors. He can charge a lump sum licence fee and/or a royalty fee (per unit) for the use of knowledge.

Second, in case it is permitted to produce similar knowledge (or knowledge with similar productivity effects as the original knowledge), the monopoly effect lasts for only a limited period of time. Extra surplus value vanishes as soon as the onceinnovative knowledge becomes generalised due either to imitation of the original knowledge within the sector or the end of temporary legal protection of knowledge. This does not mean that knowledge becomes readily available to everybody after a certain period of time. Followers should still invest time and effort to produce similar knowledge, and they may choose to obtain a licence from the original inventor instead and even to get consulting services to integrate knowledge with their production processes, given that knowledge cannot be perfectly codified and involves absorption costs (Foray, 2004, pp. 95-96). In any case, because the economic benefit from new, innovative knowledge can be significant, and such knowledge can sometimes be a source of huge competitive advantage, capitalists strive to produce knowledge. In addition, as knowledge becomes generalised eventually and can become rendered obsolete by new knowledge, leading capitalists also continue to innovate to strive to be ahead of competitors.

Third, knowledge is freely available. In this case, knowledge is considered a natural force such as air flow and solar energy which should be applied in the production process using "complementary assets" (Foray, 2004, p. 98) such as related technologies and workers with scientific and technological knowledge (e.g. wind power needs to be extracted from air flow and sunlight should be absorbed using 
solar panels to turn solar energy to useful energy). ${ }^{186}$ As is the case with natural forces, free knowledge is so prevalent that we do not usually notice its presence. For example, in most countries, electricity is taken for granted as much as sunlight. Of course, electricity is a commodity, but none pays for knowledge related to the generation of electricity and even its existence is rarely acknowledged.

This type of classification can go further. For example, knowledge can be either perfectly monopolised, with its imitation or diffusion being completely blocked through technical and/or legal means, or freely available. Knowledge can also either be readily usable once obtained or require significant adaptation and absorption efforts including education, training, and process alterations. ${ }^{187}$ Most knowledge probably sits between the two extremes both in terms of excludability and absorption cost. We may therefore classify all possible configurations into a number of categories, ${ }^{188}$ considering the three cases we have reviewed only as examples, and

186 "The properties of steam always existed. Its industrial usefulness is a new scientific discovery which the capitalist has appropriated. As a consequence of this scientific discovery, the productivity of labour and with it relative surplus value rose. In other words, the quantity of unpaid labour which the capitalist appropriated from a day's labour grew with the aid of steam. The difference between the productive power of steam and that of the soil is thus only that the one yields unpaid labour to the capitalist and the other to the landowner, who does not take it away from the worker, but from the capitalist. The capitalist is therefore so enthusiastic about this element "belonging to no one" (CW31, p. 278).

187 "Winter (1987) made a significant advance by recognising that knowledge, and hence corporate knowledge, is a more complex object than the simple dichotomy between codified and tacit suggests. He noted that for many purposes, what matters is the extent to which knowledge can be transferred or imitated. Accordingly, Winter (1987) developed a taxonomy whereby he distinguished among eight pairs of attributes of knowledge: articulable or tacit; teachable or unteachable; articulated or nonarticulated; observable or nonobservable; simple or complicated; system-independent or system-dependent; context-independent or contextdependent; monodisciplinary or transdisciplinary. The first element of each pair denotes forms of knowledge that make it easier to transfer across individuals or organizations, while the second makes transferability more difficult" (Arora et al., 2001, p. 96).

188 As Marshall (1920) says in the context of his imaginary stone parable, the difference between rent, quasi rent and interest (normal profit) is "only one of degree" (V.IX.21):

The difference [among the three cases] is fundamental, but it is only one of degree. Biology tends to show that the animal and vegetable kingdoms have a common origin. But yet there are fundamental differences between mammals and trees; while in a narrower sense the differences between an oak tree and an apple tree are fundamental; and so are in a still narrower sense those between an apple tree and a rose bush, though they are both classed as rosaceæ. Thus our central doctrine is that interest on free capital and quasi rent on an old investment of capital shade into one another gradually; even the rent of land being not a thing by itself, but the leading species of a large genus. 
attach an economic concept to each. For example, we may say knowledge yields monopoly rent in the first case and monopoly profit in the second case, the key difference between them being the presence of legal protections. And by doing so, we can internalise knowledge into the framework of existing theories, with the study of the specificity of knowledge relegated to relatively micro level analyses.

However, this type of static and technical/legal understanding of rent (or monopoly profit) is not sufficient in the sense that it cannot go beyond stating that (a portion of) surplus profit is appropriated by some people for some technical and legal reasons. In addition, it applies across all sectors of the economy, necessarily abstracting from qualitative differences between sectors in terms of use of knowledge and reliance on intellectual property rights.

It is against this background that we engage once more with the Controversy, both the monopoly price approach and the cost approach, and with cognitive capitalism theory, focusing on their interpretations of Marx's theory of rent and the ways they bring rent and intellectual property rights into the analysis. But Section 2 begins by reviewing Marx's theory of rent, drawing on Ben Fine's contribution to the development of Marxist theory of rent, so that we can have a solid foundation for assessment of these theories. In short, there is no general theory of rent in Marx. Although Marx's analysis of ground rent in Part 6 of the third volume of Capital might be useful for developing a theory of knowledge and of intellectual property rights in particular, imposing Marx's category of ground rent on knowledge, more specifically on licence and royalty fees, should be avoided because this blurs the essential differences between landed property and intellectual property despite (superficial) similarities between them. In the Controversy, which is discussed in Section 3, one of the fiercely debated topics is whether the huge difference between the price and (individual) value of information commodities, in the presence of intellectual property rights, should be viewed as (monopoly) rent or not, which developed into a debate on the purpose and scope of Marx's theory of ground rent. In Section 4, we criticise CCT's claim that profit is increasingly becoming rent in contemporary cognitive capitalism. We demonstrate that this is based on CCT's flawed interpretation of Marx's value theory, especially the concept of profit. More fundamentally, it is not only that CCT is becoming a use value theory, as suggested in Chapter 4, but the distribution theory of CCT is on the basis of factor contribution, which is apparent in its reliance on the concept of externalities. Section 5 concludes the chapter. 


\subsection{Marx's theory of ground rent ${ }^{189}$}

Whilst the existence of landed property as such is the necessary condition for appropriating a portion of surplus value as ground rent, Marx, in his analysis of ground rent, is concerned specifically with "the form of landed property corresponding to the capitalist mode of production" (CIII, p. 1025). This capitalist form of landed property was established by divorcing "all landed property from capital and labour", which is, in turn, the result of "the constant tendency and law of development of the capitalist mode of production ... to transform labour into wagelabour and the means of production into capital". ${ }^{190}$ The essence of the historical specificity of the capitalist form of landed property is that "the landowner can behave in relation to the land just as any commodity owner can with his commodities" (p. 753). In other words, "land as a condition of labour [is completely separated] from landed property and the landlord”. (p. 755). ${ }^{191}$ On this basis, Marx's purpose of analysing this specific form of landed property is "to consider all the specific relationships of production and exchange that arise from the investment of capital on the land [emphasis added]". More specifically, Marx is interested in demonstrating that this form of landed property, although it is the precondition for, and the result of, the capitalist mode of production itself, obstructs the development of "a rational agriculture" (p. 757), i.e. the capitalist form of agriculture. In this respect, Marx's theory of ground rent is both an application of his value theory and a theory of agriculture in capitalism. ${ }^{192}$

189 This section draws on Fine $(1979,1980 b, 1982 a, 1982 b, 1990,1994)$ and Fine and SaadFilho (2010, Chapter 13). See also Swyngedouw (2010).

190 Similarly, Marx says, "The form of landed property with which we are dealing is a specific historical form [emphasis added], a form transformed by the intervention of capital and the capitalist mode of production" (CIII, p. 751). This form is historically specific in the sense that it "presupposes the expropriation of the rural workers from the soil and their subjection to a capitalist who purses agriculture for the sake of profit".

${ }^{191}$ Given the historical specificity of the object of study, "there is therefore no general theory of rent, nor can the conclusions reached for one instance in which a rent relation exists be automatically applied to others" (Fine, 1979, p. 248).

192 Fine and Saad-Filho (2010, p. 134) say:

For Marx, private ownership of land acts as an obstacle to capital accumulation, because the landowners capture part of the surplus value produced in the economy. To a limited extent the same is true of orthodox rent theory, whether Ricardian or neoclassical. ... In neoclassical theory, the agricultural producers pay rent because of a combination of 
Landed property intervenes in the formation of value and price of production and has impacts on how capitalist investment into agriculture is organised. First, landed property affects the determination of the value of agricultural commodities in the presence of productivity differences arising from fertility differences (differential rent I). Productivity differences exist in all other sectors of the economy, which is a normal state in Marx's understanding of competition. A market value is necessarily formed out of inter-sectoral competition centred on productivity, despite, and because of, productivity differences. Consequently, some individual capitals realise extra surplus value, and some realise only a part of (normal) surplus value, which drives all individual capitals to increase their productivities: to continue to realise extra surplus value in case of the leaders; and either to realise the whole surplus value produced or to survive in case of the followers. Hence, the tendency to productivity equalisation and the counter-tendency to productivity differentiation co-exist within a sector. Productivity differences arising from fertility differences, however, cannot be equalised nor, then, differentiated, and therefore there is no incentive for capital investment on the worst land unless the market value is set on the basis of the individual value of commodities produced on the worst land. In addition, that the worst land needs to be cultivated implies that either additional investments into the lands currently in use is not possible for economic and/or technical reasons due (partly) to landed property (e.g. restrictions to additional investments into existing lands) or additional investments into existing lands are not sufficient to produce as many commodities as the social need. ${ }^{193}$ Given that the owners of lands with higher fertilities demand to be compensated and there is no option but to cultivate the new land with the worst fertility, the market value is determined by the production conditions on the worst land. ${ }^{194}$

private ownership and natural or technical constrains - for example, a shortage of land, either in overall supply or in the supply of land of better quality or location.

By contrast:

Marx's starting point is the social conditions under which part of the surplus value is appropriated by the landowners in the form of rent. In other words, the theory of rent derives from the relationship between landed property and capitalist production, and these are, of necessity, historically specific, rather than technically given. (Fine \& SaadFilho, 2010, pp. 134-135)

193 "It is clear from the need to take new land into cultivation that the additional capital investments which yield no rent do not satisfy the demand" (CIII, p. 888).

194 Hence, the following does not apply to the determination of the market value of agricultural commodities: 
Second, landed property demotivates capital investments into the lands currently in use, and thereby obstructs the development of the agricultural industry as a whole (differential rent II). As in other industries, productivity increases in agriculture must go hand in hand with concentration and centralisation. Landowners, however, who are not necessarily interested in the progress of industry and its benefits, not least cheaper agricultural products and the production of relative surplus value, intervene and appropriate surplus profit arising from further capital investments on existing lands, regardless of the movement of prices of production in which these result, see Chapters 41-43 of Volume 3 of Capital. In other words, "they put away in their own private purses the result of a social development achieved without their participation ... this is equally one of the greatest obstacles to a rational agriculture" (CIII, p. 757). Capitalists invest in technological development and knowledge production to realise surplus profit. When this incentive does not exist, due to the appropriation of surplus profit by landowners, there is no point in bothering with innovation: "The farmer avoids all improvements and outlays which are not expected to give their full return during the duration of his lease". ${ }^{195}$ Consequently, the value of agricultural products is higher than it would have been without landed property. However, in case of this second form of differential rent, not all surplus profits arising from productivity improvements are necessarily appropriated by landowners due to the "change in form that involves the transfer of surplus profits

It is of no assistance to say that the sale of commodities produced under the worst conditions shows that these are required to meet the demand. If the price were higher than the mean market value in the case assumed [in other words, if the worst conditions determine the market value], the demand would be less. At a given price, a species of commodity can only take up a certain area of the market; this area remains the same through changes in price only if the higher price coincides with a smaller quantity of commodities and a lower price with a greater quantity. If the demand is so strong, however, that it does not contract when price is determined by the value of commodities produced in the worst conditions, then it is these that determine the market value. This is possible only if demand rises above the usual level, or supply falls below this. (CIII, pp. 279-280)

195 This is further exacerbated by the fact that:

As soon as the lease stipulated in the contract has expired - and this is one of the reasons why the landowner seeks to shorten the term of the lease to a minimum, as capitalist production develops - the improvements made to the land fall to the landowner as his property, as an inseparable accident of the substance, the land. (CIII, p. 757)

In addition,

The overwhelming portion of the land used for building in England that is not sold as freehold is leased by the landlords for ninety-nine years, or for a shorter time if possible. When this period has expired, the buildings fall to the landlord, together with the land itself. (p. 758) 
from the capitalist farmer to the proprietor of the land" (CIII, p. 813), which involves class struggle between landowners and capitalist farmers. In other words, in the case of differential rent II, "the limits of this transformation [of surplus profit into ground rent] are both narrower and unstable [than in differential rent I]”. Marx says:

The rent ... is fixed when the farms are leased, and the subsequent surplus profits arising from the successive investments of capital accrue to the farmer as long as the tenancy contract lasts. Hence the farmers' battle for long tenancies, and conversely the increase in 'tenancies at will', i.e. at a year's notice, given the super power of the landlord.

In sum, as Fine (1979, p. 253) concludes:

Whilst agriculture may not resist absolutely the capitalist form of development it exhibits a slow pace of progress relative to industry. This is perhaps the most important conclusion to be drawn from Marx's theory of DRII, its preoccupation with obstacles to the development of capital accumulation rather than the static formulation of the distribution of surplus value in the form of rent.

Third, landed property sets a barrier to inter-sectoral capital movement into agriculture (absolute rent). ${ }^{196}$ Due to the restrictions placed upon capital investments into existing lands (DRII) by landed property, the development of agriculture is relatively slow, with a lower organic composition of capital than in other sectors. If there were no barrier to capital inflow, the market prices would go down to the level which would give capitalists only average profit. However, landed property does not allow free use of land, even those with worst fertility:

Assuming ... that demand requires the taking up of new land which is, say, less fertile than that previously cultivated, will the owner of this land lease it for nothing just because the market price of its product has risen high enough for capital investment to pay the farmer the price of production and thus yield him the customary profit? In no way. The capital investment must yield him a rent. He leases only when a lease-price can be paid. (CIII, p. 891)

This does not mean that a landowner can charge as much rent as he wants for a new lease, which is then passed on to the buyers:

${ }^{196}$ Absolute rent is differentiated from differential rents in that in case of the former, "landed property has produced this rent itself [emphasis removed]" (CIII, 889). 
It is limited by additional capital investments on the old leaseholds [emphasis added], by competition from foreign agricultural products (assuming their free import), by competition between landed proprietors and finally by the need of the consumers and their ability to pay. (CIII, p. 892)

With respect to the first limit, "additional capital investments on the old leaseholds", Fine (1979, pp. 262-263) shows that assuming additional capital investments involve an increase in OCC at the same rate as in other sectors, absolute rent cannot be greater than the difference between the value and (potential) price of production of agricultural products. Marx also makes it clear that value limits absolute rent:197

Even though landed property can drive the price of agricultural products above their price of production, it does not depend on this, but rather on the general state of the market, how far the market price rises above the price of production and towards the value [emphasis added], and to what extent, therefore, the surplus value produced over and above the given average profit in agriculture is either transformed into rent or goes into the general equalisation of surplus value that settles the average profit. (CIII, p. 898)

In sum, Marx's theory of agricultural rent reveals that the capitalist form of landed property, especially "large-scale landed property" (p. 948) in England (at least in Marx's time), obstructs the development of large-scale agriculture, keeps the price of agricultural products at a higher level relative to other industries and affects (intensive and extensive) capitalist investments into agriculture. Necessarily, its scope is limited to agriculture, but Marx extends his theory of ground rent by applying it to buildings and mines. Whilst he considers that rent of buildings and rent of mines are different expressions of the same ground rent, ${ }^{198}$ he is interested more in specifics of each industry than in imposing existing categories on new industries. For example, he provides four observations specific to rent of buildings:

This rent is characterised first by the preponderant influence that location exerts here on the differential rent (very important, for example, in the case of vineyards, and building land in big towns); secondly, by the palpable and

\footnotetext{
197 In this respect, all three rent categories are value-determined, not value-determining. 198 "Wherever rent [emphasis added] exists, differential rent always appears and always follows the same laws as it does in agriculture. Wherever natural forces can be monopolised and give the industrialist who makes use of them a surplus profit, whether a waterfall, a rich mine, fishing grounds or a well-situated building site [emphasis added], the person indicated as the owner of these natural objects, by virtue of his title to a portion of the earth, seizes this surplus profit from the functioning capital in the form of rent [emphasis added]" (CIII, p. 908).
} 
complete passivity displayed by the owner, whose activity consists simply in exploiting advances in social development ... towards which he does not contribute and in which he risks nothing, unlike the industrial capitalist; finally, by the prevalence of a monopoly price in many cases, and particularly the most shameless exploitation of poverty ... the tremendous power this gives landed property when it is combined together with industrial capital in the same hands enables capital practically to exclude workers engaged in a struggle over wages from the very earth itself as their habitat. (CIII, p. 908)

Fine applies Marx's rent theory to the UK coal industry (Fine, 1990), the South African diamond industry and the US oil industry (Fine, 1994), see also Bina (2006) on the oil industry. Especially, in his analysis of the UK coal industry, Fine takes up the question of whether a royalty is a rent. For him as well as for Marx, rent is a category in which "landed property is economically realised, valorised" (CIII, 756), and therefore the specifics of each form of landed property should be specified and its impact on capital accumulation studied:

A direct response must be given to the issue of whether a royalty is a rent or not. The answer is both yes and no! Yes, in so far as each represents the revenue that accrues to the landlord in return for capital's access to the land for mining or farming. But also no, in so far as those conditions of access are different and must be specified in each case [emphasis added]. (Fine, 1990, p. 50)

Similarly:

For agriculture, it is seen to have the effect of obstructing intensive cultivation of the land. For coal mining we have tried to show that the existence of private royalties obstructed nationalisation and mechanisation of the British industry in the interwar period. Thus, a prerequisite for the development of a theory of mining and the revenues that it generates is an examination of the empirical form of landed property [emphasis added] that it confronts. Thus, the question of whether a royalty is a rent or not is a misleading one except in so far as it raises the questions of the access of capital to mining as opposed to agriculture. Both royalty and rent are derived from something else, the particular intervention [emphasis added] that landed property makes in relation to the economy and its development. (Fine, 1982b, p. 349)

Marx anticipated that the limited purpose and scope of his rent theory is going to be forgotten. Whilst ground rent is historically specific because its substance, the capitalist form of landed property, is historically specific, "the common character of the different forms of rent ... leads people to overlook the distinctions" (CIII, p. 772). The fact that ground rent is a form of surplus value often obscures an equally critical aspect of ground rent, that it is appropriated by landowners from the surplus profit 
realised by the capitalist farmers, in the presence of the capitalist form of landed property. And for this reason, the fundamental difference between neoclassical theory of rent and Marx's theory of ground rent is often neglected, and the latter is deployed carelessly, without specifying the property relations which it is supposed to represent, as we will see in the next two sections.

\subsection{The 'Controversy' and intellectual property rights}

Given the emphasis placed upon the narrow, but specific, scope and purpose of Marx's rent theory in the previous section, it is a foregone conclusion that Marx's theory of rent cannot be applied directly to an analysis of intellectual property rights. Nor can Marx's three categories of rent be transplanted into the realm of intellectual property rights. More fundamentally, ascribing the existence of a systematic mechanism by which a portion of surplus profit is appropriated to a category, rent or not, is not of much theoretical significance unless it is accompanied by a historically specific analysis of the property relations in question. Unfortunately, in the Controversy, the discussion about rent has been limited to whether the price of information commodities contains rent or not in the presence of intellectual property rights. Whilst this point has been fiercely debated, the specifics of intellectual property rights have not drawn much attention, other than their being the legal basis of appropriating surplus profit.

\section{Intellectual property rights and monopoly price (the monopoly price approach)}

In the monopoly price approach, the high price of information commodities is considered a monopoly price. The proponents argue that software should be distributed free of charge because the individual value of information (commodity) copies is close to zero and anyone can create a copy instantly. In other words, for them, software, by its nature, cannot be commodified; it is only through intellectual property rights that a software application becomes a commodity with a much higher price than its social value (zero) attached to it. According to Chae (2004a, p. 95), “the prices required for the normal reproduction' of commercial software products of Microsoft and [other software companies] are sustained only though state violence [sic] such as laws, police and judiciaries". The fact that software can be commodified only this way shows:

Obviously private property and the capitalist relations of production based on it, and only these, are the only barrier to the unfettered development of information commodities and their 'normal reproduction'. Therefore, this is 
also a strong piece of evidence that private property and the capitalist relations of production have decisively become the fetter of the development of the material productive powers of the society. (Chae, 2004a, p. 97)

If intellectual property rights were abolished, monopoly price would be too, and the price of information commodities would be determined by value - zero. Not surprisingly, this approach is critical of the notion of virtual multiplication. S. Kang (2010, p. 144) says, "the notion of intensified [multiplied] labour can be attached to any commodity which has monopoly price and realise monopoly profit ex post, and thus results in the justification [emphasis added] of monopoly price and monopoly profit". This conflates different levels of abstraction. The price of a commodity can be monopoly price - which is determined without respect to value - regardless of virtual multiplication. In addition, whereas virtual multiplication is concerned with the determination of value, monopoly price is a more complex concept than value:

A genuine monopoly price ... [is] determined neither by the price of production of the commodities nor by their value, but rather by the demand of the purchasers and their ability to pay, consideration of which therefore belongs to the theory of competition, where the actual movement of market prices is investigated. (CIII, p. 898)

Furthermore, virtual multiplication operates at a more abstract level than intellectual property rights and without reference to the presence, as well as the content, of intellectual property rights. Intellectual property rights need to be brought into the analysis in a way that is based on the process of virtual multiplication and reproduces it at more concrete and complex levels of abstraction.

As we have seen in Chapter 3, the monopoly price approach draws a clear distinction between knowledge (labour) and commodity(-producing labour). But it is also seen that knowledge does not take part in the determination of the value of commodities. Also important is that the monopoly price approach implicitly equates the role of knowledge with the effect of intellectual property rights. In other words, knowledge allows for a monopoly price and, therefore, has an economic role, but only when it is protected by intellectual property rights. If knowledge were not protected by intellectual property rights, monopoly pricing would not be possible, and knowledge would not have any role in the determination of price. Likewise, if software were not protected by legal means, consumers would not pay for it because they would be able to get copies free of charge. ${ }^{199}$ However, the role of knowledge does not

199 Software is produced and distributed in install package form that is vulnerable to illegal 
necessarily depend on intellectual property rights. Take the example of the CocaCola formula, the recipe of Coca-Cola. Only a few employees have access to it as it is a very important trade secret for the company. Access to this highly valuable knowledge is therefore heavily guarded, but not through legal means only. Furthermore, as mentioned earlier, even if a company has acquired a codified trade secret of one of its competitors, it is often the case that such knowledge is not properly usable without an understanding of the context under which the knowledge is produced and used. This means that acquisition of codified knowledge such as a blueprint or design does not guarantee full reproduction of the original knowledge. Even without intellectual property rights, economic advantages arising from knowledge (for individual capitals) can persist for some time and so does its role in value production.

The view of the monopoly price approach on the role of intellectual property rights has a far-reaching implication. This is precisely because intellectual property rights apply not only to information commodities but also to other types of commodities, including semiconductors, automobiles, drugs, books, music, etc. Suppose that a semiconductor company has produced a unique design of the CPU that minimises the use of electricity. From the point of view of the monopoly price approach: the social value of semiconductors produced by this company would be determined by the direct (commodity-producing) labour time and the value transferred from the means of production, but would have nothing to do with the unique design of the CPU; if CPUs (processors) were sold at the price determined by their (individual) value, which would be similar to, if not the same as, their social value, this company would suffer a loss because it would be unable to recoup the initial investment put into the design production; but fortunately, thanks to the protection of the design by

copying, not because it is the only feasible technical method, but because software is protected by intellectual property rights. The presumption is that copying is easy, but illegal, so an efficient form of distribution, i.e. install package, could be adopted. If intellectual property rights had not been available, more advanced copy protection technologies would have been applied to software install packages, or else the architecture of computing devices would have evolved into a significantly closed one. Put differently, the prevalent method of software production and distribution is closely related to intellectual property rights. It is plausible to say that the open architecture of the Internet and computing devices depends on intellectual property rights. Considering that the open source movement, which is considered an alternative to information commodities, presupposes the open architecture of the Internet and computing devices, we may say that information commodities and the open source movement are two sides of the same coin. 
intellectual property rights, the company could sell the CPUs at a monopoly price, higher than their social value. Here is another, a more concrete example. According to IHS Technology (2013), the production of an iPad Air (16GB Wi-Fi model) costs $\$ 274$, out of which $\$ 5$ is manufacturing cost and \$269 is BoM (bill of materials) including but not limited to a Nand flash memory, a DRAM, a touch screen, etc., whereas its market price is \$499. For companies specialised in manufacturing, creating an almost exact copycat of this device is not very difficult. Manufacturing cost may be (significantly) higher, but it accounts only for $5 \%$ of the production cost per unit in any case. Then, for the proponents of the monopoly price approach, the high price of this device (\$499), about twice as high as its true social value (\$269) in their view, would be a monopoly price which can be sustained only because of intellectual property rights. If Apple sold this device at $\$ 269$, they would be suffering a huge loss, and would the company have developed the essential innovative technologies and designs for the iPad in the first place?

Given the prevalence of intellectual property rights across sectors, then, commodities of any kind, produced based on knowledge protected by intellectual property rights, would be sold at a monopoly price if we take the view of the monopoly price approach. Consequently, the monopoly price approach to information commodities is the monopoly price approach to commodities in general.

The implication of this conclusion is significant. Value is the category that expresses the fundamental social relations in capitalism, the class relations between capital and labour. To say value determines price is to say the same thing as the capitallabour relations (essence) determine the economic relations (form). If the commodity price were typically a monopoly price, the capital-labour relation would not have the primacy in regulating and determining economic relations of capitalism. New social relations centred on intellectual property rights would replace the class relations as the essential social relations in capitalism, see Section 4. S. Kang (2008a, p. 19) argues that monopoly price theory is based on, and consistent with, value theory, but the category of monopoly price is for exceptional circumstances only, as in Marx's example of "wine which is of quite exceptional quality but can be produced only in a relatively small quantity" (CIII, p. 910), in which monopoly pricing involves value transfer from buyer to seller. Conversely, if monopoly price became prevalent, so would value transfer, which is determined by factors that have nothing to do with value. In such an economy, where value does not determine price, it would have no real or analytical significance except in 
determining the portion of the monopoly price contributed by workers.

In sum, despite the intention of the monopoly price approach to defend and promote value theory, its core arguments end up negating the validity of value theory and privileges instead the role of intellectual property rights in contemporary capitalism, not unlike, in some respects, CCT.

\section{Intellectual property rights and rent (the cost approach)}

The category of (ground) rent has drawn much interest among the cost approach theorists. ${ }^{200}$ According to N. Kang (2002, p. 111), it is typical for the price of information commodities to include extra surplus value, rent and monopoly profit. This means that, although the value of information commodities is seen to be higher than zero, its price is not necessarily determined by value. N. Kang's view is that commodity price is a monopoly price when one company dominates a market for whatever reasons (e.g. natural monopoly, intellectual property rights, etc.). In addition, rent is seen to accrue "when the source of surplus profit is neither capital nor labour, and not shared by all capitalists" (N. Kang, 2007, p. 191). According to this definition, knowledge and intellectual property rights are not in themselves a source of rent. Suppose that an advanced production technology is produced by an individual capitalist. The productivity of commodity-producing labour would rise, and a surplus profit (or extra surplus value) would accrue to the capitalist. This surplus profit, however, would not be transformed into rent because it would have been produced by workers under the direction of capitalists. As Marshall's distinction between rent and quasi rent reflects the distinction between naturallygiven factors and produced factors, for N. Kang, rent is for factors of production which are freely given or non-replicable. It follows that whereas the extent of competition determines monopoly price or otherwise, reproducibility determines rent or its absence:

A surplus profit arising from a patent is a monopoly profit due to a monopoly being established by legal means, but it is not a [monopoly] rent because [the

200 Similarly, many commentators have argued that productivity increases attributed to the monopoly of means of production or knowledge or natural conditions can be analysed on the basis of Marx's theory of ground rent. For example, Harvey (2001, p. 395) says:

All rent is based on the monopoly power of private owners of certain portions of the globe. Monopoly rent arises because social actors can realise an enhanced income stream over an extended time by virtue of their exclusive control over some directly or indirectly tradable item which is in some crucial respects unique and non-replicable. 
patent] is replicable. On the contrary, [surplus profits] from Picasso's drawings are rents. For they are not replicable. (N. Kang, 2007, p. 192)

Somewhat contradictorily, however, N. Kang elsewhere argues that intellectual property rights are a source of rent, which suggests that replicability can be understood in not only technical but also legal terms. He says:

Intellectual property rights are [a source of] a legal monopoly. Replication of ... knowledge ... costs nothing. Therefore, the value of knowledge is zero and its price a pure monopoly price. However, [knowledge] is inherently unique in a given period of time ... and cannot be replicated by other capitalists. During this period, then, [the price of] knowledge has the characteristic of rent [emphasis added]. (N. Kang, 2005, p. 265)

On this basis, N. Kang suggests that the network effect which is often associated with information commodities is a source of rent. For example, the use value of a copy of Microsoft Word is determined not only by its features but also by the number of users, because the more people that use the product, the easier it becomes for users to share documents. Suppose that Microsoft Word has the same use value as Apple Pages in terms of features and functionality, but due to its larger user base and larger network effect than Apple Pages, it is more useful than Apple Pages. For this reason, Microsoft Word would have a higher social value than Apple Pages. N. Kang argues that the excess is a differential rent, because the network effect (or network externality) is created by neither capital nor labour. In addition, if the network effect is so large as to establish a natural monopoly, whether through intellectual property rights or not, the price of Microsoft Word copies would be a monopoly price; Microsoft's surplus profit would be transformed into a monopoly profit (because of the monopoly) and, then, into a monopoly rent (because of the network effect being non-replicable). ${ }^{201}$ From this point of view, the price of an information commodity consists of two parts. One part is determined by value (or price of production), which may or may not include surplus profit, and, in turn, may or may not be transformed into (differential and/or absolute) rent. The other part, which may be zero or higher (depending on the extent of competition), is determined by purchasers' purchasing power, which may or may not be transformed into monopoly rent (depending on replicability). However, this way of classification applies to any commodity, and does not add anything new to the understanding of

${ }^{201}$ For similar views from a slightly different perspective, see Pasquinelli (2009) and Fuchs and Sevignani (2013) which discuss whether Google and Facebook are exploiting their customers. The presumption is that users' activities constitute labour. See also Ross (2013). 
information commodities.

Whilst Rieu (2005) agrees with N. Kang in general, he argues that rent accrues only if property rights are granted to the factors that are the source of surplus profit. From this point of view, the network effect is a source of surplus profit, which may be transformed into a differential rent depending on whether exclusivity is given or not. He says, "intellectual property rights grant legal and institutional property rights to factors that cannot be appropriated as the productive power of capital, and thus make them not accessible to all capitalists" (Rieu, 2005, p. 176). ${ }^{202}$ C.-O. Lee (2005, p. 162) argues that the high price of information commodities can better be explained by absolute rent. ${ }^{203}$

The interpretations of Marx's theory of (ground) rent implicit in the cost approach and their application to information commodities have been heavily criticised by the proponents of the monopoly price approach. The gist of their critique is that Marx's rent theory is stretched too far in a careless manner to suit the convenience of its wider application. As S. Kang (2009, p. 147) rightly points out, such extension of the scope of theory leads to Marx's category of (ground) rent becoming "degenerated into economic rent of mainstream economics" in which land is no longer distinguished from the other factors of production, and we join this critique on the basis of our discussion of Marx's theory of (ground) rent in the previous section. But it would be worth adding a few more points. First, for Marx, rent presupposes a class of landowners who have the power to block free capitalist investment into land, and this power enables them to appropriate surplus profit as rent. No such class is identified by the proponents of the cost approach. Second, related to the first point,

${ }^{202}$ Although there are diverse views on rent within the cost approach, not all of which can be reviewed here, none of them denies that rent is an important category for the analysis of the network effect and information commodities. For example, Jo (2008, Section 3, para. 3) says, "I think N. Kang's argument that the category of differential rent does not have to be limited to agriculture but can be applied to what is not created by capital (and labour controlled by capital) is correct. Special capabilities that only a limited number of persons have are a prominent example. If value is determined by socially necessary labour time as Marx suggests, such a person would create more value (e.g. twice) even if the intensity of labour is the same. At the level of Volume 3 of Capital, where not only the competition between capitalists but also the competition between workers is considered, the excess appears as different wage levels, which is hard to explain. But we can call it differential rent [emphasis added]".

203 This assumes the existence of a single information commodity sector, which we criticised in Chapter 3. 
it is wrong to suggest that replicability determines rent or its absence. Rent expresses historically specific social relations between the landowner class and the capitalist class, and can never be reduced to the replicability of factors of production. Third, whilst surplus profit is a category that is more abstract than (ground) rent for Marx, rent as a classificatory concept, depending on replicability, exists side-by-side with surplus profit. In sum, the historical specificity of Marx's rent theory is lost - "euthanasia of rent theory" (Fine, 1982a, p. 99) - as in neoclassical economics.

Both the cost and the monopoly price approaches are flawed in that they fail to incorporate the role of knowledge into value theory at abstract levels: whereas knowledge is equated with the means of production in the former, its role in value production is neglected in the latter. They short-circuit the social processes of virtual multiplication of labour and instead draw hasty conclusions about the value of information commodities. Analysis at more concrete and complex levels, especially in the presence of intellectual property rights, is also problematic. The monopoly price approach privileges the role of intellectual property rights in the formation of the monopoly price of information commodities. Given the prevalence of intellectual property rights, it implicitly follows that the commodity price is typically the monopoly price. This is at odds with Marx's value theory in which value determines price and monopoly price is only exceptional. The cost approach imposes Marx's theory of (ground) rent on intellectual property rights. Although rent is an economic category that expresses social relations around landed property, the cost approach detaches the economic form from the underlying historically specific relations and attaches it to other social relations without sufficiently analysing the latter.

\subsection{Cognitive capitalism theory, intellectual property rights and rent}

This section is concerned with one of the key arguments of CCT, in general, and of Carlo Vercellone, in particular, that the distinction between profit and rent is collapsing due to intellectual property rights. As we have seen in Chapter 4, CCT has yet to develop a theory of (cognitive) value and price, and for this reason, there is as yet no economic theory with which the appropriation of surplus products in cognitive capitalism can be assessed. CCT's view is that capital should not be allowed to appropriate any surplus product. For capital does not contribute to the production of real wealth at all in cognitive capitalism. Then, as long as capital does 
appropriate (a portion of) surplus products by way of intellectual property rights, lack of a coherent value theory is only of a secondary concern to its proponents. ${ }^{204}$ Intellectual property rights are viewed primarily from a political point of view, as the main terrain of class struggle in cognitive capitalism where capital and labour stand as two independent classes.

\section{Intellectual property rights and the political appropriation of rent}

It is argued that the category of profit disappears in cognitive capitalism. According to Vercellone (2010, p. 97), there are two conditions of existence for profit in industrial capitalism. The first concerns the role of capital in the production process. Capitalists manage, supervise and organise the labour process, and this shows "correspondence between the figure of the capitalist and that of the entrepreneur". ${ }^{205}$ The second condition is related to reinvesting surplus value or profit for expanded accumulation of capital: "Profit would play a positive role in the development of productive forces and in the struggle against scarcity". It is argued that these two conditions are only "the transitory product of an epoch of capitalism, of industrial capitalism" (p. 98), fully realised "in the golden age of Fordist growth, during which both the logic of real subsumption of labour to capital and mass production found their expression". This is different from Marx's explanation of the source of profit. Whereas, for Vercellone, profit is the remuneration of capital and wage "the remuneration of productive labour" (p. 93), for Marx, capitalists accrue

204 "The common has come into clearer view in recent years in large part thanks to the work not of economics but of lawyers and legal theorists. Debates about intellectual property make it impossible, in fact, not to focus on the common and its interaction with the public" (Hardt \& Negri, 2009, p. 281).

205 Vercellone (2010, p. 99) argues that Marx, in Volume 3 of Capital, "introduces a conceptual distinction between two determinations of capital, namely ownership and function (performing capital), and links this distinction back to that between interest as revenue from capital ownership and the active profit of the entrepreneur who manages production" to the extent that "Marx questions the terms of the opposition between profit and rent as well as the limits of a definition of rent reduced to ground rent only". He continues:

According to Marx, capital ownership was following a similar path to that of ground rent in the shift from feudalism to capitalism: it is to say that it was becoming external in relation to the sphere of production and, like land ownership, capital ownership was extracting surplus value whilst no longer exercising any function in the organisation of labour. (p. 100)

Vercellone calls this interpretation of Volume 3 of Capital "theory of capital-rent" (p. 101). 
profit not from any roles they play in the production process, but from surplus labour time performed by workers who must sell their labour powers and work for capitalists to make a living due to the monopoly of means of production by capitalists; capitalists add nothing to the surplus value they exploit from the workers. Likewise, workers earn wages not because they perform productive labour but because they sell their labour powers as commodities. Labour, be it productive or unproductive, is only the effect of the consumption of labour power in the production process. Vercellone's understanding of profit and wage as the remuneration of factor contributions is completely at odds with Marx's view and instead has more affinity with mainstream economic theory.

Based on this false understanding of the source of profit, CCT constructs a contrasting view on cognitive capitalism as follows: in cognitive capitalism, the role of organisation, co-operation, coordination of production process is being appropriated by workers; capitalists are increasingly detached from the task of management, supervision and organisation of the labour process; consequently, they do not contribute to the production of final commodities to the same extent as in the previous stage of capitalism. As a result, it is argued that profit is losing its basis because where there is no contribution, there should be no remuneration.

Appropriation of surplus products is, then, achieved by way of the expansion of the sphere of market "through a progressive colonisation of the common goods of knowledge and life by means of strengthening Intellectual Property Rights" (Vercellone, 2008a, Section II.2). ${ }^{206}$ As Dyer-Witheford (2005, p. 74) puts it, cognitive capitalism is "the commercial appropriation of general intellect". Whilst the presumption is that knowledge created by workers and non-workers should be freely available due to its nature of being non-rival, capitalists impose intellectual property rights from outside, so that they can monopolise the use of knowledge and thus appropriate monopoly rent on the basis of (artificially) limited use of knowledge. It is seen as a new enclosure movement or primitive (knowledge) accumulation, around which the antagonism between capital and labour is being reconfigured. In short, rent is seen to become the central category in cognitive

\footnotetext{
${ }^{206}$ Similarly, Vecrellone (2005, p. 10) says, "The solution sought by capital is now to establish strict intellectual property rights aiming at capturing monopoly rents”. Intellectual property rights are also seen to obstruct the progress of industry: "The new relations of ownership of knowledge obstruct the progress of knowledge through the creation of an artificial scarcity of resources" (Vercellone, 2007, p. 34).
} 
capitalism:

Because as the law of value-labour time is in crisis and the cooperation of labour appears to become increasingly autonomous from the managerial functions of capital, the very frontiers between rent and profit begin to disintegrate. (Vercellone, 2008a, para. 10)

The current transformation of capitalism is characterised by a full-fledged comeback and proliferation of forms of rent parallel to a complete change in the relationship between wages, rent and profit. (Vercellone, 2010, p. 85)

Capital-labour antagonism increasingly takes the form of antagonism between the institutions of the common as the foundations of knowledge-based economy and the logic of expropriation of cognitive capitalism that develops itself under the form of rent-a rent whereof finance is only one of the expressions even if it often synthesises all of them through the transformation of fictitious commodities into fictitious capital. (p. 92)

Accordingly, the proponents of CCT argue that class struggle in cognitive capitalism increasingly takes the form of distributional struggle, where no pre-existing economic rules apply due to immeasurability. Cognitive capitalism is pictured as a stage of capitalism where capital tries to "accentuate and exercise direct [emphasis added] control over places or people with knowledge or potential of technical creativity" (Corsani et al., 2001, p. 10). The term cognitive capitalism, then, captures "the current issues of conflict related to the redefinition of intellectual and immaterial property rights and what we call new battle fences (enclosures)" (Moulier-Boutang, 2002, para. 1).207

The conflict is a pure clash between capitalists and workers over the division of surplus products between capitalists and workers. Hardt and Negri argue that exploitation in the new stage of capitalism takes directly political and social forms due to the lack of economic forms in cognitive capitalism through which class relations can be expressed:208

207 According to Monnier and Vercellone (2014, p. 62), “the term 'capitalism' [in cognitive capitalism] indicates the permanence of its fundamental laws of functioning, as the driving role of profit and the wage relations centrality".

${ }^{208}$ For Hardt and Negri who consider not only knowledge production but also broader aspects of immateriality of contemporary capitalism, political compulsion can take diverse forms. As no systematic approach to exploitation is feasible, the political compulsion that is necessary for exploitation cannot be associated with order or measure. Rather, its effectiveness is based "on destruction (by the bomb), on judgement (by money), and on fear 
One can no longer hope to find any natural units of measure and even when such units appear they are merely fleeting results that arise a posteriori from the common organisation of society and the continuous resolution of the antagonisms that run throughout it. Economics, then, which has exhausted its powers, has to open itself to politics; it has to yield to political practice and recognise that it cannot do otherwise [emphasis added].209 (Hardt \& Negri, 2004, pp. 156-157)

In this world view, capital and labour are understood to be independent from each other. Here, a group of people called the working class, and another group of people called the capitalist class fight against each other about who takes control of knowledge. Now we have two super-powers, confronting each other: "There is a clash of Titans" (Holloway, 2002b, p. 88). ${ }^{210}$

From a CCT point of view, at the core of the directly social and political forms of compulsion is intellectual property. And given that intellectual property rights permeate all aspects of life, rent is seen to take a variety of different forms "financial, real estate, cognitive, wage, etc." (Negri \& Vercellone, 2007, para. 29).211

(by communication)" (Hardt \& Negri, 2000, p. 356).

209 At the forefront of political practice is money. Given the immeasurability of everything in cognitive capitalism, money no longer expresses the value of commodities, but the "generality" (Hardt \& Negri, 2004, p. 156) of the 'common':

The more that production is socialised and globalised, in fact, the more the monetary connections (which serve as the basis for financial instruments) are presented as indexes and expressions of general social production and the set of relations that bring together different economic actors. Only the power of money, in fact, can represent the generality of the values of production when they are expressions of the global multitudes.

210 By contrast, for Marx, capital and labour are in internal relations (although the proponents of CCT might say it is the case only in industrial capitalism). They are not two independent factors of production as they appear in the neoclassical aggregate production function. Capital cannot be replaced by labour and vice-versa. Their inter-relation is obvious in the category of variable capital, in which the concept of capital contains labour as its constituent part. As Holloway (2002b, pp. 88-89) puts it:

To overlook the internal nature of the relation between labour and capital thus means both to underestimate the containment of labour within capital (and hence overestimate the power of labour against capital) and to underestimate the power of labour as internal contradiction within capital (and hence overestimate the power of capital against labour).

See also Holloway (2002a, Chapter 9).

${ }^{211}$ According to this view, anything which can be monopolised and generate surplus profit is a source of rent. Qualitative differences between elements contributing to production are simply abstracted away. In a slightly different context, Marx criticises this type of mental generalisation: 
Vercellone (2008b; 2011, p. 35) speaks of "financial rent", and Marazzi (2010, p. 53) of "financial rent ... realised by redirecting liquidity towards the outside" and "social rent" arising from "the right to the house and the (indebted) consumption of goods and services". For Chicchi (2010, p. 149), "Financialisation reveals the becomingrent of profit [emphasis removed]". Negri (2010, p. 266) puts it more succinctly and assertively than anybody else: "The exploitation of the common is therefore financial rent [emphasis removed]". Lucarelli and Fumagalli (2008) propose to draw a distinction between material rent and immaterial rent:

Material rent is the income paid because of the productivity of a specific factor, e.g. the best land in Ricardo's terms. Immaterial rent is defined as the wealth produced by the innovative skills of labour, incorporated in a different productive factor (land or capital) whose owner (landlords or capitalists), given the institutional rules or his dominant position, is allowed to appropriate. (p. 87)

Moulier-Boutang's focus is slightly different, but we may say he is interested in a sort of human rent:

Exploitation has now become, basically, not that of the consumption of labour power, but its willingness to make itself available, its attentiveness and its ability to form new networks and to enter into cooperation, through the medium of computers linked together. It is not an exploitation of living labour's capacity to transform itself into dead labour, into a product, but of its capacity to provide answers to non-programmed questions, the answer to which is tautologically given in the question. (Moulier-Boutang, 2012, p. 163)

It is worth mentioning that the proponents of CCT approach rent from a Marshallian point of view as acknowledged by Negri and Vercellone (2007) and Vercellone (2011): ${ }^{212}$

The capacity to work has been called the capital of the worker, in so far as it is the fund which he does not consume in an individual exchange, since he can constantly repeat the exchange for the duration of his life as a worker. According to this, everything would be capital which is a fund of repeated processes of the same subject; e.g. the substance of the eye is the capital of sight, etc. Such belletristic phrases, which by means of some sort of analogy relate everything to everything else, may even appear profound when are said for the first time, and the more so the more they identify the most disparate things. If repeated, and especially if repeated complacently, as statements of scientific value, they are tout bonnement foolish. Suitable only for belletristic story-tellers and empty chatterboxes who besmear all sciences with their liquorice-sweet rubbish. (CW28, pp. 219-220)

212 "This is what Marshall described as a rent, to distinguish this good as 'free gift' which results from the general progress of society from normal sources of profit" (Negri \& Vercellone, 2007, para. 25). 
The competitiveness of firms, in fact, depends not on internal economies, but increasingly on external economies, that is, the ability to capture the productive surplus from cognitive resources of a territory. In an unprecedented historical scale, this is what A. Marshall himself called rent, in order to distinguish this 'free gift' resulting from the 'general progress of society' from normal sources of profit. In addition, capital monopolises the benefits of free collective knowledge of the society as if it were a gift of nature and this part of the surplus value is comparable in all respects to the differential rent enjoyed by the owners of the most fertile land. (Vercellone, 2011, p. 35)

Similarly, the scope of rent in Vercellone (2010, p. 95) is wide enough to include products of labour as one of its sources and, therefore, quasi rent:

The existence of rent is based upon monopolistic forms of property and positions of power that permit the creation of scarcity and the imposition of higher prices, justified by the cost of production [emphasis added]. Scarcity is induced in most cases by institutional artefacts, as shown today by the policies of reinforcement of Intellectual Property Rights.

Intellectual property rights certainly constitute a barrier to capitalist investment in that the use of protected technologies or knowledge requires licensing of technologies or other forms of transfer of knowledge. However, as Marx's analysis of a historically-specific capitalist form of landed property shows, theorising intellectual property simply as a source of surplus profit is insufficient, and this inadequacy is widespread in CCT. It is worth pointing out that there is an essential difference between intellectual property and landed property for our later discussions. Whilst landed property, in the context of agriculture in England (in Marx's time), is a pure barrier to capital investment and movement, ${ }^{213}$ intellectual property rights have contradictory impacts on capital accumulation. On the one hand, it encourages innovation by preventing competitors from imitating or catching up for a limited period time. On the other hand, for the same reason, the progress of an industry can be obstructed especially if the key technologies are

${ }^{213}$ By contrast, in case of coal mining, large-scale landed property accelerated capital investment:

In Britain the pattern of landownership was not fragmented, ownership was highly concentrated and much the same was true of royalty ownership. Rather than small landowners obstructing mining through the charges that would be made for the small quantities of coal that they owned, it was more a case of large landowners encouraging a number of mineowners to extract as much coal as possible and this explains the occurrence of fixed rents to be paid irrespective of the quantity of coal re-moved but against which royalties were set. (Fine, 1982b, p. 340) 
patented and the intellectual property owners refuse licensing. ${ }^{214}$

Significantly, intellectual property rights are not an invention of contemporary capitalism. Its modern origins date back as early as 1474 when the patent statute of Venice was issued. The United States and France enacted their patent laws in 1790 and 1791, respectively. ${ }^{215}$ In other words, some forms of intellectual property rights have always been part of the capitalist mode of production. ${ }^{216}$

\section{Externalities and basic income}

As we have seen in Chapter 4 and in the previous section, CCT is a theory of use value. Implicit in such a theory, and in the CCT literature, is that for a given product or phenomenon, contributing factors can be theoretically identified although identifying all factors in practice is almost impossible because externalities are prevalent in capitalism, as we have seen in Chapter 2.

CCT re-appropriates the concept of externalities to analytically capture the nature of cognitive labour, the 'common', and the biopolitical production in light of its being

214 Boldrin and Levine (2009, p. 994) give four examples:

- Boulton and Watt's steam engine patent most likely delayed the industrial revolution by a couple of decades.

- Selten's automobile patent set back automobile innovation in the United States by roughly the same amount of time.

- The Wright Brothers airplane patent forced innovative work on airplane technology out of the United States to France.

- The patent system of England and France forced the chemical industry to move to Germany and Switzerland, where chemical patents did not exist or were much weaker.

See also Boldrin and Levine (2008, Chapter 1) and Jaffe and Lerner (2004).

215 For a brief history of patents, see Guellec and Pottelsberghe de la Potterie (2007, Chapter 2) and Sherman and Bently (1999).

${ }^{216}$ In this respect, it is somewhat surprising that Marx does not provide any analysis of patenting although he was well aware of the existence of the patent system and its economic implications. He even read the specification of Watt's steam-engine patent:

The greatness of Watt's genius showed itself in the specification of the patent that he took out in April 1784. In that specification his steam-engine is described, not as an invention for a specific purpose, but as an agent universally applicable in industry. (CI, p. 499)

He also mentions patents in a sarcastic remark: "MacCulloch took out a patent on the "wages of past labour' long before Senior patented the 'wages of abstinence”" (p. 757). 
immeasurable and excessive (Hardt \& Negri, 2004, p. 146). First of all, it is argued that externalities arise from the weakening distinction between labour time and non-labour time:

There is no longer a factory wall that divides the one from the other, and 'externalities' are no longer external to the site of production that valorises them. Workers produce throughout the metropolis, in its every crack and crevice. In fact, production of the common is becoming nothing but the life of the city itself. (Hardt \& Negri, 2009, p. 251)

Second, more broadly, it is not only in the production process and but also in the life process as a whole where (cognitive) value is created.

Economists register the common in mystified form through the notion of 'externalities' ... More generally and fundamentally, positive externalities refer to social wealth created outside the direct productive process, the value of which can be captured only in part by capital. The social knowledges, relationships, and forms of communication that result from immaterial production generally fit into this category. (Hardt \& Negri, 2004, p. 147)

Third, given the hegemony of cognitive labour in cognitive capitalism, externalities are considered prevalent, posing the challenge of capturing or internalising them.

In cognitive capitalism external effects - what we have defined as externalities - cease to be marginal and tied to simple partial phenomena of indivisibility of public goods. If the core of the value to be extracted is based on intelligent, inventive and innovative labour, and if the latter mobilises the cooperation of brains in networks, then capturing positive externalities becomes the number one problem of value. (Moulier-Boutang, 2012, p. 55)

Significantly, Marx was well aware of the existence of externalities, especially those arising from co-operation and scientific discoveries:

Being independent of each other, the workers are isolated. They enter into relations with the capitalist, but not with each other. Their co-operation only begins with the labour process, but by then they have ceased to belong to themselves. On entering the labour process they are incorporated into capital. As co-operators, as members of a working organism, they merely form a particular mode of existence of capital. Hence the productive power developed by the worker socially is the productive power of capital. The socially productive power of labour develops as a free gift [emphasis added] to capital whenever the workers are placed under certain conditions, and it is capital which places them under these conditions. Because this power costs capital nothing, while on the other hand it is not developed by the worker until his labour itself belongs to capital, it appears as a power which capital possesses by its nature - a productive power inherent in capital. (CI, p. 451) 
This is certainly a positive externality of co-operation, but Marx's emphasis is on the illusion that it appears as the productive power of capital. For externality, a concept of use value, is not his primary concern. In fact, externalities, as is the case with everything else in capitalism, have a dual nature. First, the productivity of the social combined labour exceeds the sum total of the productivities of individual labours, and therefore more use values are created than the sum total that would have been created by isolated workers. Second, in terms of value production, however, given that co-operation and collective work are a norm in the capitalist production process, it does not affect the magnitude of value created for a given period of time. On the other hand, an increase in the productivity of social labour (across the economy) drives down the value of labour power, and therefore relative surplus value rises. In addition, that capitalists appropriate this free gift does not violate any principle of commodity exchange; as Marx mentions in the quote above, "it is capital which places [workers] under these conditions [of co-operation]" in the first place.

As a theory of use value, CCT only considers the first, use value aspect of externalities. For its proponents, externalities play a crucial role in use value production, so there should be some corresponding remuneration. Given the nature of co-operation, collaboration and cognition being inherently immeasurable and communal, it is impossible and meaningless to be concerned with individual contributions. The collective contributions, currently being appropriated by capitalists as rent, then, should be re-appropriated by workers, both employed and unemployed. ${ }^{217}$ Hence, they advocate basic income, arguing that CCT "complements and reinforces ... ethical conceptions, giving to BPI [basic primary income] new basis resulting from the rise of the cognitive nature of labour and from the recognition of the social character of the creation of wealth" (Monnier \& Vercellone, 2014, p. 61). In other words:

BPI, as social wages, would at least partially correspond to the collective
remuneration of this always-collective dimension, of a productive activity of
value that extends over the whole of social times and is translated, in often
unprecedented forms, by the lengthening of effective labour time and an
increase in absolute surplus value. (Monnier \& Vercellone, 2014, pp. 66-67)

217 "In our approach, unemployment and precocity are, in effect, produced by the structural logic that waged labour depends on in a monetary economy of production ... they are the expression of a monetary limit that makes employment the required condition for accessing money" (Monnier \& Vercellone, 2014, p. 64). 
Similarly, according to Moulier-Boutang (2012, p. 158), "The guaranteed social income (GSI) is not a remuneration for an individual's contribution to an input/output function of production", but it "remunerates a productive activity of pollination and makes it possible to take intangibles into account". For Lucarelli and Fumagalli (2008), basic income not only "represent[s] the compensation for the social productivity" (p. 83) but also "reduce[s] the instability inherent in CC [cognitive capitalism]" (p. 85) by ensuring a fairer income distribution. From a class struggle point of view, "the struggles around rent (in particular for a basic income) are first and foremost a means-a means for the construction of a political subject" (Negri, 2010, p. 268).

Attempting to provide a theoretical basis for basic income, CCT unduly ties the justification of basic income to the validity of CCT. If we indeed live in cognitive capitalism where positive externalities of co-operation, collaboration, communication and knowledge are being appropriated as rent, CCT provides a clear case that this portion of total output, which all of us have produced together, should be re-appropriated as basic income. However, if Marx's value theory is still valid because either cognitive capitalism is yet to come or CCT is wrong and misleading, basic income needs other theoretical justifications than externalities because there is no place of externalities as such in Marx's value theory. In this respect, CCT is a double-edged sword to basic income. It provides a theoretical framework. But it implies that basic income can be theoretically justified only within, and because of, the framework. ${ }^{218}$ This is not to deny the cause of basic income, but only to point out that a theory of use value such as CCT can provide basic income with only a shaky foundation.

\subsection{Concluding remarks}

With Marx's theory of ground rent being an application of, and rooted in, his value theory, misinterpretations of his value theory necessarily lead to misinterpretations of rent theory as well. This is most prominent in CCT. Having rejected the validity of labour as the sole substance of value, each immeasurable life activity is suggested as a particular source of cognitive value or the source of a particular value. It follows that if a (unique) activity's output can be monopolised, it becomes a particular source of rent, constituting $a$ theory of particular rent. However, different effects of

${ }^{218}$ For an attempt to justify basic income on the basis of the cost approach, see Ahn (2012). 
(intellectual) property rights on different activities are simply ignored, and rent, a horizontal category, is applied from without to analytically capture the allegedly salient fact in contemporary capitalism that a portion of output is appropriated by way of legal means. By doing so, CCT abstracts from the very particularity which it claims to cherish. Although there is a multiplicity of rent theories, they are particular in name only. Our view is different. There is no such thing as general theory of intellectual property rights, let alone general theory of rent. This is because the effects of intellectual property rights are different in different industries, and, therefore, one concept - rent - cannot express different economic and social relations in different industries, which is the topic the next chapter is concerned with. 


\section{Summary of the thesis and directions for future research}

\subsection{Summary of the thesis}

Previous chapters were concerned mainly with critically engaging with existing accounts of knowledge in contemporary capitalism. The main points covered in these chapters can be summarised as follows. First, knowledge-based growth models of NGT, especially Romer's 1990 model, privilege some aspects of knowledge whilst endogenising it on the basis of a neoclassical framing. Many restrictions are placed upon knowledge, in general, and its utilisation and diffusion, in particular, to generate exponential knowledge growth, leading to some implausible consequences: knowledge, once produced, is protected by intellectual property rights permanently; knowledge necessarily leads to the establishment of a permanent monopoly; a firm can produce either knowledge or final goods, but not both; with monopoly profit arising from knowledge being fully appropriated as remuneration for human capital, knowledge, although protected by intellectual property rights, is not the source of surplus profit; the allocation of resources between the intermediate and final goods sectors and the knowledge sector emerges as the major challenge the economy as a whole faces, etc. After all, instead of reconstructing economic growth on the basis of knowledge, NGT only seeks to identify conditions under which the aggregate knowledge stock grows exponentially.

Second, for the monopoly price approach in the Controversy, in the presence of intellectual property rights, knowledge plays no role in the determination of value, but a critical role in the determination of price. Intellectual property rights imposed upon knowledge, which should otherwise be freely available, allow for monopoly pricing. Given that knowledge is protected by intellectual property rights in most other industries, although to varying degrees, it is implicit in the monopoly price approach that monopoly pricing is preponderant in the economy; if the price of information commodities is a monopoly price in general, so are the prices of other commodities. It follows, although not explicitly acknowledged by its proponents, that value is seen not to determine price in contemporary capitalism. Analytical primacy is therefore accorded to intellectual property rights, not to capital-labour relations.

Third, as is the case with the monopoly price approach, cognitive capitalism theory argues that (industrial-)value no longer determines price in contemporary 
capitalism, especially in knowledge-intensive sectors. This is taken as expressing fundamental changes that contemporary capitalism is allegedly undergoing, that is, the emergence of cognitive capitalism, in which workers increasingly appropriate the role of knowledge production and cognitive labour becomes the hegemonic form of labour. Coupled with the flawed understanding of value theory that the separation between conception and execution is the prerequisite for value production, this is seen to undermine the validity of Marx's value theory. Instead, it is argued that in cognitive capitalism, surplus products are appropriated through directly political, social, and legal means, especially intellectual property rights.

Fourth, externalities play an important role in CCT, a theory of use value, with unpaid life activities, through co-operation, collaboration and communication, being seen to contribute significantly to production. According to CCT, surplus products are being appropriated by capital as rent, the central category in CCT, by way of intellectual property rights, which can potentially be re-appropriated by members of society as basic income; and rent and intellectual property rights are the major terrain of class struggle in cognitive capitalism. Interestingly, externalities are essential to NGT, also a theory of use value. In NGT, long-term sustained economic growth depends on exponential growth of knowledge, requiring that the productivity of knowledge-producing labour be proportional to the current knowledge stock; new knowledge improves not only the productivity of commodity-producing labour but also the productivity of knowledge-producing labour. In this respect, CCT has an affinity with neoclassical economics despite its purported commitment to Marx's method. Furthermore, for the major proponents of CCT, profit is the remuneration for capital (not a form of surplus value) as in neoclassical economics, and rent arises from monopoly of anything as long as it is a source of surplus profit (not an economic form in which a historically specific property relation is realised and expressed).

Fifth, for the cost approach, there is no distinction between knowledge and commodities; knowledge is considered more or less as means of production, which transfers value to the final products in a piecemeal fashion. When knowledge and, more generally, externalities, are sources of surplus profit by being monopolised through intellectual property rights or otherwise, surplus profit is seen to be transformed into rent depending on replicability or the presence of property rights. As is the case with CCT, rent is seen as being a special case of surplus profit, detached from Marx's analysis of the historically specific capitalist form of landed property. 
In light of these flawed theories of knowledge in contemporary capitalism, an alternative approach - the virtual multiplication approach - was put forward in Chapter 3. It was argued and shown that the role of knowledge can be incorporated into value theory in a consistent and coherent manner. The starting point is to draw a clear structural distinction between knowledge and commodities; knowledge is not a commodity and therefore it does not have value. Knowledge, however, affects the determination of the productivity and complexity of (collective) commodityproducing labour within and across sectors, respectively, and therefore takes part in the determination of the value of commodities (produced on the basis of the knowledge). As a corollary, an individual capital realises surplus profit if the level of its use of knowledge is higher than the sectoral average and/or if it operates in a knowledge-intensive sector. These social processes of virtual multiplication of labour, determining the value-creating capacity of commodity-producing labour, is a relatively abstract formulation of the role of knowledge in contemporary capitalism. Whilst it is shown that knowledge is compatible with value theory, the multiplication approach, contrary to CCT, does not analyse historically specific configurations of knowledge production in contemporary capitalism. Nor does it attempt to provide a definitive answer to the nature of the price of (information) commodities, contrary to the monopoly price and cost approaches. Further, although knowledge is seen as fundamentally distinct from commodities as in NGT, this distinction is not projected to the economy as a whole, with a separate knowledge sector being ascribed the role of economic growth as opposed to equilibrium.

\subsection{Extension of the virtual multiplication approach}

In this respect, on the one hand, the virtual multiplication approach is a defence of value theory against the claim of CCT that it is no longer valid in contemporary capitalism. On the other hand, it provides an abstract logical foundation upon which more concrete and complex, and constructive, theories of knowledge can be built in accordance with Marx's method of moving from the abstract to the concrete. In developing such a theory, the following principles should be applied. First, it should be a value theory of knowledge, not a use value theory. This is not to deny the importance of the dimension of use value, given that use value is the precondition for value. However, in capitalism, production is, above all, for capital accumulation (surplus value production), with use value production and its growth only being the by-product of value production. The roles of knowledge in value production and 
their consequences for capital accumulation have to be clarified before the relations between knowledge and use value production can be satisfactorily studied. Second, as the analysis incorporates more concrete and complex elements, so should the distinction between knowledge and commodities be developed and reproduced at more concrete and complex levels. For example, whilst intellectual property rights allow for, and facilitate, the commodification of knowledge, it should not be seen as blurring the distinction between knowledge and commodities in any way, but as a historical and concrete form of the distinction. Third, related to the previous point, intellectual property rights should be brought into the analysis at relatively concrete and complex levels, where the distribution of surplus profit and the capitalisation of intellectual property are discussed. Fourth, however, this should not be taken as limiting the role of intellectual property rights to appropriating (part of) surplus profit arising from knowledge. The effects of intellectual property rights on capital accumulation across the circuits of capital should be identified and analysed, especially to show how they both accelerate and decelerate capital accumulation, without collapsing different levels of abstraction. Fifth, there can be no general theory of intellectual property rights, because they have different roles and effects in different industries. For example, copyright is essential in the recorded music industry and patents in the pharmaceutical industry to the extent that the existence of these industries relies on intellectual property rights, although patents play at best a minor role in the aircraft industry, especially with respect to competition within the industry. It is, then, crucial for an analysis of intellectual property rights in an industry to examine how intellectual property rights and competition interact with each other.

It is a strong point of the virtual multiplication approach that it allows for combining, or linking, logical analyses with historical ones. In other words, the unfolding of the abstract and simple distinction between knowledge and commodities can be analysed from both logical and historical perspectives. For the latter, the distinction can take different forms in different times and places: in terms of degree of separation (e.g. learning by doing vs. education); in terms of level of collectivity (e.g. individual skills vs. knowledge materialised in fixed capital); within a firm (e.g. between $R \& D$ department and manufacturing department); across firms within an industry (e.g. between fabless semiconductor firms and semiconductor manufacturers); and even across industries (e.g. management consulting as a knowledge sector).

More specifically, for Marx, large-scale industry is an outcome of the systematic 
separation of knowledge from individual workers, with production being increasingly organised around fixed capital embodying science. ${ }^{219}$ At the same time, in Marx's view, scientific discoveries, in his time, lay outside the domain of capital, separated from direct labour, so that capital only appropriates science to raise productivity and the degree of control in the production process (CW34, p. 33). ${ }^{220}$ After all, the real subsumption of labour under capital was made possible by the incorporation of scientific discoveries and massive natural forces into the direct production process. This historical development is reflected in his distinction between universal labour and communal labour (CIII, p. 199) as mentioned in Chapter 3. With the former being performed outside not only the direct production process but also the capital-labour relation, "invention becomes a business, and the application of science to immediate production itself becomes a factor determining and soliciting science" (CW29, p. 90).

This historical configuration of the division between knowledge production and commodity production prevalent at Marx's time gave way to a new form in the late 1800 s and early 1900s. According to Lamoreaux and Sokoloff (2005), whilst intellectual property rights, more specifically, the patents system, gave rise to the emergence of invention as a business, creative inventors gradually lost their independence from large firms. ${ }^{221}$ Knowledge production became increasingly subsumed under the control of capital during this period, especially with the rise of in-house R\&D laboratories in large firms:

As technology became more complex and science-based during the late nineteenth century, creative individuals with the requisite skills and knowledge may have required more capital to pursue careers at invention than local partners (or other traditional sources of funding) could readily

219 In his analysis of the chapters on machinery in the 1861-63 manuscript, Smith (2009, p. 118) says:

Marx ... refers explicitly to the increasing importance of scientific-technological knowledge, insisting that there is a structural tendency for science to be subsumed under the capital form. As far as these central ideas are concerned, there is nothing new about 'new growth theory'.

220 "It is the analysis and application of mechanical and chemical laws-originating directly from science-that enables the machine to perform the same labour as was previously performed by the worker. However, the development of machinery takes this course only when large-scale industry has already attained a high level of development and all the sciences have been forced into the service of capital" (CW29, pp. 89-90).

${ }^{221}$ See also Lamoreaux and Sokoloff (1999). 
provide. The marked decrease by the early twentieth century in the number of productive inventors who managed their careers without forming long-term attachments with firms, together with the sharp decline in patenting rates in the regions where independent inventors had mainly been concentrated, suggests that the need to mobilise substantial amounts of capital may indeed have operated as a barrier to success in, or even to entry into, inventive activity by this period. (Lamoreaux and Sokoloff, 2005, p. 26)

For Mirowski (2011), these changes resulted in the establishment of the "captains of erudition regime" of American science organisation, which dates back to the 1890 os and is characterised by the emergence of in-house R\&D labs. Against the accounts of the history of science in which science has always been essentially commerciallyoriented, he suggests that the organisation and funding of science in the United States have undergone transitions from the "captains of erudition regime" through the "cold war regime" to the "globalised privatisation regime", see Mirowski (2011, pp. 94-95) for a summary of the characteristics of each regime. More specifically, in his account, R\&D has gone through fundamental changes over the last 100 years: from privately-funded in-house $R \& D$ in corporate $R \& D$ labs, through semi-public funded R\&D in semi-autonomous R\&D labs, to outsourced and offshored R\&D. ${ }^{222}$ In the latter case, R\&D and, more generally, knowledge are not only commerciallyoriented but also commodified:

[D]ependable R\&D is a distinct fungible commodity in a well-developed market, one so competitive that it can lower the costs relative to doing it internal to each firm ... [N]o matter how 'commercialised' science may or may not have been in the previous American science regimes, until recently it was this state of affairs that was uniformly absent. ${ }^{223}$ (p. 122)

Against this historical background, Arora et al. (2001) explore factors determining the extent of the commodification of technology or "the division of innovative

222 For Jessop (2007, p. 122):

Novel features of the current period are the growing application of knowledge to the production of knowledge in developing the technical and social forces of production; the increased importance of knowledge as a fictitious commodity in shaping the social relations of production; and the increased importance of intellectual property as a revenue category that modifies the overall distribution of social wealth.

${ }^{223}$ Mirowski (2011, p. 7) explains the transition to the globalised privatisation regime as an outcome of neoliberalism: "I argue that much of the modern commercialisation of science and commodification of the university has followed a script promulgated by neoliberal thinkers". Whilst he rightly points out the correspondence between material changes and ideological expressions, there is a danger that analytical primacy is placed upon the latter. See Fine (2012b) for a critique of such a view. 
labour" (Arora et al., 2001, p. 6).224 The presumption is that the expansion of markets for technology is desired in general ${ }^{225}$ as firms can benefit from specialisation; markets for technology "promote the diffusion and efficient use of existing technology and can enhance the rate of technological advance" (p. 8), for which intellectual property rights provide an essential institutional framework. It is, however, also shown that constraining factors including, but not limited to, context dependence, tacitness of knowledge, transaction costs and uncertainty obstruct the deepening of $\mathrm{R} \& \mathrm{D}$ outsourcing and commodification. Although these factors are seen to harmoniously interact with each other to produce an outcome - the analysis is necessarily static - with an emphasis placed upon the institutional factors, their analysis precludes a deterministic approach, highlighting the transformative effects of technological development and their interplay with intellectual property rights and industry-specific competitive conditions in determining the size of the industryspecific markets for technology. ${ }^{226}$

This brings us back to the point that there is no general value theory of intellectual property rights and knowledge as their significance on industry structure and competition varies across industries. ${ }^{227}$ In the next section, we will briefly review

224 See also Arora and Gambardella (2010).

${ }^{225}$ According to Arora et al. (2001, p. 31), in 1996, "the size of the market for technology in North America is [estimated to be] approximately $\$ 25$ billion; while in Europe and Japan it is approximately $\$ 6.6$ and $\$ 8.3$ billion, respectively". Robbins (2009), using the Internal Revenue Service's Statistics of Income (SOI) data, shows that in 2002, the total royalty income of all manufacturing industries is $\$ 72.7$ billion (p. 158). Based on the same data set, it is also shown that the average growth rate of royalty income between 1994 and 2004 is 11 percent (p. 140).

226 "The rise of markets for technology during the past decade is not an inexorable trend but historically contingent. Thus, while markets for technology flourished in nineteenth-century America, by the 1930s, the dominant model for privately conducted R\&D had become the large corporation with an R\&D laboratory, and with only limited trade in technology. In the last two decades of the twentieth century, technology trades have grown markedly. The question is whether in the twenty-first century the two modes will coexist on a more balanced basis, or whether there will be a new phase, with R\&D integrated almost exclusively in large corporations once again ... Undoubtedly, the transformation of some of the basic institutions of the economic system will profoundly shape how markets for technology evolve. As we look ahead, we hope that a little understanding of the past will prove valuable in dealing with the important transformations that the future will bring" (Arora et al., 2001, p. 287).

227 This by no means suggests that horizontal critical approaches to intellectual property 
three cases in which intellectual property rights play important roles but in different ways. The aim is both to provide a sketch of a positive and more concrete theory of knowledge in contemporary capitalism based on value theory and to point to future directions of research.

\subsection{Future directions: (constructive) value theories of knowledge}

\section{Digital music and the transformation of the recorded music industry}

The recorded music industry has been undergoing fundamental transformations since the invention of the MP3 format by Fraunhofer Institute in 1990. Music listeners started copying songs from audio CDs to their computers and portable music players and, with the wide adoption of the Internet, increasingly shared them amongst one another on an unprecedented scale. Napster, a global P2P file sharing network, was founded in 1999 and used by millions for (illegal) sharing of 'ripped' MP3 files until it was ordered to shut down after only two years of operation due to copyright infringement. In 2003, Apple launched the iTunes Music Store which, alongside more effective and ruthless copyright enforcement regimes in major markets, further accelerated the transition of the recorded music industry from physical to digital. ${ }^{228}$ Another important recent trend in the recorded music industry is the rapid growth of music subscription services, although in varying degrees across territories. In 2014, global subscription streaming revenues increased by $39.0 \%$, whereas digital permanent downloads revenues decreased by $8.0 \%$ whilst still remaining the largest source of digital income (52\%) (IFPI, 2015, p. 7).

There is, however, continuity between physical and digital music. It is not only that

rights, especially those focusing on the use of intellectual property rights in commodifying the cultural and traditional in the context of globalisation (Drahos, 1996; Drahos \& Barithwaite, 2002; May, 2006 and 2007; May \& Sell, 2006), should be discarded.

${ }^{228}$ In 2014, this ongoing transition reached an important milestone; the industry's global digital revenues (from permanent downloads, streaming service subscriptions, etc.) were the same as the physical revenues (from CDs, vinyl LPs, etc.) and will certainly surpass the latter in 2015 (IFPI, 2015, p. 6). Between 2007 and 2014, the digital revenues grew at an annualised rate of $6.4 \%$ globally, whereas the recorded music market as a whole continued to shrink, albeit at a diminishing rate (the market contracted by $0.4 \%$ in 2014). Inflationadjusted recorded music revenues in 2014 were only 30\% of those in 2007 (Boluk, 2015, Part I, para. 1). Simply put, digital has been failing to offset declining physical sales. 
physical music still accounts for the half of the recorded music revenues, but record labels continue to function as powerful intermediaries between artists and music listeners. Although value chain dynamics in the recorded music industry have been evolving rapidly, broadly speaking, the traditional artist-label-retailer structure still remains. It is therefore important to briefly review how physical music is produced and distributed before analysing the results of the interplay between digital technologies and intellectual property rights in the recorded music industry.

Typically, the production of a new album starts with an artist signing a recording contract with a record label. The artist, then, produces a master recording of new music (recording costs are usually born by the artist), based on which the record label's production department mass produces music CDs. These physical products are supplied to retailers mostly through (major) distributors. ${ }^{229}$ Put differently, the record label is an industrial capital (employing workers to produce physical products) and the retailer a commercial capital (adding no value to commodities but only realising already produced values). The major difference from other types of commodities is that knowledge, i.e. master recording, is produced almost entirely outside the industrial capital, that is, artists are self-employed knowledge workers. In other words, the distinction between knowledge and commodities appears as the social division of labour between artists (composing and recording) and record labels (manufacturing and distribution).

Although record labels also play important roles in marketing, promotion and supply chain management, whether a new album is successful or not essentially depends on the quality of music and cultural meanings attached to it. Therefore, it is not only that music is required to produce recorded music commodities, but the quantity sold is affected heavily by (the quality of) music. For this reason, royalties are paid to artists for each record sold, around 10\% of the wholesale price (Passman, 2014, p. 76). ${ }^{230}$ Artist royalties, however, cannot be considered as rent although they arise from the monopoly of intellectual property, i.e. the copyright in the sound recording. First, the copyright in a new album is transferred to the record label when a recording contract is signed. It is as if the record label outsources the production

${ }^{229}$ Major record labels (Universal Music Group, Warner Music Group and Sony Music Entertainment) are also recorded music distributors.

${ }^{230}$ The wholesale price of an album is typically $70 \%$ of the retail price. 
of a new recording (R\&D) to the artist. ${ }^{231}$ Second, the core competency of a record label lies in its capability of introducing successful new albums and artists on a regular basis, not in physical music commodity production. The A\&R (Artists \& Repertoire) department ${ }^{232}$ of a record label is proactively involved in finding new artists, nurturing them and maintaining and managing existing artists. In this respect, record labels are an important part of music-making (or knowledge production) and not a passive collector of rent:

The Company [Warner Music Group]'s Recorded Music business primarily consists of the discovery and development of artists [emphasis added] and the related marketing, distribution and licensing of recorded music produced by such artists. (Warner Music Group Corp., 2015, p. 5)

Following the launch of the iTunes Store and its uniform pricing (\$0.99 per song), individual (digital) songs became the dominant form of recorded music commodities. Whilst this was inevitable given the preponderance of 'piracy' at that time, this undoubtedly contributed to the rapid decline of recorded music revenues as listeners' behaviour changed from buying a whole album to buying one or two 'hit' songs from the album. On the other hand, this change encouraged wider adoption of legal digital music among music listeners and expedited the transition of the recorded music industry from physical to digital. The impact of the transition to digital on the industry is often discussed from the perspective of supply chain and governance (Graham, Burnes, Lewis, \& Langer, 2004) with digital technologies considered to weaken the role and power of intermediaries such as record labels and to facilitate the formation of direct commercial relationships between producers and consumers. ${ }^{233}$ However, a more fundamental impact has been on the relationships

${ }^{231}$ Some popular artists own the copyrights to their recordings and have control of distribution. In addition, regardless of the transfer of the copyright to the sound recording to the label, the copyright to the musical work remains with the composers and lyricists.

232 "A\&R executives ... are among the most important industry people. They are responsible for finding and signing talent, as well as finding songs, matching producers and artists, and generally overseeing projects" (Passman, 2014, p. 130).

233 "In 2013, Macklemore became the first unsigned artist in nearly 20 years to have a number-one single in the United States, 'Thrift Shop'. The track was a grassroots success story born on social music sites such as SoundCloud and Hype Machine, rather than in state of the art studios and ad agency lofts. And if 'Thrift Shop' didn't scare music labels, Macklemore quickly gave them a second reason to be. Three months later, he proved he was no 'one hit wonder' with another chart topper: 'Can't Hold Us'. A third track, 'Same Love' hit \#11 shortly thereafter" (Boluk, 2015, Part II, para. 37). 
between record labels and retailers; the latter transformed from commercial capitals to industrial capitals. For digital distribution, record labels no longer manufacture recorded music commodities, but provide the sound recordings (i.e. knowledge) to retailers in digital form. Once a song has been purchased, the retailer produces a digital copy of the sound recording and delivers it to the customer through the Internet. From a retailer point of view, then, a record label is no longer a supplier of music commodities, but more or less a group of rights holders wielding significant bargaining power through collective licensing. ${ }^{234}$ Not surprisingly, record labels gradually changed the nature of their core business to become recording copyright pools, often obstructing innovations on the retailer side.

With the switch cost between permanent digital music downloads services being almost zero, retailers increasingly attempted to differentiate their service offerings. For example, in 2011, Amazon launched 'Amazon cloud player', a digital locker service, which allows users to keep their music collections in the cloud. In 2012, Apple introduced 'Mastered for iTunes' to optimise the sound quality of master recordings for digital distribution. Major digital music retailers also abandoned DRM (digital rights management) one by one, to enhance user experiences, especially sharing of music across devices. All of these innovations required renegotiation of licensing terms with the record labels as their focus had shifted from selling physical products to exploiting and seeking new business opportunities and securing new revenue streams. Being intellectual property owners vis-à-vis retailers, record labels increasingly placed severe restrictions on the use of their intellectual properties and, by doing so, constrained retailers' investments into innovations. ${ }^{235}$ The emphasis has been more on securing stable revenue streams to the record labels than on expediting the adoption of digital music at the expense of the retailers' own profitability although the retailers preferred the latter.

This trend has accelerated with the rapid growth of the subscription streaming model. ${ }^{236}$ Music streaming service subscribers neither buy nor own individual songs

${ }^{234}$ However, for each digital song or album sold, retailers still technically pay the record label the wholesale price, about $70 \%$ of the retail price, not royalty.

235 These restrictions cover wide areas, from bundling of products and pricing (e.g. buy one get one free) to technical implementations (e.g. how many re-downloads of a purchased song are allowed).

${ }^{236}$ Spotify, a subscription streaming service, has been leading the transition of digital music from permanent downloads to subscription streaming since its launch in 2008. 
and albums, but instead get access to the full catalogue with tens of millions of songs for a monthly subscription fee. For a subscription streaming service, then, individual songs and albums are no longer commodities. Rather, the commodity which subscription streaming music services produce and sell is the streaming service as a whole, consisting of access to the music catalogue and other service features necessary for users to discover and consume digital music such as search, recommendations and curated playlists. ${ }^{237}$ As in the permanent downloads and ownership model, about $70 \%$ of subscription revenues are distributed to record labels and publishers. This portion is, in turn, distributed among record labels and artists (through record labels) according to market share calculated based on number of streams served. For example, if a record label accounts for $5 \%$ of monthly total plays, $5 \%$ of the label/publisher portion of the monthly revenue is distributed to the record label. ${ }^{238}$

This new revenue share scheme has set in motion the following tendencies. First, whilst record labels (and artists) compete against each other, vis-à-vis subscription streaming service providers, they form a united front. They are interested in increasing the (collective) share of the label/publisher portion and there is nothing to gain from differentiating individual licensing terms. ${ }^{239}$ It is in this context that streaming service providers are often criticised for paying artists much less than one cent per play and, by doing so, exploiting them. ${ }^{240}$ Second, with the (business)

237 Not surprisingly, for a subscription music streaming service, obtaining licences from as many record labels as possible is a key to the success. For example, it is considered as one of the advantages of Apple Music over Spotify that Taylor Swift made her hit album '1989' and her back catalogue available for Apple Music after Apple agreed to pay artists royalties during free-trial periods as Swift suggested (She removed her back catalogue including '1989' in 2014 from Spotify and she is still withholding this album from Spotify at time of writing). For more on this topic, see Swift (2015) - her open letter to Apple - and Duboff (2015).

${ }^{238}$ For more on royalty distribution, see Spotify Ltd. (n.d., Royalties: in detail).

239 This is similar to Marx's view that capitalists are united as a class whilst competing fiercely against each other. "The capitalists, no matter how little love is lost among them in their mutual competition, are nevertheless united by a real freemasonry vis-à-vis the working class as a whole" (CIII, p. 300).

${ }^{240}$ For a response, see Spotify Ltd. (n.d., Wait, I thought Spotify paid per stream?):

We [Spotify] personally view 'per stream' metrics as a highly flawed indication of our value to artists for several reasons. For one, our growing user population might listen to more music in a given month than the month before (resulting in a lower effective "per stream'), while generating far more aggregate royalties for artists. As with any subscription service, our primary goal is to attract and retain as many paying subscribers 
success of record labels (and artists) being tied more closely to the success of subscription streaming services, record labels have increasingly intervened in the operations of streaming services. For example, record labels have been pressuring Spotify to abandon the ad-supported free subscription tier since the revenue stream generated from the free-tier is much lower than that for the premium subscription (Knopper, 2015; Boluk, 2015). This reflects a clash of interests. Streaming service providers' priority is to build up the subscriber base, free or premium (paid-for), on which they can expand their business by offering other products and services. ${ }^{241} \mathrm{On}$ the other hand, for record labels, the focus is on developing and exploiting business opportunities, intensively and extensively, and maximising the value of their intellectual property rights. In short, from a record label point of view, music is a "portfolio business" (IFPI, 2015, p. 7). Music can and should be sold, packaged, used as marketing tool, and consumed in as many different and commercially viable ways as possible since a record label's success hinges on securing diversified revenue streams:

The strength of the industry today is seen in the wide-ranging portfolio of diverse businesses operating in the market. The consumer is now being offered an incredible array of music experiences and artists have more opportunities to reach the widest possible audience - Francis Keeling, Global Head of Digital Business, Universal Music Group. (p. 9)

Third, with catalogue outselling current releases (The Nielsen Company, 2015) due in part to easier content discovery in digital music, ${ }^{242}$ the importance of $A \& R$ is questioned. According to Dave Goldberg, "Catalogue provides 50\% of the revenue and $200 \%$ of the profits of recorded music ... In addition, streaming revenues tend to be more heavily weighted to catalogue. Pandora and Spotify are probably $65 \%$ catalogue" (Kafka, 2015, para. 12). Hence, "catalogue replenishment [should be] the only goal of the new release business ... New releases will be tested on consumers before added money is spent to ensure that it isn't wasted" (para. 17).

In conclusion, digital technologies, in the presence of intellectual property rights, have been fundamentally transforming the recorded music industry and the roles of

as we possibly can, and to pass along greater and greater royalties to the creators of the music in our service.

${ }^{241}$ Major streaming service providers also sell 'merchandise' such as t-shirts, concert tickets and autographed vinyl records.

${ }^{242}$ An album or a song released more than 18 months ago is categorised as 'catalogue'. 
the record labels in particular. As rights holders, record labels attempt to maximise the value of their intellectual properties under ever-changing business environments, but this cannot be seen simply as passive rent-seeking behaviour. Although they do sometimes obstruct innovations, they are putting a lot of effort into developing (and exploiting) new business opportunities, shaping and driving the development of the industry. Royalty alone is not sufficient to analyse and capture the key dynamics in the recorded music industry and, if used in isolation, obscures the multifaceted and complex relationships between artists, record labels and retailers.

\section{ARM: Chipless semiconductor company}

A more positive case for intellectual property rights is found in the semiconductor industry. During the 1980 s and 1990s, the minimum level of capital to maintain manufacturing facilities increased rapidly due to ever-intensifying competition on a global scale. As a result of this, the traditional model in which vertically-integrated companies both design and manufacture semiconductors lost its dominance. Specialisation gained momentum, decoupling design (fabless firms) from manufacturing (foundries) (Macher, Mowery, \& Hodges, 1999; Macher, Mowery, \& Di Minin, 2008; Brown \& Linden, 2008). In addition, there was a further division of innovative labour, with the fabless model splitting into fabless companies outsourcing chip manufacturing to foundries and chipless companies specialised purely in design and licensing intellectual property instead of selling chips (Arora et al., 2001, pp. 76-88). It was not only that the distinction between knowledge and commodities took the form of the division between fabless firms and foundries in the semiconductor industry, but specialisation within chip design further deepened. From a technological point of view, this was "a response to the growing complexity of chip design" (p. 77), made possible and driven by "the development of computerised design tools" and "the standardisation of manufacturing technologies" (Langlois, 2013, p. 158).

ARM is one of the most well-known and successful chipless companies. ${ }^{243}$ By the end of 2014, ARM had licensed its technologies to 389 semiconductor firms $(1,198$ licences). Out of 33 billion chips containing a processor produced in 2014, 12 billion made use of ARM technologies (a 37\% market share). One of the core competencies

${ }^{243}$ See Bedford (2012) for a brief history of ARM. 
of ARM is its design of low-power high-performance chips for handheld devices; ARM's market share in the mobile device segment, including smartphones, tablets and laptops, was $86 \%$ in 2014, up from 59\% in 2010, with 2 billion smartphones containing at least one chip based on ARM technologies (ARM Holdings plc, 2014 and 2015).244

Apparently this chipless licensing model depends greatly on intellectual property rights. ${ }^{245}$ Chip designs are delivered in soft macros (circuit descriptions written in a hardware description language) and/or hard macros (physical and graphical descriptions specific to a foundry) which, like software source code, can be used an unlimited number of times for the production of chips (Greenbaum, 2011). Then, without intellectual property rights, from a downstream customer point of view, there would be less incentive to enter a multi-year licensing contract, paying royalty for each chip produced. On the other hand, a chipless company would try to increase the licensing fee portion on the total deal value, raising the minimum capital requirements for new capitals to enter the semiconductor industry. Consequently, the notion of sharing risks and growing the industry together would dissipate, there would be fewer licensing deals and vertical integration would gradually replace specialisation.

The chipless licensing model is generally considered to be mutually beneficial to both chipless companies and downstream licensees. With downstream industries, ranging from computers to consumer electronics and telecommunications, rapidly developing in market size, diversity and performance, there has always been the need for better-performing processors. Especially with the introduction of Systemon-Chip (SoC), integrating all the necessary components (e.g. CPU and GPU) required to power a computer or smartphone into a single chip, semiconductor companies have focused their efforts more on optimising the design of SoC for the

\footnotetext{
244 Vance (2014, para. 5) says, "In fact, you can argue that ARM-based products are now the most-used consumer products in the world, outflanking even Coca-Cola and McDonald's by some measures".

245 "While licensing and cross licensing of semiconductor patents by semiconductor manufacturers may be mainly in response to the complex nature of the product, patents are also being used increasingly as a means for defining the property rights on inventions to facilitate the trade of these property rights. The creation and enforcement of intellectual property, while far from sufficient for a division of innovative labour, is clearly a precondition" (Arora et al., 2001, p. 89).
} 
downstream customers' target devices, relying more on ARM and other chipless companies such as Imagination Technologies for the basic and fundamental R\&D (e.g. processor architecture), which otherwise would cost each semiconductor company between $\$ 50$ million to $\$ 150$ million a year, according to ARM's estimate. ${ }^{246}$ Basically, chipless companies, especially ARM who owns the intellectual properties around the RISC-based ARM architecture based on which ARM processors are designed, ${ }^{247}$ are industry $R \& D$ centres ${ }^{248}$ which are funded by the payments of up-front licence fees and per-chip royalties by the semiconductor industry as a whole. ${ }^{249}$ With its success tied to that of downstream customers, ARM has been introducing new processor designs which can meet market needs and get buy-ins from leading licensees on a regular basis. It is known to work with up to

246 "ARM designs technology that once would have been developed by the R\&D teams inside each company in the semiconductor industry. ARM has demonstrated that it is cheaper to license technology than to continue in-house development. The design of an ARM processor requires a large amount of $\mathrm{R} \& \mathrm{D}$ investment and expertise. We estimate that every semiconductor company would need to spend between $\$ 50$ million and $\$ 150$ million every year to reproduce what ARM does. This represents an additional $\$ 20$ billion of annual cost for the industry. By designing once and licensing many times, ARM spreads the R\&D costs over the whole industry and thereby helps make digital electronics cheaper" (ARM Holdings plc., 2010, p. 2).

${ }^{247}$ ARM licenses both processors based on the ARM architecture and the ARM architecture itself. The latter is licensed by major semiconductor companies such as Qualcomm and Apple who design their own processors based on the ARM architecture. For an overview of the licensing options ARM provides, see Shimpi (2013).

${ }^{248}$ ARM’s R\&D expenditures grew from £139.7 million in 2010 to £224.2 million in 2014. During this period ARM's revenues increased from $£ 406.6$ million to $£ 795.2$ million and the R\&D intensity (R\&D expenditures / total revenues) was 28.2\%. See ARM (2011, 2012, 2013, 2014, 2015).

${ }^{249}$ Competition among semiconductor companies is, then, centred on SoC design whilst the performance of processors continually improves thanks to the industry-wide processor architecture R\&D performed by ARM and other chipless companies. Interestingly, whilst the sectoral knowledge level in terms of computing power has been growing rapidly, doubling every two years according to the so-called Moore's law, this has not entailed as much growth in productivity (output per hour of work). Whilst the computing power of a chip is determined by transistor density, it is a chip, not a transistor, which is a semiconductor commodity. In other words, knowledge production in the semiconductor industry takes the form of product quality improvement, not of productivity increase as such. Whilst for Marx, an increase in social productivity is beneficial to capitalists by way of increasing relative surplus value, for this reason, knowledge production in the semiconductor industry has little impact on the rate of exploitation. 
three semiconductor companies to cover major market segments when it designs a new processor.

In sum, intellectual property rights in the semiconductor industry accelerate capital accumulation and the formation of new capitals by enabling specialisation in chip design. Whilst ARM and other chipless companies earn royalty payments as record labels in the music industry, the nature of intellectual property which is economically realised in royalty and its roles in industry dynamics in the semiconductor industry are considerably different from those in the recorded music industry.

\section{Apple: outsourcing of manufacturing}

As is the case with the fabless companies in the semiconductor industry, since the $1980 \mathrm{~s}$, there has been a trend of outsourcing of manufacturing that was previously performed in-house across industries, for example, the computer, consumer electronics and fashion industries. Especially, many multinational companies increasingly outsource manufacturing to countries that provide greater access to supply chain and/or cheaper labour.

Outsourcing of manufacturing, or contract manufacturing (Lüthje, 2002), is of interest in two respects. First, it presupposes the existence of specialised companies in both knowledge production (design) and commodity production (manufacturing), respectively. As we have seen in the case of chipless companies, this requires intellectual property rights because, otherwise, contract manufacturing companies would easily create and sell copycats. Second, when a company outsources manufacturing entirely, no direct labour is performed by the workers employed by the company. Outsourcing and information commodities are, then, similar to each other in the sense that they do not require direct labour in the production process, although for different reasons. After all, information commodities are not an exceptional case. They should not be taken as a marginal exception which can be ignored (as in neoclassical economics) or as the epitome of a new mode of production (as in cognitive capitalism theory). Instead, it should be understood as an example of the production process configuration in which next to no living labour is involved.

Under a manufacturing service contract, by definition, direct labour for assembly, testing and etc. is performed by the workers employed by the contract manufacturing company, which basically provides a manufacturing service, 
essentially an agreed-upon labour time by average worker, to the customer. Such manufacturing service, in which labour is usually simple and repetitive, is fundamentally distinct from the commodities which the customer produces, by way of outsourcing, and sells. For example, Foxconn employees, who assemble and test Apple's iPads, produce contract manufacturing services, not iPads. Like mobile apps and digital music for which online purchase and download (content delivery) are completely automated, Apple's iPad production process (from Apple's point of view) should be understood as an automated process connecting suppliers, contract manufacturing companies (e.g. Foxconn) and delivery companies, whilst also coordinating between them. Although no Apple employee performs direct labour in the production process, Foxconn employees contribute to the value of an iPad because their product - contract manufacturing service - is consumed during this automated production process, thereby transferring value to iPads in a piecemeal fashion.

This does not mean that the value of an iPad is reduced to the total costs of parts, components, manufacturing service, delivery service, etc., which is around \$274 at time of writing (iPad Air 16GB Wi-Fi model). Apple is well known to have a higher level of knowledge, in terms of design, engineering, features and functionality of both software and hardware, than its competitors and the average level of knowledge in the tablet industry as a whole may be higher than the economy-wide social average.

Therefore, if all direct labours were performed by Apple employees in the US, their labour would be virtually multiplied to a significant degree. As Table 1 shows, the contract manufacturing cost per iPad is estimated to be only $\$ 5$, which accounts for $1 \%$ of the retail price and $1.8 \%$ of the total costs (costs of goods sold) per device excluding delivery. Suppose that wages account for $60 \%$ of the total manufacturing costs (\$3), the average Chinese wage is half the average US wage (\$6) and the rate of exploitation is $100 \%$. Then, the manufacturing cost per device would go up to $\$ 8$ (= $\$ 2+\$ 6)$, a new value of $\$ 12(=\$ 6+\$ 6)$, instead of $\$ 6(=\$ 3+\$ 3)$, would be added and $\$ 2$ would be transferred during the production process. The costs of goods sold per iPad (excluding delivery) would then go up from $\$ 274$ to $\$ 277(=\$ 269+\$ 2+$ \$6). In other words, by way of outsourcing manufacturing to Foxconn, Apple can increase surplus profit per iPad by up to $\$ 3$ (0.6\% of the retail price and about $1.5 \%$ of estimated surplus profit). Ignoring delivery costs, the individual value (or price of production) of an iPad would be $\$ 283$ (=\$269+\$2 +\$6+\$6) with Apple's surplus profit being $\$ 216$, which may or may not include monopoly profit. 


\begin{tabular}{|c|c|c|c|c|c|c|c|c|}
\hline \multirow{2}{*}{$\begin{array}{c}\begin{array}{c}\text { Preliminary iPad Air Cost } \\
\text { Estimates }\end{array} \\
\text { Components / Hardware Elements }\end{array}$} & \multicolumn{4}{|c|}{ Wi-Fi + Cellular } & \multicolumn{4}{|c|}{ Wi-Fi } \\
\hline & $16 G B$ & $32 \mathrm{~GB}$ & $64 G B$ & $128 \mathrm{~GB}$ & $16 G B$ & $32 \mathrm{~GB}$ & $64 \mathrm{~GB}$ & $128 \mathrm{~GB}$ \\
\hline (Retail pricing) & $\$ 629$ & $\$ 729$ & $\$ 829$ & $\$ 929$ & $\$ 499$ & $\$ 599$ & $\$ 699$ & $\$ 799$ \\
\hline Implied Margin & $51 \%$ & $56 \%$ & $60 \%$ & $61 \%$ & $45 \%$ & $53 \%$ & $58 \%$ & $59 \%$ \\
\hline Total BOM Cost & $\$ 304$ & $\$ 313$ & $\$ 315$ & $\$ 355$ & $\$ 269$ & $\$ 278$ & $\$ 290$ & $\$ 320$ \\
\hline Manufacturing Cost & $\$ 6$ & $\$ 6$ & $\$ 6$ & $\$ 6$ & $\$ 5$ & $\$ 5$ & $\$ 5$ & $\$ 5$ \\
\hline $\mathrm{BOM}+$ Manufacturing & $\$ 310$ & $\$ 319$ & $\$ 321$ & $\$ 361$ & $\$ 274$ & $\$ 283$ & $\$ 295$ & $\$ 325$ \\
\hline Nand Flash (Memory) & $\$ 9.20$ & $\$ 18.00$ & $\$ 30.00$ & $\$ 60.00$ & $\$ 9.20$ & $\$ 18.00$ & $\$ 30.00$ & $\$ 60.00$ \\
\hline DRAM (Memory) & $\$ 10.50$ & $\$ 10.50$ & $\$ 10.50$ & $\$ 10.50$ & $\$ 10.50$ & $\$ 10.50$ & $\$ 10.50$ & $\$ 10.50$ \\
\hline Touch Screen (Display) & $\$ 90.00$ & $\$ 90.00$ & $\$ 90.00$ & $\$ 90.00$ & $\$ 90.00$ & $\$ 90.00$ & $\$ 90.00$ & $\$ 90.00$ \\
\hline Processor (64bit A7 + M7) & $\$ 18.00$ & $\$ 18.00$ & $\$ 18.00$ & $\$ 18.00$ & $\$ 18.00$ & $\$ 18.00$ & $\$ 18.00$ & $\$ 18.00$ \\
\hline Cameras $(5 \mathrm{MP}+1.2 \mathrm{MP})$ & $\$ 9.00$ & $\$ 9.00$ & $\$ 9.00$ & $\$ 9.00$ & $\$ 9.00$ & $\$ 9.00$ & $\$ 9.00$ & $\$ 9.00$ \\
\hline Wireless Section - BB/RF/PA & $\$ 32.00$ & $\$ 32.00$ & $\$ 32.00$ & $\$ 32.00$ & & & & \\
\hline User Interface \& Sensors & $\$ 10.00$ & $\$ 10.00$ & $\$ 10.00$ & $\$ 10.00$ & $\$ 10.00$ & $\$ 10.00$ & $\$ 10.00$ & $\$ 10.00$ \\
\hline WLAN / BT / FM / GPS (dual-band) & $\$ 5.00$ & $\$ 5.00$ & $\$ 5.00$ & $\$ 5.00$ & $\$ 5.00$ & $\$ 5.00$ & $\$ 5.00$ & $\$ 5.00$ \\
\hline Power Management & $\$ 7.25$ & $\$ 7.25$ & $\$ 7.25$ & $\$ 7.25$ & $\$ 7.25$ & $\$ 7.25$ & $\$ 7.25$ & $\$ 7.25$ \\
\hline Battery (32.9Wh Pack) & $\$ 19.00$ & $\$ 19.00$ & $\$ 19.00$ & $\$ 19.00$ & $\$ 19.00$ & $\$ 19.00$ & $\$ 19.00$ & $\$ 19.00$ \\
\hline Mechanical / Electro-Mechanical & $\$ 45.00$ & $\$ 45.00$ & $\$ 45.00$ & $\$ 45.00$ & $\$ 42.00$ & $\$ 42.00$ & $\$ 42.00$ & $\$ 42.00$ \\
\hline Box Contents & $\$ 6.00$ & $\$ 6.00$ & $\$ 6.00$ & $\$ 6.00$ & $\$ 6.00$ & $\$ 6.00$ & $\$ 6.00$ & $\$ 6.00$ \\
\hline
\end{tabular}

Table 1. Preliminary iPad Air2 cost estimates. Source: IHS Technology (2013)

And suppose once more for illustrative purposes, that iPad-producing labour (performed by Apple employees) is virtually multiplied by the factor of 10 and therefore a new value of $\$ 120$, instead of $\$ 12$, is created during the production process. Then, whereas the individual value of an iPad is $\$ 283$, its social value would be $\$ 391(=\$ 269+\$ 2+\$ 120) .{ }^{250}$

The social value of an iPad would not deviate much in spite of Apple outsourcing manufacturing to Foxconn. And given the small manufacturing cost portion of the total costs, individual value and surplus profit would not change much either. ${ }^{251}$

250 Ignoring the transformation of values into prices of production, out of $\$ 216$, Apple's surplus profit per iPad, $\$ 108$ (= \$499 - \$391) would be monopoly profit.

${ }^{251}$ Given that an additional surplus profit of $\$ 3$ is not that large, it is hard to justify outsourcing entirely on this basis. Certainly there are other reasons why outsourcing (to China) is more favourable. For example, see Duhigg and Bradsher (2012). However, see also Cohen and Zysman (1987, p. 7) for the risks involved in outsourcing: 
More generally, in the presence of intellectual property rights, a capital with advanced technologies (e.g. Apple) has a choice of either directly employing commodity-producing workers or outsourcing manufacturing altogether. In the case of direct employment of workers, the capital can realise surplus profit arising from the process of virtual multiplication of commodity-producing labour, in addition to (normal) surplus value, with the latter much smaller than the former.

In the case of outsourcing, the capital with advanced technologies realises surplus profit only (the difference between social value and individual value, with contract manufacturing costs being a part of the latter) since it does not exploit workers directly. Instead the capital purchases contract manufacturing services - means of production - from a contract manufacturing company (e.g. Foxconn), which realises (normal) surplus value since it employs and exploits workers who perform simple and repetitive labour, producing contract manufacturing services.

In outsourcing, then, intellectual property is economically realised through neither a licence fee nor a royalty. Instead, the rights holder realises surplus profit by way of purchasing contract manufacturing services on the condition that the rights holder's intellectual properties are used exclusively for manufacturing of the rights holder's products as stipulated in the service contracts. However, the economic benefit derived from outsourcing (and intellectual property rights) is no less significant; an intellectual property rights holder can focus on, and invest more in, R\&D instead of maintaining huge manufacturing facilities and employing commodity-producing workers.

Based on the analysis of the three cases, we can conclude that intellectual property rights are economically realised in different ways in different industries, of which royalties and licence fees are just one. In the recorded music industry, royalties are a norm, but record labels and artists increasingly ask for advances (pre-payments of royalties), which are recouped over time. For chipless companies, striking a right balance between royalty and licence fee is crucial to ensure that their revenues grow in tandem with the growth of the industry as a whole whilst reducing risks by accepting lump-sum cash payments from each new customer.

At the heart of our argument is a contention that ... tight linkages tie a broad core of service jobs to manufacturing - but on a much larger scale. Shift out of manufacturing and it is more likely that you will find that you have shifted out of such services as product and process engineering, than into those services. This is true of a large number of high-level service activities, the very services that are supposed to drive the argument for development by sectoral succession - out of industry and up into services. 


\subsection{Concluding remarks}

This chapter and the thesis as a whole cover only a small part of the (variegated) presence of knowledge in capitalism across different levels of abstraction, different industries and different spheres of the economy.

Ideally, each chapter of the three volumes of Capital should be examined with the view to make explicit, and properly situate, the role of knowledge specific to the scope and level of abstraction concerned, complemented by theories of intellectual property rights drawing from industry-specific studies in a similar depth and style to Marx's theory of agricultural ground rent. At the logical level, ultimately the concept of productive powers (or forces) could be reconstructed as the most concrete, complex and collective form of knowledge encompassing science, technology, modes of co-operation and even relations of production (Cohen, 1978; Suchting, 1982; Sayer, 1987; Hunt, 1998). However, more importantly, knowledge has always been associated with change and historical narrative in theories, discourses and policy discussions and, therefore, wedding a logical analysis with a historical one is absolutely necessary. For example, the surge of startups in the software, Internet, electronics and biotechnology industries since the 1990 s cannot be explained without referring to financialisation or the unprecedented expansion of interest bearing capital, not least venture capital and private equity firms. In addition, knowledge, once turned into intellectual property, can accrue a stable stream of income and be capitalised (fictitious capital). Patent pooling is used to maximise the commercial value of patents and there are even securities backed by intellectual properties. In 1997, the famous singer David Bowie raised $\$ 55$ million by selling 'Bowie Bonds' backed by his recorded music (Celebrity bond, n.d.). The growing divergence between market value and book value is often attributed to 'intangibles' which must be fuelled in part by the easier access to the capital market. Knowledge has always been important and economically valuable, but the extent of commodification and capitalisation of knowledge in contemporary capitalism is probably unprecedented as the continuing growth of markets for technology suggests.

All these cannot be satisfactorily explained solely on the basis of value theory but value theory certainly provides a coherent and flexible theoretical framework which, in combination with historical materials and contingencies, can provide powerful analyses, precisely because all these concrete and complex developments are underpinned fundamentally by the value relation, that is, the commodity forms of 
exploitative social relations. Hopefully, by way of critiques and constructive theorisations of knowledge, this thesis takes a small step in the right direction. 


\section{References}

Aghion, P., Akcigit, U., \& Howitt, P. (2013). What do we learn from Schumpeterian growth theory? (NBER Working Paper 18824). Cambridge, MA: National Bureau of Economic Research.

Aghion, P., \& Howitt, P. (1992). A model of growth through creative destruction. Econometrica, 6o(2), 323-351.

$\mathrm{Ahn}, \mathrm{H}$. (2012). 기본소득의 가치론적 기초 - 정보재 가치논쟁 재론 [Value theory of basic income: the debate on the value of information goods revisited]. 마르크스주의 연구 [Marxism 21], 9(4), 42-67.

$\mathrm{Ahn}, \mathrm{H}$. (2014). 정보지대와 노동가치론: 전희상의 논평에 대한 답변 [Information rent and the labour theory of value: Reply to the critique of Heesang Jeon]. 마르크스주의 연구 [Marxism 21], 10(4), 168-190.

Antonelli, C. (2007). The foundations of the economics of innovation: From the classical legacies to the economics of complexity (Working paper 2007-2). University of Turin, Italy: Department of Economics.

ARM Holdings plc. (2010). Annual report and accounts 2009: Smarter technology efficiently connecting the digital world. Retrieved from http://ir.arm.com/phoenix.zhtml?c=197211\&p=irol-reportsannual.

ARM Holdings plc. (2011). Annual report and accounts 2010: 20 years of growth delivering future opportunities. Retrieved from http://ir.arm.com/phoenix.zhtml?c=197211\&p=irol-reportsannual.

ARM Holdings plc. (2012). Annual report and accounts 2011: Enabling the world's leading companies to succeed. Retrieved from http://ir.arm.com/phoenix.zhtml?c=197211\&p=irol-reportsannual.

ARM Holdings plc. (2013). Annual report and accounts 2012: We are connecting intelligence. Retrieved from http://ir.arm.com/phoenix.zhtml?c=197211\&p=irolreportsannual.

ARM Holdings plc. (2014). Strategic report 2013: Enabling innovation 
everywhere. Retrieved from http://ir.arm.com/phoenix.zhtml?c=197211\&p=irolreportsannual.

ARM Holdings plc. (2015). Strategic report 2014: Shaping the connected world.

Retrieved from http://ir.arm.com/phoenix.zhtml?c=197211\&p=irolreportsannual.

Arora, A., Fosfuri, A., \& Gambardella, A. (2001). Markets for technology: The economics of innovation and corporate strategy. Cambridge, MA: The MIT Press.

Arora, A., \& Gambardella, A. (2010). Ideas for rent: an overview of markets for technology. Industrial and Corporate Change, 19(3), 775-803.

Arrow, K. (1962). The economic implications of learning by doing. The Review of Economic Studies, 29(3), 155-173.

Arrow, K. (2000). Increasing returns: Historiographic issues and path dependence. The European Journal of the History of Economic Thought, 7(2), 171-180.

Arthur, C. (2004a). The new dialectic and Marx's Capital. Leiden: Brill.

Arthur, C. (2004b). Money and the form of value. In R. Bellofiore, \& N. Taylor (Eds.), The constitution of capital: Essays on Volume I of Marx's Capital (pp. 3562). Basingstoke, UK: Palgrave Macmillan.

Arthur, C. (2005). Value and money. In F. Moseley (Ed.), Marx's theory of money: Modern appraisals (pp. 111-123). Basingstoke, UK: Palgrave Macmillan.

Arthur, C. (2014). Marx, Hegel and the value-form. In F. Moseley, \& T. Smith (Eds.), Marx's Capital and Hegel's Logic: A reexamination (pp. 269-291). Leiden: Brill.

Arvidsson, A. (2009). The ethical economy: Towards a post-capitalist theory of value. Capital \& Class, 97, 13-29.

Aufheben (2006). Keep on smiling: Questions on immaterial labour. Aufheben, 14, $23-44$.

Aufheben (2007). Review: Moishe Postone's Time, labour and social domination Capital beyond class struggle? Aufheben, 17, 30-52.

Banaji, J. (1979). From the commodity to capital: Hegel's dialectic in Marx's Capital. 
In Elson, D. (Ed.), Value: The representation of labour in capitalism (pp. 14-45). London: CSE Books.

Baumol, W. (2012). The Cost disease: Why computers get cheaper and health care doesn't. New Haven, CT: Yale University Press.

Bauwens, M. (2009). Class and capital and peer production. Capital \& Class, 97, 121-141.

Bedford, M. (2012, March 2). How ARM took on the world - and won. PC Plus, 318. Retrieved from http://www.techradar.com/news/computing/how-arm-took-onthe-world-and-won-1067393.

Beniger, J. (1986). The Control revolution: Technological and economic origins of the Information Society. Cambridge, MA: Harvard University Press.

Beiser, F. (2005). Hegel. London: Routledge.

Bidet, J. (2007) [1984]. Exploring Marx's 'Capital': Philosophical, economic and political dimensions, translated by David Fernbach. Leiden: Brill Academic Publishers.

Bina, C. (2006). The globalisation of oil: A prelude to a critical political economy. International Journal of Political Economy, 35(2), 4-34.

Boldrin, M., \& Levine, D. (2008). Against intellectual monopoly. New York, NY: Cambridge University Press.

Boldrin, M., \& Levine, D. (2009). Does intellectual monopoly help innovation? Review of Law \& Economics, 5(3), 991-1024.

Boluk, L. (2015, July 28). Less money, mo' music \& lots of problems: A look at the music biz (posted in Redef originals). Retrieved from http://redef.com/original/less-money-mo-music-lots-of-problems-the-pastpresent-and-future-of-the-music-biz.

Bouwens, M. (2009). Class and capital in peer production. Capital \& Class, 97, 121141.

Bowring, F. (2004). From the mass worker to the multitude: A theoretical contextualisation of Hardt and Negri's Empire. Capital \& Class, 83, 101-131. 
Braverman, H. (1974). Labour and monopoly capital: The degradation of work in the twentieth century. New York, NY: Monthly Review Press.

Brown, C., \& Linden, G. (2008). Semiconductor engineers in a global economy. In Committee on the Offshoring of Engineering, National Academy of Engineering, The Offshoring of Engineering: Facts, Unknowns, and Potential Implications (pp. 149-178). Washington, DC: The National Academy Press.

Brown, N., \& Szeman, I. (2005). What is the Multitude?: Questions for Michael Hardt and Antonio Negri. Cultural Studies, 19(3), 372-87.

Brynjolfsson, E. (1993). The productivity paradox of information technology. Communications of the ACM, 36(12), 67-77.

Brynjolfsson, E., \& Saunders, A. (2010). Wired for innovation: How information technology is reshaping the economy. Cambridge, MA: MIT Press.

Brynjolfsson, E., \& Yang, S. (1996). Information technology and productivity: A review of the literature. In M. Zelkowitz (Ed.), Advances in computers (volume 43) (pp. 179-215). San Diego, CA: Academic Press.

Caffentzis, G. (2005). Immeasurable value?: An essay on Marx's legacy. The Commoner, 10, 87-114.

Caffentzis, G. (2008). From the Grundrisse to Capital and beyond: Then and now. Workplace, 15, 59-74.

Camfield, D. (2007). The multitude and the kangaroo: A critique of Hardt and Negri's theory of immaterial labour. Historical Materialism, 15(2), 21-52.

Carchedi, G. (2011). Behind the crisis: Marx's dialects of value and knowledge. Leiden: Brill.

Celebrity bond. (n.d.). In Wikipedia. Retrieved September 27, 2015, from https://en.wikipedia.org/wiki/Celebrity_bond.

Chae, M. (2004a). 과학기술혁명과 상품의 가치 - 가격 - 이른바 ‘정보재' 가격 문제를 중심으로 [Scientific and technological revolution and the value and price of commodities - on the problem of the price of the so-called 'information goods']. 진보평론 [Radical Review], 2O, 221-259. Reproduced in N. Kang et al. (2007), 
$55^{-100}$.

Chae, M. (2004b). 정보재의 가치와 관련한 몇 가지 쟁점에 대하여 [On some issues related to the value of information commodities]. 현장에서 미래를 [Envisioning Future from Workplace], 104, 83-105.

Chae, M. (2008). 정보재 가치논쟁과 경제학의 혁명 [Controversy about the value of information commodities and revolution in economics]. 정세와 노동 [Situations and Labour], 36, 55-81.

Chicchi, F. (2010). On the threshold of capital, at the thresholds of the common. In A. Fumagalli, \& S. Mezzadra (Eds.), Crisis in the global economy: Financial markets, Social struggles, and New political scenarios (pp. 139-152), translated by Jason Francis Mc Gimsey. Los Angeles: MIT Press, Series Semiotext(e)/Active Agents.

Cohen, C., \& Zysman, J. (1987). Manufacturing matters: The myth of the postindustrial society. New York, NY: Basic Books.

Cohen, G. A. (1978). Karl Marx's theory of history: A defence. Oxford: Oxford University Press.

Corrado, C., Haltiwanger, J., \& Sichel, D. (2005). Measuring capital in the new economy. Chicago: University of Chicago Press.

Corrado, C., \& Hulten, C. (2010). How do you measure a "technological revolution"? American Economic Review: Papers \& Proceedings, 100, 99-104.

Corsani, A., Dieuaide, P., Lazzarato, M., Monnier, J.-M., Moulier-Boutang, Y., Paulré, B., \& Vercellone, C. (2001, October 11-14). Le Capitalisme cognitif comme sortie de la crise du capitalism industriel: un programme de recherche. Paris, Colloque de l'école de la régulation. Retrieved from http://webcom.upmfgrenoble.fr/regulation/Forum/Forum_2001/Forumpdf/o1_CORSANI_et_alii.p df.

Cremin, C., \& Roberts, J. (2011). Postmodern left-liberalism: Hardt and Negri and the disavowal of critique. Critical Sociology, 37(2), 179-197.

David, P., \& Foray, D. (2002). An introduction to economy of the knowledge society. International Social Science Journal, 54(171), pp. 9-23. 
De Angelis, M. (1995). Beyond the technological and the social paradigms: A political reading of abstract labour as the substance of value. Capital \& Class, 57, 107-134.

Dooley, P. (1991). Marshall's parable of the meteoric stones: Rent, quasi rent and interest. American Journal of Economics and Sociology, 5o(2), 197-206.

Drahos, P. (1996). A philosophy of intellectual property. Aldershot: Ashgate.

Drahos, P., \& Braithwaite, J. (2002). Information feudalism: Who owns the knowledge economy? London: Earthscan.

Duboff, J. (2015, September). Taylor Swift: Apple crusader, \#GirlSquad captain, and the most influential 25-year-old in America. Vanity Fair. Retrieved from http://www.vanityfair.com/style/2015/o8/taylor-swift-cover-mario-testinoapple-music.

Duhigg, C., \& Bradsher, K. (2012, Jan 21). How the U.S. lost out on iPhone work. The New York Times. Retrieved from http://www.nytimes.com/2012/01/22/business/apple-america-and-a-squeezedmiddle-class.html.

Dyer-Witheford, N. (1999). Cyber-Marx: Cycles and circuits of struggle in high technology capitalism. Chicago, IL: University of Illinois Press.

Dyer-Witheford, N. (2005). Cognitive capitalism and the contested campus. In G. Cox, Geoff, \& J. Krysa (Eds.), Engineering culture: On 'the author as (digital) producer' (pp. 71-93). New York: Autonomedia (DATA browser 02).

Ebert, T., \& Zavarzadeh, M. (2014). The digital metaphysics of cognitive capitalism: Abandoning dialectics, the North Atlantic left invents a spontaneous communism within capitalism. International Critical Thought, 4(4), 397-417.

Fine, B. (1979). On Marx's theory of agricultural rent. Economy and Society, 8(3), 241-278, reproduced in B. Fine (Ed.) (1986).

Fine, B. (1980a). Economic theory and ideology. London: Edward Arnold.

Fine, B. (1980b). On Marx's theory of agricultural rent: A rejoinder, Economy and Society, 9(3), 327-331, reproduced in B. Fine (Ed.) (1986). 
Fine, B. (1982a). Theories of the capitalist economy. London: Edward Arnold.

Fine, B. (1982b). Landed property and the distinction between royalty and rent. Land Economics, 58(3), pp. 338-350.

Fine, B. (Ed.). (1986). The value dimension: Marx versus Ricardo and Sraffa. London: Routledge \& Kegan Paul.

Fine, B. (1990). The Coal question: Political economy and industrial change from the nineteenth century to the present day. London: Routledge.

Fine, B. (1994). Coal, diamonds and oil: Towards a comparative theory of mining? Review of Political Economy, 6(3), 279-302.

Fine, B. (1998). Labour market theory: A constructive reassessment. London: Routledge.

Fine, B. (2000). Endogenous growth theory: A critical assessment. Cambridge Journal of Economics, 24(2), 245-265.

Fine, B. (2003). New growth theory. In: H.-J. Chang (Ed.), Rethinking development economics (pp. 201-207). London: Anthem Press.

Fine, B. (2006). New growth theory: More problem than solution. In B. Fine, \& K. S. Jomo (Eds.), The new development economics: After the Washington consensus (pp. 68-86). New Delhi; London: Tulika Books \& Zed Books.

Fine, B. (2008). Debating Lebowitz: Is class conflict the moral and historical element in the value of labour power? Historical Materialism, 16(3), 105-114.

Fine, B. (2012a). Exploitation and surplus value. In B. Fine, A. Saad-Filho, \& M. Boffo (Eds.), The Elgar companion to Marxist economics (pp. 118-124). Cheltenham: Edward Elgar.

Fine, B. (2012b). Neo-liberalism in retrospect? It's financialisation, stupid. In K. Chang, B. Fine, \& L. Weiss (Eds.), Developmental politics in transition: The neoliberal era and beyond (pp. 51-69). Basingstoke: Palgrave MacMillan.

Fine, B., Gimm, G., \& Jeon, H. (2010). Value is as value does: Twixt knowledge and the world economy, Capital \& Class, 34(1), 69-83.

Fine, B., \& Saad-Filho, A. (2010). Marx’s ‘Capital' (5th ed.). London: Pluto Press. 
Foray, D. (2004). The economics of knowledge. Cambridge, MA: MIT Press.

Fuchs, C., \& Sevignani, S. (2013). What is digital labour? What is digital work? What's their difference? And why do these questions matter for understanding social media? tripleC, 11(2), 237-293.

Fumagalli, A. (2010). Bioeconomics and the valorisation process. In V. Cvijanovic, A. Fumagalli, \& C. Vercellone (Eds.), Cognitive capitalism and its reflections in South-Eastern Europe (pp. 41-59). Frankfurt am Main: Peter Lang.

Ghosh, J. (2012). New introduction: Women, labour, and capital accumulation in Asia. In P. Custers (Ed.), Capital accumulation and women's labour in Asian economies (pp. ix-xxv). New York, NY: Monthly Review Press.

Gordon, R. (2000). Does the "New Economy" measure up to the great inventions of the past? Journal of Economic Perspectives, 14(4), 49-74.

Gordon, R. (2010). Revisiting U.S. productivity growth over the past century with a view of the future (NBER Working Paper 3098). Cambridge, MA: National Bureau of Economic Research.

Graham, G., Burnes, B., Lewis, G. \& Langer, J. (2004). The transformation of the music industry supply chain: A major label perspective. International Journal of Operations \& Production Management, 24(11), 1087-1103.

Greenbaum, E. (2011). Open source semiconductor core licensing. Harvard Journal of Law \& Technology, 25(1), 131-157.

Grossman, G., \& Helpman, E. (1991a). Quality ladders in the theory of growth. Review of Economic Studies, 58(1), 43-61.

Grossman, G., \& Helpman, E. (1991b). Innovation and growth in the global economy. Cambridge, MA: MIT Press.

Grossman, G., \& Helpman, E. (1994). Endogenous innovation in the theory of growth. Journal of Economic Perspectives, 8(1), 23-44.

Guellec, D. and van Pottelsberghe de la Potterie, B. (2007). The Economics of the European patent system. Oxford: Oxford University Press.

Ha, T. (2015). 인지자본주의와 정보재 가치 [The cognitive capitalism and the value 
of information goods]. 사회경제평론 [The Review of Social \& Economic studies], $47,1-37$.

Harcourt, G. (1972). Some Cambridge controversies in the theory of capital. Cambridge: Cambridge University Press.

Hardt, M. (1999). Affective Labour. Boundary 2, 26(2), 89-100.

Hardt, M., \& Negri, A. (2000). Empire. Cambridge, MA: Harvard University Press.

Hardt, M., \& Negri, A. (2004). Multitude: War and democracy in the age of Empire. New York, NY: Penguin.

Hardt, M., \& Negri, A. (2009). Commonwealth. Cambridge, MA: The Belknap Press of Harvard University Press.

Harvey, D. (2001). Spaces of capital: Towards a critical geography. New York, NY: Routledge.

Harvey, D. (2010). A companion to Marx's Capital. London: Verso.

Hassard J., \& Rowlinson, M. (1994). Economics, politics and labour process theory. Capital \& Class, 53, 65-97.

Hassard J., \& Rowlinson, M. (2000). Marxist political economy, revolutionary politics, and labour process theory. International Studies of Management and Organisation, 3o(4), 85-111.

Haug, W. F. (2009). Immaterial labour (Historical-Critical Dictionary of Marxism), translated by Joseph Fracchia. Historical Materialism, 17, 177-185.

Haug, W. F. (2010). General intellect (Historical-Critical Dictionary of Marxism), translated by Joseph Fracchia. Historical Materialism, 18, 209-216.

Hayek, F. (1945). The use of knowledge in society. The American Economic Review, 35(4), 519-530.

Heinrich, M. (2013). The 'Fragment on Machines': a Marxian misconception in the Grundrisse and its overcoming in Capital. In R. Bellofiore, G. Starosta, \& P. Thomas (Eds.), In Marx's laboratory: Critical interpretations of the Grundrisse (pp. 197-212). Leiden: Brill. 
Herrera, R. (2011). A critique of mainstream growth theory: Ways out of the neoclassical science (-fiction) and toward Marxism. In P. Zarembka, \& R. Desai (Eds.), Revitalizing Marxist theory for today's capitalism (Research in Political Economy, Volume 27) (pp. 3-63). Bingley, UK: Emerald Group Publishing Limited.

Holloway, J. (2002a). Change the world without taking power: The meaning of revolution today. London: Pluto.

Holloway, J. (2002b). Going in the wrong direction: Or, mephistopheles - not Saint Francis of Assisi. Historical Materialism, 10(1), 79-91.

Howkins, J. (2001). The Creative economy: How people make money from ideas. New York, NY: Penguin.

Hunt, E., \& d'Arge, R. (1973). On lemmings and other acquisitive animals: propositions on consumption. Journal of Economic Issues, 7(2), 337-53.

Hunt, E. (1980). A radical critique of welfare economics. In E. Nell (Ed.), Growth, profits, and property (pp. 239-249). Cambridge: Cambridge University Press.

Hunt, I. (1998). A dialectical interpretation and resurrection of historical materialism. In R. Panasiuk, \& L. Nowak (Eds.), Marx's theories today (pp. 153195). Amsterdam: Rodopi.

Husson, M. (2003). Sommes-nous entrés dans le « capitalisme cognitif »? Critique communiste, $\mathrm{n}^{\circ} 169-170$.

Husson, M. (2007). Notes critiques sur le capitalisme cognitive. ContreTemps, $\mathrm{n}^{\circ} 18$.

Huws, U. (1999). Material world: The myth of the "weightless economy" In L. Panitch, \& C. Leys (Eds.), Socialist register (pp. 29-55). New York, NY: Monthly Review Press.

Huws, U. (2003). The making of a cybertariat: Virtual work in a real world. New York, NY: Monthly Review Press.

IFPI (2015). IFPI digital music report 2015: Charting the path to sustainable growth. Retrieved from http://www.ifpi.org.

IHS Technology (2013, November 5). Press release: new iPad Air costs less to make 
than third-generation iPad model, IHS teardown reveals. Retrieved from https://technology.ihs.com/463579/new-ipad-air-costs-less-to-make-than-thirdgeneration-ipad-model-ihs-teardown-reveals.

Jaffe, A., \& Lerner, J. (2004). Innovation and its discontents: How our broken patent system is endangering innovation and progress and what to do about it. Princeton, NJ: Princeton University Press.

Jeon, H. (2009). 지식노동과 정보재 가치 논쟁 [Knowledge labour and the controversy over the value of information goods], 마르크스주의 연구 [Marxism 21], 6(1), 230-272.

Jeon, H. (2010a). 정보상품 독점가격론 비판 [A critique of the monopoly price theory of information commodities], 마르크스주의 연 구 [Marxism 21], 7(3), 308327.

Jeon, H. (2010b). Cognitive capitalism or cognition in capitalism?: A critique of cognitive capitalism theory. Spectrum, 2(3), 90-117.

Jeon, H. (2011). The value and price of information commodities: An assessment of the South Korean controversy. In P. Zarembka, \& R. Desai (Eds.), Revitalising Marxist theory for today's capitalism (Research in Political Economy, Volume 27) (pp. 191-222). Bingley, UK: Emerald Group Publishing Limited.

Jeon, H. (2012). Knowledge economy. In B. Fine, A. Saad-Filho, \& M. Boffo (Eds.), The Elgar companion to Marxist economics (pp. 180-186). Cheltenham: Edward Elgar.

Jeon, H. (2013). 정보재 가치논쟁의 노동의 배수화 접근에 대한 두 가지 쟁점: 안현효의 '기본소득의 가치론적 기초 - 정보재 가치논쟁 재론'에 대한 논평 [Defending the multiplication approach in the Korean controversy on the value and price of information goods: A response to Ahn]. 마르크스주의 연구 [Marxism 21], 1O(2), 218-233.

Jessop, B. (2001). Capitalism, the regulation approach, and critical realism. In A. Brown, S. Fleetwood, \& J. M. Roberts (Eds.), Critical realism and Marxism (pp. 88-115). London: Routledge.

Jessop, B. (2007). Knowledge as a fictitious commodity: insights and limits of a 
Polanyian analysis. In A. Buğra, \& K. Ağartan (Eds.), Reading Karl Polanyi for the 21st century: Market economy as a political project (pp. 115-134). Basingstoke: Palgrave.

Jessop, B., \& Sum, N.-L. (2006). Beyond the regulation approach: Putting capitalist economies in their place. Cheltenham, UK: Edward Elgar.

Jo, W. (2008). 사소한 문제, 큰 소동 - ‘정보재가치논쟁’에 대한 논평 [Trivial problems and big disturbance - A review of 'Debate on the value of information commodities']. 진보평론 [Radical Review], 35, 238-256.

Jones, C. (1995). R\&D-based models of economic growth. Journal of Political Economy, 103(4), 759-784.

Jones, C. (1998). Introduction to economic growth (1st ed.). New York, NY: W. W. Norton \& Company.

Jones, C. (1999). Growth: With or without scale effects. American Economic Review, 89(2), 139-144.

Kafka, P. (2015, August 16). A radical plan to save the big music labels: Shrink the big music labels. re/code. Retrieved from http://recode.net/2015/o8/16/aradical-plan-to-save-the-big-music-labels-shrink-the-big-music-labels/.

Kang, N. (2002). 정보혁명의 정치경제학 [The political economy of the information revolution]. 문화과학사 [Munhwagwahaksa].

Kang, N. (2004). 정보상품의 가치와 잉여가치 [The value and surplus value of information commodities]. 진보평론 [Radical Review], 21, 239-248. Reproduced in N. Kang et al. (2007), 101-112.

Kang, N. (2005). 정보혁명과 지대에 관한 소고 [A short essay on the information revolution and rent]. 마르크스주의 연구 [Marxism 21], 2(1), 213-227. Reproduced in N. Kang et al. (2007), 251-268.

Kang, N. (2007). 정보의 가치와 특성 [The value and characteristics of information]. In N. Kang et al. (2007), 179-205.

Kang, N., Kang, S., Rieu, D., Park, S., Lee, K., Lee, C.-O., \& Chae, M. (2007). 정보재 
가치논쟁 [Debate on the value of information commodities]. Osan: Hanshin University Press.

Kang, S. (2008a). 소프트웨어의 가치와 가격에 대한 연구: ‘정보재 가치 논쟁'에 대한 비판적 검토를 중심으로 [Study on the value and price of software]. PhD thesis in Economics, Seoul National University.

Kang, S. (2008b). 디지털 정보상품의 가치와 가격: '버전 단위의 가치'는 성립가능한가? [Value and price of digital information commodity: Is 'value per version' feasible?], 사회경제평론 [The Review of Social \& Economic studies], 32, 269-298.

Kang, S. (2010). 정보재 가치논쟁: 특별잉여가치와 지대에 관한 쟁점 [Information goods value controversy: A critique on the problem of extra surplus value and ground rent]. 마르크스주의 연구 [Marxism 21], 7(1), 137-173.

Kenway, J., Bullen, E., Fahey, J., \& Robb, S. (2006). Haunting the knowledge economy. London: Routledge.

Kim, C. (2008). 정보재 가치논쟁에 대한 비판적 평가 [A critical review of the controversy on the value of information goods]. 마르크스주의 연구 [Marxism 21], 5(1), 253-299.

Knopper, S. (2015, March 15). 'We need to limit free': Major labels begin to question Spotify model. Rolling Stone. Retrieved from http://www.rollingstone.com/music/news/major-labels-question-free-model20150320.

Kumar, K. (1995). From post-industrial to post-modern society: New theories of the contemporary world. Oxford: Blackwell.

Kurtzman, J. (1997). An interview with Paul Romer. strategy+business, 6. Retrieved from http://www.strategy-business.com/article/9472?gko=715e4.

Lamoreaux, N., \& Sokoloff, K. (1999). Inventive activity and the market for technology in the United States (NBER Working Paper 7107). Cambridge, MA: National Bureau of Economic Research.

Lamoreaux, N., \& Sokoloff, K. (2005). The decline of the independent inventor: A 
Schumpeterian story (NBER Working Paper 11654). Cambridge, MA: National Bureau of Economic Research.

Langlois, R. (2013). Organising the electronic century. In G. Dosi, \& L. Galambos (Eds.), The third industrial revolution in global business (pp. 119-167). Cambridge: Cambridge University Press.

Lapavitsas, C. (2005). The universal equivalent as monopolist of the ability to buy. In F. Moseley (Ed.), Marx's theory of money: Modern appraisals (pp. 95-110). Basingstoke, UK: Palgrave Macmillan.

Lazzarato, M. (1996). Immaterial labour. In: P. Virno, \& M. Hardt (Eds.), Radical thought in Italy: A potential politics. Minneapolis. MN: University of Minnesota Press.

Lebert, D. (2011). Errements du capitalisme cognitif?: Éléments de réponse à la critique de Fine, Jeon et Gimm (2010) [Errors of the cognitive capitalism approach? A reply to Fine, Jeon and Gimm (2010)]. European Journal of Economic and Social Systems, 24(1-2), 101-118.

Lebert, D., \& Vercellone, C. (2011). Introduction. European Journal of Economic and Social Systems, 24(1-2), 7-12.

Lee, C.-O. (1990). On the three problems of abstraction, reduction and transformation in Marx's labour theory of value (PhD thesis in Economics). University of London.

Lee, C.-O. (1993). Marx's labour theory of value revisited. Cambridge Journal of Economics, 17(4), 463-478.

Lee, C.-O. (2005). 정보재 가치론 논쟁에서의 몇 가지 논점 [Several discussion points in the debate on the value of information commodities], 진보평론 [Radical Review], 25, 216-230. Reproduced in N. Kang et al. (2007), 153-168.

Lee, K. (2004). 정보재 단위인 알고리즘, 그 가치 및 가격의 문제 [Algorithm as the unit of information commodity and its value and price]. 진보평론 [Radical Review], 22, 250-268. Reproduced in N. Kang et al. (2007), 113-134.

Leopold, D. (2007). The young Karl Marx: German philosophy, modern politics, and human flourishing. Cambridge: Cambridge University Press. 
Lev, B. (2001). Intangibles: Management, measurement and reporting. Washington, DC: Brookings Institution Press.

Lucarelli, S., \& Fumagalli, A. (2008). Basic income and productivity in cognitive capitalism. Review of social economy, 66(1), 71-92.

Lucarelli, S., \& Vercellone, C. (2011). Welfare systems and social services during the systemic crisis of cognitive capitalism. European Journal of Economic and Social Systems, 24(1-2), 77-97.

Lucarelli, S., \& Vercellone, C. (2014). The thesis of cognitive capitalism. New research perspectives. An introduction. Knowledge cultures, 1(4), 15-27. Retrieved from https://www.academia.edu/6177363/

Lucas, R. (1988). On the mechanics of economic development. Journal of Monetary Economics, 22(July), 3-42.

Lüthje, B. (2002). Electronics contract manufacturing: Global production and the international division of labour in the age of the Internet. Industry and Innovation, 9(3), 227-247.

McNally, D. (2004). The dual form of labour in capitalist society and the struggle over meaning: Comments on Postone. Historical Materialism, 12(3), 189-208.

Machlup, F. (1962). The Production and distribution of knowledge in the United States. Princeton: Princeton University Press.

Macher, J., Mowery, D., \& Di Minin, A. (2008). Semiconductors. In J. Macher, \& D. Mowery (Eds.), Innovation in global industries: U.S. firms competing in a new world (pp. 101-140). Washington, DC: The National Academy Press.

Macher, J., Mowery, D., \& Hodges, D. (1999). Semiconductors. In D. Mowery (Ed.), U.S. industry in 2000: Studies in competitive performance (pp. 245-286). Washington, DC: The National Academy Press.

Marazzi, C. (2010). The violence of financial capitalism. In A. Fumagalli, \& S. Mezzadra (Eds.), Crisis in the global economy: Financial markets, social struggles, and new political scenarios (pp. 17-6o), translated by Jason Francis Mc Gimsey. Los Angeles: MIT Press, Series Semiotext(e)/Active Agents.

Marshall, A. (1920). Principles of economics (8th ed.). London: Macmillan. 
Marx, K. (1976) [1867]. Capital: Volume I (CI), translated by Ben Fowkes with an introduction by Ernest Mandel. London: Penguin Books.

Marx, K. (1978) [1885]. Capital: Volume II (CII), translated by David Fernbach with an introduction by Ernest Mandel. London: Penguin Books.

Marx, K. (1981) [1894]. Capital: Volume III (CIII), translated by David Fernbach with an introduction by Ernest Mandel. London: Penguin Books.

Marx, K., \& Engels, F. (1975-). Collected works (CWnn). London: Lawrence and Wishart.

May, C. (2002). The information society: A Sceptical view. Cambridge: Polity Press.

May, C. (2006). The denial of history: Reification, intellectual property rights and the lessons of the past. Capital \& Class, 88, 33-56.

May, C. (2007). The World Intellectual Property Organisation: Resurgence and the Development Agenda. London: Routledge.

May, C., \& Sell, S. (2006). Intellectual property rights: A critical history. Boulder, CO: Lynne Rienner Publishers.

Meiksins, P. (1994). Labour and monopoly capital for the 1990s: a review and critique of the labour process debate. Monthly Review, 46(6), 45-59.

Mirowski, P. (2007). Review essay: Did the (returns to) scales fall from their eyes? Journal of the History of Economic Thought, 29(4), 481-494.

Mirowski, P. (2009). Why there is (as yet) no such thing as an economics of knowledge. In H. Kincard, \& D. Ross (Eds.), The Oxford handbook of philosophy of economics (pp. 99-156). Oxford: Oxford University Press.

Mirowski, P. (2011). Science-mart: Privatising American science. Cambridge: Harvard University Press.

Mishan, E. (1971). The postwar literature on externalities: an interpretative essay. Journal of Economic Literature, 9(1), 1-28.

Mokyr, J. (2002). The gifts of Athena: Historical origins of the knowledge economy. Princeton, NJ: Princeton University Press. 
Monnier J.-M, \& Vercellone, C. (2014). The foundations and funding of basic income as primary income. Basic Income Studies, 9(2), 59-77.

Morini, C. (2008). The feminisation of labour in cognitive capitalism. Feminist Review, 87, 40-59.

Morini, C., \& Fumagalli, A. (2010). Life put to work: Towards a life theory of value. Ephemera: Theory \& Politics in Organisation, 10(3), 234-252.

Moulier-Boutang, Y. (2002, October 23-25). Nouvelles frontières de l'économie politique du capitalisme cognitif. Presented at Communication au Colloque Textualités et Nouvelles Technologies, Musée d'Art Contemporain de Montréal. First published in Revue éc/artS, 3, 121-135. Retrieved from http://people.ffii.org/ rmages/swpat/YMB_14_12_02.pdf.

Moulier-Boutang, Y. (2004). Les nouveaux enjeux de la propriété intellectuelle dans le capitalisme actuel. Retrieved from http://www.multitudes.net/Les-nouveauxenjeux-de-la/.

Moulier-Boutang, Y. (2006, April 29-30). Antagonism under cognitive capitalism: class composition, class consciousness and beyond. Presented at Immaterial labour, multitudes and new social subjects: Class composition in cognitive capitalism, University of Cambridge, 29-30 April. Retrieved from http://www.multitudes.net/Antagonism-under-cognitive/.

Moulier-Boutang, Y. (2012) [2008]. Cognitive capitalism, translated by Ed Emery. Cambridge: Polity Press.

Negri, A. (1991) [1979]. Marx beyond Marx: Lessons on the 'Grundrisse', translated by Harry Cleaver, Michael Ryan and Maurizio Viano. London: Pluto Press.

Negri, A. (2008). Reflections on Empire. Cambridge: Polity Press.

Negri, A. (2010). Postface: A Reflection on income in the "Great Crisis" of 2007 and beyond (originally written in February 2009). In A. Fumagalli, \& S. Mezzadra (Eds.), Crisis in the global economy: Financial markets, social struggles, and new political scenarios (pp. 263-271), translated by Jason Francis Mc Gimsey. Los Angeles: MIT Press, Series Semiotext(e)/Active Agents.

Negri, A., \& Vercellone, C. (2007). Il rapporto capitale/lavoro nel capitalismo 
cognitivo. Posse, 2007(Ottobre), 46-56. Retrieved from https://halshs.archivesouvertes.fr/halshs-00264147/document

Nelson, R. (1998). The agenda for growth theory: A different point of view. Cambridge Journal of Economics, 22(4), 497- 520.

The Nielsen Company (2015). 2014 Nielsen music report. Retrieved from http://www.nielsen.com/content/dam/corporate/us/en/public\%2ofactsheets/S oundscan/nielsen-2014-year-end-music-report-us.pdf.

Ollman, B. (2003). Dance of the dialectic: Steps in Marx's method. Urbana: University of Illinois Press.

Olsson, O. (2001). The appearance of knowledge in growth theory. Economic Issues, 6(1), 1-20.

Organisation for Economic Co-operation and Development (OECD). (1996). The knowledge-based economy. Paris: OECD.

Park, M.-S. (2007). Homogeneity masquerading as variety: the case of horizontal innovation models. Cambridge Journal of Economics, 31(3), 379-392.

Pasquinelli, M. (2009). Google's PageRank algorithm: A diagram of the cognitive capitalism and the rentier of the common intellect. In K. Becker, \& F. Stalder (Ed.). Deep search: The politics of search beyond Google (pp. 152-162). Piscataway: Transaction Publishers.

Passman, D. (2014). All you need to know about the music business (8th ed.). London: Penguin Books.

Paulré, B. (2004, November 25). Introduction au capitalisme cognitif. 1e journée d'étude organisée par le GRES et MATISSE-ISYS CNRS-Université Paris 1, Paris, le 25 novembre 2004 (à paraître). Retrieved from http://seminaire.samizdat.net/spip.php?article84.

Paulré, B. (2008). Finance et accumulations dans le capitalisme post-industriel. Multitudes, 32, 77-89.

Postone, M. (1993). Time, labour, and social domination: A reinterpretation of Marx's critical theory. Cambridge: Cambridge University Press. 
Prendergast, R. (2010). Accumulation of knowledge and accumulation of capital in early 'theories' of growth and development. Cambridge Journal of Economics, 34(3), 413-431.

Ricardo, D. (1817). Principles of political economy and taxation (3rd ed.). London: John Murray. Retrieved from http://www.econlib.org/library/Ricardo/ricPCover.html

Rieu, D. (2005). 정보상품의 가치와 지대 [The value and rent of information commodities]. 진보평론 [Radical Review], 26, 257-265. Reproduced in N. Kang et al. (2007), 169-178.

Robbins, C. (2009). Measuring payments for the supply and use of intellectual property. In M. Reinsdorf, \& M. J. Slaughter (Eds.), International trade in services and intangibles in the era of globalisation (pp. 139-171). Chicago: The University of Chicago Press.

Romer, P. (1986). Increasing returns and long-run growth. The Journal of Political Economy, 94(5), 1002-1037.

Romer, P. (1987). Crazy explanations for the productivity slowdown. In S. Fischer, S (Ed.), NBER Macroeconomics Annual (pp. 163-202). Cambridge, MA: MIT Press.

Romer, P. (1989). Increasing returns and new developments in the theory of growth (NBER Working Paper 3098). Cambridge, MA: National Bureau of Economic Research.

Romer, P. (1990). Endogenous technological change. The Journal of Political Economy, 98(5), S71-S102.

Romer, P. (1994a). The origins of endogenous growth. Journal of Economic Perspectives, 8(1), 3-22.

Romer, P. (1994b). New goods, old theory, and the welfare costs of trade restrictions. Journal of Development Economics, 43, 5-38.

Romer, P. (1996). Why, indeed, in America?: Theory, history, and the origins of modern economic growth. The American Economic Review, 86(2), 202-206.

Rosdolsky, R. (1977). The Making of Marx's Capital. London: Pluto Press. 
Ross, D. (2013). The place of free and open source software in the social apparatus of accumulation. Science \& Society, 77(2), 202-226.

Saad-Filho, A. (2002). The value of Marx: Political economy for contemporary capitalism. London: Routledge.

Sala-i-Martin, X. (1997). I just ran four million regressions (NBER Working Paper 6252). Cambridge, MA: National Bureau of Economic Research.

Sayer, D. (1987). The Violence of abstraction: The analytic foundation of historical materialism. Oxford: Blackwell.

Sherman, B, \& Bently, L. (1999). The making of modern intellectual property law: The British experience, 1760-1911. Cambridge, UK: Cambridge University Press.

Shimpi, A. (2013, June 28). The ARM diaries, Part 1: How ARM's business model works, AnandTech. Retrieved from http://www.anandtech.com/print/7112/thearm-diaries-part-1-how-arms-business-model-works.

Smith, K. (2002). What is the knowledge economy? Knowledge intensity and distributed knowledge bases. (Institute for New Technologies, The United Nations University, Discussion Paper 2002-6). Maastricht: The Netherlands.

Smith, T. (1990). The logic of Marx's 'Capital': Replies to Hegelian objections. Albany, NY: State University of New York Press.

Smith, T. (2009). The chapters on machinery in the 1861-63 manuscripts. In R. Bellofiore, \& R. Fineschi (Eds.), Re-reading Marx: New perspectives after the critical edition (pp. 112-127). Albany, NY: State University of New York Press.

Smith, T. (2013). The 'General Intellect' in the Grundrisse and beyond. Historical Materialism, 21(4), 1-21.

Solow, R. (1956). A contribution to the theory of economic growth. Quarterly Journal of Economics, 70, 65-94.

Solow, R. (1957). Technical change and aggregate production function. The Review of Economics and Statistics, 39(3), 312-320.

Solow, R. (1994). Perspectives on growth theory. Journal of Economic Perspectives, $8(1), 45-54$. 
Solow, R. (1996). Growth theory. In D. Greenway, M. Bleaney, \& I. Stewart (Eds.), $A$ guide to modern economics (pp. 218-236). London: Routledge.

Solow, R. (1997). Learning from 'learning by doing': Lessons for economic growth. Stanford: Stanford University Press.

Solow, R. (2000). Growth theory: An exposition (2nd ed.). Oxford: Oxford University Press.

Solow, R. (2007). The last 50 years in growth theory and the next 10. Oxford Review of Economic Policy, 23(1), 3-14.

Spencer D. (2000). Braverman and the contribution of labour process analysis to the critique of capitalist production: Twenty-five years on. Work, Employment and Society, 14(2), 223-244.

Spotify Ltd. (n.d.). Spotify explained. Retrieved from http://www.spotifyartists.com/spotify-explained.

Standage, T. (1998). The Victorian Internet: The remarkable story of the telegraph and the nineteenth century's on-line pioneers. New York, NY: Walker \& Company.

Steedman, I. (2003). On "measuring" knowledge in new (endogenous) growth theory. In N. Salvadori (Ed.), Old and new growth theories. An assessment (pp. 127-133). Cheltenham: Edward Elgar.

Stiglitz, J. (1999). Knowledge in the modern economy. In R. Vaitilingham (Ed.), The economics of knowledge driven economy (pp. 37-57). London: Department of Trade and Industry.

Suchting, W. (1982). "Productive Forces" and "Relations of Production" in Marx. Analyse und Kritik, 4(2), 159-181.

Swift, T. (2015, June 22). To Apple, Love Taylor. Retrieved from http://taylorswift.com/news/251533.

Swyngedouw, E. (2012). Rent and landed property. In B. Fine, A. Saad-Filho, \& M. Boffo (Eds.), The Elgar companion to Marxist economics (pp. 310-315). Cheltenham: Edward Elgar. 
Toms, S. (2008). 'Immeasurability': A critique of Hardt and Negri. Ephemera: Theory \& Politics in Organisation, 8(4), 433-446.

Toscano, D. (2007). From pin factories to gold farmers: Editorial introduction to a research stream on cognitive capitalism, immaterial labour, and the general intellect. Historical Materialism, 15(1), 3-11.

Triplett, J. (1999). The Solow productivity paradox: What do computers do to productivity. Canadian Journal of Economics, 32(2), 309-334.

Tsogas, G. (2012). The commodity form in cognitive capitalism. Culture and Organisation, 18(5), 377-395.

UNCTAD, \& UNDP (2008). Creative economy report 2008: The challenge of assessing the creative economy: Towards informed policy-making (UNCTAD/DITC/2008/2). Geneva: United Nations.

UNCTAD, \& UNDP (2010). Creative Economy Report 2010: A Feasible Development Option (UNCTAD/DITC/TAB/2010/2). Geneva: United Nations.

Vance, A. (2014, February 24). The unlikely tale of how ARM came to rule the world. Bloomberg Business. Retrieved from

http://www.bloomberg.com/bw/articles/2014-02-24/the-unlikely-tale-of-howarm-came-to-rule-the-world.

Varian, H., Farrell, J., \& Shapiro, C. (2004). The economics of information technology: An introduction. Cambridge, UK: Cambridge University Press.

Vercellone, C. (2004, October 14). Sens et enjeux de la transition vers le capitalisme cognitif: une mise en perspective historique. Paper presented at Transformations du travail et crise de l'économie politique, Université de Paris 1 PanthéonSorbonne.

Vercellone, C. (2005, November 4-6). The Hypothesis of cognitive capitalism. Paper presented at the Historical Materialism annual conference in 2005. Retrieved from https://halshs.archives-ouvertes.fr/halshs-00273641.

Vercellone, C. (2007). From formal subsumption to general intellect: Elements for a Marxist reading of the thesis of cognitive capitalism. Historical Materialism, 15(3), 13-36. 
Vercellone, C. (2008a, February). The new articulation of wages, rent and profit in cognitive capitalism, translated by Arianna Bove. Paper presented at The Art of Rent, Queen Mary University School of Business and Management, London, United Kingdom. Retrieved from https://halshs.archives-ouvertes.fr/halshsoo265584/document.

Vercellone, C. (2008b). Finance, rente et travail dans le capitalisme cognitif. Multitudes, 32, 27-38.

Vercellone, C. (2010). The crisis of the law of value and the becoming-rent of profit. In A. Fumagalli, \& S. Mezzadra (Eds.), Crisis in the global economy: Financial markets, social struggles, and new political scenarios (pp. 85-118), translated by Jason Francis Mc Gimsey. Los Angeles: MIT Press. Series Semiotext(e)/Active Agents.

Vercellone, C. (2011). De l'ouvrier-masse au travail cognitif: Valeur, travail et répartition dans le capitalisme cognitif [From mass worker to cognitive labour. Value, labour and distribution in cognitive capitalism]. European Journal of Economic and Social Systems, 24(1-2), 15-44.

Virno, P. (2007). General intellect. Historical Materialism, 15(4), 3-8.

Wardell, M. (1999). Labour processes: Moving beyond Braverman and the deskilling debate. In M. Wardell, T. Steiger, \& P. Meiksins (Eds.), Rethinking the labour process (pp. 1-16). Albany, NY: State University of New York Press.

Warner Music Group Corp. (2015). 1O-K annual report 2014. Retrieved from http://investors.wmg.com.

Warsh, D. (2006). Knowledge and the wealth of nations: A story of economic discovery. New York, NY: W.W. Norton.

Webster, F. (2002). Theories of the information society (2nd ed.). London: Routledge.

Weston, T. (2012). Marx on the dialectics of elliptical motion. Historical Materialism, 2O(4), 3-38.

Winter, S. (1987). Knowledge and competence as strategic assets. In D. Teece (Ed.), The Competitive Challenge: Strategies for Industrial Innovation and Renewal (pp. 159-184). New York: Harper and Row. 
World Bank (2007). Building knowledge economies: Advanced strategies for development. Washington, DC: World Bank.

Wright, S. (2002). Storming heaven: Class composition and struggle in Italian Autonomist Marxism. London: Pluto Press.

Wright, S. (2005). Reality check - are we living in an immaterial world. Mute, 2(1). Retrieved from http://www.metamute.org/editorial/articles/reality-check-arewe-living-immaterial-world.

Wright, S. (2008). Mapping pathways within Italian Autonomist Marxism: A preliminary survey. Historical Materialism, 16, 111-140.

Young, A. (1998). Growth without scale effects. The Journal of Political Economy, 106(1), 41-63. 